\title{
The Synthesis of Aigialomycin D Analogues
}

by

Samuel Z. Y. Ting

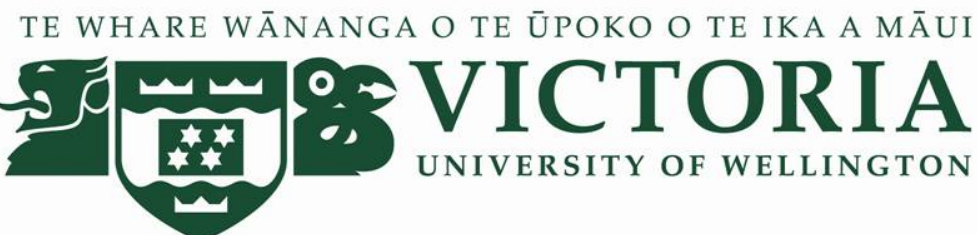

\author{
A thesis submitted to \\ Victoria University of Wellington \\ in fulfilment of the requirements for the degree \\ of Master of Science (by thesis) \\ in Chemistry.
}

Victoria University of Wellington 2010 



\begin{abstract}
Aigialomycin $\mathrm{D}$ is a fungal natural product possessing kinase inhibition properties. It is a member of a class of compounds known as the resorcylic acid lactones, a expansive group containing compounds exhibiting a vast array of biological activities. These include kinase and Hsp90 inhibition, highly desirable properties in the drug development field.

This research project sought to capitalise on previous work involving the successful total synthesis of aigialomycin D. By developing the synthetic methodology, analogues of aigialomycin D could be prepared for biological testing to obtain valuable structureactivity relationship information. The focus of this thesis involves the successful synthesis of aigialomycin D diastereomer, 5',6'-epi,epi-aigialomycin D and the attempted synthesis of $10^{\prime}$-epi-aigialomycin $\mathrm{D}$, via the synthetic strategy developed previously in combination with enantiomeric starting material fragments.
\end{abstract}

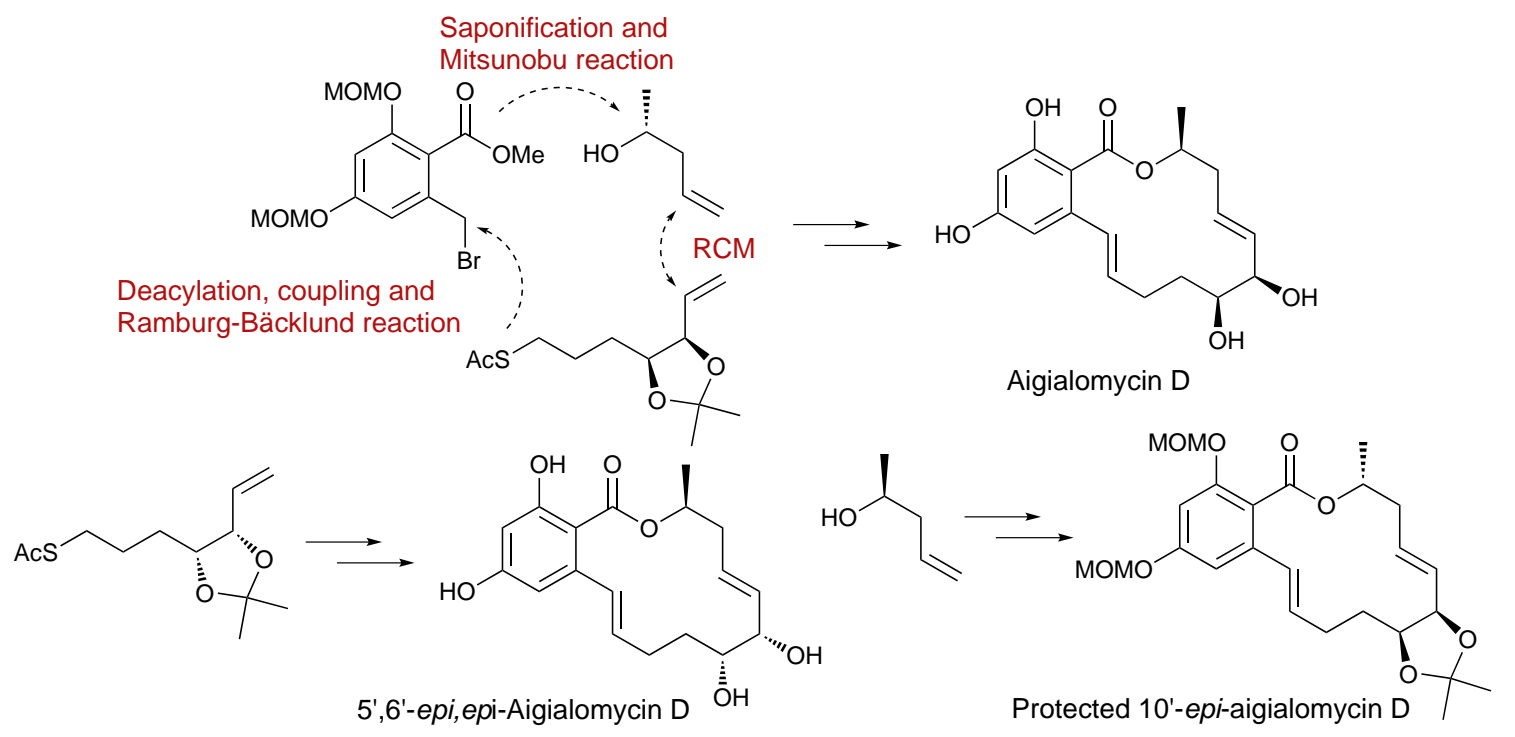

The synthesis of functional group analogues, $6^{\prime}$-oxo-aigialomycin D, $7^{\prime}, 8^{\prime}$-cyclopropyl aigialomycin D and 5-chloro-agialomycin D were also attempted via derivatisation of late-stage intermediates in the aigialomycin D synthesis. The thesis herein recounts the successes and failures in the synthesis of various aigialomycin D analogues.

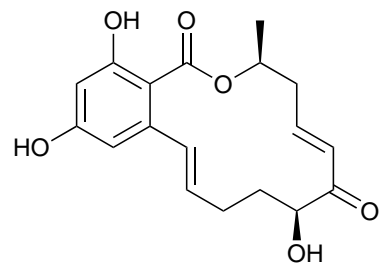

6'-oxo-aigialomycin D

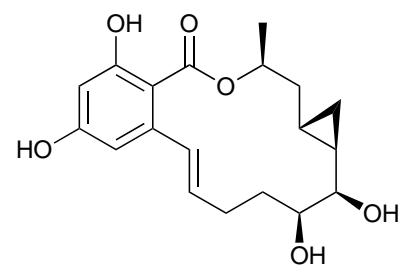

7',8'-cyclopropyl aigialomycin D

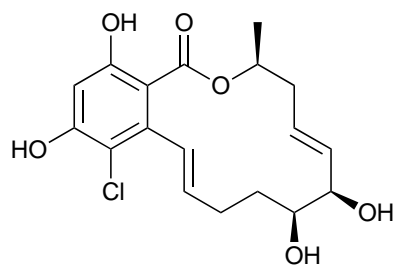

5-chloro-AmD 



\section{Acknowledgments}

First, I must acknowledge the two people directly responsible for me having this thesis and this acknowledgements section to write in the first place, Dr Brendan Burkett and Dr Joanne Harvey. Brendan, after deciding against industrial chemistry, it was you I turned to. Arming me with an assortment of chemicals, a microwave, with a goal of making funny little nitrogen rings, you set me on the path of organic synthesis, so thanks Brendan. After taking over the reins, Joanne, your energy and high spirit made every success feel like a victory, and those failures a little less important, thanks Joanne. There is also my co-supervisor Assoc. Prof. Paul Teesdale-Spittle, despite constant claims to be the only one in group meeting to not to understand the answer, you were usually just the first one to notice the problem, and your questions and comments were always insightful.

Dr Lynton Baird, not only did you give me a nice little total synthesis to work with, you were always ready to offer some inside knowledge into the temperament of aigialomycin D and were incredibly helpful in my journey to continue your work.

To all the comrades from my time in Laby 209 (Febly, Hemi, Johnny, Mark, the Peters, Dr Russell, and Thomas), thanks for providing inspiration, entertainment, and distraction on those long days in the lab. Special thanks to Russell, for going above and beyond as a lab manager and fumehood buddy, and for the meticulous attention to detail when proofreading my thesis.

Thanks to the natural products group (especially Jono and Jacqui) for all the help and patience with all my HPLC and general purification queries, as well as being a fantastic group of neighbours. I am also grateful to all the support staff within the school who always seemed happy to spare some time for whatever problem I may have had, chemical or administrative.

Then, there is the many great people in and around Laby, from those who came through undergrad-postgrad with me to the people I met along the way. Whenever I felt like only semi-detaching myself from the chemistry world, there was also plenty of good company, whether it was for end of week drinks, midweek yum cha, or a secluded anarchist party. 
Finally, to all the friends and family who had to deal with me when I wasn't immersed in the world of organic chemistry, providing escape and solace, thanks for all the support. And of course, Natalie, most likely the only person who may actually read this rambling, you have been amazing throughout this experience. You were always happy to wait around till I was finished in the lab to keep me company on the way home, even as that time got pushed further into the night, and you never complained. All I can promise is to do the same when it's your turn, with Oliver in tow of course.

Anyway, enough rambling, to all those who supported me, thanks, and to anyone reading, enjoy. 


\section{Table of Contents}

$\begin{array}{lll}\text { Abstract } & \text { iii }\end{array}$

Acknowledgments $\quad$ v

Table of Contents vii

List of Figures $\quad$ xi

List of Schemes $\quad$ xiii

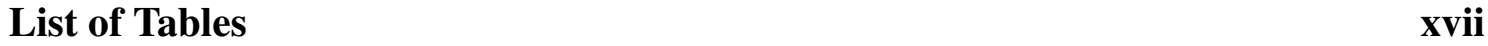

List of Abbreviations $\quad$ xix

1 Introduction 1

1.1 An Introduction to Analogue Synthesis . . . . . . . . . . . . . . . 1

1.2 Resorcylic Acid Lactones . . . . . . . . . . . . . . . . . . . . . . . 2

1.2.1 A Brief Description and History of Resorcylic Acid Lactones. . . 2

1.2.2 The Biosynthesis of Resorcylic Acid Lactones . . . . . . . . . . 4

1.2.3 An Overview of Structure-Activity Relationships Within the Resorcylic Acid Lactones . . . . . . . . . . . . . . 7

1.3 Aigialomycin D . . . . . . . . . . . . . . 16

1.3.1 Previous Published Syntheses of Aigialomycin D . . . . . . . . . 18

1.3.2 The VUW Synthesis of Aigialomycin D . . . . . . . . . . . 23 
1.4 Research Objectives . . . . . . . . . . . . . . . . . . . . . . 29

1.4.1 Proposed Synthetic Methodology . . . . . . . . . . . . . 31

2 Synthesis of Methyl Orsellinate 35

2.1 Investigation of Previous Methyl Orsellinate

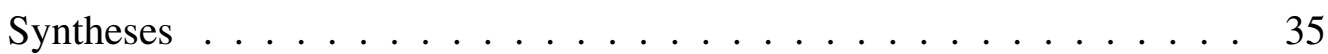

2.2 Optimisation Studies on the in situ Cyclisation of the Triketo-ester . . . . 38

2.3 Synthesis of Resorcylic Bromoester 44 . . . . . . . . . . . . . . . . 39

3 Synthesis of Aigialomycin D

3.1 Synthesis of the Thioacetate $43 \ldots \ldots \ldots$. . . . . . . . . 41

3.2 Synthesis of AmD from Thioacetate 43 and Resorcylic Bromoester 44. . . 43

4 Synthesis of 5',6'-epi,epi-Aigialomycin D 49

4.1 Synthesis of Thioacetate $81 \ldots \ldots$. . . . . . . . . . . . . . 49

4.1.1 Development and Optimisation of the Wittig Reaction Route to Alkene $83 \ldots \ldots \ldots \ldots$. . . . . . . . . . . . 50

4.1.2 Optimisation of the Diol Cleavage/Wittig Sequence . . . . . . . . 54

4.2 Synthesis of $5^{\prime}, 6^{\prime}$-epi,epi-Aigialomycin D . . . . . . . . . 56

5 Synthesis of 10'-epi-Aigialomycin D (64) 63

5.1 Synthesis of Ester $66 \ldots \ldots \ldots \ldots$

5.1.1 Stereo-Retentive Esterification Model Studies . . . . . . . . . . . 64

5.1.2 Attempted Stereo-retentive Esterification of Acid 45 . . . . . . 65 
5.2 Attempted synthesis of 10'-epi-Aigialomycin D (64) from Ester 66 . . . . 67

6 Computational Studies

6.1 Calculated Energy of Lowest Energy Conformers . . . . . . . . . . . . . 74

6.2 Structural Analysis of Lowest Energy Conformers . . . . . . . . . . . . . 75

7 Attempted Synthesis of Late-Stage Aigialomycin D Analogues 79

7.1 Attempted Synthesis of $6^{\prime}$-oxo-AmD (70) $\ldots \ldots \ldots$

7.2 Attempted synthesis of $7^{\prime}, 8^{\prime}$-cyclopropyl AmD (71) . . . . . . . . 80

7.3 Attempted Synthesis of 5-chloro-AmD (65) $\ldots \ldots \ldots$. . . . . . 81

8 Conclusions and Future Work $\quad 83$

8.1 Concluding Remarks $\ldots \ldots \ldots$. . . . . . . . . . . . 83

8.2 Future work .......................... 84

$\begin{array}{llr}9 & \text { Experimental } & 87\end{array}$

9.1 General Experimental Details . . . . . . . . . . . . . . . . . 87

9.2 Experimental Details for the Synthesis of Reagents _ . . . . . . . . 88

9.3 Experimental Details for Chapter $2 \ldots \ldots \ldots 8$

9.4 Experimental Details for Chapter 3 . . . . . . . . . . . . . . . . 90

9.5 Experimental Details for Chapter $4 \ldots \ldots$. . . . . . . . . . . 99

9.6 Experimental Details for Chapter 5 . . . . . . . . . . . . . . . . . 109 
9.7 Experimental Details for Chapter $6 \ldots \ldots$. . . . . . . . . . . 114

9.8 Experimental Details for Chapter $7 \ldots \ldots$. . . . . . . . . . . 114

Appendix

References

121 


\section{List of Figures}

1.1 General structure and numbering of RAL family . . . . . . . . . . . 3

1.2 A selection of RALs and relevant bioactivties . . . . . . . . . . . . 4

1.3 A selection of natural RALs and known inhibition targets. . . . . . . . 9

1.4 Selected biologically inactive natural RALs. . . . . . . . . . . . . . . . 10

1.5 Selected analogues and their biological activities from SAR studies by Winssinger et al. and Shinonaga et al. . . . . . . . . . . . 11

1.6 General SAR information of WNT-5A and Hsp90 inhibiting RALs. . . . 11

1.7 Natural RALs which have displayed kinase inhibition properties. . . . . . 13

1.8 Reported analogues of hypothemycin and radicicol A. . . . . . . . . . . . 14

1.9 The development of E6201 through analogue synthesis. . . . . . . . . . 15

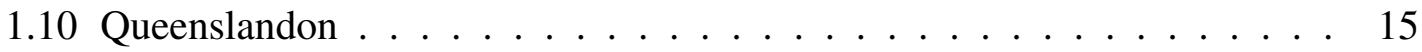

1.11 Caryospomycins . . . . . . . . . . . . . . 15

1.12 Hamigeromycins . . . . . . . . . . . . . . . . . . 16

1.13 Aigialomycins isolated by Isaka et al . . . . . . . . . . . . 17

1.14 Aigialomycins $\mathrm{F}$ and $\mathrm{G}$, and natural epoxy-AmD analogue 8. . . . . . 17

1.15 AmD analogues synthesised by Winssinger et al . . . . . . . . 18

$1.166^{\prime}$-epi-AmD (9) and 6'-epi-4-methyl AmD (10). . . . . . . . . . . 18

1.17 AmD analogues, 10'-epi-AmD (64) and 5-chloro-AmD (65). . . . . . 28

1.18 Proposed diastereomeric analogues of AmD . . . . . . . . . . . 30 
1.19 Proposed functional group analogues of AmD . . . . . . . . . . . . 30

4.1 Molecular models of acid 45 and the $5^{\prime}, 6^{\prime}$-epi,epi-acid 89. . . . . . . . 59

4.2 ${ }^{1} \mathrm{H}$ NMR spectrum of 2:1 mixture of putative isomer 93 and epi,epi-AmD

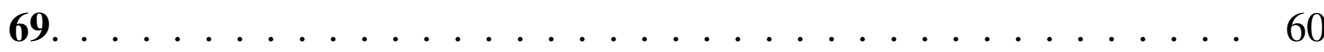

5.1 ${ }^{1} \mathrm{H}$ NMR spectrum of the putative $10^{\prime}$-epi-AmD synthesis products $\mathbf{1 0 0}$ and 101. . . . . . . . . . . . . . . . . . . . . 69

$6.110^{\prime}$-epi-AmD and $6^{\prime}, 10^{\prime}$-epi,epi-AmD isomers. . . . . . . . . . 73

6.2 Lowest energy conformation of AmD . . . . . . . . . . . . . . 75

6.3 Lowest energy conformations of $5^{\prime}, 6^{\prime}$-epi,epi-AmD and $\left(7^{\prime} Z\right)-5^{\prime}, 6^{\prime}$-epi,epi-

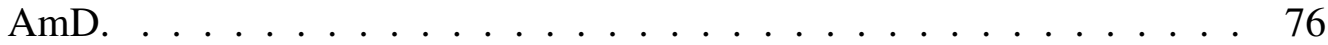

6.4 Lowest energy conformation of $10^{\prime}$-epi-AmD. . . . . . . . . . . 76

6.5 Lowest energy conformations of $6^{\prime}, 10^{\prime}$-epi,epi-AmD and $\left(7^{\prime} Z\right)-6^{\prime}, 10^{\prime}-$ epi,epi-AmD. ........................ 77

7.1 Proposed late-stage AmD analogues . . . . . . . . . . . . . . . . . . 79 


\section{List of Schemes}

1.1 Proposed biosynthesis of zearalenone . . . . . . . . . . . . 5

1.2 Proposed biosynthesis of hypothemycin. . . . . . . . . . . . . . 6

1.3 Proposed biosynthesis of monocillin I and radicicol. . . . . . . . . . . . . 6

1.4 Proposed Michael addition of a cysteine thiol to the enone functionality. . 13

1.5 Danishefsky's synthetic strategy for AmD and the key alkyne protected as a cobalt complex. . . . . . . . . . . . . . . . 19

1.6 Pan's synthetic strategy for AmD . . . . . . . . . . . . . . . . . . . . . 19

1.7 Winssinger's synthetic strategy for AmD . . . . . . . . . . . . . . . 20

1.8 Chen's synthetic strategy for AmD . . . . . . . . . . . . . 20

1.9 Montgomery's synthetic strategy for AmD . . . . . . . . . . . . . . . . 21

1.10 Jennings' and Bajwa's synthetic strategy for 6'-epi-AmD (9) and 2methyl-AmD (35). . . . . . . . . . . . . . . . 22

1.11 Barrett's synthetic strategy for AmD . . . . . . . . . . . . 23

1.12 The VUW synthetic strategy for AmD . . . . . . . . . . . . . . . . . 24

1.13 Synthesis of bromide 44 from methyl orsellinate . . . . . . . . . . . . . . 24

1.14 Synthesis of $\alpha, \beta$-unsaturated ester $\mathbf{5 0}$ from D-ribose. . . . . . . . . . 25

1.15 Synthesis of thioacetate $\mathbf{4 3}$ from $\alpha, \beta$-unsaturated ester $\mathbf{5 0}$ and attempted selective reduction with $\mathrm{CuCl}_{2} \ldots \ldots \ldots \ldots 25$

1.16 Synthesis of sulfone $\mathbf{5 7}$ from the coupling of bromide $\mathbf{4 4}$ with thioacetate

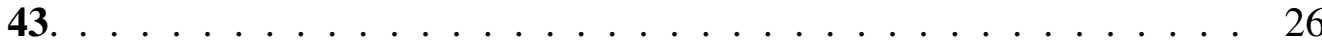


1.17 Synthesis of AmD (4) from sulfone 57 . . . . . . . . . . . . . . 27

1.18 Synthesis of tetrahydro-AmD 61 and 2,4-deoxy-AmD 62 . . . . . . . . . 27

1.19 Unsuccessful synthesis of epi-AmD 64. . . . . . . . . . . . . . . . 28

1.20 Unsuccessful synthesis of 5-chloro-AmD $65 . \quad \ldots \ldots \ldots$

1.21 Proposed optimised synthesis of iodide 48 . . . . . . . . . . . . . 31

1.22 Proposed synthesis of $5^{\prime}, 6^{\prime}$-epi,epi-AmD (69). . . . . . . . . . . 32

1.23 Proposed synthesis of $10^{\prime}$-epi-AmD (64). . . . . . . . . . . 32

1.24 Proposed synthesis of 6 -oxo-AmD 70. . . . . . . . . . 33

1.25 Proposed synthesis of $7^{\prime}, 8^{\prime}$-cyclopropyl-AmD 71. . . . . . . . . . 33

2.1 Two-step, one-pot synthesis of the methyl orsellinate from methyl ace-

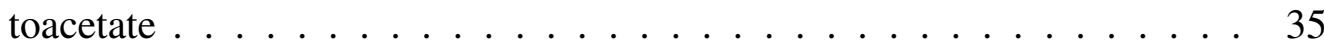

2.2 Base catalysed condensation of methyl acetoacetate. . . . . . . . . . 36

2.3 Cyclisation of triketo-ester $\mathbf{7 4}$ to methyl orsellinate $\ldots \ldots$. . . . . 37

2.4 Synthesis of resorcylic bromoester 44 . . . . . . . . . . . . . . . 39

3.1 Synthesis of the thioacetate fragment from D-ribose. . . . . . . . . . . . 41

3.2 Synthesis of iodo-sugar $\mathbf{4 8}$ and proposed equilibrium mechanism . . . . . 42

3.3 Synthesis of thioacetate 43 from iodo-sugar $48 \ldots \ldots$. . . . . . . . . 43

3.4 Coupling of thioacetate 43 and resorcylic bromoester $44 \ldots \ldots$

3.5 Attempted MOM-protection of $55 \ldots \ldots$. . . . . . . . . . . 44

3.6 Proposed mechanism for the decarboxylation of the resorcylic acid moiety. 44 
3.7 The proposed degradation of MOM-chloride . . . . . . . . . . . . . 45

3.8 MOM-protection followed by saponification of ester $55 \ldots \ldots$. . . . . . 46

3.9 Synthesis of sulfone 59 from acid $45 \ldots \ldots$. . . . . . . . . . . . 47

3.10 Synthesis of AmD (4) from sulfone $59 \ldots \ldots$. . . . . . . . . . 47

4.1 Proposed synthetic strategy towards $5^{\prime}, 6^{\prime}$-epi,epi-AmD . . . . . . . . . 49

4.2 Proposed synthesis of thioacetate 81 . . . . . . . . . . . . . . . 50

4.3 Attempted synthesis of alkene 83. . . . . . . . . . . . . . 50

4.4 Synthesis of TMS-protected alkene 84. . . . . . . . . . . . . 51

4.5 Synthesis of alkene 83 and various TMS protected alkenes. . . . . . . . 52

4.6 Synthesis of alkene 83. . . . . . . . . . . . . . . . 54

4.7 Proposed synthesis of $\alpha, \beta$-unsaturated ester 72. . . . . . . . . . 55

4.8 Synthesis of $\alpha, \beta$-unsaturated ester 72 $\ldots \ldots \ldots \ldots$

4.9 Proposed synthesis of $5^{\prime}, 6^{\prime}$-epi,epi-AmD (69). . . . . . . . . . . 56

4.10 Synthesis of thioacetate $\mathbf{8 1}$ from $\alpha, \beta$-unsaturated ester 72. . . . . . . . 57

4.11 Synthesis of acid 89 from thioacetate 81 and resorcylic bromoester 44. . . 57

4.12 Synthesis of $5^{\prime}, 6^{\prime}$-epi,epi-AmD 69 from acid 89. . . . . . . . . 58

4.13 Proposed acid-catalysed isomerisation of $5^{\prime}, 6^{\prime}$-epi,epi-AmD (69). . . . . 61

5.1 Proposed synthesis of $10^{\prime}$-epi-AmD 64. . . . . . . . . . 63

5.2 Esterification model study $\ldots \ldots \ldots$. . . . . . . . . 63

5.3 Model stereo-retentive esterification system and proposed Steglich esterification mechanism. . . . . . . . . . . . . . . 64 
5.4 Steglich esterification of acid $45 \ldots \ldots \ldots \ldots$

5.5 Attempted HBTU coupling of acid 45 and alcohol 13. . . . . . . . . . 66

5.6 Mitsunobu esterification of acid 45 with $(S)-4-$ penten-2-ol $(\mathbf{9 8}) \ldots \ldots$. . . . 67

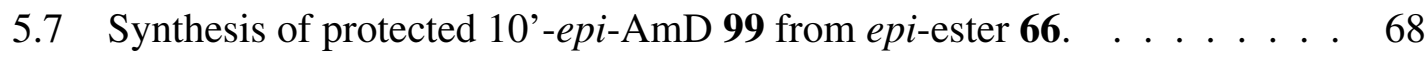

5.8 Deprotection of protected 10'-epi-AmD 99. . . . . . . . . . . 68

5.9 Proposed C6'-epimerisation mechanism. . . . . . . . . . . . . . 70

7.1 Attempted synthesis of $6^{\prime}$-oxo-AmD 70. . . . . . . . . . . 80

7.2 Attempted Simmons-Smith cyclopropanations of alkenes $\mathbf{5 9}$ and 4. . . . 81

7.3 Attempted synthesis of 5-chloro-AmD 65. . . . . . . . . . 81

8.1 Examples of possible C2-analogues of AmD . . . . . . . . . 85 


\section{List of Tables}

2.1 Cyclisation of triketo-ester $74 \ldots \ldots \ldots$

4.1 Attempted Wittig reaction of 2,3- $O$-isopropylidene-ribose $(\mathbf{8 2}) \ldots \ldots$

4.2 Optimisation of the Wittig reaction of 2,3-O-isopropylidene-ribose (82) . 53

4.3 Optimisation of the in situ TMS-deprotection . . . . . . . . . . . . . 54

4.4 Optimisation of the diol cleavage/Wittig reaction of diol $83 \ldots 55$

5.1 Esterification model studies. . . . . . . . . . . . . . . . 65

6.1 SCF energies of the lowest energy conformations of AMD and analogues $\quad 74$ 



\section{List of Abbreviations}

Ac Acyl

Am Aigialomycin

AOX Alcohol oxidase

aq. $\quad$ Aqueous

B3LYP Becke three-parameter with Lee-Yang-Parr

$\mathrm{Bu} \quad$ Butyl

$c \quad$ Concentration

CDK Cyclin-dependant kinase

CoA coenzyme A

conc. Concentrated

COSY $\quad{ }^{1} \mathrm{H}-{ }^{1} \mathrm{H}$ NMR Correlation spectroscopy

Cy Cyclohexane

CYP Cytochrome P450

d $\quad \operatorname{Day}(\mathrm{s})$

$\delta \quad$ Chemical shift

DCC Dicyclohexylcarbodiimide

DDQ 2,3-Dichloro-5,6-dicyanobenzoquinone

DIAD Diisopropyl azodicarboxylate

DFT Density function theory

DMAP 4- $(N, N)$-Dimethylaminopyridine

DMF $\quad N, N$-Dimethylformamide

EDCI 1-[3-(Dimethylamino)propyl]-3-ethylcarbodiimide

eq. $\quad$ Equivalent(s)

Et Ethyl

FMO Flavin-dependent monooxygenase

FT-IR Fourier Transform Infra-Red Spectroscopy

GST Glutathione $S$-transferase

h $\quad \operatorname{Hour}(\mathrm{s})$

HPLC High Pressure Liquid Chromatography

HRMS High Resolution Mass Spectrometry 


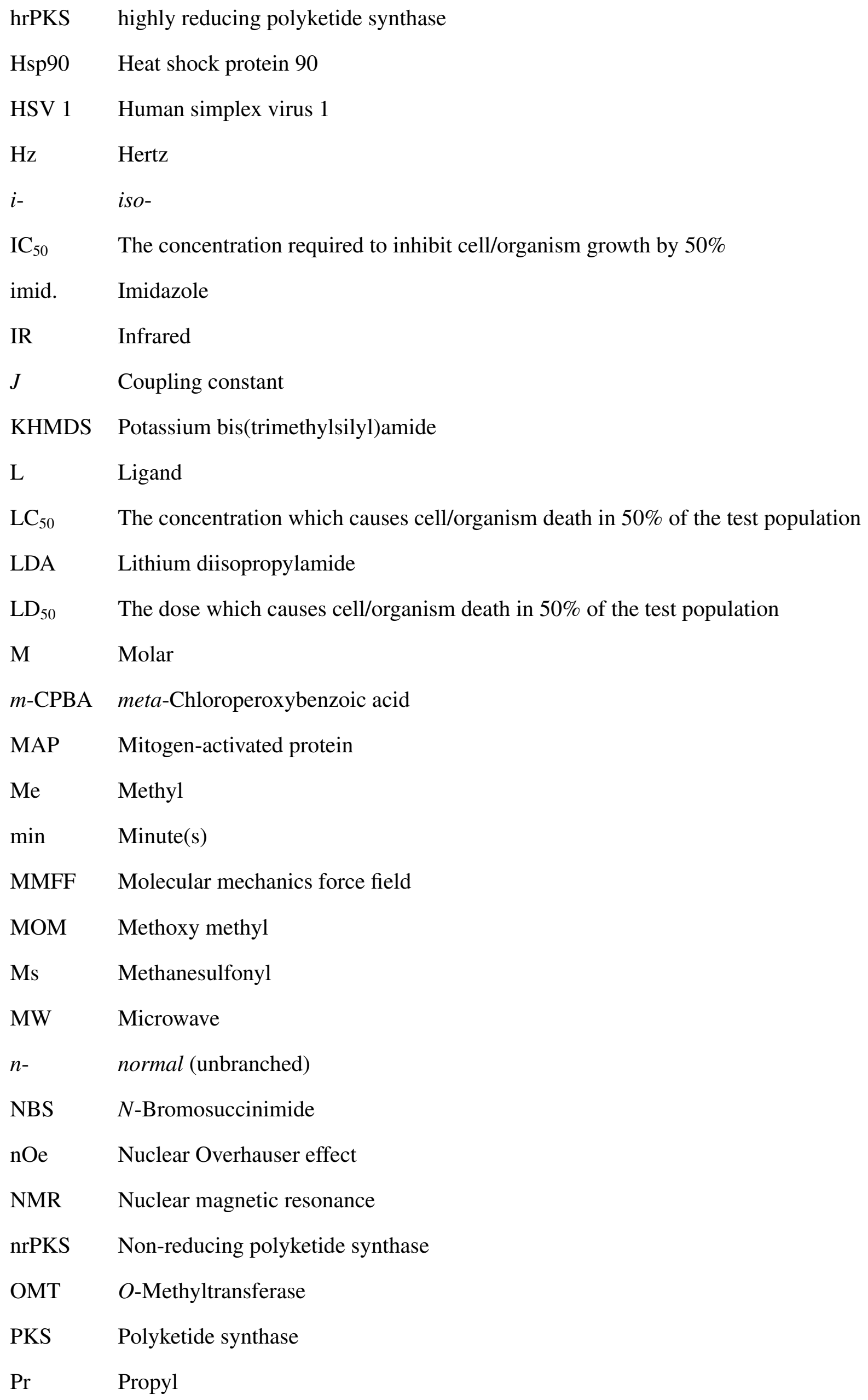




$\begin{array}{ll}\text { Ph } & \text { Phenyl } \\ \text { PPM } & \text { Parts per million } \\ \mathrm{q} & \text { Quartet } \\ \mathrm{R} & \text { Unspecified substituent } \\ \mathrm{R}_{F} & \text { Retention factor } \\ \mathrm{R}_{t} & \text { Retention time }\end{array}$

RAL Resorcylic acid lactone

RCM Ring-Closing Metathesis

Red-Al Sodium bis(2-methoxyethoxy)aluminum hydride

rt Room temperature

S Singlet

SAR Structure-activity relationship

sat. Saturated

SCF Self-consistent field

SM Starting material

t Triplet

$t-\quad$ tert-

TBAI Tetrabutylammonium iodide

TBS tert-Butyldimethylsilyl

TD Tolerated dose

Tf Trifluoromethanesulfonyl

THF Tetrahydrofuran

TLC Thin Layer Chromatography

TMS Tetramethylsilane or trimethylsilyl

WNT-5A Wingless-type mouse mammary tumor virus integration-site family, member 5A 



\section{Chapter 1|}

\section{Introduction}

\subsection{An Introduction to Analogue Synthesis}

Drug discovery is a massive field of social and commercial value (with top pharmaceutical drugs commonly accumulating annual sales in the US\$ billions) that encompasses many disciplines of chemistry and biology. From the initial discovery of a potential drug, it takes many years and co-operation between multiple disciplines to get a potential drug on the market. An important part of that process is the drug optimisation stage. The role of drug optimisation is to take compounds that have exhibited potentially useful biological activity and turn them into viable drug candidates.

Natural products provide useful inspiration for potential drug candidates, however, it is uncommon for natural products to be suitable for medicinal use for various reasons, such as poor pharmacokinetic properties, target selectivity or chemical stability. This is reflected in a survey of recent market drugs. Very few (6\%) of the 1024 drug compounds introduced between 1981 and 2008 are unmodified natural products, with 27\% natural product derived, and $17 \%$ possessing a natural product pharmacophore. ${ }^{* 1}$ This is where analogue synthesis-based structural activity relationship (SAR) studies can be highly valuable in the development of potential drug candidates.

The basic concept of analogue synthesis-based SAR studies is to synthesise analogues of a chosen compound, which can then be subjected to biological testing to investigate the effect of the chemical modifications. These studies can help provide a more fundamental understanding of the importance of individual structural features of a compound for its observed biological activity, and rationalise the importance of certain structural features, e.g. in affecting the stability of the compound, or increasing nucleophilicity/electrophilicity of a group that binds to the biological target site.

${ }^{*}$ A pharmacophore is the combination of steric and electronic features of a compound (or class of compounds) that interact with a specific biological target to trigger or inhibit its function. 
Once the general SARs of a compound have been elucidated, analogue synthesis can be used to search for potential chemical modification that will improve the druglike properties of a compound without having an adverse effect on desired biological properties. Examples of properties that analogue synthesis studies may seek to improve are:

- Physiological solubility, stability and absorption to maximise the amount of the drug that reaches the desired target, improving the efficacy of a drug and potentially reducing adverse effects due to unwanted biological activity.

- The selectivity of a drug for a desired biological target, reducing unwanted sideeffects of a drug.

- The potency of the drug, reducing the quantity required for treatment.

- Structural simplification of a compound, to enable a more efficient synthesis of a compound, potentially lowering the environmental and financial costs of drug production.

For these purposes, analogue synthesis-based SAR studies in combination with other techniques such as computational studies and co-crystallisation of protein-bound drug candidates, can help provide invaluable understanding of chemical and biological properties of potential drug candidates. From this, safer, more effective pharmaceutical drugs can be developed to improve the lives of the people they affect.

\subsection{Resorcylic Acid Lactones}

\subsubsection{A Brief Description and History of Resorcylic Acid Lactones.}

Resorcylic acid lactones (RALs) are a class of mycotoxins isolated from various strains of fungi defined by the presence a $\beta$-resorcylic acid ring and a 14-membered lactone macrocycle with a methyl substituent at the $\mathrm{C} 10^{\prime}$-position (Figure 1.1). The first 
example of an RAL, radicicol, was isolated from Monocillium nordinii ${ }^{\dagger}$ in $1953 .^{2}$ Historically, radicicol was a vanguard of RAL research, generating interest due to potential antibacterial ${ }^{3-5}$ and cytotoxic ${ }^{6}$ properties. Also of early historical importance was zearalenone, isolated from Gibberella zeae in $1962 .{ }^{7}$ Zearalenone generated interest as the compound responsible for the toxicity of an agriculturally damaging fungus. Additionally, the majority of work elucidating the mechanism of the biosynthesis of RALs has been done on zearalenone, which was shown to be biosynthesised through a polyketide synthase (PKS) pathway, the details of which are provided in subsection 1.2.2.

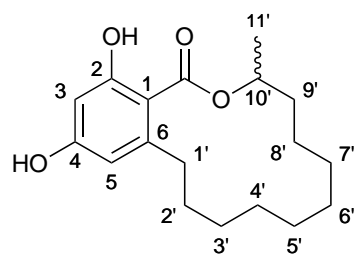

Figure 1.1. General structure and numbering of RAL family

While other RALs were isolated (LL-Z1640-1 to LL-Z1640-4 in $1978,{ }^{8}$ hypothemycin in $1980,{ }^{9}$ and monocillins $\mathrm{I}-\mathrm{V}$ in $1987^{10}$ ), RALs only garnered limited interest from the known biological properties of radicicol. It was not until the late 1990's that RALs became a significant class of compounds for medicinal research, initiated by the discovery of radicicol as a potent and selective inhibitor of Hsp90, ${ }^{11,12 \ddagger}$ as well as the discovery of hypothemycin and L-783277 as kinase inhibitors. ${ }^{13}$ Interest in RALs was further bolstered by the discovery of additional compounds displaying interesting biological activity, such as the aigialomycins in $2002,{ }^{14}$ and the pochonins in $2003 .{ }^{15}$ Further details of reported RALs (natural and synthetic) and their known biological properties are given in subsection 1.2.3. Some examples of selected RALs and their targets are given in Figure 1.2. These examples highlight the potential value of SAR studies, with minor variations to the general RAL skeletal structure resulting in significant changes to selectivity and activity.

\footnotetext{
${ }^{\dagger} M$. nordinii is a mycoparasite known to kill pine stem rusts of Cronartium coleosporioides and Endocronartium harkenssii

${ }^{\ddagger}$ Hsp90 (heat shock protein 90) is an ATP-dependant molecular chaperone involved in the stabilisation, activation and degradation of various proteins.
} 
<smiles>CO[C@@H](C)C[C@@H]1O[C@H]1/C=C\C=CC(=O)Cc1c(Cl)c(O)cc(O)c1C(=O)O</smiles>

Radicicol

Hsp90 inhibitor (20 nM)<smiles>CO[C@H](C)C[C@@H](O)[C@@H](Cl)/C=C\C=C\C(=O)Cc1c(Cl)c(O)cc(O)c1C(=O)O</smiles>

Pochonin C

HSV inhibitor $(6 \mu \mathrm{M})$<smiles>COc1cc(O)c(C(=O)O[C@H](C)CCCC(=O)[C@@H](O)[C@H](O)C/C=C/c2cc(OC)c(OC)cc2OC)c(OC)c1</smiles>

Hamigeromycin A No known significant bioactivity<smiles>CC(CCCCC(=O)CCCC=Cc1cc(O)cc(O)c1C(=O)O)OC(=O)c1ccccc1</smiles><smiles>C/C=C/C(=O)[C@@H](O)[C@H](O)CC/C=C\C[C@@H](C)OC(=O)c1c(O)cc(OC)cc1O</smiles>

LL-Z1640-2

TAK-1 inhibitor (8.1 nM)<smiles>COc1cc(O)c(C(=O)O[C@H](C)C/C=C/C(=O)[C@@H](O)[C@@H](O)C/C=C/c2cc(OC)c(OC)cc2OC)c(O)c1</smiles>

Caryospomycin C Nematicide<smiles>COc1cc(OC)cc([C@@H]2O[C@@H]2CC[C@@H](O)[C@H](O)C(=O)/C=C\CC[C@@H](C)OC(=O)c2c(O)cc(OC)cc2O)c1</smiles>

Hypothemycin MAP kinase inibitor (17-90 nM)<smiles>C[C@@H]1C[C@H]2O[C@H]2/C=C\C=C/C(=O)Cc2cc(O)cc(O)c2C(=O)O1</smiles>

Monocillin I Hsp90 inhibitor (0.34 $\mu \mathrm{M})$<smiles>CO[C@H](C)C/C=C/[C@@H](O)[C@@H](O)CC/C=C/c1cc(O)cc(O)c1C(=O)O</smiles>

Aigialomycin D

Antimalarial (18 $\mathrm{nM})$

CDK1 and 5 inhibitor $(6 \mu \mathrm{M})$

Figure 1.2. A selection of RALs and relevant bioactivties

\subsubsection{The Biosynthesis of Resorcylic Acid Lactones}

Research on zearalenone has shown the biosynthesis to go through a polyketide synthase (PKS) pathway, involving the condensation and subsequent cyclisation of acetyl-CoA ${ }^{\S}$ as shown in Scheme 1.1. The biosynthesis of zearalenone begins with a highly reducing PKS (hrPKS), a large multi-domain enzyme with various domains used for condensing and reducing acyl-CoA units to form a reduced hexaketide-thioester chain. This thioester chain is then transferred to a non-reducing PKS (nrPKS) where further acyl-CoA units are condensed to form a mixed reduced/unreduced nonaketide. The resorcylate moiety is then formed through an aldol condensation of the unreduced portion of the chain, followed by esterification between the reduced chain hydroxyl and thioester functional groups to form the macrolactone ring and release zearalenone from the enzyme. ${ }^{16-18}$

\footnotetext{
${ }^{\S}$ CoA (coenzyme A) functions as a acyl group donor.
} 


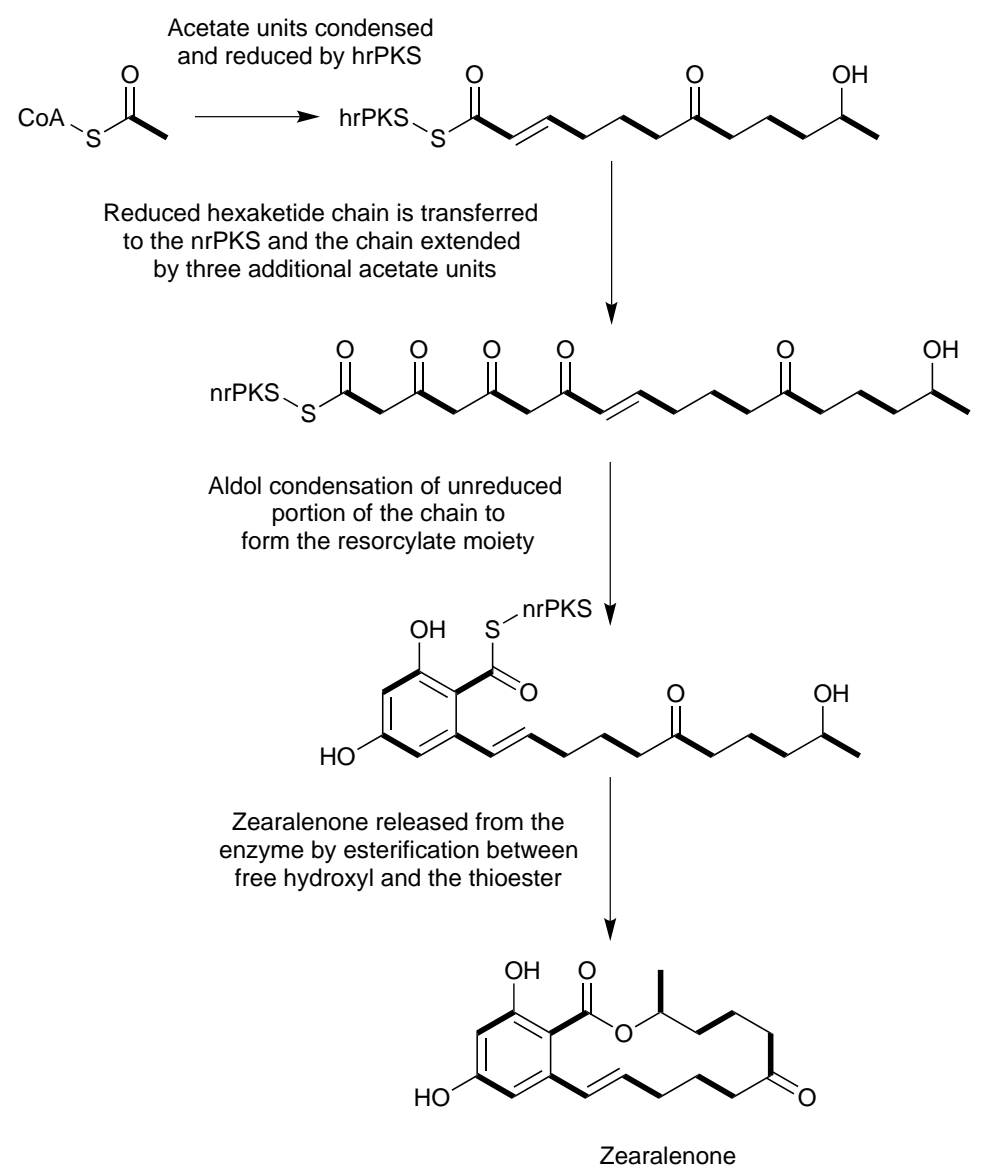

Scheme 1.1. Proposed biosynthesis of zearalenone. Acyl-units carbon atoms are represented by bold bonds.

It has been proposed the biosynthesis of hypothemycin and radicicol go through a similar pathway, involving a hrPKS and nrPKS, with structural variations arising from differing reduction patterns in the hrPKS step and putative post-PKS enzymatic alterations (e.g. epoxidation, halogenation). ${ }^{19,20}$ Scheme 1.2 and Scheme 1.3 shows how various post-PKS enzymes may be employed to afford the rich diversity of compounds in the RAL family. For example, hypothemycin is proposed to be biosynthesised via aigialomycin $\mathrm{C}$, from the initial product, $7^{\prime}, 8^{\prime}$-dehydrozearalenol (Scheme 1.2). After the formation of $7^{\prime}, 8^{\prime}$-dehydrozearalenol through a PKS pathway, the putative post-PSK enzymatic alterations are selective $4-O$-methylation by an $O$-methyltransferase (OMT), $1^{\prime}, 2^{\prime}$-epoxidation by a flavin-dependent monooxygenase (FMO) and 5'-hydroxylation of $7^{\prime}, 8^{\prime}$-dehydrozearalenol by a cytochrome P450 (CYP) monooxygenase to afford aigialomycin $\mathrm{C}$. Then, subsequent $6^{\prime}$-oxidation by an alcohol oxidase (AOX), Z/E isomerisation of the $7^{\prime}$-alkene by a glutathione S-transferase (GST) and 4'-hydroxylation by another CYP to afford hypothemycin. ${ }^{19}$ 

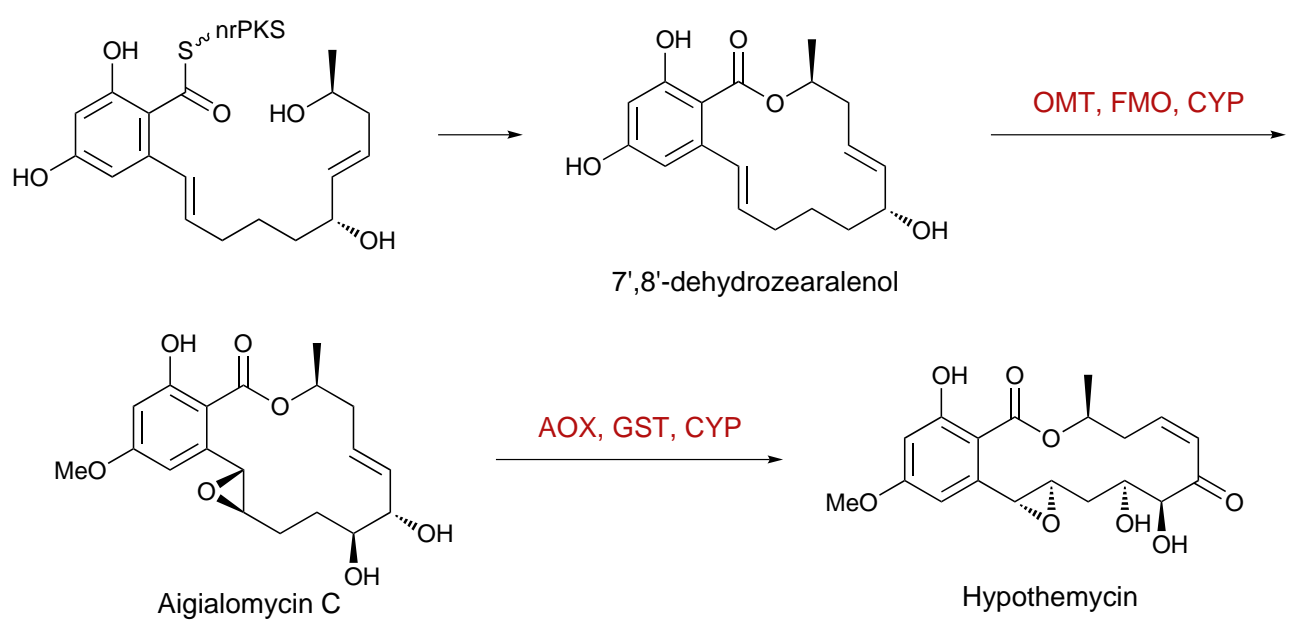

Scheme 1.2. Proposed biosynthesis of hypothemycin. ${ }^{19}$

The biosynthesis of monocillin I and radicicol are thought to go through a similar pathway, with the exception of a chlorination step by putative fungal flavin-dependant halogenase to initially form pochonin D in the biosynthesis of radicicol. A putative CYP epoxidase is responsible for epoxidation of the $7^{\prime}$-alkene to form monocillin I and the 5-chloro equivalent, ponchonin A. The origin of the $\left(5^{\prime} Z\right)$-alkene is uncertain, as PKSs almost exclusively provide $(E)$-alkenes, and the radicicol gene cluster does not possess a GST, which has been shown to facilitate isomerisation of the alkene in hypothemycin analogues. A possible origin of the $(Z)$-alkene of radicicol and monocillin $I$ is a $5^{\prime}$ hydroxylation catalysed by a CYP followed by a dehydration step (Scheme 1.3). ${ }^{20}$

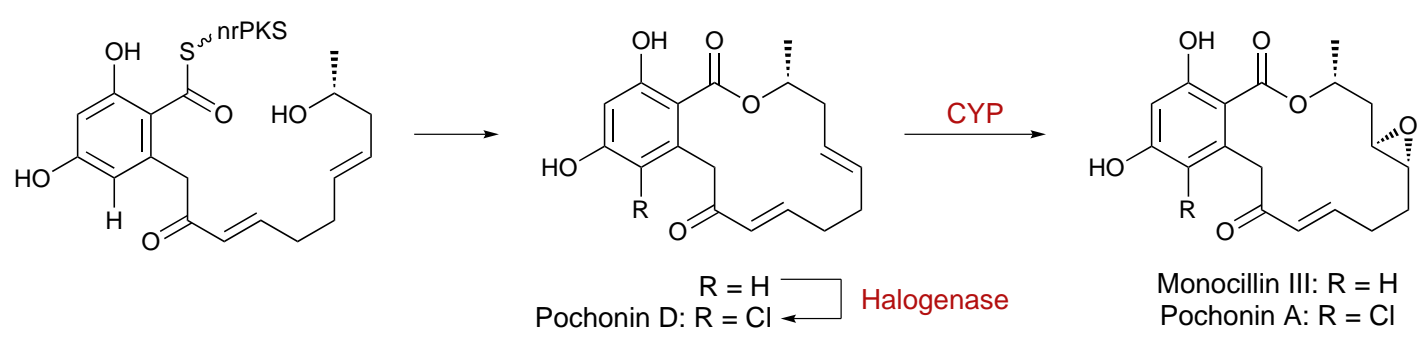

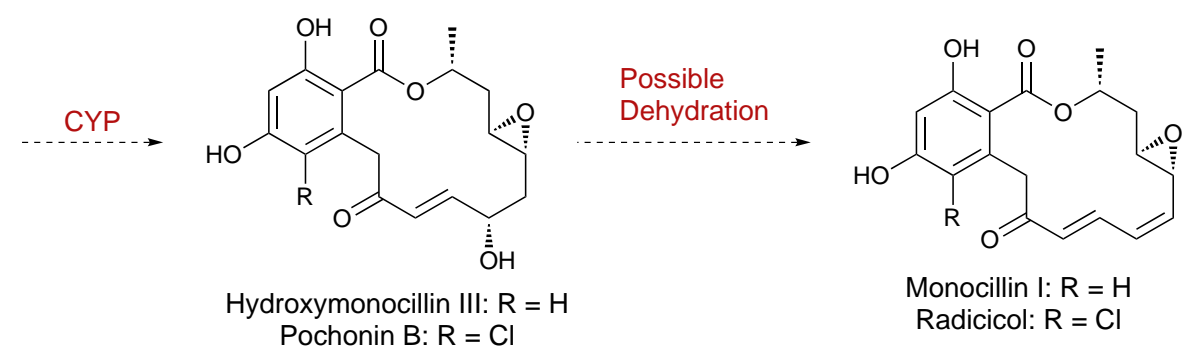

Scheme 1.3. Proposed biosynthesis of monocillin I and radicicol. ${ }^{20}$ 


\subsubsection{An Overview of Structure-Activity Relationships Within the Resorcylic Acid Lactones}

Investigations into the biological activity of the RALs have focused on two groups of compounds: the first group includes radicicol, the pochonins, and related compounds, which have been the focus of considerable research due to their Hsp90 inhibition properties; the second group includes hypothemycin, LL-Z1640-2, and related compounds, which have garnered interest due to their selective kinase inhibition properties. Other RALs have been isolated that display less noteworthy biological activity, but are useful when considering SARs within the class of compounds.

\section{Resorcyclic Acid Lactones as HSP90 Inhibitors}

Hsp90 is a molecular chaperone that plays an important role in many biological processes relating to the transport, activation, stabilisation and degradation of various proteins. The important functions of Hsp90 are in the folding of both nascent and denatured proteins, ensuring they are in an activated or stabilised form, and in preventing aggregation. Hsp90 is present under normal conditions to assist in these tasks. When exposed to cellular stresses (e.g. infection, inflammation, changes to temperature, or exposure to toxins) Hsp90 is over-expressed to maximise the amount of functional proteins, which are known to include various oncogenic proteins, such as Raf, mutant $\mathrm{p} 53$, Her2 ${ }^{21}$ and telomerase. ${ }^{22}$ As a result, Hsp90 has the potential to facilitate the proliferation and survival of various proteins associated with oncological pathways, ${ }^{23,24}$ making Hsp90 inhibition an attractive target for cancer therapy. ${ }^{25,26}$ Preliminary studies also suggest that Hsp90 inhibitors accumulate more efficiently in tumour cells than normal cells. ${ }^{27}$ The specific Hsp90 inhibitor used was a geldanamycin analogue, 17-allylamino-17-demethoxygeldanamycin (17-AAG), currently in phase II clinical trials, which has a similar biological mechanism to radicicol. ${ }^{28-30}$ 
Studies have shown that, despite the lack of structural similarity between ATP and either radicicol or geldanamycin, both inhibit Hsp90 by competitive binding to the ATP binding site of Hsp90. ${ }^{31}$ Importantly, radicicol has been shown to only bind to the unique Lshaped binding pocket (Bergerat fold) present in Hsp90, ${ }^{32,33}$ and consequently does not compete with ATP binding in other biological processes. Radicicol also binds to Hsp90 in its lowest energy comformation, ${ }^{34}$ while geldanamycin compounds must adopt a higher energy conformaton, ${ }^{35,36}$ suggesting radicicol or radicicol analogues may be a good alternative or even improvement on 17-AAG.

Radicicol has been shown to bind to Hsp90 non-covalently, suggesting the structural features important for biological activity are those which govern the conformation, and hydrogen bonding of radicicol to the ATP binding site of Hsp90. Two other groups of naturally occurring RALs, the monocillins (isolated in 1980 from M. nordinii) ${ }^{37}$ and the pochonins (isolated in 2003 from Pochonia chlamydosporia var. catenulata strain P 0297) have also exhibited Hsp90 inhibition properties. ${ }^{15}$ Both groups of RALs are highly structurally similar to radicicol, characterised by a trans-enone functionality and a $\left(10^{\prime} R\right)$-methyl group. Figure 1.3 highlights the minor structural variations between these compounds, and their effect on Hsp90 inhibition. Inhibition of human simplex virus 1 (HSV 1) and WNT-5A ${ }^{\top}$ are also reported, indicating anti-viral properties ${ }^{15}$ and potential for hair growth treatment, ${ }^{38}$ respectively.

IWNT-5A (Wingless-type mouse mammary tumour virus integration-site family, member 5A) is one of the glycoproteins secreted by the WNT family, which are intercellular signalling molecules known to play important roles in development processes, such as cell proliferation. 


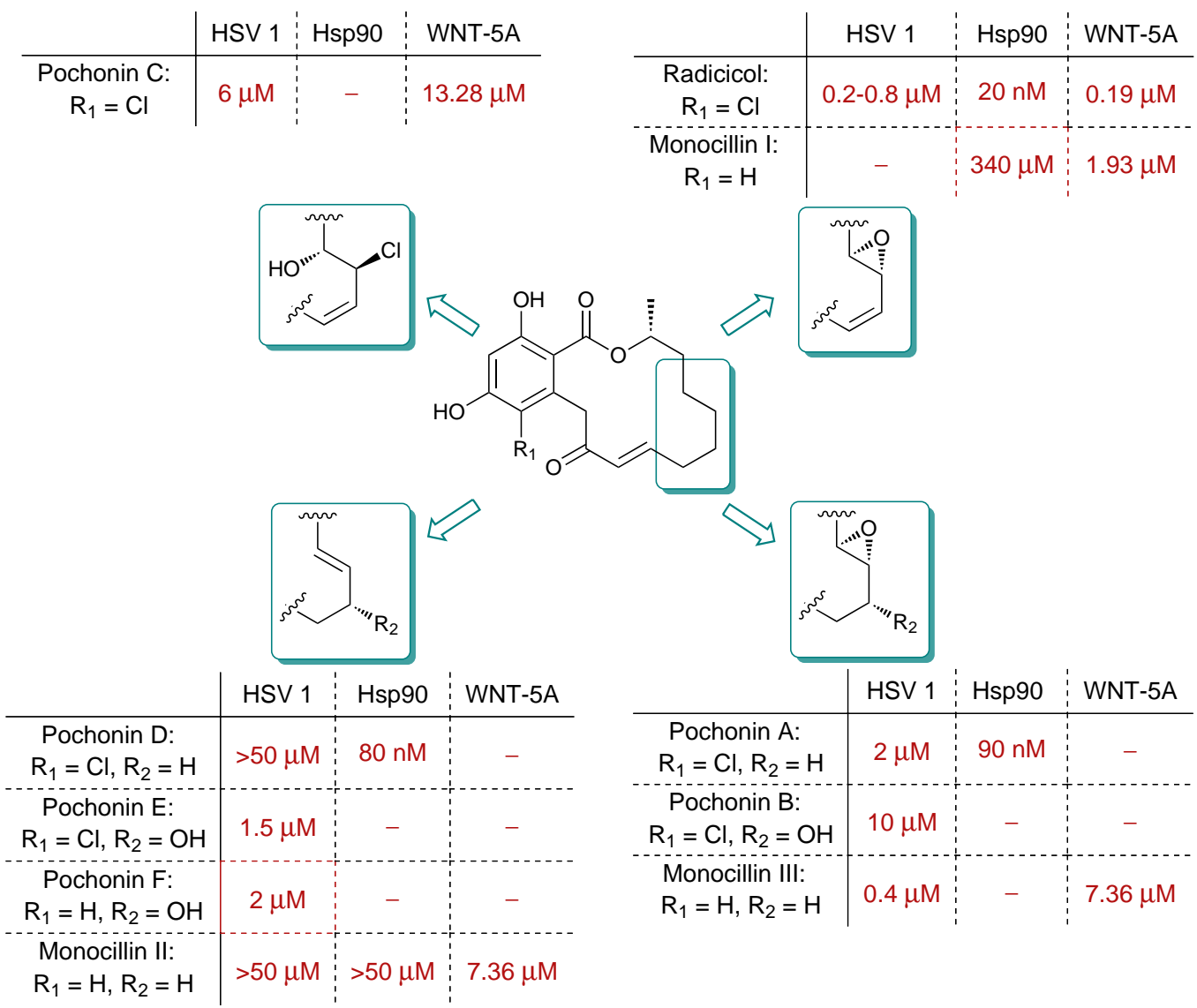

Figure 1.3. A selection of natural RALs and known inhibition targets $\mathrm{IC}_{50}$. (- indicates testing of the compound for this activity has not been reported).

Figure 1.3 shows the isolated RALs that have been found to possess HSV 1, Hsp90 and/or WNT-5A inhibition properties. These compounds highlight the effect of various alterations around the $\mathrm{C}^{\prime}-\mathrm{C}^{\prime}$ portion of the molecule and chlorination at the $\mathrm{C} 5$ position. Similar RALs have also been isolated (monocillin IV, monocillin V, nordinone and nordinonediol, Figure 1.4), that have no reported biological activity. ${ }^{10,37}$ In contrast to the previously mentioned RALs (Figure 1.3), these RALs possess no functionality from the $\mathrm{C}^{\prime}-\mathrm{C}^{\prime}$ portion of the molecule or chlorination at the $\mathrm{C} 5$-position, suggesting certain functionality is required at those positions for the compound to inhibit the desired biological targets. 


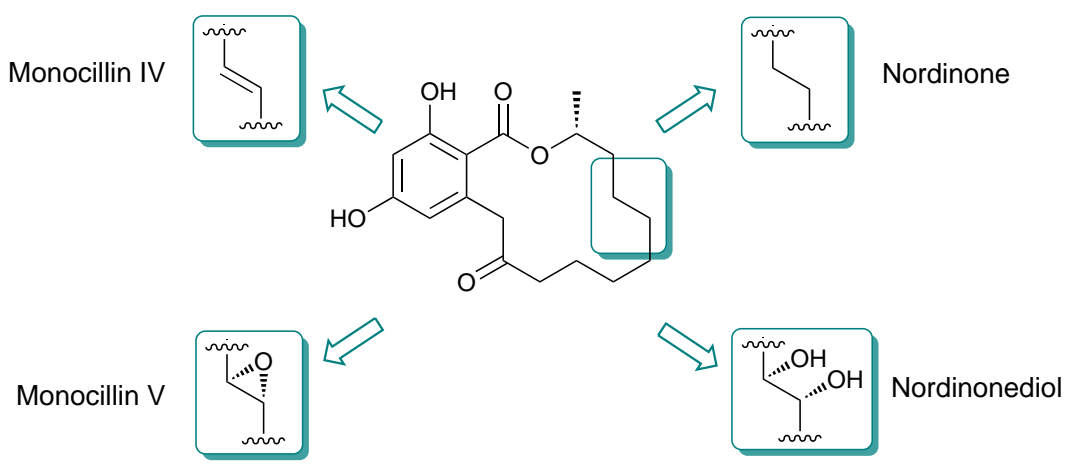

Figure 1.4. Selected biologically inactive natural RALs.

Natural RALs provide useful SAR information, but are limited in the type and number of structural features that occur naturally. Analogue synthesis allows for a more extensive and systematic analysis of SARs, and can provide greater insight into both the importance of structural features to biological activity, and the nature of their role (e.g. Michael acceptor, effect on conformation, hydrogen bonding). Detailed SAR studies have been conducted around the general structure provided in Figure 1.3, and these show the value of analogue synthesis-based SAR studies. ${ }^{39-41}$ These studies were done by synthesising a combination of analogues possessing single or multiple structural variations, then comparing the results of biological testing. Early SAR studies were done by making small variations, such as hydrogenating the alkene moieties, and correlating the effect on Hsp90 inhibition. ${ }^{39}$ SAR studies also involved variation of the macrocycle size from 12to 16-membered, which suggested 13-, 15- and 16-membered macrocycles may retain activity. ${ }^{40}$ However, these studies were done with $3^{\prime}, 4^{\prime}$-dihydro-analogues, which are less active. Later research by Winssinger et al. on more active pochonin D analogues showed 13- or 15 -membered macrocycles led to a significant reduction in biological activity. ${ }^{41}$ This highlights a flaw of SAR studies; alterations at one position may negate or enhance the effect of alterations at another.

The unpredictability of correlating SARs of varying systems was further highlighted by additional results reported by Winssinger et $a l .{ }^{41}$ It was found that the 5-dechloropochonin $\mathrm{D}$ analogue (monocillin II) showed a similar $\mathrm{EC}_{50}$ value as pochonin $\mathrm{D}$, while, in combination with the modification of the $10^{\prime}$-methyl to a ethyl group, chlorination at the C5-position led to a five-fold increase in affinity. However, in combination with methylation at the $\mathrm{C6}^{\prime}$-position, chlorination was found to lower the affinity to 
Hsp90. Other results reported by Winssinger et al. suggested that a hydroxyl at the C6'position, and replacement of the $\mathrm{C} 2$ '-carbonyl with an oxime increases the potency of the compound. Further evidence was also provided for the importance of the enone system, with $3^{\prime}, 4^{\prime}$-dihydro analogues all exhibiting decreased affinity to Hsp90. Two promising analogues that have been developed by these SAR studies are shown in Figure 1.5.
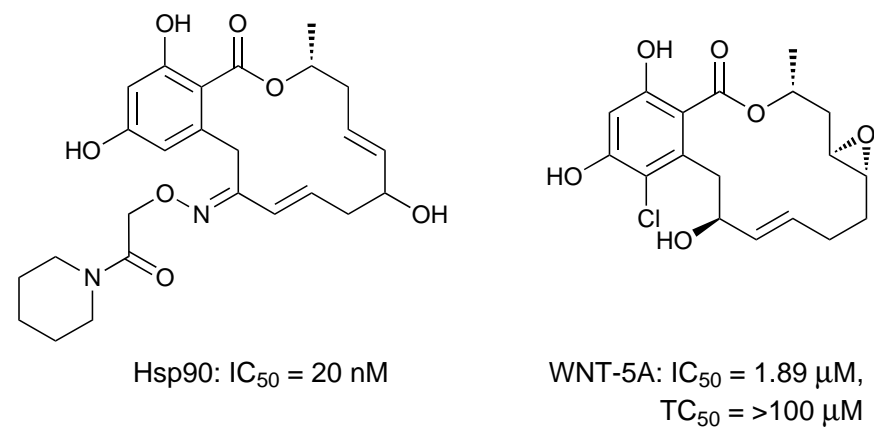

Figure 1.5. Selected analogues and biological activities from SAR studies by Winssinger et al.(left) and Shinonaga et al.(right).

Work by Shinonaga et al. further supports the importance of the enone system for biological activity and stability, showing analogues lacking a $\mathrm{sp}^{2}$-hybridised centre at the $\mathrm{C}^{\prime}$-position exhibited lower biological activity and lower stability under acidic conditions. This research also provided SARs relating to the toxicity of analogues, with results suggesting $\mathrm{C} 5$-dechloro analogues are relatively more toxic, and $\mathrm{C} 3$ '-hydroxyl and $\mathrm{C} 3^{\prime}$-oxime analogues are relatively less toxic. ${ }^{38}$ A diagram summarising the SAR information from the studies outlined previously is provided in Figure 1.6.

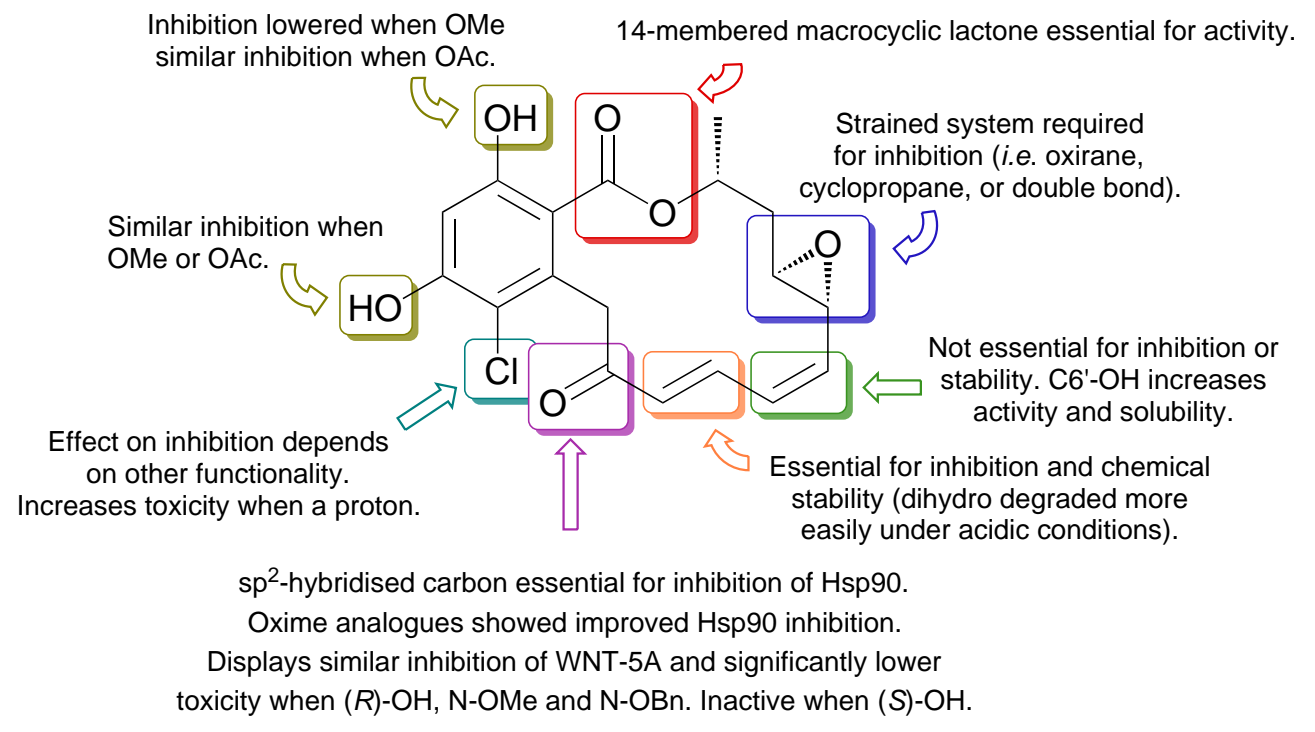

Figure 1.6. General SAR information of WNT-5A and Hsp90 inhibiting RALs. 


\section{Resorcylic Acid Lactones as Kinase Inhibitors}

Kinases are phosphotransferase enzymes responsible for transferring phosphate groups from a donor molecule (usually ATP) to various substrates. An important class of these enzymes are the protein kinases; through phosphorylation of protein substrates, they can play a critical role in various cellular processes, including those associated with oncological pathways. One such pathway is the mitogen-activated protein kinase (MAPK) pathway, a three-tiered kinase cascade of signal transducing enzymes which directly influences processes such as cell survival, proliferation and adaption. The cascade is comprised of a MAPK, which is activated via phosphorylation by a MAPK kinase (commonly abbreviated as MAPKK, MKK or MEK), which in turn is activated via phosphorylation by a MEK kinase (commonly abbreviated as MAPKKK, MKKK or MEKK), with the entire process up-regulated in response to physical and chemical stresses. ${ }^{42}$ It is the MAPKs involved in this cascade that are a major target for RALs being developed as therapeutic cancer treatment.

The first RALs discovered to possess kinase inhibition properties, hypothemycin and L783277, were found to inhibit MEK1, with $\mathrm{IC}_{50}$ values of $15 \mathrm{nM}$ and $4 \mathrm{nM}$, respectively. ${ }^{13}$ Other notable RALs exhibiting kinase inhibition are LL-Z1640-2, an inhibitor of TAK1 and ERK2 ${ }^{\|}$with $\mathrm{IC}_{50}$ values of $8.1 \mathrm{nM}$ and $8.0 \mathrm{nM}$, respectively, ${ }^{43,44}$ and radicicol A, an inhibitor of VEGF-R2/R3, FLT3 and PDGFR- $\beta^{* *}$ with $\mathrm{IC}_{50}$ values of 26, 66, 110 and $210 \mathrm{nM}$, respectively. ${ }^{45}$ These compounds display a high structural similarity, including a $\left(10^{\prime} S\right)$-methyl group [compared with the $\left(10^{\prime} R\right)$-methyl seen in Hsp90 inhibiitng RALs], a $6^{\prime}-8^{\prime}$-cis-enone, $\left(4^{\prime} S, 5^{\prime} S\right)$-diol and 4-O-methyl.

\footnotetext{
"IAK1 (transforming growth factor- $\beta$ activated kinase 1) is a MAPKKK and ERK2 (extracellular signalregulated kinase 2) is a MAPK.

${ }^{* *}$ VEGF-R2/R3 (vascular endothelial growth factor receptor 2 and receptor 3), FLT3 (fibromyalgia syndrome-like tyrosine kinase 3 ) and PDGFR- $\beta$ (platelet-derived growth factor receptor- $\beta$ ) are tyrosine receptor kinases.
} 
<smiles>COc1cc(O)cc([C@@H]2O[C@@H]2CC[C@@H](O)[C@H](O)C(=O)/C=C\C[C@@H](C)OC(=O)c2c(O)cc(OC)cc2O)c1</smiles>

Hypothemycin MEK1 inibitor (15 nM)<smiles>COc1cc(O)cc(/C=C/C[C@@H](O)[C@H](O)C(=O)/C=C\C[C@@H](C)OC(=O)c2c(O)cc(OC)cc2O)c1</smiles>

LL-Z1640-2

TAK1 inibitor (8.1 nM)

ERK2 inibitor (8.0 nM)<smiles>COc1cc(O)cc(CCC[C@@H](O)[C@H](O)C(=O)/C=C\C[C@@H](C)OC(=O)c2c(O)cc(OC)cc2O)c1</smiles>

L-783277

MEK1 inhibitor (4 nM)

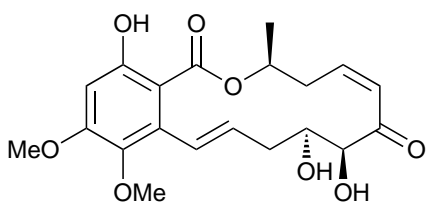

Radicicol A

VEGF-R2/R3 inibitor (26 nM, $66 \mathrm{nM}$ ),

FLT3 inibitor (110 nM),

PDGFR- $\beta$ inibitor (210 nM)

Figure 1.7. Natural RALs which have displayed kinase inhibition properties.

A more comprehensive study found hypothemycin displays significant inhibition ${ }^{\dagger \dagger}$ against 21 out of the 123 kinases tested. 20 of these contained a cysteine (cys) residue, of these, 18 incorporated a cys residue which corresponds to the cys166 in ERK1/2. ${ }^{46}$ From co-crystallisation with ERK2, LL-Z1640-2 was shown to convalently bond to the cys 166 residue. ${ }^{43}$ It was proposed that this covalent bonding would occur thorough a Michael addition of the cysteine thiol to the C $8^{\prime}$-position (Scheme 1.4). This proposed mechanism would indicate the Michael acceptor properties of the RAL is a crucial factor in determining kinase inhibition properties.
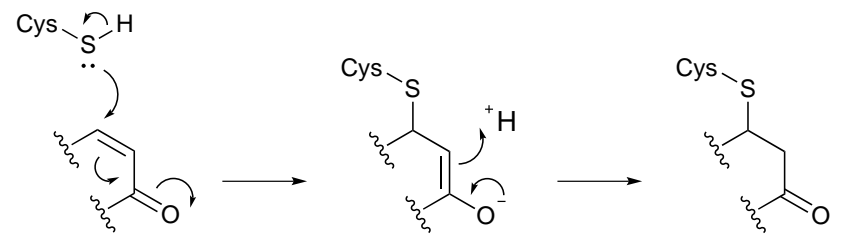

Scheme 1.4. Proposed Michael addition of a cysteine thiol to the enone functionality.

Synthesis and subsequent biological testing of a 4-O-desmethyl hypothemycin analogue showed an increased potency against three human cancer lines (COL829, HT29 and SKOV3) compared to hypothemycin. ${ }^{47}$ Two radicicol $\mathrm{A}$ analogues have also been synthesised and tested, a 5-desmethoxy analogue and a 5-chloro analogue; both of these analogues were found to be less potent compared to radicicol A against all targets based on $\mathrm{IC}_{50}$ values. The most comprehensive SAR studies on kinase-inhibiting RALs

\footnotetext{
${ }^{\dagger \dagger}$ Greater than $20 \%$ inhibition at $200 \mathrm{nM}$.
} 
through analogue synthesis has been done on the development of LL-Z1640 as a antiinflammatory drug. ${ }^{48-50}$<smiles>C[C@H]1/C=C\C(=O)[C@@H](O)[C@H](O)C[C@@H]2O[C@H]2c2cc(O)cc(O)c2C1=O</smiles>

4-O-desmethyl hypothemycin<smiles>COc1cc(O)cc(/C=C/C[C@@H](O)[C@H](O)C(=O)/C=C\C[C@H](C)OC(=O)c2c(O)cc(OC)cc2O)c1</smiles>

5-desmethoxy radicicol A<smiles>COc1cc(O)c(C(=O)O[C@H](C)C/C=C\C(=O)[C@@H](O)[C@H](O)C/C=C/c2cc(Cl)c(OC)cc2Cl)c(OC)c1</smiles>

5-chloro radicicol $\mathrm{A}$

Figure 1.8. Reported analogues of hypothemycin and radicicol A.

\section{The Development of E6201: A Potential Anti-Inflammatory Drug}

A considerable amount of research has been reported on improving the metabolic stability, in vivo potency and bioavailability of LL-Z1640-2 as an anti-inflammatory drug through analogue synthesis. However, as these results were published either during or after the duration of the research reported in this thesis, a heavily abridged account of the results will be provided. The first goal of the structure optimisation was to improve the metabolic stability of the compound, while retaining biological activity; ${ }^{\ddagger \ddagger}$ this was done by targeting the double bond of the enone functionality. ${ }^{48} \mathrm{C} 7^{\prime}$ - and $\mathrm{C} 8^{\prime}$-alkene substituted analogues and $C 9^{\prime}$-substituted analogues were synthesised. A $\left(9^{\prime} S\right)$-methyl analogue was found to possess significantly higher metabolic stability while retaining reasonable biological activity. Improvement of the in vivo inhibition properties was then attempted by the substitution of various groups at the C4- and C5-position of the resorcylic ring as well as the synthesis of $\mathrm{C} 1^{\prime}$-ether and $\mathrm{C} 1^{\prime}$-amide analogues. ${ }^{49}$ Substitution of the C4-positions yielded the most positive results, with further research in this direction to improve the bioavailability of the compound ultimately leading to the development of clinical trial candidate E6201. ${ }^{50}$

\footnotetext{
${ }_{\ddagger}^{\ddagger}$ Desired biological activity was tested in a TNF $\alpha$ - PLAP reporter assay, and non-specific cytotoxic activity in a $\beta$-actin-PLAP (ACT-PLAP) reporter assay. Stability was measured by the amount (\%) of the compound remaining after $2 \mathrm{~h}$ at $37^{\circ} \mathrm{C}$ in mouse plasma.
} 


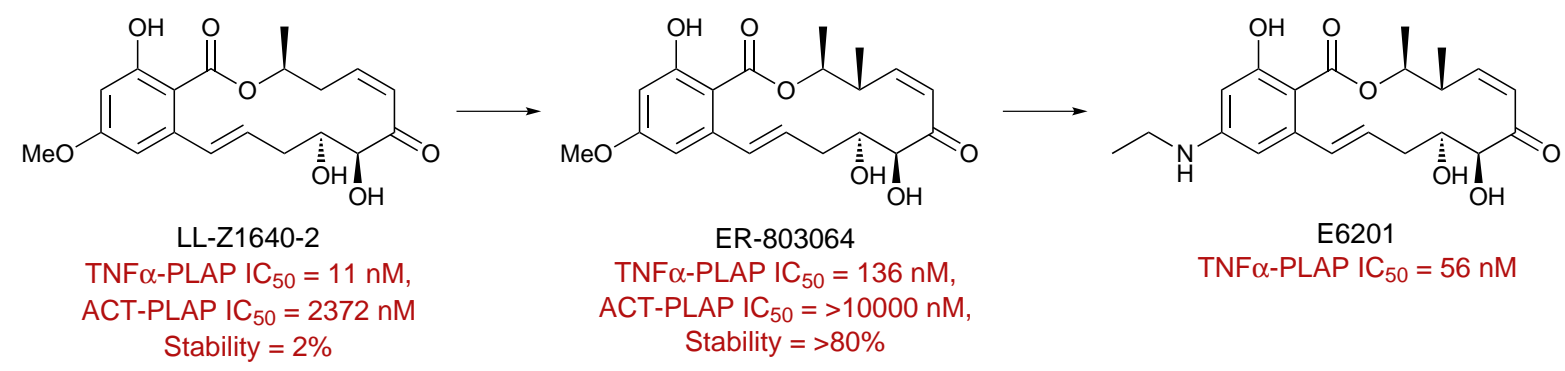

Figure 1.9. The development of E6201 through analogue synthesis.

\section{Miscellaneous Resorcyclic Acid Lactones}

Some other RALs have been isolated but possess limited biological activity. Queenslandon (Figure 1.10), isolated in 2002 from fungal strain Chrysosporium queenslandicum IFM51121, has exhibited anti-fungal activity. ${ }^{51}$

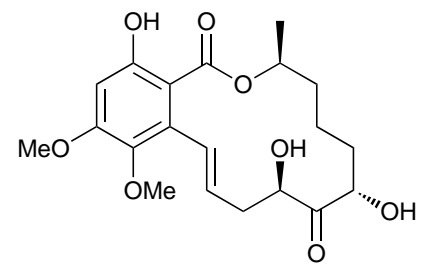

Figure 1.10. Queenslandon

The caryospomycins (Figure 1.11), isolated in 2007 from fresh-water fungus Caryospora callicarpa YMF1.01026, have been shown to possess nematicidal activity, with $\mathrm{LC}_{50}$ values around $100 \mathrm{ppm}$ over a $36 \mathrm{hr}$ period. ${ }^{52}$ No research into the cytotoxic or kinase inhibition properties of any caryospomycins has been reported.

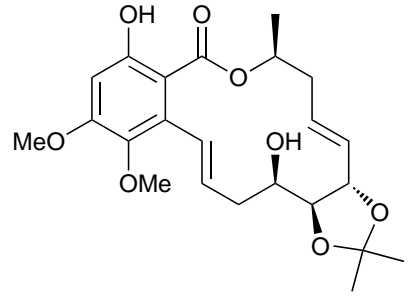

Caryospomycin A

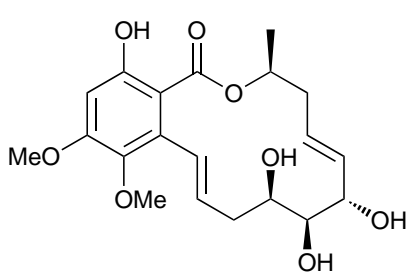

Caryospomycin B<smiles>COc1cc(O)c(C(=O)OC(C)C/C=C\C(=O)[C@@H](O)[C@@H](O)C/C=C/c2cc(OC)c(OC)cc2OC)c(O)c1</smiles>

Caryospomycin C

Figure 1.11. Caryospomycins 
The most recently isolated group of RALs, the hamigeromycins (Figure 1.12), have shown limited biological activity. Tests against three human cancer cell lines (KB, MCF-7, and NCI-H187)* at $50 \mu \mathrm{M}$ and Plasmodium falciparum $\mathrm{K} 1$ at $10 \mu \mathrm{M}$ showed no useful biological activity. Against Vero cells, only hamigeromcyin A and C displayed growth inhibition, with respective $\mathrm{IC}_{50}$ values of 42 and $13 \mu \mathrm{M} .^{53,54}$

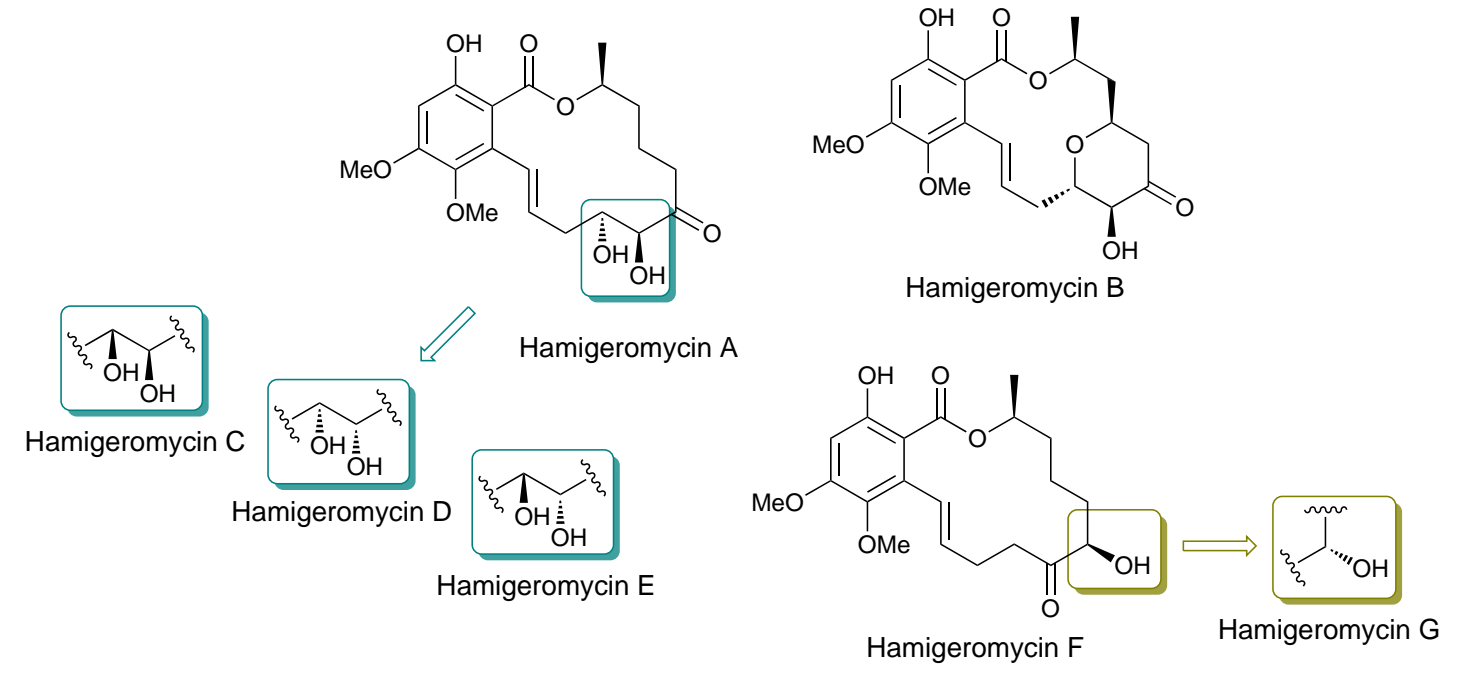

Figure 1.12. Hamigeromycins

\subsection{Aigialomycin D}

Aigialomycins (Ams) A-E (1-5) were isolated from mangrove fungus Aigialus parvus BCC 5311 in 2002 by Isaka et al. ${ }^{14}$ Of the aigialomycins, only aigialomycin D (AmD) has been shown to possesses useful biological activity. Biological testing has shown AmD possesses moderate anti-malarial properties, with an $\mathrm{IC}_{50}$ of $6.6 \mu \mathrm{M}$ against $P$. falciparum, and moderate cyctotoxic properties, with $\mathrm{IC}_{50}$ values of $3.0,18$ and $1.8 \mu \mathrm{M}$ against $\mathrm{KB}$, BC-1 and Vero cancer cells, respectively. The observed cytotoxicity may arise from the kinase inhibition properties of $\mathrm{AmD}$, with $\mathrm{IC}_{50}$ values of 5.7, 5.8 and $14 \mu \mathrm{M}$ for the inhibition of kinases CDK1/cyclin B, CDK5/p25 and GSK-3, ${ }^{\dagger}$ respectively. ${ }^{55}$

${ }^{*} \mathrm{~KB}$ is an oral carcinoma cell line. MCF-7 is a breast cancer cell line. NCI-H187 is a small cell, lung carcinoma cell line.

${ }^{\dagger}$ CDK1 (cyclin-dependent kinase 1) and CDK5 are protein kinases involved in the regulation of the cell cycle. GSK-3 (glycogen synthase kinase-3) are serine/threonine protein kinases that play a key role in various signalling processes. 


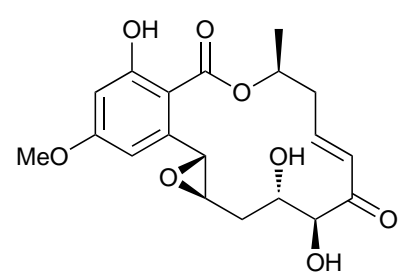

Aigialomycin A (1)<smiles>CO[C@H](C)C/C=C/[C@@H](O)[C@H](O)CC/C=C/c1cc(O)cc(O)c1C(=O)O</smiles>

Aigialomycin D (4)

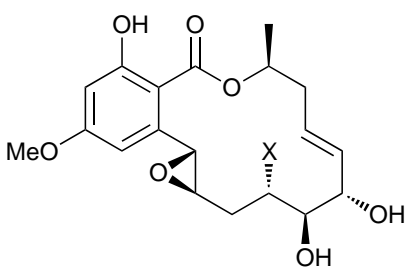

Aigialomycin $\mathrm{B}(2): \mathrm{X}=\mathrm{OH}$ Aigialomycin $\mathrm{C}(\mathbf{3}): \mathrm{X}=\mathrm{H}$

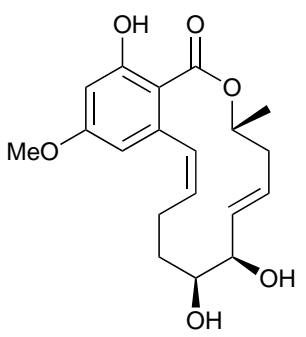

Aigialomycin E (5)

Figure 1.13. Aigialomycins isolated by Isaka et al.

Two additional aigialomycins, F (6) and G (7), were later isolated from the same fungus, however, they possess 6-membered lactones instead of the 14-membered macrolactones seen in other RALs, and have no known biological activity. ${ }^{56} \mathrm{~A} 1^{\prime}, 2^{\prime}$-epoxy analogue of AmD (8), isolated from Hypomyces subiculosus DSM 11931, also showed no useful biological activity against human cancer cell lines (COLO829, HT29 and SKOV3). ${ }^{\ddagger 47}$<smiles>COc1cc(O)c2c(c1)[C@H](O)[C@@H](C[C@H](O)[C@H](O)[C@H](O)C=CC[C@H](C)O)OC2=O</smiles>

Aigialomycin F (6)<smiles>COc1cc(O)c2c(c1)[C@H](O)[C@H](C[C@H](O)C(=O)CCCC(C)O)OC2=O</smiles>

Aigialomycin G (7)<smiles>C[C@H](O)C/C=C/[C@@H](O)[C@@H](O)CCC1O[C@H]1c1cc(O)cc(O)c1C(=O)O</smiles>

Epoxy-AmD 8

Figure 1.14. Aigialomycins $\mathrm{F}$ and $\mathrm{G}$, and natural epoxy-AmD analogue 8 .

Limited SAR studies have previously been done on AmD. Winssinger et al. published the synthesis of ten AmD analogues (Figure 1.15), mostly focusing on the 5',6'-diol portion of AmD. These analogues included deoxy-, methyl- and benzyl-analgoues as well as a $8^{\prime}$-methoxy-6'-alkene analogue. Second generation $1^{\prime}, 2^{\prime}$-dihydro analogues of the previous analogues were also prepared. Tests for kinase inhibition properties against CDK1/cyclin B, CDK5/p25, GSK-3 and PfGSK3 showed no activity for any of the tested analogues. ${ }^{55}$

${ }^{\ddagger}$ COLO829 is a melonoma cell line, and HT29 is a colon cancer cell line; both express mutant B-raf gene products. SKOV3 is an ovarian carcinoma cell line that expresses the wild-type B-raf gene product. 


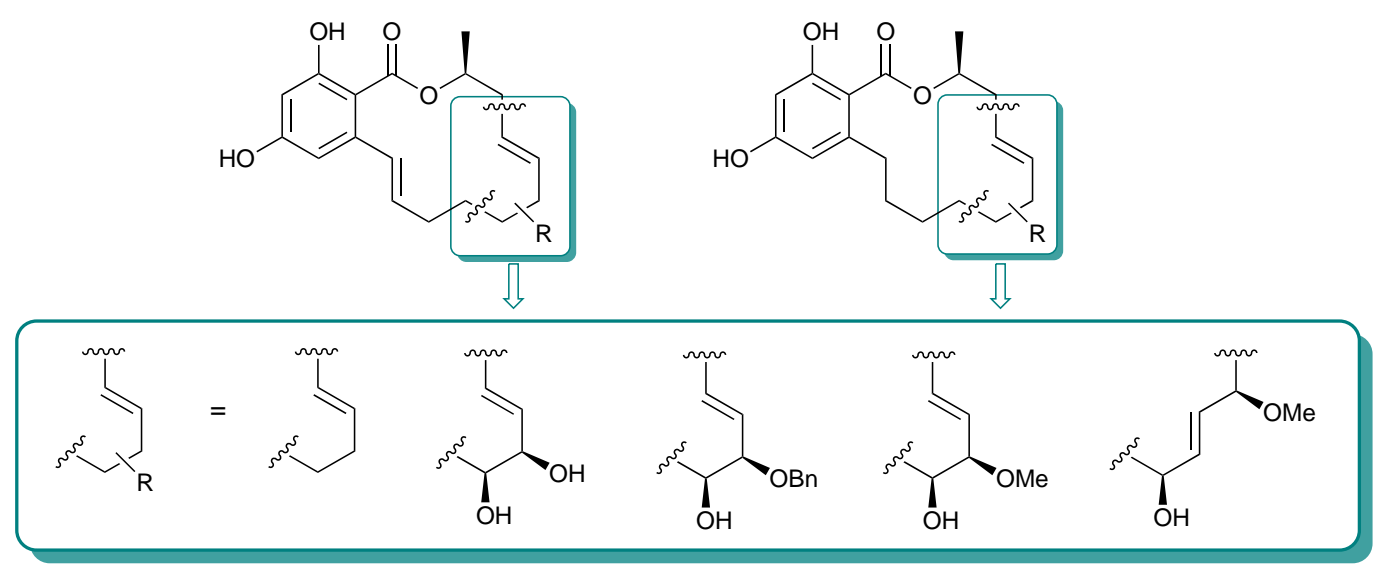

Figure 1.15. AmD analogues synthesised by Winssinger et al.

The syntheses of 6'-epi-AmD 9 and 4-methyl AmD 10 have also been reported, however no biological testing was reported. ${ }^{57,58}$

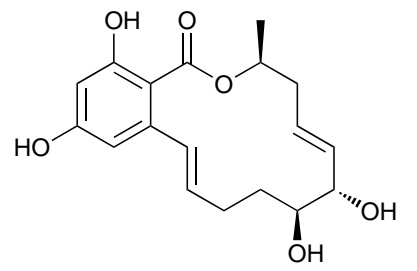

6'-epi-AmD (9)

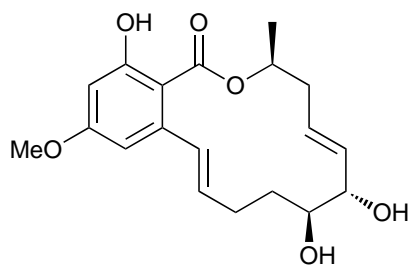

6'-epi-methyl-AmD (10)

Figure 1.16. 6'-epi-AmD (9) and 6'-epi-4-methyl $\mathrm{AmD}(\mathbf{1 0})$.

\subsubsection{Previous Published Syntheses of Aigialomycin D}

The first reported synthesis of AmD was published in 2004 by Danishefsky et al. (Scheme 1.5). ${ }^{59}$ The synthesis began with 2-deoxy-D-ribose to provide the correct stereochemistry of the diol moeity, which was transformed to aldehyde 11. A Barbier reaction of this aldehyde with propargyl bromide (12) and zinc dust, afforded a terminal alkyne. Then carboxylation with $n$-butyllithium and carbon dioxide, followed by a Mitsunobu reaction with $(R)$-4-penten-2-ol (13) gave the main body of the macrocycle. After protecting the alkyne as cobalt complex 14, the macrocycle was formed with a ring-closing metathesis (RCM) reaction catalysed by Grubbs' second generation catalyst. Deprotection of the alkyne followed by a Diels-Alder reaction with cyclic diene $\mathbf{1 5}$ gave the resorcylate moiety. Martin's sulfurane conditions were then used to give the $1^{\prime}$-alkene through dehydration of the $\mathrm{C} 2$ '-hydroxyl. Finally, global deprotection afforded $\mathrm{AmD}$ in a total of 18 linear steps and overall yield of $8 \%$. 

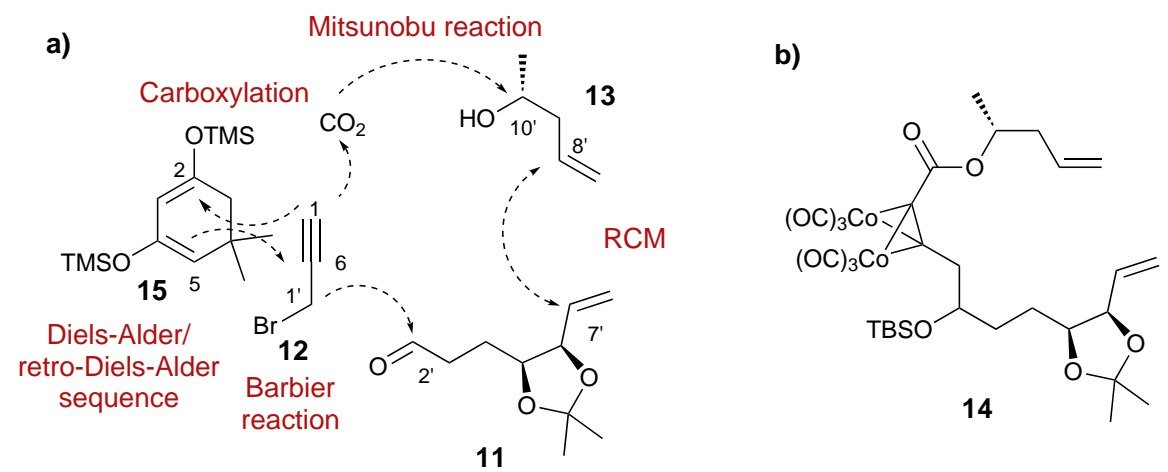

Scheme 1.5. a) Danishefsky's synthetic strategy for AmD. b) The key alkyne protected as a cobalt complex.

The next synthesis of AmD was reported in 2006 by Pan et al. (Scheme 1.6) ${ }^{60}$ Sharpless asymmetric epoxidation followed by a stereoselective ring-opening were used to provide the diol stereochemistry. Kocienski's modified Julia reaction was used to couple sulfone 16 with benzylic aldehyde 17, giving the desired $\left(1^{\prime} E\right)$-alkene. Another Kocienski modified Julia reaction with chiral sulfone 18, derived from commercially available $(S)$-butane-1,3-diol, was used to provide the final part of the molecule and the $\left(7^{\prime} E\right)$ alkene. Carboxylation of aromatic bromide 19 with $n$-butyllithium and carbon dioxide and subsequent Yamaguchi macrolactonisation were then used to afford protected AmD. Global deprotection then provided AmD in 18 steps and an overall yield of $2.5 \%$.

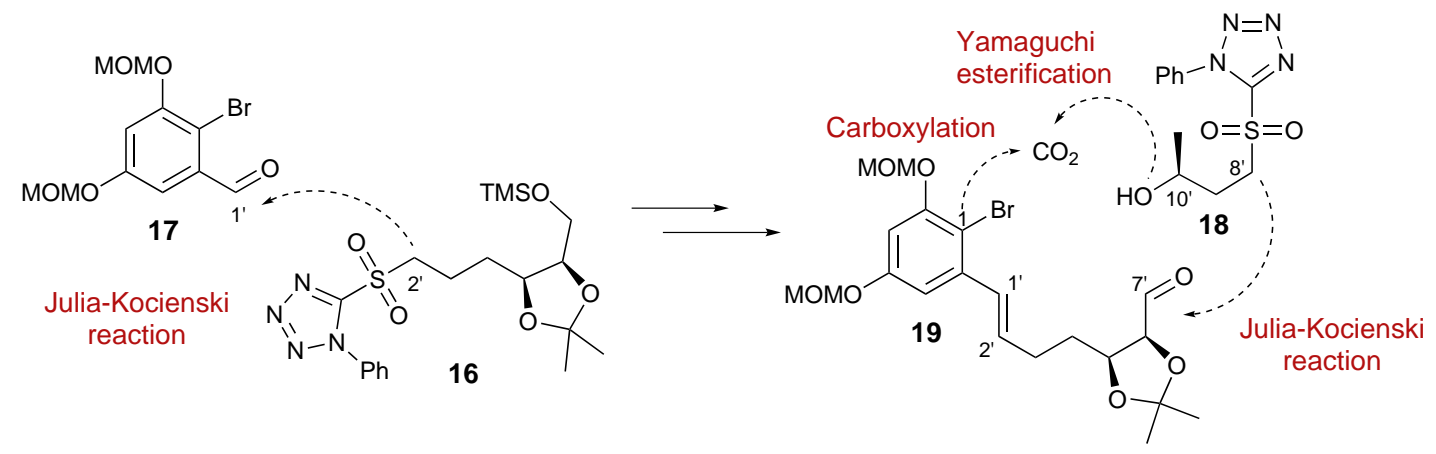

Scheme 1.6. Pan's synthetic strategy for AmD

Another synthesis of AmD was published in 2006 by Winssinger et al. (Scheme 1.7). ${ }^{55}$ First, a Mitsunobu reaction was used to couple orsellinic acid 20 with $(R)$-4-penten-2ol (13) to afford the resorcylate portion and provide the $\mathrm{C} 10^{\prime}$ stereocentre. Selenide 21 was then formed by deprotonation of the orsellinate and subsequent reaction with diphenyldiselenide. Bromide $\mathbf{2 2}$ was formed by Sharpless asymmetric epoxidation followed by a stereoselective ring-opening, and subsequently coupled with selenide 21 . 
A RCM with Grubbs' second generation catalyst followed by oxidative elimination of the selenide with hydrogen peroxide provided the $\left(7^{\prime} E\right)$ - and $\left(1^{\prime} E\right)$-alkenes, respectively. Importantly, it was found that if the RCM was done after the oxidation and elimination of the selenide, a significant amount of an undesired six-membered ring was formed by a competing RCM reaction. Global deprotection then yielded AmD in 10 steps and an overall yield of $21 \%$. The Winssinger synthesis was also adapted as solid supported synthesis, replacing the selenide with a thiophenol-based Merrifield resin. This methodology was used to synthesise the AmD analogues shown in Figure 1.15 by employing various bromide precursors in place of 22.

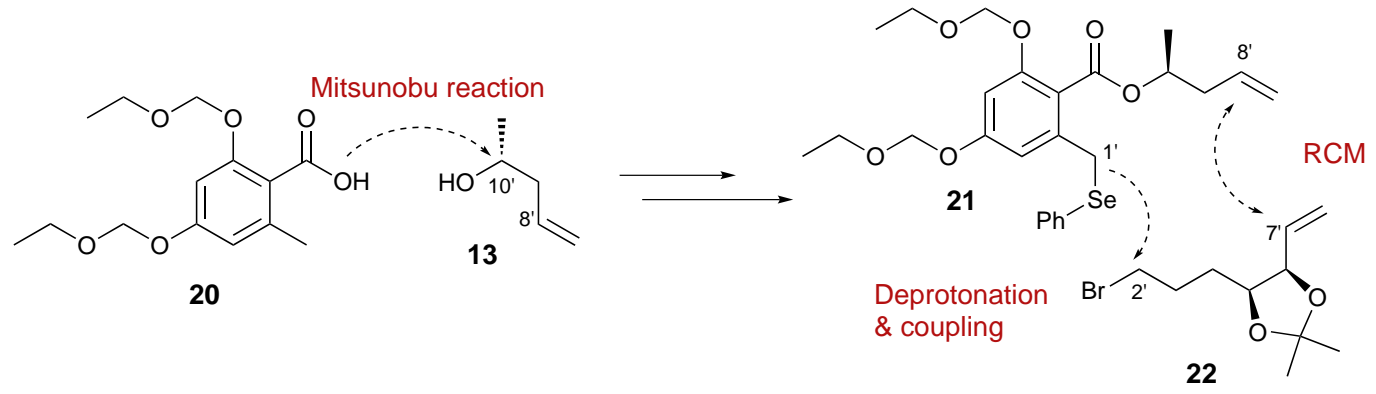

Scheme 1.7. Winssinger's synthetic strategy for AmD

The fourth synthesis of AmD was published in 2007 by Chen et al. (Scheme 1.8). ${ }^{61}$ DErythronolactone (23) was used to synthesise Weinreb amide 24 with the desired diol stereochemistry. A Mitsunobu reaction with the protected orsellinic acid 25 and $(R)$ 4-penten-2-ol (13) was used to form the resorcylate and $\mathrm{C} 10^{\prime}$ stereocentre, which was subsequently coupled with Weinreb amide $\mathbf{2 4}$ using lithium diisopropylamide (LDA). Then, a RCM reaction with Grubbs' second generation catalyst, followed by global deprotection afforded AmD in 11 steps and an overall yield of $19 \%$.

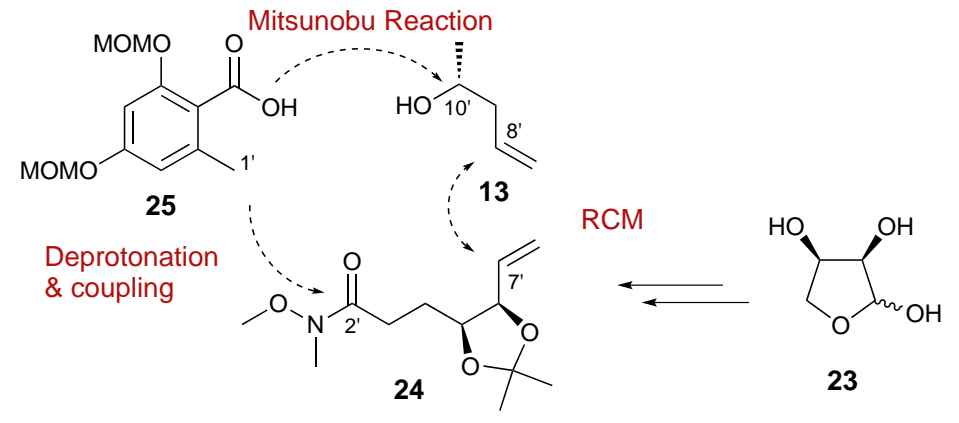

Scheme 1.8. Chen's synthetic strategy for AmD 
The fifth synthesis of AmD was published in 2008 by Montgomery et al. (Scheme 1.9). ${ }^{57}$ As seen in previous syntheses, a Mitsunobu reaction was used to form the resorcylate portion and provide the $\mathrm{C} 10^{\prime}$ stereocentre. The odobenzoic acid 26 and $(R)-4$-pentyn-2-ol (27) were coupled to form a resorcylate iodide with a terminal alkyne. A Suzuki coupling was then used to couple the iodide and the boronic acid $\mathbf{2 8}$ (prepared from a commercially available chiral alcohol), providing the desired $\left(1^{\prime} E\right)$-alkene. The $6^{\prime}$-OTBS group was then oxidised to form aldehyde 29 and the macrocycle (30) was formed by cyclisation with $\mathrm{Ni}(\mathrm{COD})_{2}{ }^{\S}$ and IMes. $\mathrm{HCl}$. This reaction yielded a 1:1 mixture of diastereomers that afforded $\mathrm{AmD}$ and $6^{\prime}$-epi-AmD upon global deprotection in 8 steps and an overall yield of $7 \%$.
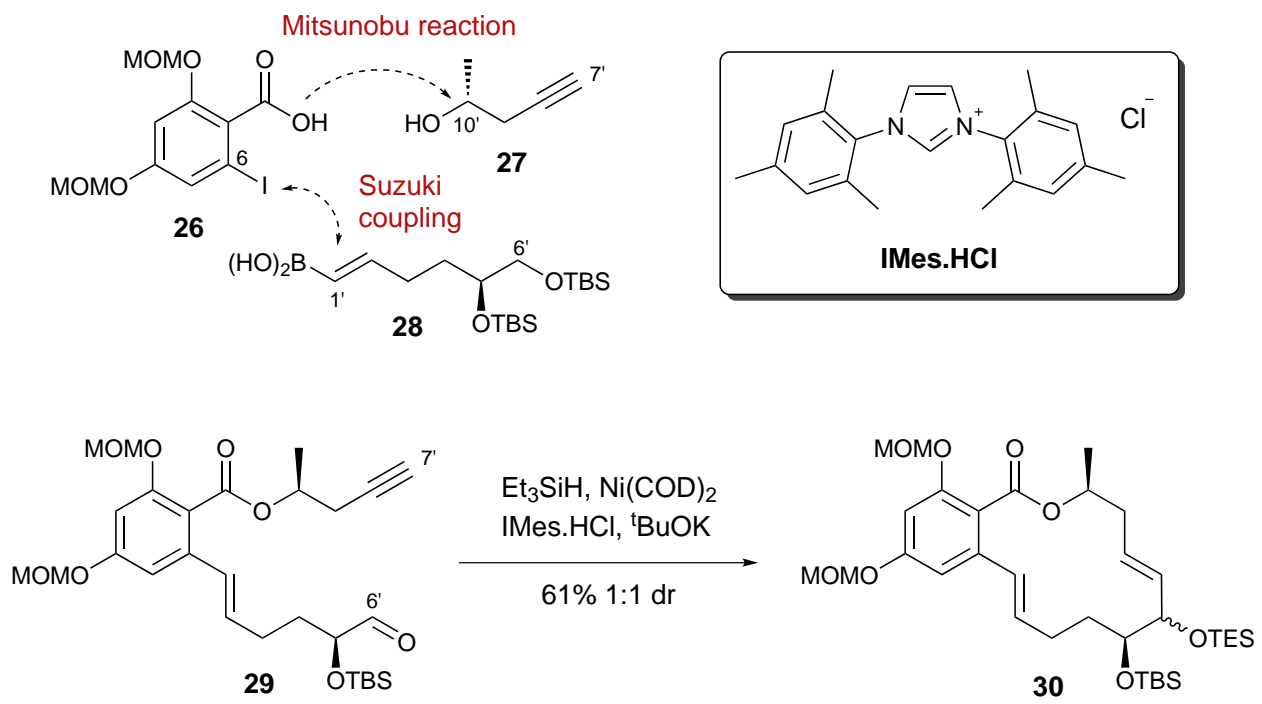

Scheme 1.9. Montgomery's synthetic strategy for AmD

Synthesis of 6'-epi-AmD (9) from an attempted synthesis of AmD was reported in 2008 by Jennings and Bajwa (Scheme 1.10). ${ }^{58}$ Commercially available chiral pool precursors were used to prepare the $\mathrm{C}^{\prime}$ and $\mathrm{C} 10^{\prime}$ stereocentre containing fragments, aldehyde $\mathbf{3 1}$ and alkyne 32. Coupling of aldehyde $\mathbf{3 1}$ and alkyne $\mathbf{3 2}$ favoured formation of the C6'-epi hydroxyl (1:2, natural:C6'-epi), therefore, to enrich the ratio of the desired stereochemistry, the C6'-hydroxyl was oxidised to a ketone, then reduced with Red$\mathrm{Al}^{\top}$ and protected as an isopropylidene acetal to afford $\mathbf{3 3}$ as an inseparable mixture of diastereomers (6:1, natural:C6'-epi). Alcohol $\mathbf{3 3}$ was then coupled with substituted styrene 34. An RCM reaction was then attempted using Grubbs' second generation

\footnotetext{
${ }^{\S} \mathrm{Ni}(\mathrm{COD})_{2}=\mathrm{Bis}($ cyclooctadiene $)$ nickel $(0)$

\ Red-Al = sodium bis(2-methoxyethoxy)aluminum hydride
} 
catalyst, however, this reaction provided $84 \%$ of an undesired six-membered ring product and only $13 \%$ of the desired macrocycle. Interestingly, the macrocycle product of the RCM was a single diastereomer, the $\mathrm{C6}^{\prime}$-epimer. 2-Methyl-6'-epi-AmD (35) was synthesised employing the same methodology, by starting with the 2-methoxy-styrene 36.
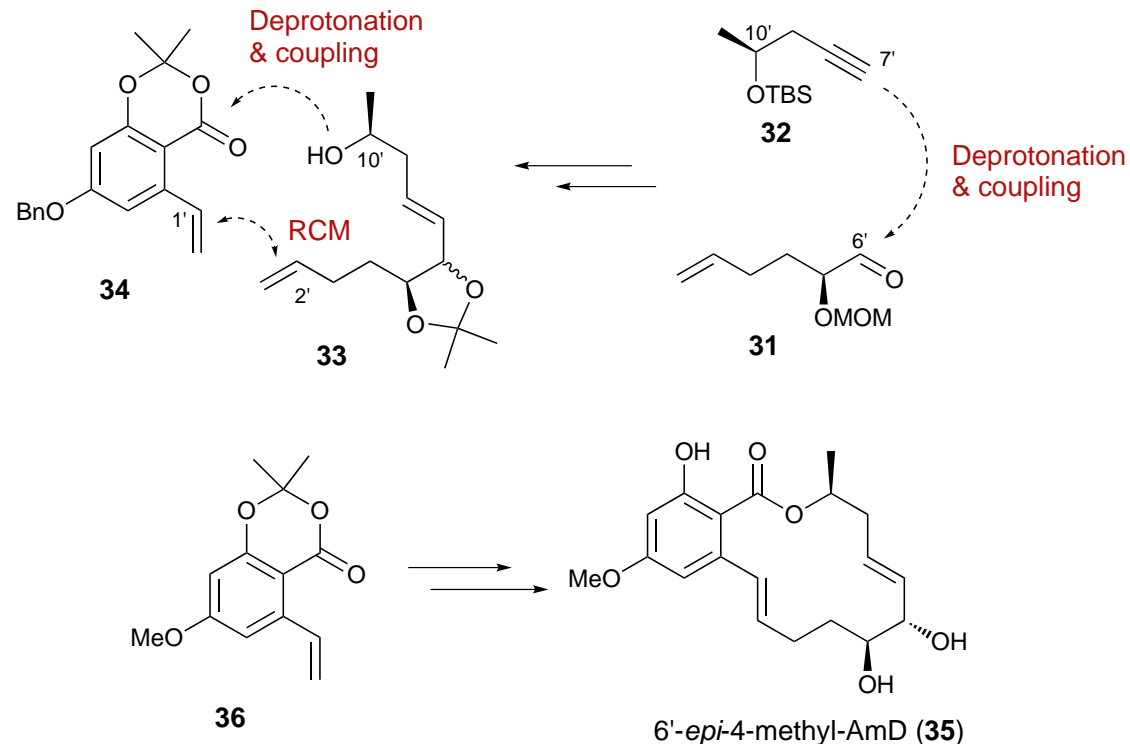

Scheme 1.10. Jennings' and Bajwa's synthetic strategy for 6'-epi-AmD (9) and 2-methyl-AmD (35).

Another synthesis of AmD was reported in late 2009 by Barrett et al. (Scheme 1.11). ${ }^{62}$ In this synthesis, the entire molecular skeleton was constructed as linear chain, which was subsequently aromatised and cyclised to form $\mathrm{AmD}$ in a similar manner to the biosynthetic PKS pathway for synthesising RALs. This was achieved by synthesising dioxinone ester $\mathbf{3 7}$ from dioxinone $\mathbf{3 8}$, which would become the resorcylate moiety, and acid choride 39 was derived from chiral pool precursor acetonide $\mathbf{4 0}$, which would become the diol portion of AmD. These two fragments were coupled to form fragment 41, that contained the desired diol stereochemistry and $\left(1^{\prime} E\right)$-alkene. Then, upon refluxing in toluene, the dioxinone moiety rearranged to form a ketene, which was trapped in situ with $(S)$-4-penten-2-ol, and aromatised in situ with cesium acetate followed by acetic acid to provided the resorcylate moiety and $\mathrm{C} 10^{\prime}$ stereocentre containing diene 42 . A RCM reaction with Grubbs' second generation catalyst, followed by global deprotection afforded AmD (4) in 11 steps and an overall yield of $15 \%$. 


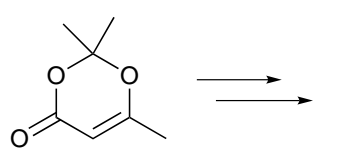

38<smiles>CC(=O)OC=C(O)CC1=C(C)C(=O)OC(C)(C)O1</smiles><smiles>[C+]1CCCCC1</smiles><smiles>CC#CCC</smiles>

40<smiles>C/C=C\C1OC(C)(C)OC1CC/C=C/[I-]C(=O)Cl</smiles>

39

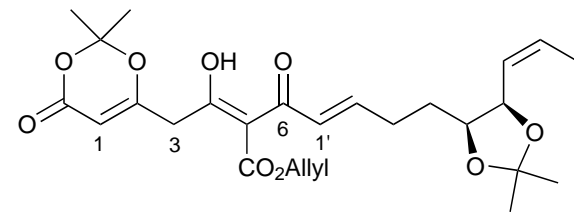

41

1) morpholine, $\mathrm{Pd}\left(\mathrm{PPh}_{3}\right)_{4}$

2) PhMe, D, (S)-4-penten-2-ol; $\mathrm{CsOAc}, \mathrm{AcOH}$<smiles>C=C[C+]=CC1OC(C)(C)OC1CC/C=C/c1cc(O)cc(O)c1C(=O)OC(C)CCOCCOC(C)=O</smiles>

Scheme 1.11. Barrett's synthetic strategy for AmD

\subsubsection{The VUW Synthesis of Aigialomycin D}

The Victoria University of Wellington (VUW) synthesis of AmD was developed by a previous member of this research group, $\mathrm{PhD}$ student Dr Lynton Baird. This route involved the coupling of three portions (Scheme 1.12). Thioacetate 43 was prepared in eight steps from D-ribose to incorporate the desired diol stereochemistry. This was coupled to resorcylic bromoester 44, prepared in three steps from methyl acetoacetate. A Mitsunobu reaction was then employed to couple $(R)$-4-penten-2-ol (13) with acid 45 to provide the $\mathrm{C} 10^{\prime}$ stereochemistry as seen in previous syntheses. Like previous syntheses, a RCM reaction was also used to close the macrocycle. However, a salient feature of this synthesis is the masking of the $1^{\prime}$-alkene as a sulfone until the end of the synthesis, when it is revealed with a Ramberg-Bäcklund reaction, thus avoiding any byproducts associated with attempting a RCM reaction on a triene system. As with previous syntheses, a base orthogonal protection scheme was also used, employing acid-sensitive protecting groups. ${ }^{63,64}$ 


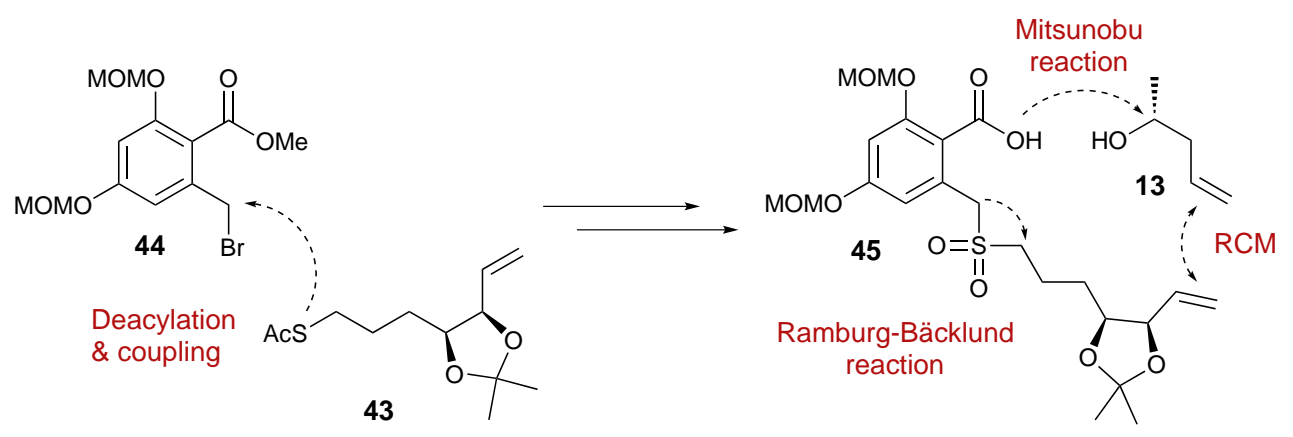

Scheme 1.12. The VUW synthetic strategy for AmD

For Dr Baird's synthesis, methyl orsellinate (46) was synthesised in a one-pot condensation/cyclisation reaction of methyl acetoacetate (47) as previously reported by Chiarello et al. ${ }^{65}$ The reaction was found to be very unreliable and heavily dependant on the quality of the reagents used; occasionally only starting material was recovered and the most successful result provided a modest $40 \%$ yield. Methyl orsellinate was then acetylated (acetic anhydride, triethylamine in dichloromethane, 98\%) followed by bromination with $N$-bromosuccinimide (NBS) and benzoyl peroxide in carbon tetrachloride (71\%) to yield aromatic bromide 44. Acetate protecting groups are essential for this reaction, as the electron withdrawing properties of acetyl groups deactivate the ring towards electrophilic aromatic substitution. When more electron donating groups, such as methyl ethers were used, bromine substitution at the C5-position was found to be the major process.

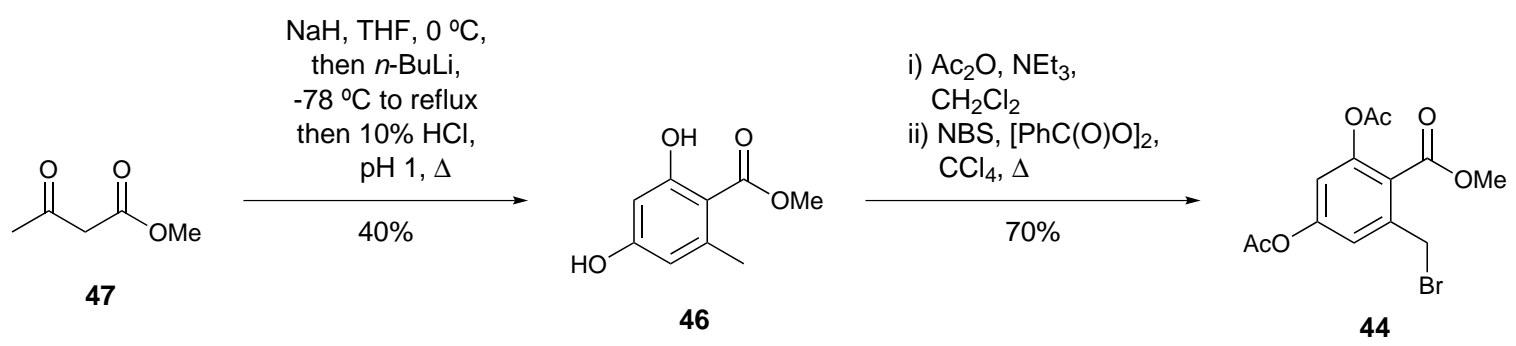

Scheme 1.13. Synthesis of bromide 44 from methyl orsellinate

Iodide 48 was prepared in three steps in an overall yield of $46 \%$ from D-ribose using a known literature method. ${ }^{66} \mathrm{~A}$ Vasella reaction was then used to provide aldehyde $49 .{ }^{67}$ Upon completion, the reaction mixture was filtered through silica to remove the zinc salts from the reaction, and the Wittig reagent added to the reaction mixture to afford the $\alpha, \beta$ unsaturated ester $\mathbf{5 0}(74 \%, 1: 4.7 E: Z)$. The mixture of $(E)$ - and $(Z)$-alkenes obtained from the Wittig reaction was not an issue as the next step was the reduction of this alkene. 


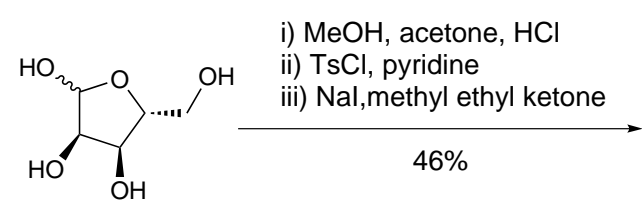

D-Ribose

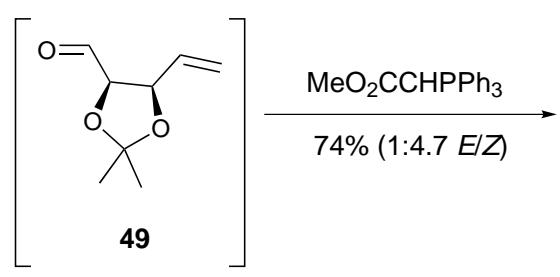

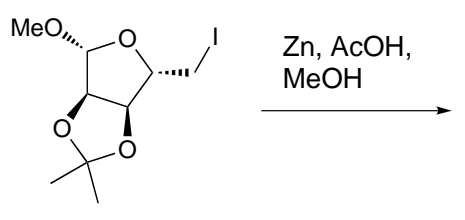

48

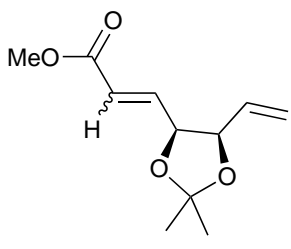

50

Scheme 1.14. Synthesis of $\alpha, \beta$-unsaturated ester $\mathbf{5 0}$ from D-ribose.

The selective reduction of the $\alpha, \beta$-unsaturated ester was attempted with $\mathrm{NaBH}_{4}$ at $0{ }^{\circ} \mathrm{C}$, but yielded only starting material. Addition of transition metal catalyst $\mathrm{CuCl}$ was found to greatly improve the reduction, with desired saturated ester $\mathbf{5 1}$ obtained in excellent yield (96\%) with no by-products detected. By comparison, it was found that when $\mathrm{CuCl}_{2}$ was employed as the transition metal catalyst, various by-products were isolated, including fully saturated ester 52 (5\%), dehydro ester 53 (10\%) and lactone 54 (10\%). Thioacetate $\mathbf{4 3}$ was then synthesised effortlessly in three steps from ester $\mathbf{5 1}$ in an overall yield of $89 \%$. This was achieved by reduction of the ester to an alcohol with lithium aluminium hydride (97\%), followed by mesylation of the alcohol with methanesulfonyl (mesyl) chloride (97\%), and finally conversion of the mesylate to the thioacetate with potassium thioacetate $(95 \%)$.

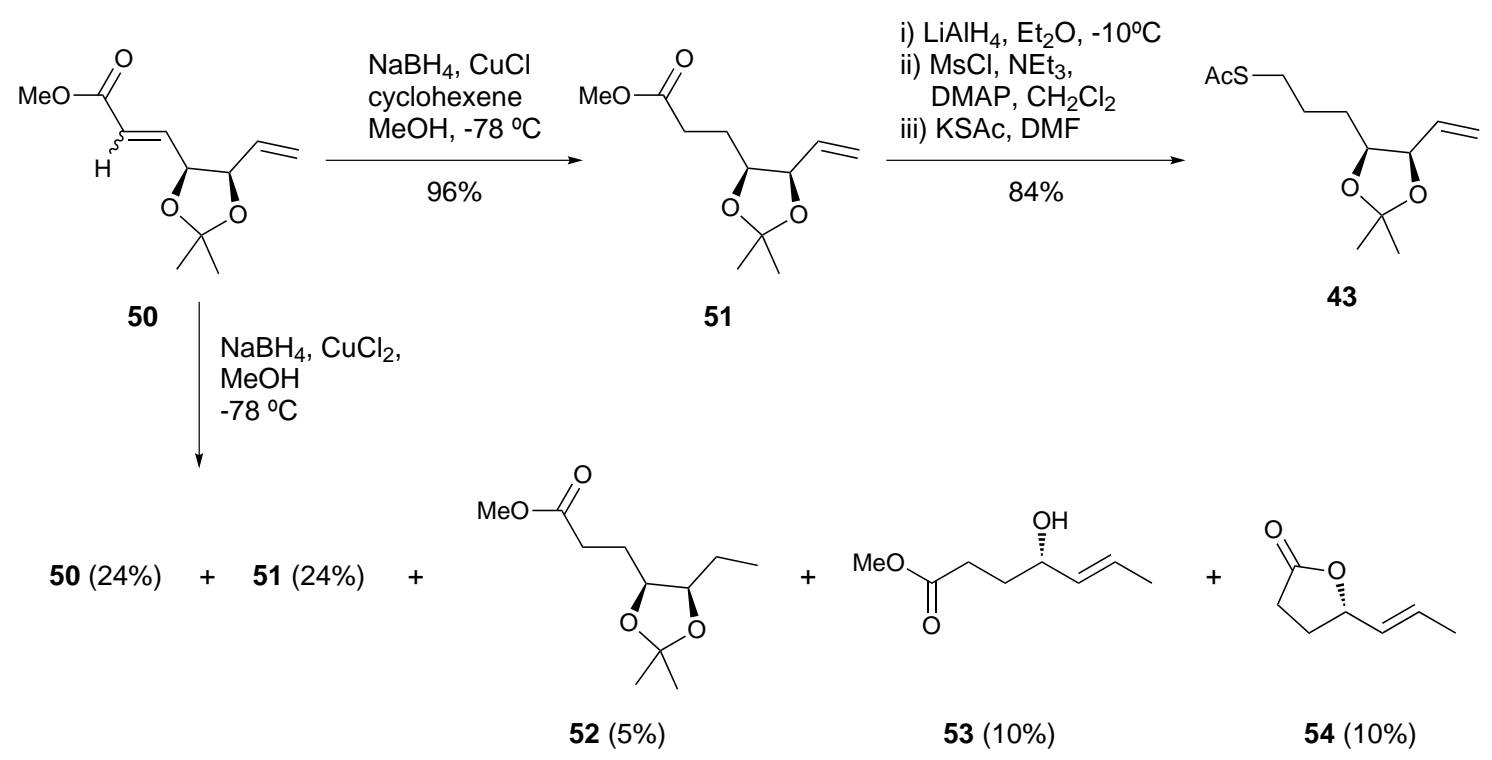

Scheme 1.15. Synthesis of thioacetate $\mathbf{4 3}$ from $\alpha, \beta$-unsaturated ester $\mathbf{5 0}$ and attempted selective reduction with $\mathrm{CuCl}_{2}$. 
Bromide 44 and thioacetate 43 were then coupled by an in situ deprotection with potassium carbonate in methanol to yield coupled product 55 (86\%). Attempted saponification of this methyl ester showed decarboxylation at the C1-position occurred when the C2-hydroxyl was not protected. Therefore, coupled product $\mathbf{5 5}$ was protected with MOM-chloride, by deprotonation with sodium hydride in dimethylformamide (DMF) followed by addition of MOM-chloride (74\%). Saponification of the protected MOM-product with potassium hydroxide in 1:1 methanol/water at reflux for 12 hours proceeded with ease to afford carboxylic acid 45 in $98 \%$ yield. Acid 45 was then coupled with chiral alcohol $(R)-4$-penten-2-ol in a Mitsunobu reaction $(94 \%) .{ }^{68}$ The thioether 56 was then oxidised to sulfone $\mathbf{5 7}$ with meta-chloroperoxybenzoic acid ( $m$-CPBA) in dichloromethane at $0{ }^{\circ} \mathrm{C}(84 \%)$.

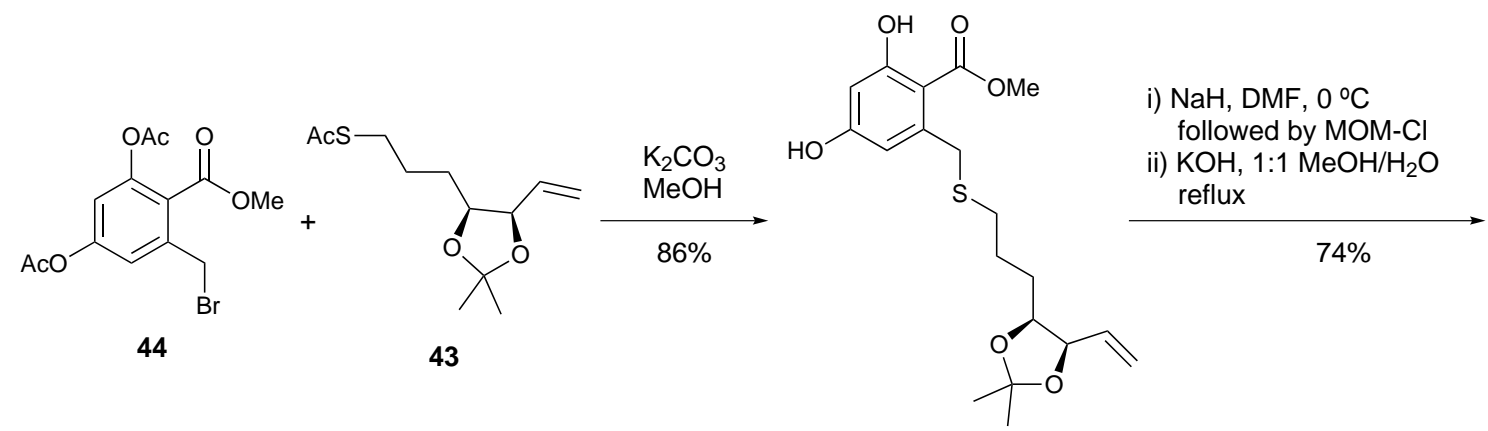

55
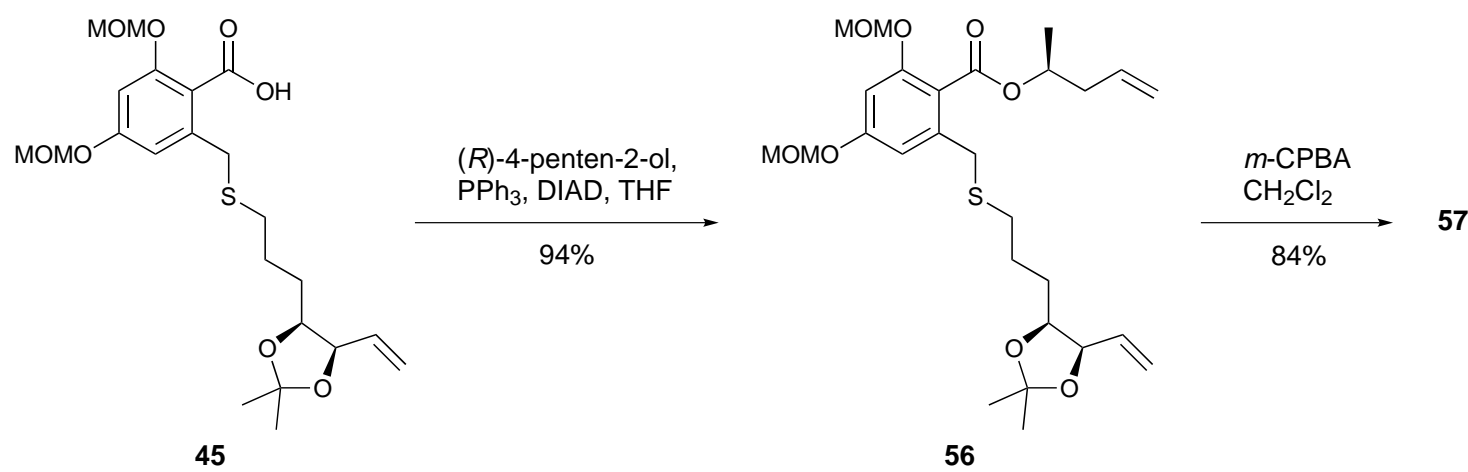

Scheme 1.16. Synthesis of sulfone 57 from the coupling of bromide 44 with thioacetate 43.

Next, a RCM reaction with Grubbs' second generation catalyst (58) provided the macrocycle $59(86 \%)$ containing the desired $\left(7^{\prime} E\right)$-alkene. Finally, a Ramberg-Bäcklund reaction was used to reveal the $1^{\prime}$-alkene providing only the desired $(E)$-isomer $(\mathbf{6 0})$. The Meyers-modification of the Ramberg-Bäcklund reaction was used, which is a onepot in situ $\alpha$-halogentation and $\alpha$-deprotonation, leading to the spontaneous chelotropic exclusion of sulfur dioxide to form the alkene. ${ }^{69}$ The original Ramberg-Bäcklund reaction 
required an $\alpha$-halo-sulfone starting material. ${ }^{70}$ Global deprotection then afforded AmD (4) in 16 steps (longest linear sequence) and an overall yield of $9 \%$.

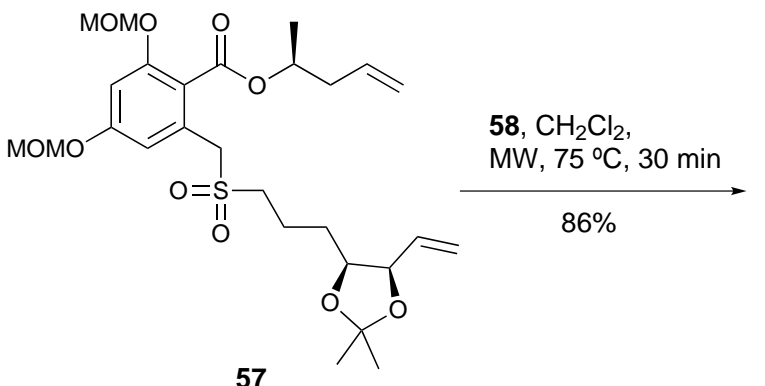

57

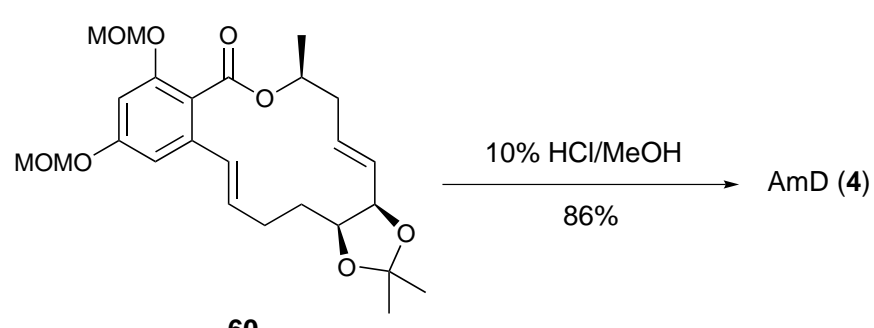

60

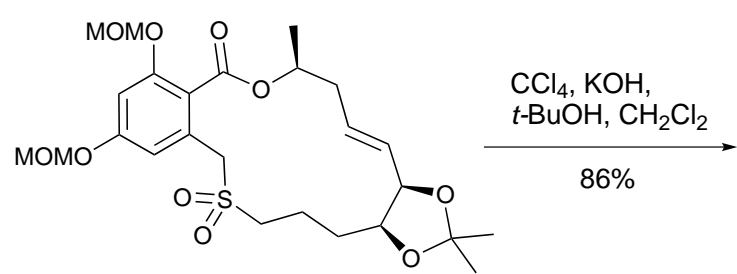

59

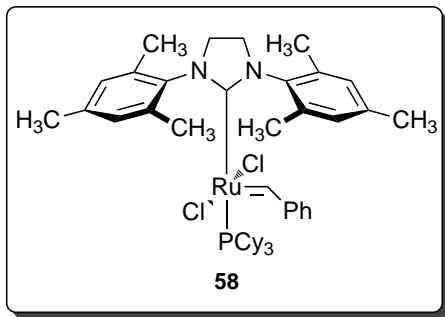

Scheme 1.17. Synthesis of AmD (4) from sulfone 57.

Two analogues of AmD were also successfully synthesised, tetrahydro-AmD (61) and 2,4-deoxy-AmD (62). ${ }^{64}$ Tetrahydro-AmD (61) was synthesised by palladium catalysed hydrogenation of the $1^{\prime}$ - and $7^{\prime}$-alkenes of protected AmD $\mathbf{6 0}$, followed by global deprotection in $89 \%$ yield over two steps. 2,4-Deoxy AmD (62) was synthesised by starting with methyl 2-methyl benzoate (63) instead of methyl orsellinate, to which the previously employed methodology was applied. All subsequent reactions were found to proceed similarly to those in the natural AmD synthesis.

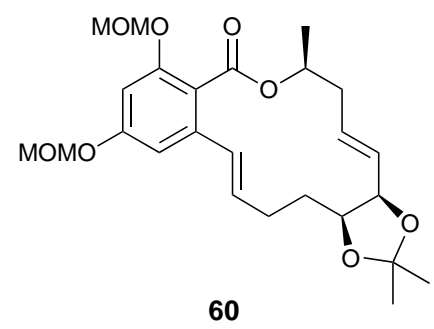

60<smiles>COC(=O)c1ccccc1C</smiles>

63
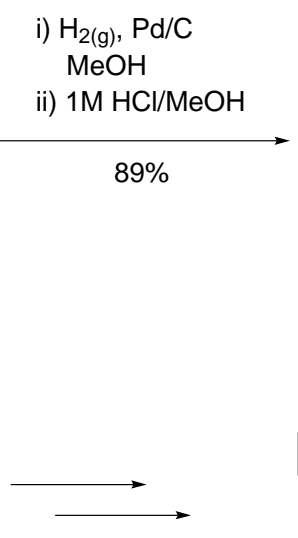<smiles>CO[C@H](C)CCC[C@@H](O)[C@H](O)CCCCc1cc(O)cc(O)c1C(=O)O</smiles>

Tetrahydro-AmD 61<smiles>CO[C@H](C)C/C=C/[C@@H](O)[C@H](O)CC/C=C/c1ccccc1C(=O)O</smiles>

2,4-deoxy-AmD 62

Scheme 1.18. Synthesis of tetrahydro-AmD 61 and 2,4-deoxy-AmD 62. 
Unsuccessful attempts were made to synthesise two other AmD analogues: 10'-epi-AmD (64) and 5-chloro-AmD (65). ${ }^{64}$<smiles>CO[C@H](C)C/C=C/C(O)C(O)CC/C=C/c1cc(O)cc(O)c1C(=O)O</smiles>

$10^{\prime}-e p i-A m D(64)$<smiles>CO[C@H](C)C/C=C/[C@@H](O)[C@H](O)CC/C=C/c1c(Cl)c(O)cc(O)c1C(=O)O</smiles>

5-chloro AmD (65)

Figure 1.17. AmD analogues, $10^{\prime}$-epi-AmD (64) and 5-chloro-AmD (65).

The alternative stereochemistry at the $\mathrm{C} 10^{\prime}$-position was obtained by using a Steglich esterification to couple acid $\mathbf{4 5}$ and (R)-4-penten-2-ol, which does not lead to inversion of the stereocentre as a Mitsunobu reaction does. This reaction was found to be low yielding (32\%), which ultimately resulted in insufficient material to finish the synthesis. The oxidation of the obtained thioether $\mathbf{6 6}$ to sulfone $\mathbf{6 7}$ and the RCM reaction were found to give similar yields to the natural product synthesis. The Ramberg-Bäcklund reaction of $\mathbf{6 8}$ was also tried, however attempts to purify the compound by silica flash column chromatography failed.<smiles>C=CC1OC(C)(C)OC1CCCSCc1cc(OC)cc(OC)c1C(=O)O</smiles><smiles>C=CC[C@H](C)OC(=O)c1c(CS(=O)(=O)CCCC2OC(C)(C)O[C@@H]2C=C)cc(OC)cc1OC</smiles>

(R)-4-penten-2-ol, DMAP, DCC, $\mathrm{CH}_{2} \mathrm{Cl}_{2}$ $32 \%$

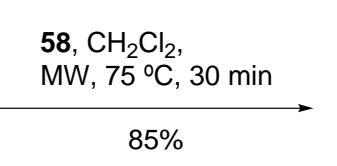

58, $\mathrm{CH}_{2} \mathrm{Cl}_{2}$, $85 \%$

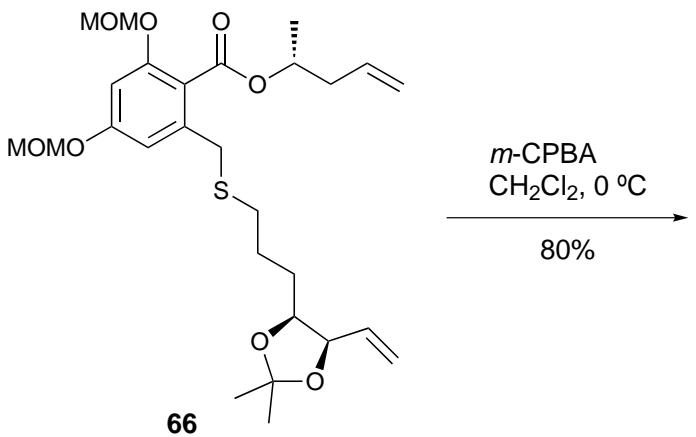

66

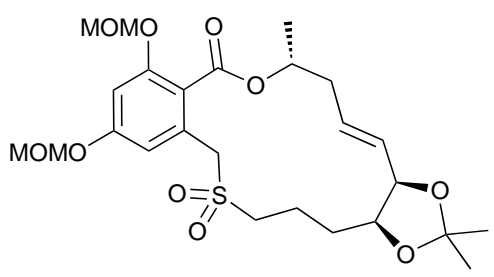

68

Scheme 1.19. Unsuccessful synthesis of epi-AmD 64. 
Chlorination of protected $\mathrm{AmD}(\mathbf{6 0})$ was attempted with calcium hypochlorite in $10 \%$ aqueous acetic acid, a method successfully employed in previous radicicol syntheses. ${ }^{71,72}$ Only starting material was recovered from this reaction.
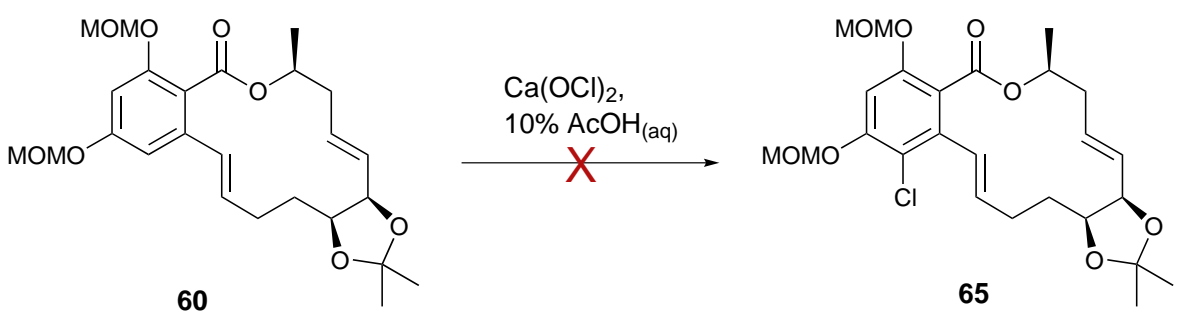

Scheme 1.20. Unsuccessful synthesis of 5-chloro-AmD 65.

\subsection{Research Objectives}

The aim of the research described herein was to synthesise specific AmD analogues in order to conduct SAR studies of AmD. The syntheses of the chosen analogues would involve variation of the methodology previously developed by Dr Baird. Potential analogues were chosen based upon chemical availability and potential SAR importance, as indicated from previous studies on related compounds. Two types of analogues were proposed: diastereomers of the three chiral centres of $\mathrm{AmD}$, and analogues with varied chemical functionality. AmD represents an interesting section of the RAL family, as it is the only member with known kinase inhibition properties that does not possess the enone functionality seen in other RALs. Hence, SAR studies on these AmD analogues should provide important information relating to the biological activity mechanism and selectivity of AmD-like compounds compared with more thoroughly investigated RAL compounds. Identification of unique mechanisms or selectivity would be valuable for the evaluation of $\mathrm{AmD}$ related compounds as potential medicinal compounds. Results of SAR studies from the compounds synthesised in this research should also serve to expand the knowledge base of SAR information for RALs, a class of compounds valuable for medicinal research arising from exhibited potent and selective Hsp90 and kinase inhibition properties. 
Diastereomeric analogues 10'-epi-AmD (64) and 5',6'-epi-AmD (69) were selected in order to elucidate the importance of the chiral centres and consequent conformation for the biological activity of AmD.\|

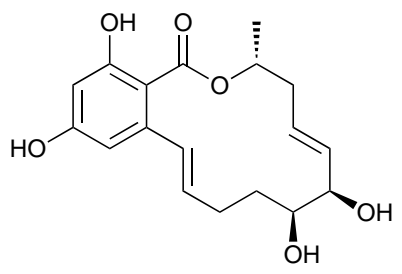

10'-epi-AmD (64)

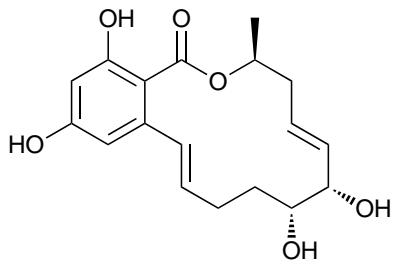

5',6'-epi,epi-AmD (69)

Figure 1.18. Proposed diastereomeric analogues of AmD.

Previous research has shown a Michael addition at the $\mathrm{C} 8^{\prime}$-position by a cys thiol is one of the main mechanisms of kinase inhibition displayed by numerous RALs. Thus, $6^{\prime}$-oxoAmD 70 was also proposed to improve the Michael acceptor properties at the $\mathrm{C}^{\prime}$ position of AmD. The reactivity of the $7^{\prime}$-alkene could also be investigated with $7^{\prime}, 8^{\prime}$-cyclopropylAmD 71.

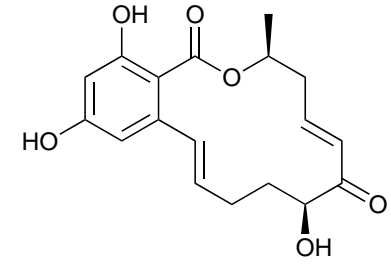

6'-Oxo-AmD 70

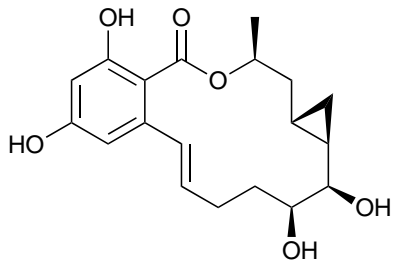

7',8'-Cyclopropyl-AmD 71

Figure 1.19. Proposed functional group analogues of AmD.

Once synthesised, these compounds would be submitted for biological assays. Cell biology experiments and chemical genetics would be used to evaluate the biological properties.

A secondary aim of this research was to optimise the synthetic methodology developed by Dr Baird to help facilitate the synthesis of the proposed analogues and future analogues of AmD. This involved a shortened synthesis of the thioacetate fragment (43) and various other modifications. The low yielding and unreliable synthesis of methyl orsellinate was also a focus of optimisation research.

\footnotetext{
${ }^{\|}$These two analogues are enantiomers of one another and diastereomers of AmD.
} 


\subsubsection{Proposed Synthetic Methodology}

An optimised synthesis of iodide $\mathbf{4 8}$ was proposed (Scheme 1.21). The use of acetyl chloride instead of conc. hydrochloric acid for the protection of D-ribose could potentially increase the yield of the product. Methyl esterification and isopropylidene formation are both reversible acid catalysed reactions, with excess water causing a reversion to starting material. Hence, it was proposed that the use of acetyl chloride to form anhydrous hydrochloric acid in situ would reduce the amount of water, and drive the equilibrium of the reaction towards the desired product. A one-step iodination at the C5-position of D-ribose was also proposed (Scheme 1.21), instead of the two-step reaction sequence used previously that involved conversion of the hydroxyl to a tosylate and subsequent displacement with nucleophilic iodine (Scheme 1.14).

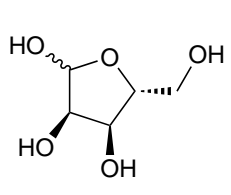

D-Ribose i) $\mathrm{MeOH}$, acetone, $\mathrm{AcCl}$

ii) $\mathrm{I}_{2}, \mathrm{PPh}_{3}$, imidazole

$2: 1$ toluene $/ \mathrm{CH}_{3} \mathrm{CN}$
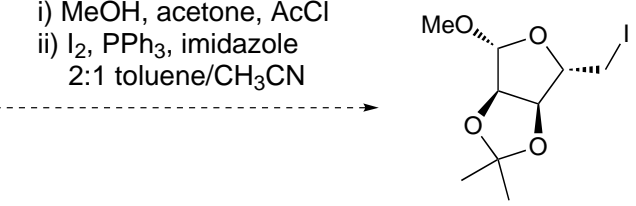

48

Scheme 1.21. Proposed optimised synthesis of iodide 48 .

A synthesis of 5',6'-epi,epi-AmD (69) from D-ribose was proposed (Scheme 1.22). The $\alpha, \beta$-unsaturated ester $\mathbf{7 2}$ possessing the desired diol stereochemistry could be prepared by a Wittig reaction with known aldehyde $\mathbf{7 3}$, which can be prepared in three steps from D-ribose. ${ }^{73}$ The previously developed synthetic methodology could then be used to afford the epi,epi-AmD 69. The periodate cleavage/Wittig reaction sequence could also potentially be done as a two-step, one-pot reaction (analogous to methodology employed in the synthesis of natural $\mathrm{AmD}$ ) by employing polymer-bound ${ }^{74}$ or silicabound $^{75}$ periodate. The polymer- or silica-bound periodate could be filtered off upon completion of the oxidative cleavage, and the Wittig reagent added to the reaction mixture, avoiding the isolation of the unstable and volatile aldehyde (73). The use of polymer- or silica-bound periodate also removes the need for water as a co-solvent, which is usually necessary due to the low solubility of sodium periodate in organic solvents, such as dichloromethane. 

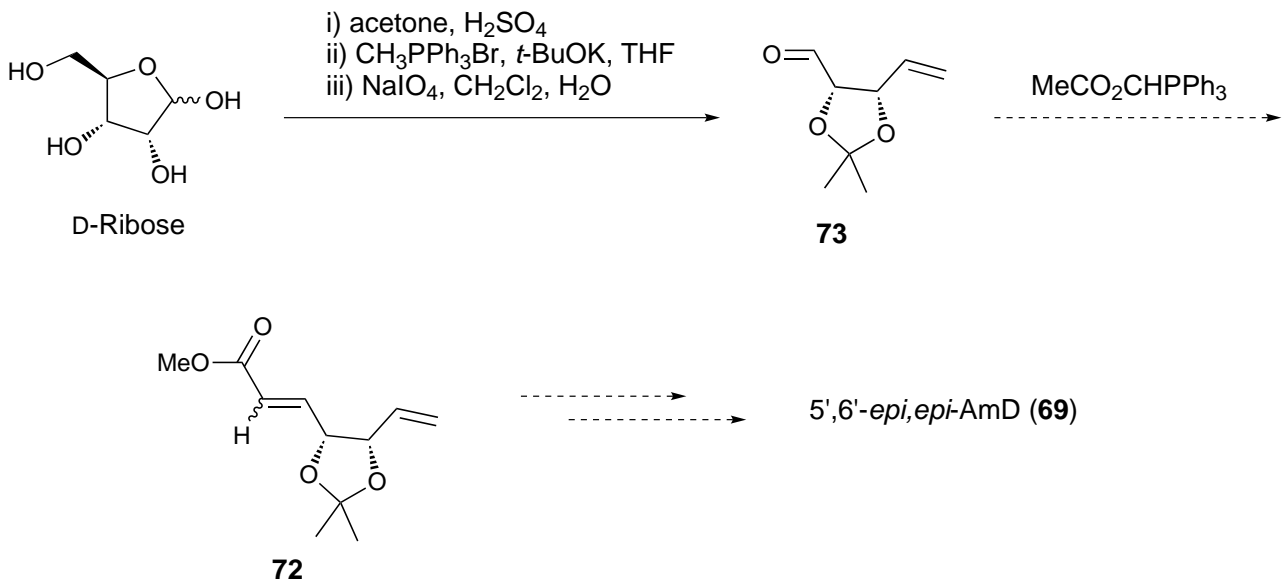

Scheme 1.22. Proposed synthesis of $5^{\prime}, 6^{\prime}$-epi,epi-AmD (69).

Previous work by Dr Baird suggested a non-inversive esterification reaction, instead of the Mitsunobu reaction, would be the only synthetic alteration required to synthesise $10^{\prime}$-epi-AmD (64). However, the low yields observed from the DCC-mediated Steglich esterification suggested an alternate esterification method would be required. Steglich esterification using EDCI, ${ }^{76}$ esterification with $\mathrm{HBTU}^{77}$ and Yamaguchi esterification ${ }^{78}$ are all non-inversive esterification methods which would provide the desired stereochemistry. Alternatively, Mitsunobu reaction conditions with $(S)$-4-penten-2-ol could also provide the desired stereochemistry (Scheme 1.23).

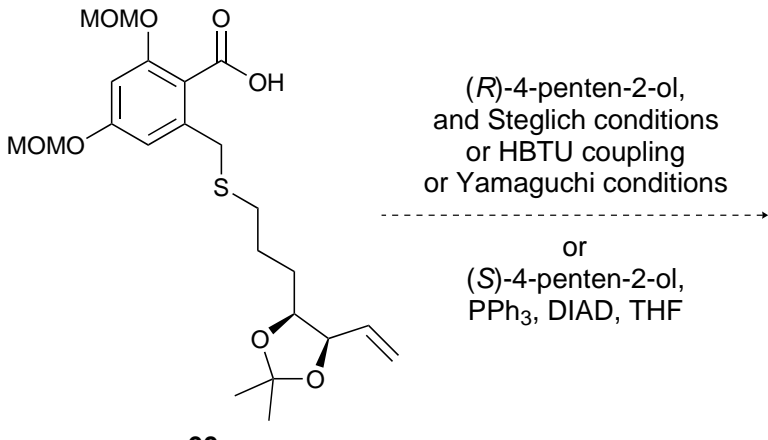

60

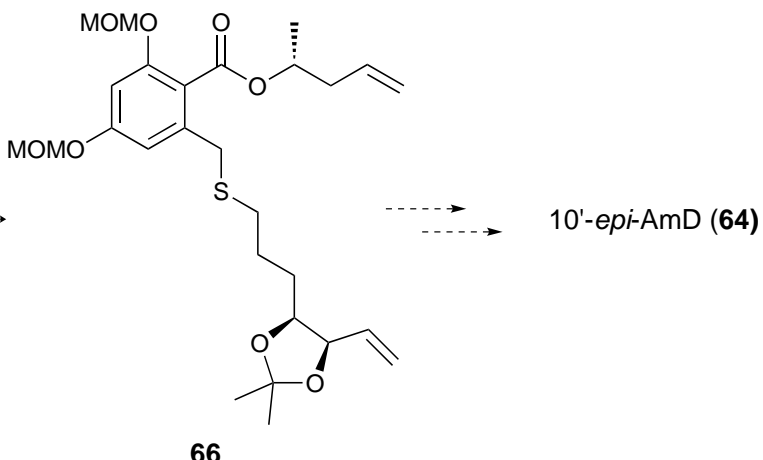

66

Scheme 1.23. Proposed synthesis of $10^{\prime}$-epi-AmD (64).

It was proposed that $6^{\prime}$-oxo-AmD (70) could be prepared through selective oxidation of AmD itself (Scheme 1.24). Literature precedent exists for the selective oxidation of allylic alcohols, such as the $\mathrm{C6}^{\prime}$-hydroxyl of AmD, with manganese dioxide ${ }^{79}$ or DDQ. ${ }^{80-82}$ DDQ would be the preferred oxidant due to the potential of manganese dioxide to cause 1,2-diol cleavage. ${ }^{83-86}$ 


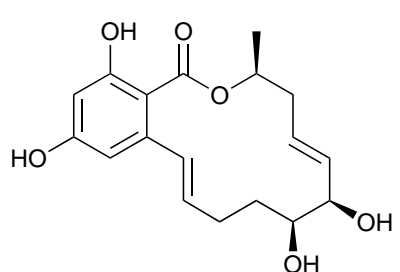

4

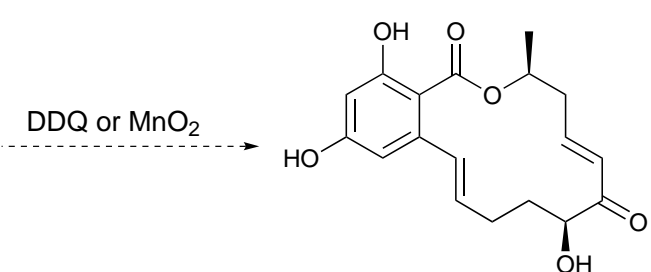

6'-oxo-AmD 70

Scheme 1.24. Proposed synthesis of 6'-oxo-AmD 70.

The cyclopropanation of alkene $\mathbf{5 9}$ using Simmons-Smith conditions ${ }^{87}$ would be attempted to ultimately afford cyclopropyl-AmD 71 (Scheme 1.25). The proposed stereochemistry of the cyclopropyl group is based on literature precedence, showing that addition occurs on the same face as the allylic ether due to coordination of the reactive zinc species with the oxygen of the ether. ${ }^{88}$ The rationale for performing the cyclopropanation on the pre-Ramberg-Bäcklund product is to avoid the potential sidereaction of cyclopropanation at the $1^{\prime}$-alkene. However, the allylic alcohol system of AmD may sufficiently direct the desired Simmons-Smith cyclopropanation at the C7'alkene, allowing the reaction to be done on $\mathrm{AmD}$.
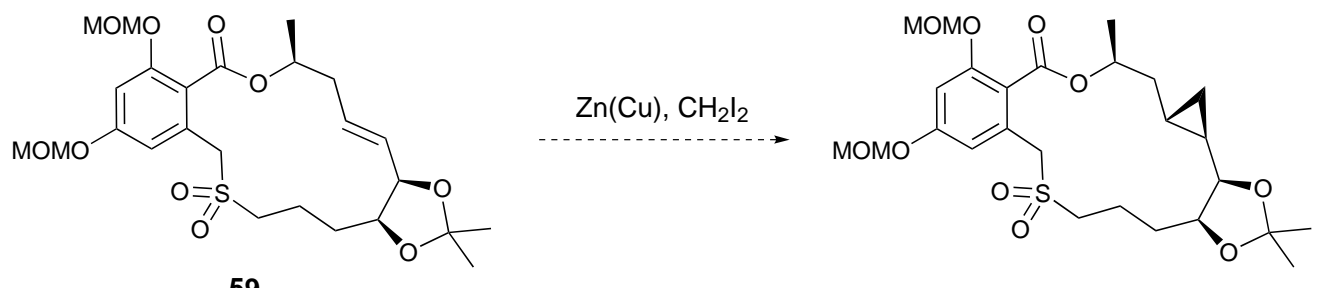

59

Cyclopropyl-AmD 71

Scheme 1.25. Proposed synthesis of $7^{\prime}, 8^{\prime}$-cyclopropyl-AmD 71. 



\section{Chapter 2|}

\section{Synthesis of Methyl Orsellinate}

Due to the inefficiency and inconsistency of current methyl orsellinate (46) syntheses, attempts were made to optimise its formation. The reaction was first attempted using the one-pot method employed by Dr Baird, ${ }^{63,64}$ where the triketo-ester (74) is formed by addition of methyl acetoacetate (75) to a solution of sodium hydride in THF stirring at $0{ }^{\circ} \mathrm{C}$, followed by addition of $n$-butyllithium at $-78^{\circ} \mathrm{C}$ and stirring of the solution, first for 12 hours at room temperature, then a further 24 hours at reflux. The triketo-ester is then cyclised by acidifying the solution to $\mathrm{pH} 1$ with $10 \%$ hydrochloric acid and stirring at room temperature for 12 hours. The results of this reaction were found to be very inconsistent, with yields of $0-50 \%$ recorded.

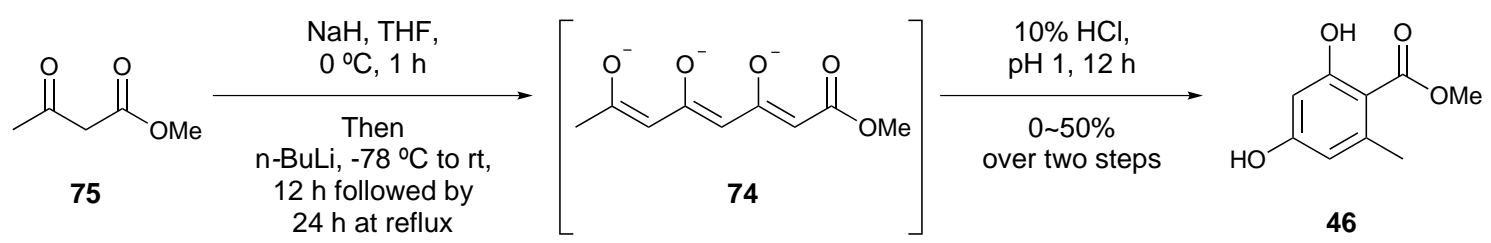

Scheme 2.1. Two-step, one-pot synthesis of the methyl orsellinate from methyl acetoacetate

\subsection{Investigation of Previous Methyl Orsellinate Syntheses}

The original synthesis of methyl orsellinate reported by Harris and Harris ${ }^{89}$ involved a two-step reaction sequence, whereby the triketo-ester was isolated before the cyclisation step. The triketo-ester was synthesised via a Claisen condensation of mono- and dianionic methyl acetoacetate (75). This was first achieved by addition of a solution of the mono-anion in THF (formed by deprotonation of $\mathbf{7 5}$ with sodium hydride) to a solution of the di-anion in THF (formed by deprotonation of 75 with LDA), affording the triketo-ester in $31 \%$ yield. ${ }^{90}$ A one-pot variant was later developed by Chiarello et 
$a l .{ }^{65}$ that involved deprotonation of $\mathbf{7 5}$ with sodium hydride to form the mono-anion, and successive deprotonation with a strong lithium base (e.g. LDA or $n$-butyl lithium) to form the di-anion. It was proposed that only a catalytic amount of the mono-anion would be required (which could be achieved by using less than one equivalent of the lithium base) because a further equivalent would be regenerated by proton transfer of the more acidic $\alpha$-proton of the di-anionic triketo-ester to the di-anion of 75 (Scheme 2.2). The di-anion of $\mathbf{7 5}$ could also be deprotonated by the methoxide liberated by the Claisen condensation. Proton transfer from the resulting methanol to the di-anion of $\mathbf{7 5}$ would also lead to the regeneration of the mono-anion. This one-pot reaction was found to afford the triketoester in an improved yield of 59\%. ${ }^{91,92}$ Optimisation of the condensation step as part of the onepot methyl orsellinate synthesis was attempted by Dr Baird via variation of the solvent used (THF, diethyl ether and hexanes), the reaction temperature during $n$-butyllithium addition $\left(0,-40\right.$ or $\left.-78^{\circ} \mathrm{C}\right)$ and the reaction time (24-40 hours), with no success. ${ }^{64}$

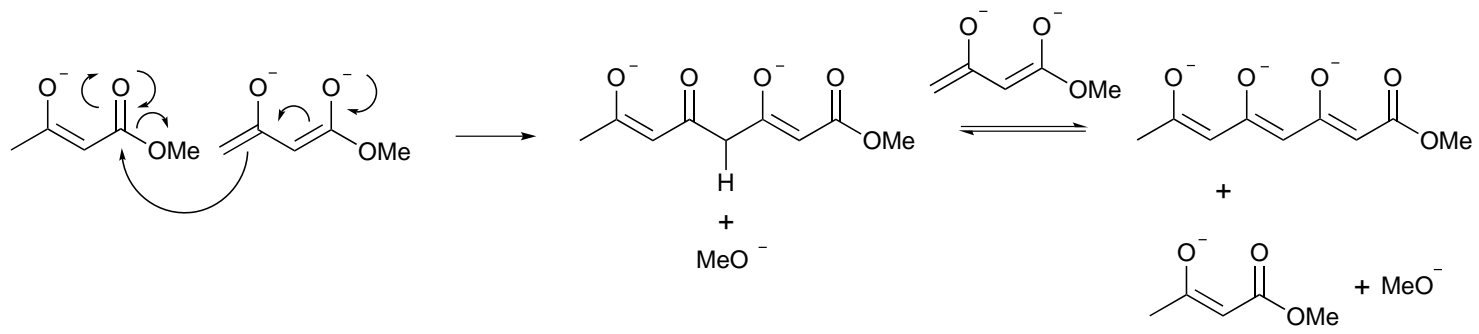

Scheme 2.2. Base catalysed condensation of methyl acetoacetate.

Cyclisation of trianionic $\mathbf{7 4}$ to methyl orsellinate (46) can be achieved under a variety of conditions. The first reported cyclisation to methyl orsellinate employed basic conditions, with methanolic sodium acetate providing $\mathbf{4 6}$ in $50 \%$ yield. Aqueous potassium hydroxide was also found to facilitate the cyclisation to methyl orsellinate (46) to a lesser degree, in a yield of 27\%, along with 2,4,6-trihydroxyacetophenone [76 (39\%)] and orsellinic acid [77 (13\%)] as shown in Scheme 2.3. ${ }^{93}$ It has also been noticed that 74 efficiently cyclises to form methyl orsellinate on activated silica gel ( $81 \%$ yield). ${ }^{92}$ Optimisation of the cyclisation led to the use of a $\mathrm{pH} 9.2$ buffer, affording methyl orsellinate in a $67 \%$ yield from methyl acetoacetate. ${ }^{94}$ Near the completion of this research, it was reported by another group that cyclisation could be achieved efficiently with caesium carbonate in methanol followed by acidic work-up, in a yield of $87 \%$ from $74 .^{95}$ The aforementioned cyclisation methods were all conducted on the isolated triketo-ester, while the focus of this 
research project was to develop a one-pot method similar to that reported by Chiarello et $a l .,{ }^{65}$ and previously used by Dr Baird.

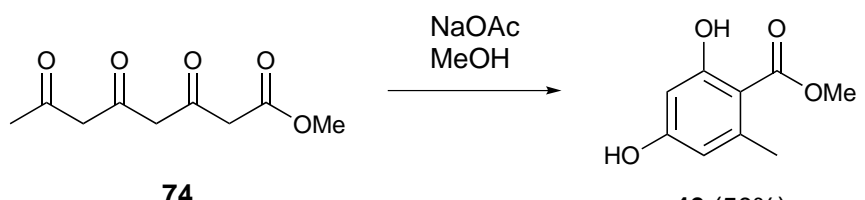

74

$46(50 \%)$

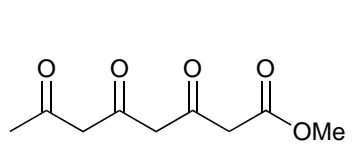

74

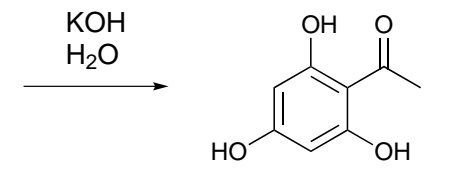

$76(39 \%)$

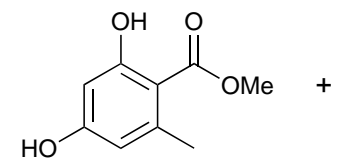

$46(27 \%)$

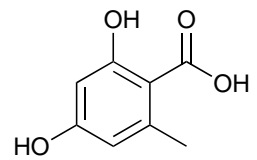

$77(13 \%)$

Scheme 2.3. Cyclisation of triketo methyl ester to methyl orsellinate. ${ }^{93}$

Our investigation of the methyl orsellinate synthesis began with the one-pot synthesis developed by Chiarello et al. Monitoring the reaction with TLC showed one spot $\left(\mathrm{R}_{F}=\right.$ 0.40) before acidification. After acidification, three spots were visible by TLC. $\mathrm{R}_{F}$ values of 0.55 (corresponding to methyl acetoacetate), 0.45 (corresponding to methyl orsellinate) and a baseline spot were observed, of which was presumed to be orsellinic acid (77) or a related carboxylic acid compound(s). ${ }^{1} \mathrm{H}$ NMR spectroscopy of the product mixture also suggested the presence of a significant amount of methyl acetoacetate. It is unknown whether degradation to methyl acetoacetate through a retro-Claisen-like reaction was occurring or if the first TLC of the reaction mixture was inaccurate due to the effect of components in the reaction mixture on the retention factors of methyl acetoacetate. From this initial analysis, the cyclisation step was identified as the possible reason for the low and inconsistent yields obtained previously. As studies focusing on isolating the triketo-ester and cyclising it in a separate step were concurrently undertaken by a summer student in the research group with limited success, ${ }^{*}$ the separate condensation/cyclisation approach was not further studied in this research.

*Dunn, E.; Ting, S.; Harvey, J., Unpublished results, 2010. 


\subsection{Optimisation Studies on the in situ Cyclisation of the}

\section{Triketo-ester}

To assess potential alternative cyclisation methods, $\mathbf{7 4}$ was formed as outlined previously (section 2.1) and the reaction mixture was then divided into five aliquots. Each sample was subjected to different cyclisation conditions overnight at room temperature, then checked by TLC before being isolated and examined by ${ }^{1} \mathrm{H}$ NMR spectroscopy (Table 2.1).

Table 2.1. Cyclisation of triketo-ester 74

\begin{tabular}{|c|c|c|c|c|c|c|c|c|}
\hline \multirow[t]{2}{*}{ Entry } & \multirow[t]{2}{*}{ Conditions $^{a}$} & \multicolumn{3}{|c|}{ TLC spots $^{b}$} & \multicolumn{3}{|c|}{${ }^{1} H$ NMR results ${ }^{b}$} & \multirow{2}{*}{$\begin{array}{c}\text { Yield } \\
(\%)\end{array}$} \\
\hline & & $\mathrm{SM}$ & MO & $\mathrm{BL}$ & SM & MO & $\mathrm{BP}$ & \\
\hline 1 & $\begin{array}{l}\text { Acidified to } \mathrm{pH} 1 \text { with } \\
10 \% \mathrm{HCl}\end{array}$ & $\checkmark$ & $\checkmark$ & $\checkmark$ & $\checkmark$ & $\checkmark$ & $\checkmark$ & 20 \\
\hline 2 & $\begin{array}{l}\text { Buffered at pH } 2 \text { with } \\
\mathrm{HCl} / \mathrm{KCl}\end{array}$ & trace & $\checkmark$ & trace & minor & $\checkmark$ & trace & 40 \\
\hline 3 & $\begin{array}{l}\text { Acidified to pH } 3 \text { with } \\
\text { AcOH }\end{array}$ & trace & $\checkmark$ & trace & $\checkmark$ & $\checkmark$ & trace & 60 \\
\hline 4 & $\begin{array}{l}\text { Stirred with silica gel } \\
(100 \mathrm{mg} / \mathrm{mL})\end{array}$ & $\checkmark$ & $\checkmark$ & $x$ & $\checkmark$ & trace & $x$ & 10 \\
\hline 5 & $\begin{array}{l}\text { Buffered at } \mathrm{pH} 9.2 \\
\text { with } \mathrm{NaHCO}_{3} / \mathrm{Na}_{2} \mathrm{CO}_{3}\end{array}$ & $x$ & X & $\checkmark$ & $x$ & $x$ & $\checkmark$ & 0 \\
\hline
\end{tabular}

The initial cyclisation method of Chiarello et al. ${ }^{65}$ was included as a control (entry 1, Table 2.1). Milder acidic conditions seemed to reduce the amount of TLC baseline products (entries 2 and 3, Table 2.1), with acidification to $\mathrm{pH} 3$ (acetic acid) giving the highest yield of methyl orsellinate (60\%, entry 3, Table 2.1$)$. Inspired by the cyclisation on silica gel reported by Harris et al. ${ }^{92}$ silica gel was added to an aliquot of the reaction mixture. While the TLC of this reaction showed promising results, with no baseline spots, the ${ }^{1} \mathrm{H}$ NMR spectrum of the crude product showed only traces of methyl orsellinate, and this was confirmed by the low isolated yield of $10 \%$ (entry 4, Table 2.1). Cyclisation in an aqueous solution buffered at $\mathrm{pH} 9.2$ (sodium bicarbonate/sodium carbonate) was then attempted to explore whether this method could be employed to cyclise the triketo-ester in its tri-anionic form, as it would likely exist in the reaction mixture. No methyl orsellinate or methyl acetoacetate were observed by TLC or ${ }^{1} \mathrm{H}$ NMR, and no methyl orsellinate was isolated (entry 5, Table 2.1). 
Hydrolysis of a methyl ester to a carboxylic acid can occur under harsh acidic or basic conditions in the presence of water, therefore, the exclusion of water could reduce carboxylic acid related by-products. Two anhydrous cyclisation methods were attempted: i) quenching the reaction with methanol followed by acidification to $\mathrm{pH} 1.5$ with acetyl chloride, and ii) quenching the reaction with methanol followed by acidification to $\mathrm{pH}$ 5 with glacial acetic acid. The results of both these methods were promising, with yields of $40 \%$ and $66 \%$, respectively. The latter result is especially interesting, as it suggests cyclisation of the triketo-ester to methyl orsellinate is possible under milder acidic conditions than previously reported. Unfortunately, cyclisation with acetic acid in methanol was also found to be inconsistent, with yields of methyl orsellinate from subsequent reactions in the range of $20-60 \%$. Residual acetic acid, leading to the formation of a concentrated acidic solution upon evaporation of the solvent and resulting degradation of the products, was considered as a possible explanation for the inconsistent yields. Neutralisation of the acid with saturated sodium bicarbonate was trialled as a possible solution with little success, providing yields of 15-20\%. Due to time constraints and with adequate amounts of methyl orsellinate obtained, no further optimisation was undertaken.

\subsection{Synthesis of Resorcylic Bromoester 44}

The synthesis of resorcylic bromoester $\mathbf{4 4}$ was achieved as previously reported by Harvey et al. ${ }^{63}$ After the synthesis of methyl orsellinate (46) as discussed in the previous section, the phenolic groups of $\mathbf{4 6}$ were acetylated with acetic anhydride and triethylamine. Benzylic bromination was then accomplish by refluxing the acetylated methyl orsellinate in carbon tetrachloride with NBS and a catalytic amount of a radical initiator (benzoyl peroxide) to afford rescorcylic bromide $\mathbf{4 4}$ in a yield of $79 \%$ over two steps (Scheme 2.4).

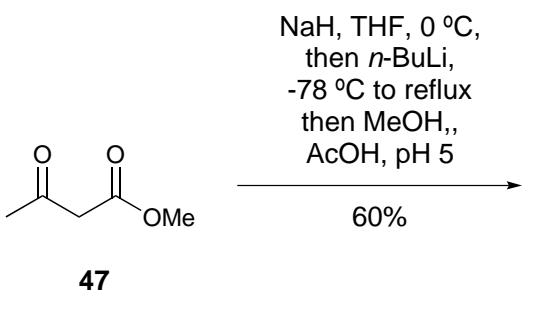

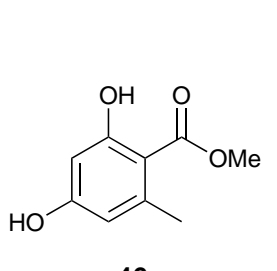

46

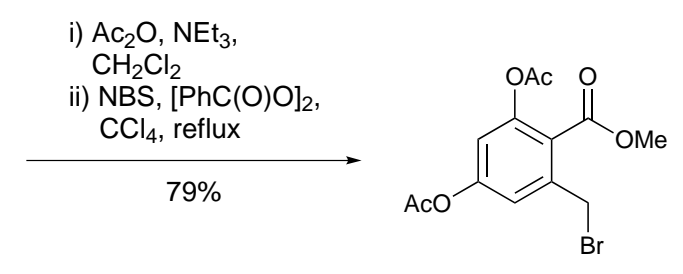

44

Scheme 2.4. Synthesis of resorcylic bromoester 44 . 



\section{Chapter $3 \mid$}

\section{Synthesis of Aigialomycin D}

The majority of target analogues within this research project could be prepared through divergent modifications of the AmD synthesis developed at VUW, ${ }^{63,64}$ or through derivatisation of $\mathrm{AmD}$ itself. Thus, repetition of the $\mathrm{AmD}$ synthesis was required and provided a logical first step en route to the synthesis of AmD analogues. To facilitate the synthesis of these and any future analogues, various optimisations were made to the methodology, aimed to improve the yield and reproducibility, reduce the number of reaction steps and/or simplifying experimental procedures.

\subsection{Synthesis of the Thioacetate 43 .}

A simplified, and potentially higher yielding, seven-step synthesis of thioacetate $\mathbf{4 3}$ from D-ribose via iodide 48 was proposed (Scheme 3.2).
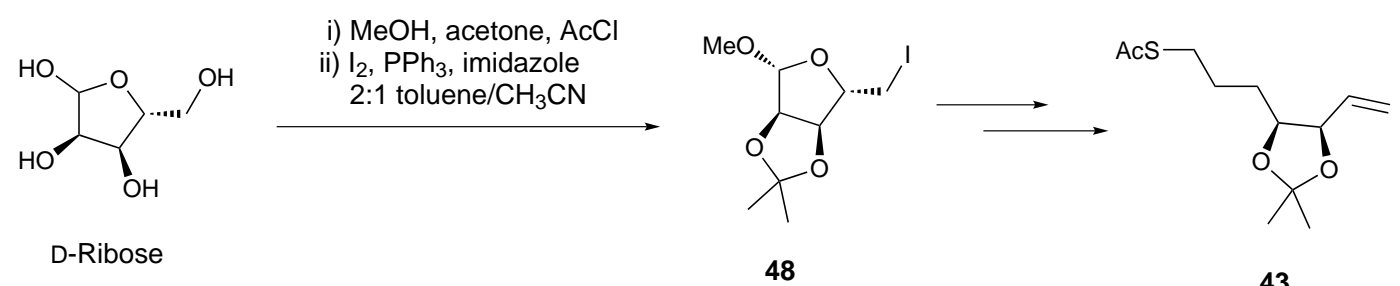

Scheme 3.1. Synthesis of the thioacetate fragment from D-ribose.

First, D-ribose was protected as methyl 2,3-O-isopropylidene- $\beta$-D-ribofuranoside (78) using acid-catalysed acetal formation in a solution of 1:1 acetone/methanol. Instead of employing concentrated hydrochloric acid as used previously, which is a $\sim 35 \%$ aqueous solution, acetyl chloride was used to form anhydrous hydrochloric acid in situ, minimising the amount of water in the reaction. It was hoped that this would drive the equilibrium towards the desired product (Scheme 3.2). An improved yield of $80 \%$ of the protected sugar 78 was obtained in sufficient purity for immediate use, with none of the $\alpha$-anomer observed. The C5-hydroxyl was then iodinated via a known literature method of refluxing 
the substrate in a solution of toluene/acetonitrile (2:1) with triphenylphosphine, imidazole and iodine, ${ }^{96}$ affording iodide $\mathbf{4 8}$ in $80 \%$ yield and an overall yield of $64 \%$ over two steps from D-ribose.

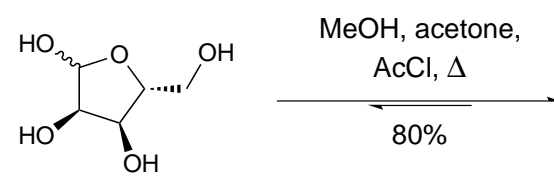

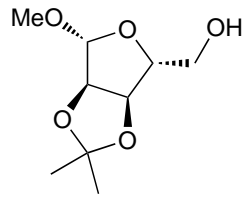

78

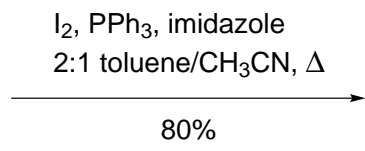

$80 \%$

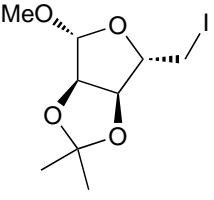

48

Scheme 3.2. Synthesis of iodo-sugar $\mathbf{4 8}$ and proposed equilibrium mechanism

Thioacetate 43 was then prepared from iodide 48 as reported by Harvey et al. ${ }^{63}$ A Vasella reaction was conducted with zinc powder and acetic acid in refluxing methanol, to form aldehyde 49. To avoid isolation of the unstable aldehyde, the reaction mixture was filtered through a silica plug to remove zinc salts, then the stabilised Wittig reagent [methyl (triphenylphosphoranylidene)acetate] added directly to the cooled eluent. This reaction was found to give a similar ratio of $E: Z$ isomers (1:5.1) and yield (75\%) of $\alpha, \beta$-unsaturated ester $\mathbf{5 0}$ as previously reported. The selective reduction of the $\alpha, \beta$ unsaturated ester also proceeded as previously reported, however, it was found that freshly purified copper (I) chloride was required for the reaction to go to completion. ${ }^{*}$ Ester $\mathbf{5 1}$ was then reduced to the corresponding alcohol (lithium aluminium hydride in diethyl ether at $-10^{\circ} \mathrm{C}$ ) followed by conversion to its mesylate ( mesyl chloride, DMAP and triethylamine in dichloromethane). Nucleophilic displacement of the mesylate group was achieved through reaction with potassium thioacetate in DMF to afford thioacetate 43 in an overall yield of $38 \%$ in seven steps from D-ribose (Scheme 3.3). This is an improvement over the eight-step route that gave an overall yield of $28 \%$ from D-ribose previously reported by Harvey et al. ${ }^{63}$

${ }^{*}$ Copper (I) chloride is a pale grey powder that can turn light green over the course of weeks, even when stored under argon, possibly due to exposure to adventitious moisture. 


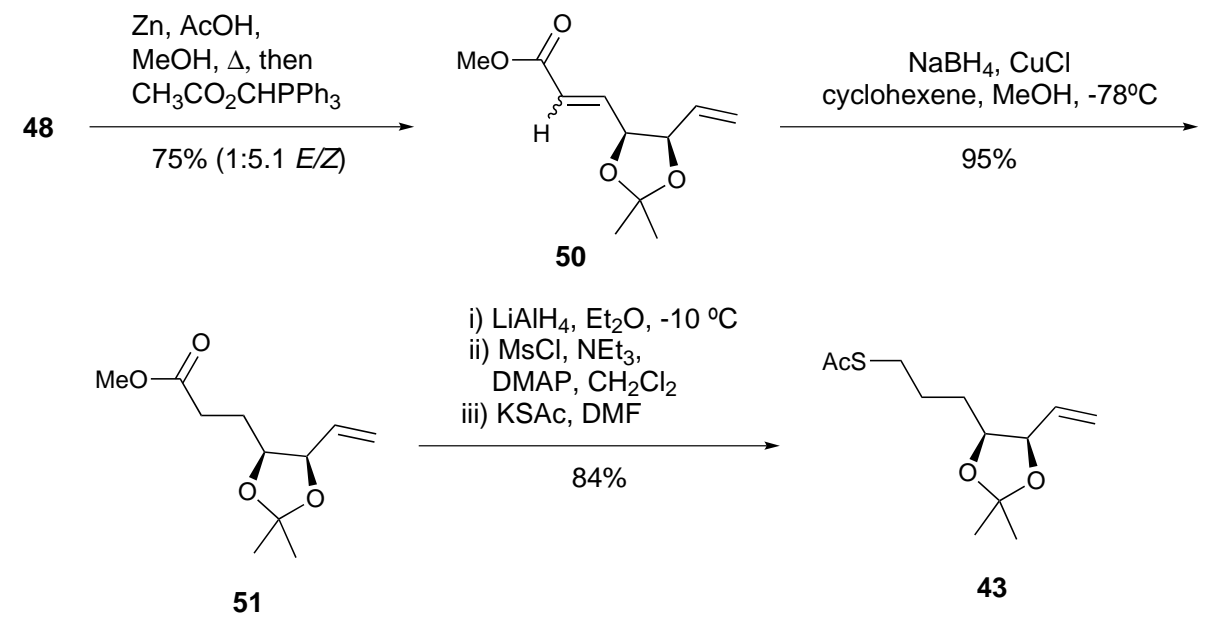

Scheme 3.3. Synthesis of thioacetate 43 from iodo-sugar 48

\subsection{Synthesis of AmD from Thioacetate 43 and Resor- cylic Bromoester 44.}

Slight variations were made to the route from thioacetate 43 to $\mathrm{AmD}(4)$ reported by Dr. Baird. ${ }^{63,64}$ The coupling of resocylic bromide $\mathbf{4 4}$ to deacetylated thioacetate $\mathbf{4 3}$ proceeded without issue. However, significant difficulties were then encountered when attempting to protect the hydroxyl groups of product $\mathbf{5 5}$ as methoxymethyl ethers.

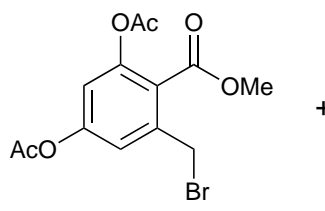

44

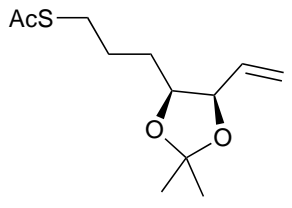

43

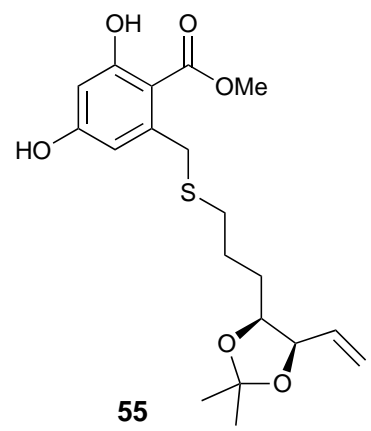

Scheme 3.4. Coupling of thioacetate 43 and resorcylic bromoester 44

The original method involved deprotonation of the phenolic groups with sodium hydride in DMF at $0{ }^{\circ} \mathrm{C}$, followed by addition of MOM-chloride, to afforded the desired product (75\%). ${ }^{63}$ However, when this method was repeated in the current work, lower yields were obtained (50-60\%), with the major by-product being mono-protected product 79 (Scheme 3.5). 


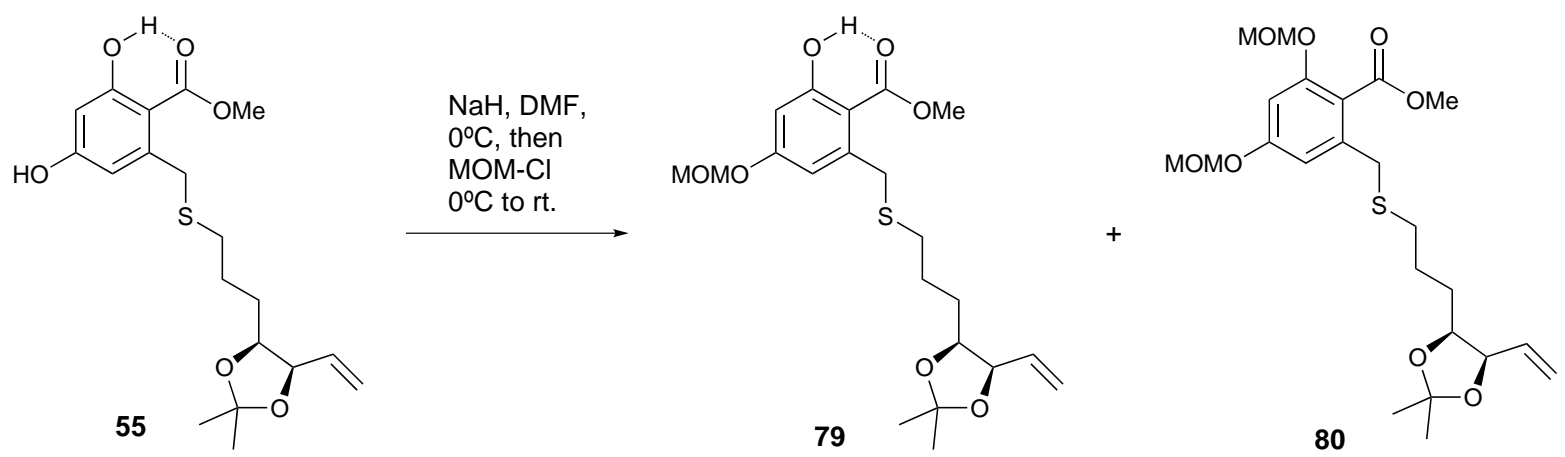

Scheme 3.5. Attempted MOM-protection of $\mathbf{5 5}$

The difficulty in protecting the C2-hydroxyl is likely due to hydrogen bonding between the C2-hydroxyl and the neighbouring ester carbonyl, forming a stable six-membered system. Evidence for this hydrogen bonding is seen in the ${ }^{1} \mathrm{H}$ NMR spectrum, where the C2-hydroxyl proton is seen as a sharp singlet at $11.68 \mathrm{ppm}$ (see Appendix for relevant spectra).$^{\dagger}$ Another interesting consequence of the proposed hydrogen bonding of this hydroxyl is the apparent effect on polarity, with protection of the C2-hydroxyl as a methoxymethyl ether leading to a decrease in $\mathrm{R}_{f}$ on silica TLC, implying an increase in polarity. ${ }^{\ddagger}$ This is counter intuitive as protection of hydroxyl groups is usually expected to decrease the polarity of the compound. The stability of the C2-hydroxyl system would appear to negate the necessity for protection of this group; ${ }^{\S}$ however it was known that the unprotected hydroxyl facilitates decarboxylation of the carboxylic acid functionality under saponification conditions, ${ }^{97-99}$ through the proposed mechanism of Scheme 3.6. ${ }^{64}$

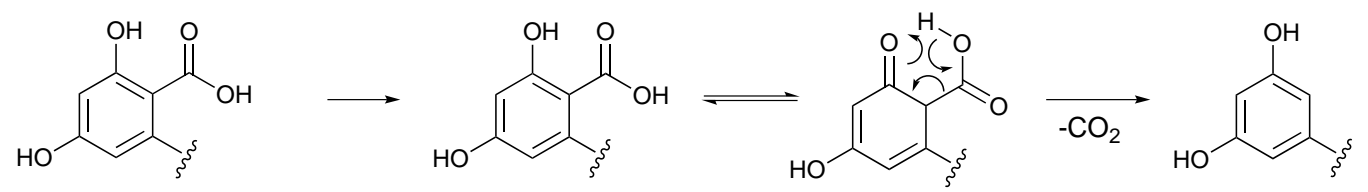

Scheme 3.6. Proposed mechanism for the decarboxylation of the resorcylic acid moiety.

In an attempt to obtain the fully protected product $\mathbf{8 0}$, MOM-protection of the monoMOM product 79 was attempted utilising the same method. Unfortunately a similar ratio of di-MOM:mono-MOM products was obtained. The reaction was also attempted

\footnotetext{
${ }^{\dagger}$ Hydroxyl protons are commonly observed as broad peaks or not observed at all in ${ }^{1} \mathrm{H}$ NMR spectra due to the exchangeability of these protons. The shape of the peak can be characteristic of the exchange rate of the proton.

${ }^{\ddagger}$ Mono-MOM 79 had an $\mathrm{R}_{f}$ of 0.50 , compared with 0.34 for di-MOM 80 and 0.27 for the unprotected 55 in 2:1 hexanes/ethyl acetate.

${ }^{\S}$ Hydroxyl groups are usually protected to decrease the polarity of the compound, making it easier to isolate and purify, and to minimise unwanted side-reactions associated with their reactivity.
} 
with tetrabutylammonium iodide (TBAI) as an additive, which was expected to form the more reactive MOM-iodide in situ. Unfortunately, TBAI had no observable effect on the reaction. The possible degradation of the MOM-chloride reagent was then considered. In the presence of water, MOM-chloride could be hydrolysed to MOM-OH, which could then react with another equivalent of MOM-chloride to form the MOM-O-MOM dimer (Scheme 3.7). Degradation of MOM-chloride to formaldehyde and methanol would also likely occur. The presence of these by-products would not only decrease the concentration of the MOM-chloride in the reaction mixture, but their formation would also release hydrochloric acid, which could have an adverse effect on the reaction. It was hypothesised that hydrochloric acid could either quench the reaction or deprotect the product in situ. Due to time constraints and the unavailability of alternative batches of MOM-chloride, neutralisation with DMAP or triethylamine was attempted as a possible solution, however neither was found to have an observable effect on the reaction. Excess sodium hydride was not used due to its potential to deprotonate the benzylic protons, leading to additional by-product formation.

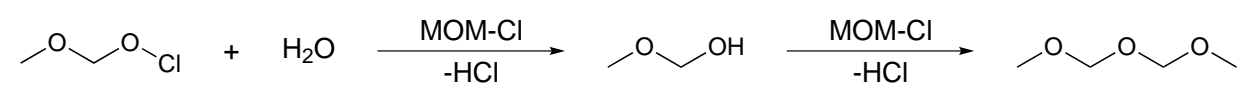

Scheme 3.7. The proposed degradation of MOM-chloride

Purification of the MOM-chloride was also attempted by washing with saturated calcium carbonate followed by fractional distillation. While ${ }^{1} \mathrm{H}$ NMR spectroscopy of the reagent suggested that purification led to a significant increase in the ratio of the degraded reagent to MOM-chloride, use of the purified MOM-chloride afforded di-MOM 80 in $\sim 80 \%$ yields (Scheme 3.8). Interestingly, the only by-product isolated was starting material; no mono-MOM product was observed.

Next, ester 80 was saponified to carboxylic acid $\mathbf{4 5}$ by refluxing with potassium hydroxide in a solution of 2:1 methanol/water. Originally, the acid was isolated after neutralisation of the basic reaction mixture with $10 \%$ acetic acid. However the acetic acid was difficult to separate from the organic layer, leading to degradation of the compound, most likely due to deprotection of the acid sensitive methoxymethyl ether and isopropropylidene protecting groups. Removal of the acetic acid by evaporation led to loss of product, again 
probably due to deprotection of the compound $\mathbf{4 5}$. When excess washing with water was used, acid 45 was extracted into the aqueous layer. To get around this problem, use of a weak inorganic acid was proposed in place of acetic acid because it could easily be removed with an aqueous wash. Use of a $10 \%$ aqueous solution of potassium hydrogen sulfate was found to successfully avoid acid-catalysed degradation, and gave acid $\mathbf{4 5}$ in excellent yield (Scheme 3.8).

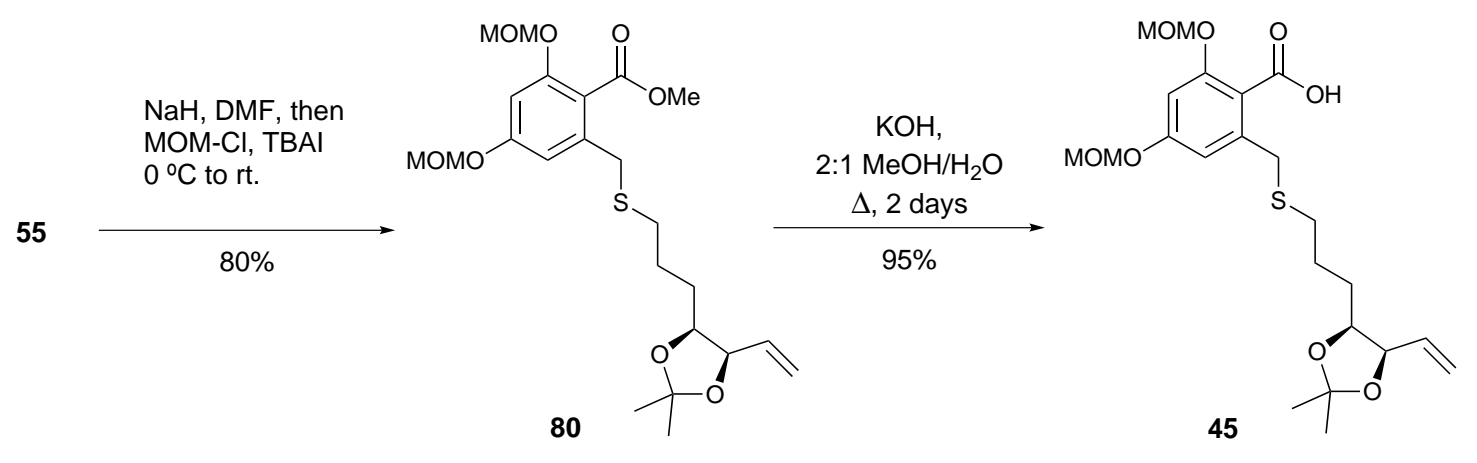

Scheme 3.8. MOM-protection followed by saponification of ester $\mathbf{5 5}$

A Mitsunobu reaction was then used to couple acid 45 and (R)-4-penten-2-ol (13) to give diene 56. The optimal order of reagent addition was found to be addition of the alcohol to a solution of triphenylphosphine and DIAD in THF at $0{ }^{\circ} \mathrm{C}$. This mixture was stirred for 30 minutes to allow formation of the activated alcohol. Acid $\mathbf{4 5}$ was then added as a solution in THF. It was found that the reaction took a few days to reach completion, however, quenching the reaction after 24 hours avoided degradation. Unfortunately, the remaining acidic starting material was inseparable from the by-products of the reaction, preventing its recovery.

Oxidation of thioether 56 with $m$-CPBA in dichloromethane then afforded sulfone 57. Next, a microwave-assisted RCM, catalysed by Grubbs’ second generation catalyst (58), was utilised to form the macrocycle 59. This reaction proceeded smoothly, however, removal of the catalyst residue proved difficult. The catalyst residue was found to streak on a silica column in the various solvent systems used, contaminating all product eluted from the column. Stirring with activated carbon was investigated to determine whether the catalyst residue would be preferentially absorbed onto the carbon. However, significant product loss was observed and traces of the catalyst residue were still present. Ultimately, repeated flash column chromatography proved the most efficient method of removing the 
catalyst by-product with minimal loss of product. Additionally, possible remaining traces of the catalyst did not seem to interfere with subsequent reactions.

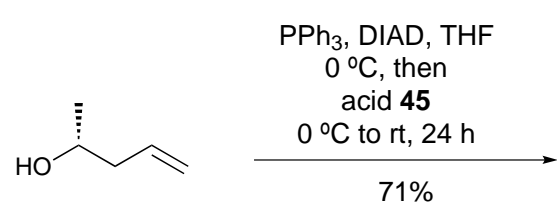

13

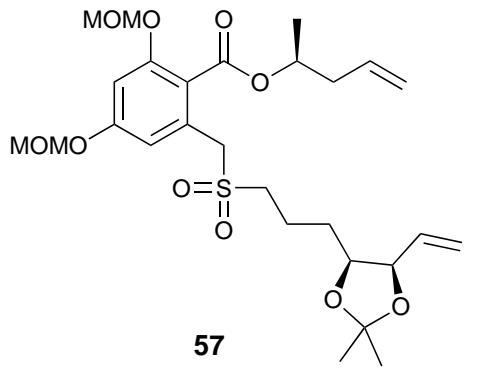

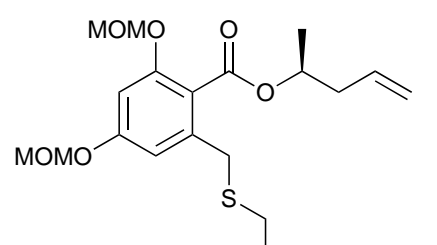

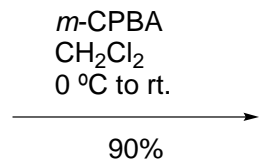

56

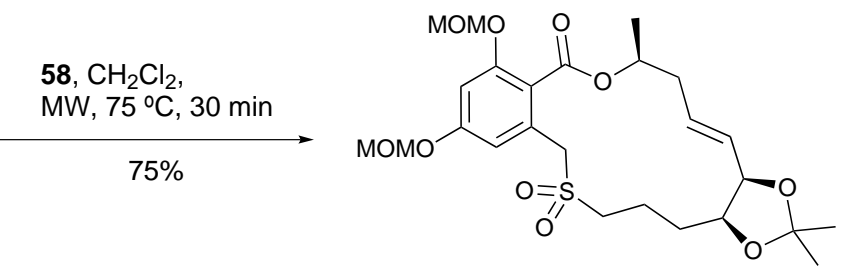

59

Scheme 3.9. Synthesis of sulfone $\mathbf{5 9}$ from acid 45

The second alkene was subsequently revealed using a Ramberg-Bäcklund reaction. Using the Meyers-modified Ramberg-Bäcklund reaction, ${ }^{69}$ carbon tetrachloride was added dropwise to a stirred solution of the sulfone $\mathbf{5 9}$ and excess potassium hydroxide (20 eq.) in 5:2 tert-butanol/dichloromethane, yielding protected AmD 60. The desired $\left(1^{\prime} E\right)$ alkene was the exclusive product observed from this reaction. Global acidic deprotection was then achieved by stirring the protected $\mathrm{AmD}$ in a solution of $1: 1 \mathrm{v} / \mathrm{v}$ methanol/1 $\mathrm{M}$ hydrochloric acid at room temperature for 3 days to afford $\mathrm{AmD}(4)$ in an overall yield of $6 \%$ in 15 steps (longest linear sequence) from D-ribose.

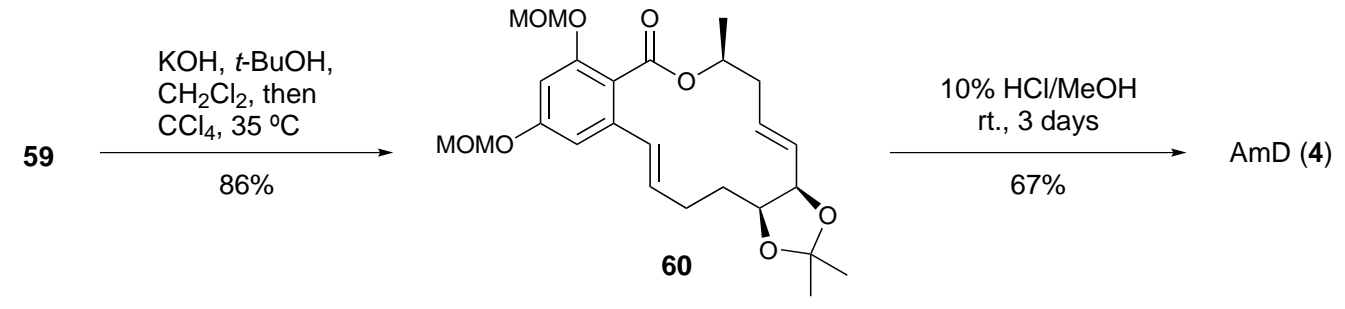

Scheme 3.10. Synthesis of AmD (4) from sulfone 59 



\section{Chapter 4}

\section{Synthesis of 5',6'-epi,epi-Aigialomycin D}

To avoid the arduous task of developing entirely new synthetic methodology, it was proposed that the epi,epi-AmD analogue could be synthesised via the natural AmD synthetic route through use of a starting material possessing the desired $5^{\prime} 6^{\prime}$-diol stereochemistry. We envisaged the required diol stereochemistry could be obtained from D-ribose using the pseudo-symmetry of this chiral pool reagent. Forming the alkene functionality at the $\mathrm{C} 1$-terminus of the molecule, and the aldehyde at the C4-terminus would reverse the carbon chain terminus relative to the AmD synthesis. The resultant aldehyde $\mathbf{7 3}$ thereby may converge with the previously employed synthetic methodology (Scheme 4.1). Through this route previously tested synthetic methodology could be used, and the use of the vastly more expensive L-ribose in a route mirroring that of the natural AmD could be avoided.

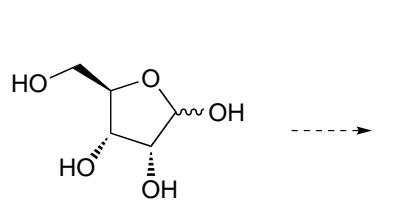

D-Ribose

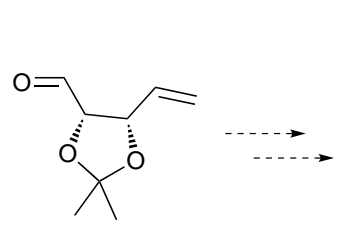

73

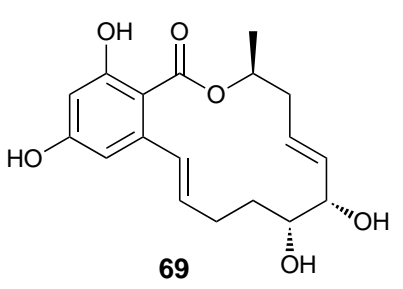

69

Scheme 4.1. Proposed synthetic strategy towards 5',6'-epi,epi-AmD.

\subsection{Synthesis of Thioacetate 81}

The synthetic route to thioacetate $\mathbf{8 1}$, with the $5^{\prime}, 6^{\prime}$-epi,epi stereochemistry relative to $\mathrm{AmD}$, was proposed to proceed via aldehyde $\mathbf{7 3}$, followed by application of the previously employed methods. Aldehyde $\mathbf{7 3}$ could be prepared by a known literature method involving 2,3-O-isopropylidene protection of D-ribose, followed by a Wittig reaction at the anomeric centre to form the alkene functionality of $\mathbf{8 3}$ and a diol cleavage at the C4,C5-diol to form aldehyde $73 .{ }^{73}$ 

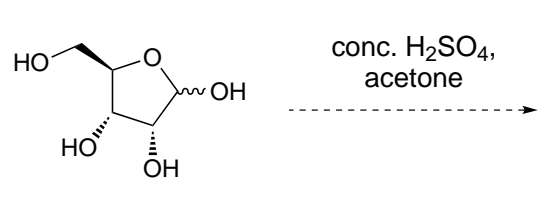

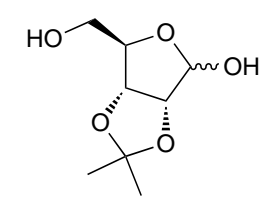

82

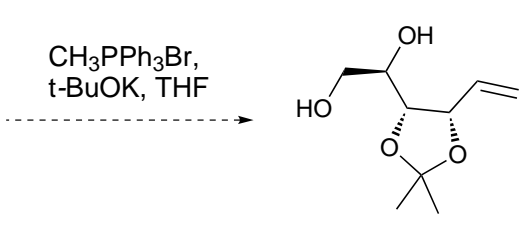

83

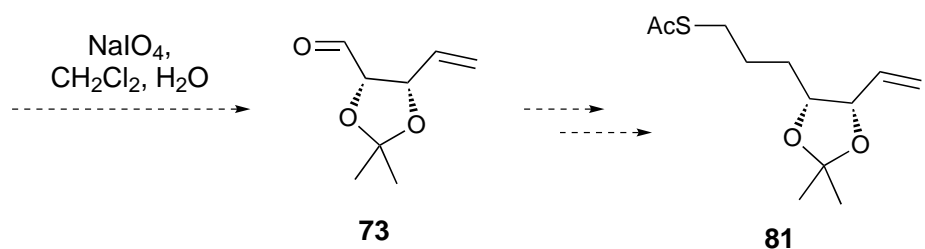

Scheme 4.2. Proposed synthesis of thioacetate 81 .

\subsubsection{Development and Optimisation of the Wittig Reaction Route to} Alkene 83

First, D-ribose was protected to give 2,3-O-isopropylidene-ribose $(\mathbf{8 2}, 84 \%)$ by use of a catalytic amount of concentrated sulfuric acid and acetone (Scheme 4.3). In solution, the protected sugar $\mathbf{8 2}$ would form an equilibrium between the hemiacetal species and an open-chain aldehyde species. It is with this open-chain aldehyde species that the following Wittig reaction was expected to occur. The Wittig reaction was attempted by addition of a solution of the protected sugar $\mathbf{8 2}$ in THF to a solution of the ylide, pre-formed by stirring methyl triphenylphosphonium bromide (2.3 eq.) in a solution of potassium tert-butoxide (2.8 eq.) in THF. ${ }^{73}$ No reaction was observed after 24 hours, with only starting material and a triphenylphosphine by-product isolated from the reaction. Variations in the reaction conditions were then explored.

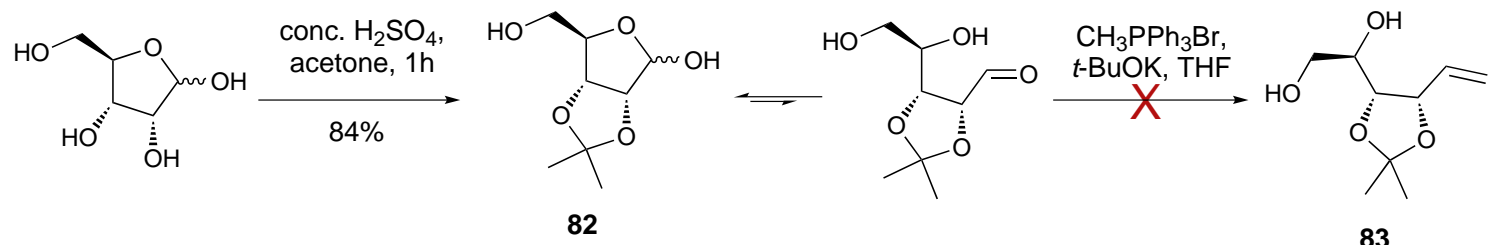

Scheme 4.3. Attempted synthesis of alkene 83 .

Extending the reaction time to three days at room temperature followed by two days at reflux still gave only starting material (entry 2, Table 4.1). To account for the possible poor quality of the potassium tert-butoxide, either an excess of (entry 3, Table 4.1) or freshly prepared potassium tert-butoxide (entry 4, Table 4.1) were also used, but 
only starting material was isolated in either trial. Addition of 18-crown-6 (to improve the reactivity of potassium tert-butoxide) also had no success (entry 5, Table 4.1). Quenching of the Wittig reagent before addition of the sugar was considered as a potential cause of the lack of reactivity. To test this hypothesis, the order of reagent addition was altered. Instead of pre-forming the ylide, potassium tert-butoxide was added to a solution of protected sugar $\mathbf{8 2}$ and methyl triphenylphosphonium bromide in THF. Again, no reaction was observed (entry 6, Table 4.1). The use of alternative bases to pre-form the ylide was then investigated. n-Butyllithium and LDA were tried with no success (entry 7-9, Table 4.1); however, when the ylide was pre-formed with potassium bis(trimethylsilyl)amide (KHMDS), a trace amount of trimethylsilyl (TMS)-protected alkene 84 was obtained (entry 10, Table 4.1).

Table 4.1. Attempted Wittig reaction of 2,3-O-isopropylidene-ribose (82)

\begin{tabular}{|c|c|c|}
\hline Entry & Conditions $^{a}$ & Product \\
\hline 1 & Literature method ${ }^{73}$ (step 2, Scheme 4.2) & Only SM observed \\
\hline 2 & $\begin{array}{l}\text { Left stirring for } 3 \text { days at rt. and } 2 \text { days at } \\
\text { reflux }\end{array}$ & Only SM observed \\
\hline 3 & Excess $t$-BuOK used (4.0 eq.) & Only SM observed \\
\hline 4 & $\begin{array}{l}\text { Excess freshly prepared } t \text {-BuOK used } \\
(4.0 \text { eq.) }\end{array}$ & Only SM observed \\
\hline 5 & $\begin{array}{l}\text { Wittig pre-formed with } t \text {-BuOK (3.0 eq.) } \\
\text { and } 18 \text {-crown- } 6 \text { ( } 0.1 \text { eq. })\end{array}$ & Only SM observed \\
\hline 6 & $\begin{array}{l}t \text {-BuOK added to a solution of the } \\
\text { protected sugar and } \mathrm{CH}_{3} \mathrm{PPH}_{3} \mathrm{Br}\end{array}$ & Only SM observed \\
\hline 7 & $\begin{array}{l}\text { Wittig reagent pre-formed with } n \text {-BuLi at } \\
-78^{\circ} \mathrm{C}\end{array}$ & Only SM observed \\
\hline 8 & $\begin{array}{l}\text { Wittig reagent pre-formed with LDA }(3.0 \\
\text { eq.) at }-78^{\circ} \mathrm{C}\end{array}$ & Only SM observed \\
\hline 9 & $\begin{array}{l}\text { Wittig reagent pre-formed with LDA ( } 4.0 \\
\text { eq.) at }-78^{\circ} \mathrm{C}\end{array}$ & Only SM observed \\
\hline 10 & Wittig pre-formed with KHMDS (2.4 eq.) & $\begin{array}{l}\text { Traces of TMS-protected } \\
\text { alkene } 84\end{array}$ \\
\hline
\end{tabular}

${ }^{a}$ Literature method $^{73}$ (step 2, Scheme 4.2) used with variations as indicated

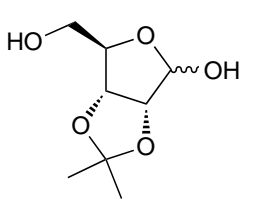

82

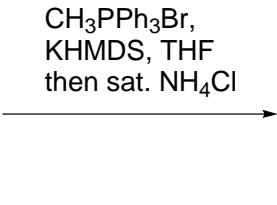

KHMDS, THF

then sat. $\mathrm{NH}_{4} \mathrm{Cl}$

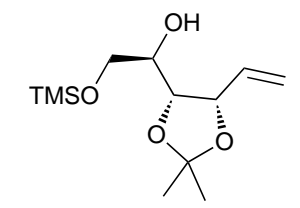

84

Scheme 4.4. Synthesis of TMS-protected alkene 84. 
The slight reactivity with KHMDS could be due to its mild silylating properties, the chemical properties of KHMDS, or a combination of both. First, the role of the observed silylation was investigated. TMS-chloride was employed as a more efficient silylating agent based upon the hypothesis that if the silylation is a crucial element of the reaction, increasing the efficiency of the silylation may increase the efficiency of the conversion to the alkene. To maximise the efficiency of silylation, the sugar $\mathbf{8 2}$ was pre-treated with TMS-chloride and imidazole to provide silylation conditions, before addition to a solution of the ylide reagent, pre-formed with KHMDS. These conditions provided almost complete conversion to the alkene (entry 1, Table 4.2, Scheme 4.5), a considerable improvement over the use of only KHMDS. Unfortunately, the starting material was inseparable from the product, and three different TMS protected products* were also isolated from the reaction. ${ }^{\dagger}$ The majority of the TMS groups were found to be removed in situ during the mildly acidic liquid-liquid extraction with a saturated ammonium chloride solution.

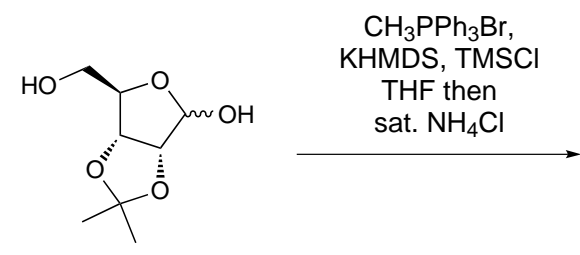

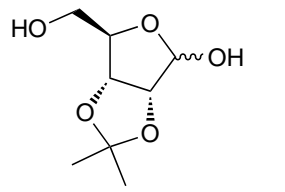

82

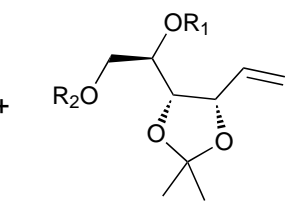

$\mathrm{R}_{1}=\mathrm{TMS}, \mathrm{R}_{2}=\mathrm{TMS}$

$R_{1}=T M S, R_{2}=H$

$\mathrm{R}_{1}=\mathrm{H}, \mathrm{R}_{2}=\mathrm{TMS}$

$\mathrm{R}_{1}=\mathrm{H}, \mathrm{R}_{2}=\mathrm{H}(\mathbf{8 3})$

Scheme 4.5. Synthesis of alkene $\mathbf{8 3}$ and various TMS protected alkenes.

To test whether the improved result was simply due to the imidazole, a solution of sugar 82 and imidazole was added to a solution of the Wittig reagent deprotonated with $n$ butyllithium, a base which can form ylide $\mathrm{H}_{2} \mathrm{C}=\mathrm{PPh}_{3}$ but does not possess silylating properties. This reaction afforded only starting material (entry 2, Table 4.2). This indicated that silylation was a key component in the success of the reaction, therefore, tertbutyldimethylsilyl chloride (TBDMS-Cl) was tested as an alternative, less labile silylating agent. Addition of a solution of the silylating agent (TBDMS-Cl), imidazole and sugar 82 to a solution of the ylide pre-formed with $n$-butyllithium showed no observable Wittig

\footnotetext{
*These products appeared to be the 4- $O$-TMS, 5- $O$-TMS and 4,5-di- $O$-TMS protected alkenes based on ${ }^{1} \mathrm{H}$ NMR spectroscopy of the combined products. They were not purified and characterised.

${ }^{\dagger}$ An estimated yield based on the ${ }^{1} \mathrm{H}$ NMR spectrum was $\sim 70 \%$ of the desired alkene $(\mathbf{8 5})$ and $>1 \%$ of each TMS-protected product.
} 
reaction, instead only 5-O-TBDMS and 1,5-di- $O$-TBDMS protected starting material were isolated (entry 3, Table 4.2). To determine whether the successful reaction (entry 1, Table 4.2) was due to the unique properties of TMS, or if KHMDS was also necessary for the reaction, a solution of TMS-chloride, imidazole and sugar $\mathbf{8 2}$ was added to a solution of the Wittig reagent formed with $n$-butyllithium (entry 4, Table 4.2). No product was isolated from this reaction, suggesting KHMDS is necessary for the desired reaction to occur.

Table 4.2. Optimisation of the Wittig reaction of 2,3-O-isopropylidene-ribose (82)

\begin{tabular}{|c|c|c|}
\hline Entry & Conditions & Products \\
\hline 1 & $\begin{array}{l}\text { Solution of TMSCl ( } 1.2 \text { eq.), imid. ( } 1.5 \\
\text { eq.), sugar added to ylide pre-formed with } \\
\text { KHMDS ( } 3.2 \text { eq.). Scheme } 4.5\end{array}$ & $\begin{array}{l}\sim 70 \% \text { alkene }{ }^{a} \text { and three TMS- } \\
\text { alkene products }\end{array}$ \\
\hline 2 & $\begin{array}{l}\text { Solution of imid. and sugar added to ylide } \\
\text { pre-formed with } n \text {-BuLi. }\end{array}$ & Only SM observed \\
\hline 3 & $\begin{array}{l}\text { Solution of TBDMSCl (1.2 eq.), imid. } \\
(1.5 \text { eq. }) \text { and sugar added to ylide pre- } \\
\text { formed with } n \text {-BuLi ( } 3.0 \text { eq..) }\end{array}$ & $\begin{array}{l}\text { 5- } O \text {-TBDMS and } 1,5-O- \\
\text { TBDMS protected SM. }\end{array}$ \\
\hline 4 & $\begin{array}{l}\text { Solution of TMSCl ( } 1.2 \text { eq.), imid. ( } 1.5 \\
\text { eq.) and sugar added to ylide pre-formed } \\
\text { with } n \text {-BuLi ( } 3.0 \text { eq.) }\end{array}$ & Only SM observed. \\
\hline
\end{tabular}

${ }^{a}$ As an inseparable mixture of $0.2: 1 \mathrm{SM}$ /product.

To simplify the synthetic methodology, imidazole was omitted from the reaction mixture, and harsher deprotection conditions (addition of $10 \%$ hydrochloric acid at $0{ }^{\circ} \mathrm{C}$ ) were trialled to ensure complete removal of the TMS groups. These conditions were initially found to be very encouraging, affording only the desired alkene 83 in $87 \%$ yield (entry 1, Table 4.3), but the hydrochloric acid deprotection proved inconsistent. Repeated attempts of the reaction required longer times stirring in an acidic solution to completely remove the TMS groups. Prolonged stirring with $10 \%$ hydrochloric acid led to lower yields, likely due to the ensuing loss of the isopropylidene group and consequently loss of this material in the aqueous work-up (entries $2 \& 3$, Table 4.3). As significant isopropylidene deprotection appeared to occur before complete TMS deprotection was achieved in 10\% hydrochloric acid, a milder acid was investigated. For this purpose a $20 \%$ aqueous solution of potassium hydrogen sulfate was employed (entry 4, Table 4.3). This proved successful, as the desired product could be consistently isolated in ca. $80 \%$ yield after one hour stirring at $0{ }^{\circ} \mathrm{C}$ (Scheme 4.6). 
Table 4.3. Optimisation of the in situ TMS-deprotection

\begin{tabular}{ccccc}
\hline Entry & $\begin{array}{c}\text { Wittig reaction } \\
\text { conditions }\end{array}$ & \multicolumn{2}{c}{ in situ deprotection } & Yield (\%) \\
& Reagents & Conditions & \\
\hline 1 & step 1, Scheme 4.6 & $10 \% \mathrm{HCl}$ & $0^{\circ} \mathrm{C}, 15 \mathrm{~min}$. & 87 \\
\hline 2 & step 1, Scheme 4.6 & $10 \% \mathrm{HCl}$ & $0^{\circ} \mathrm{C}, 45 \mathrm{~min}$. & 18 \\
\hline 3 & step 1, Scheme 4.6 & $10 \% \mathrm{HCl}$ & $0^{\circ} \mathrm{C}, 30 \mathrm{~min}$. & 45 \\
\hline 4 & step 1, Scheme 4.6 & $20 \% \mathrm{KHSO}_{4}$ & $0^{\circ} \mathrm{C}, 1 \mathrm{~h}$. & 80 \\
\hline
\end{tabular}

${ }^{a}$ Isolated yield of alkene $\mathbf{8 3}$.

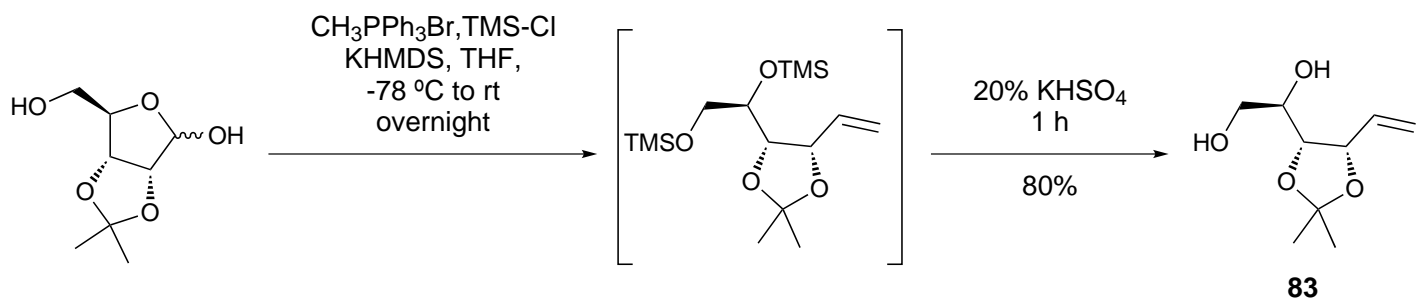

Scheme 4.6. Synthesis of alkene 83 .

These results suggest KHMDS is necessary for an effective Wittig reaction in this complex system, moreover TMS-chloride improves the yield of the reaction, but the role of each of these reagent is uncertain. The reason the reaction occurs with KHMDS but not with $n$-butyllithium, could be due to the steric or electronic nature of each base. A previous report stated the reaction could be conducted with potassium tert-butoxide, ${ }^{73}$ which suggests a sterically hindered potassium base may be required for the reaction to occur. The effect of TMS-chloride may be due to it trapping the aldehyde species in the open-chain form, which can then react with the Wittig reagent. More research would be required to determine the role of each reagent in the reaction, which was not a focus of this study. Instead, with the alkene in hand, focus shifted to the diol cleavage/Wittig reaction sequence to form $\alpha, \beta$-unsaturated ester $\mathbf{7 2}$.

\subsubsection{Optimisation of the Diol Cleavage/Wittig Sequence}

It was proposed that $\alpha, \beta$-unsaturated ester 72 could be formed by 1,2-diol cleavage of $\mathbf{8 3}$, followed by reaction of aldehyde $\mathbf{7 3}$ with the stabilised Wittig reagent, methyl (triphenylphosphoranylidene)acetate (Scheme 4.7). 


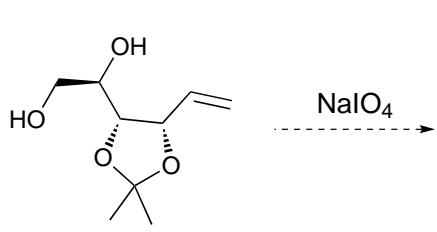

83

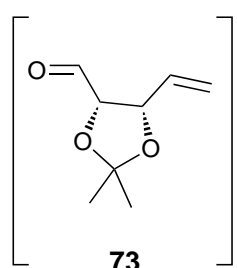

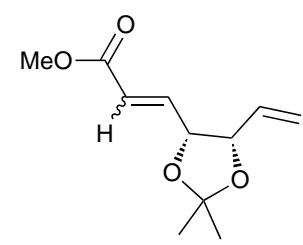

72

Scheme 4.7. Proposed synthesis of $\alpha, \beta$-unsaturated ester 72.

In order to develop a one-pot variant of this reaction sequence analogous to the natural AmD synthesis, the use of polymer- or silica-bound periodate was proposed as this would allow the reagent to be filtered off upon completion of the diol cleavage reaction and prior to the Wittig reaction. The reaction with polymer-bound periodate ${ }^{\ddagger}$ in both dichloromethane (entry 1, Table 4.4) and methanol (entry 2, Table 4.4) was attempted with limited success. This is possibly due to the low loading of the periodate on the polymer, resulting in insufficient periodate reagent, or the reactivity of the reagent. However, the concentration of the polymer-bound reagent could not be accurately determined, so the reason is unknown. Silica-bound periodate ${ }^{\S}$ was then tried as an alternative, with only slightly greater success (entry 3 , Table 4.4). Again, the concentration of the reagent loaded onto the silica was unknown and potentially insufficient, so an alternative approach was tried. Instead of using silica-bound periodate, $\mathrm{NaIO}_{4}$ was employed and silica gel added after the reaction was deemed complete by TLC in order to remove the periodate by-products. This was followed by addition of the Wittig reagent providing the $\alpha, \beta$-unsaturated ester $\mathbf{7 2}$ in $83 \%$ yield (entry 4, Table 4.4). This method allowed for accurate measurement of the periodate reagent, and no adverse affect was observed in the subsequent Wittig reaction from any residual periodate.

Table 4.4. Optimisation of the diol cleavage/Wittig reaction of diol 83

\begin{tabular}{ccccc}
\hline Entry & Reagents & Solvent & Conditions & Yield (\%) \\
\hline 1 & Polymer-bound periodate & $\mathrm{CH}_{2} \mathrm{Cl}_{2}$ & overnight, rt. & $<1 \%$ \\
\hline 2 & Polymer-bound periodate & $\mathrm{MeOH}$ & overnight, rt. & $20 \%$ \\
\hline 3 & Silica-bound periodate & $\mathrm{MeOH}$ & overnight, rt. & $35 \%$ \\
\hline 4 & $\mathrm{NaIO}_{4}{ }^{b}$ & $\mathrm{MeOH}$ & $3 \mathrm{~h}, \mathrm{rt}$. & $83 \%$ \\
\hline
\end{tabular}

${ }^{a}$ Isolated yield of $\alpha, \beta$-unsaturated ester $\mathbf{7 2}$.

${ }^{b} \mathrm{NaIO}_{4}$ by-products were removed by stirring with silica gel followed by filtration.

${ }^{\ddagger}$ Polymer-bound periodate was prepared by the procedure by Harrison and Hodge. ${ }^{74}$

${ }^{\S}$ Silica-bound periodate was prepared by the procedure by Zhong and Shing. ${ }^{75}$ 


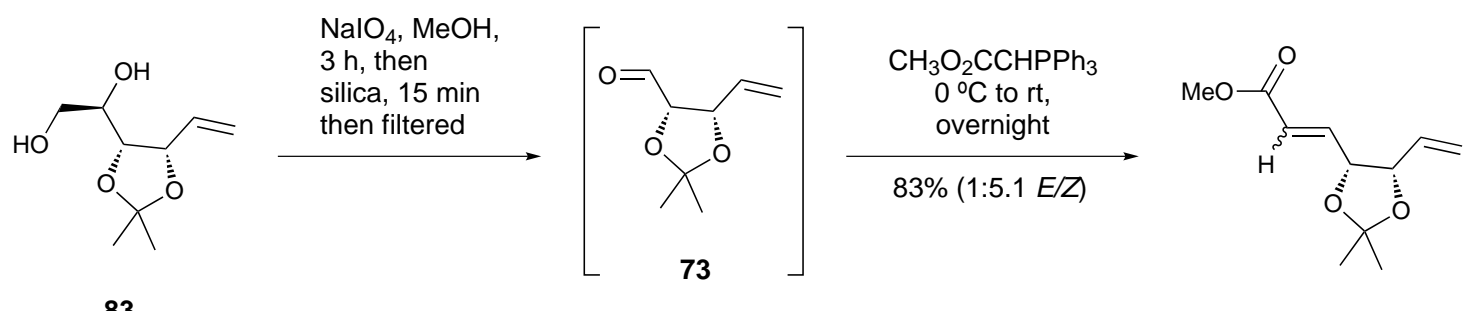

83

72

Scheme 4.8. Synthesis of $\alpha, \beta$-unsaturated ester 72 .

The Wittig reaction was found to give the same $E / Z$ ratio of isomers (1:5.1) as the natural synthesis. ${ }^{1} \mathrm{H}$ NMR spectroscopic data of the $\alpha, \beta$-unsaturated ester isomers $(E)$ and $(Z)-72$, possessing the inverse diol stereochemistry matched those of the previously synthesised $\alpha, \beta$-unsaturated ester isomers, $(E)$ - and (Z)-50 (see section 3.1).

\subsection{Synthesis of $5^{\prime}, 6^{\prime}$-epi,epi-Aigialomycin D}

It was proposed that $5^{\prime}, 6^{\prime}$-epi,epi-AmD (69) could be synthesised from $\alpha, \beta$-unsaturated ester 72 using the methodology employed in the natural AmD (4) synthesis.

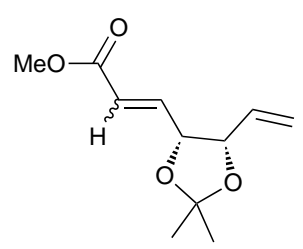

72

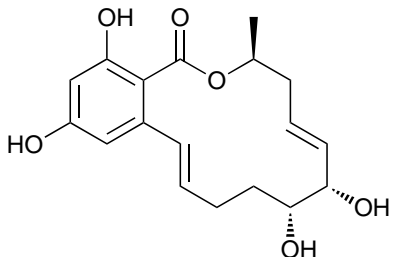

69

Scheme 4.9. Proposed synthesis of $5^{\prime}, 6^{\prime}$-epi,epi-AmD (69).

Thus, selective reduction of the $\alpha, \beta$-unsaturated ester 72 with copper (I) chloride and sodium borohydride in methanol at $-78^{\circ} \mathrm{C}$ afforded $\mathbf{8 6}$ in $88 \%$ yield. Ester $\mathbf{8 6}$ was then reduced to the corresponding alcohol $\mathbf{8 7}$ (lithium aluminium hydride in diethyl ether at $-10^{\circ} \mathrm{C}$ ) followed by conversion to its mesylate, which was displaced by potassium thioacetate to form the thioacetate $\mathbf{8 1}$ in an overall yield of $32 \%$ in seven steps from Dribose (Scheme 4.10). 


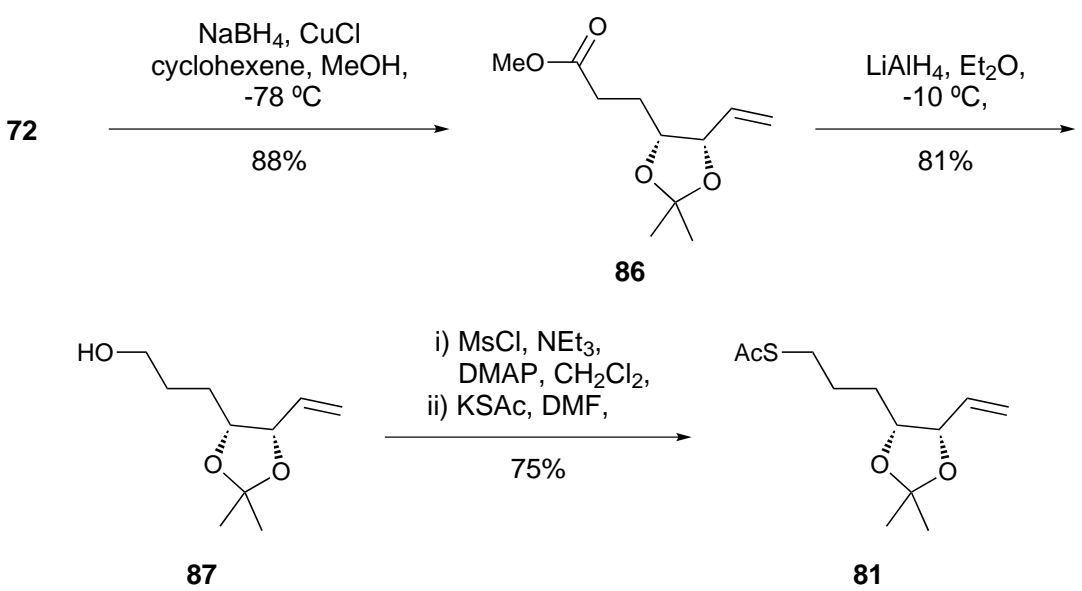

Scheme 4.10. Synthesis of thioacetate 81 from $\alpha, \beta$-unsaturated ester $\mathbf{7 2}$.

Thioacetate 81 was coupled with resorcylic bromoester $\mathbf{4 4}$ to afford coupled thioether 88. The phenolic hydroxyls were then protected as MOM-ethers by deprotonation of the phenolic groups with sodium hydride at $0{ }^{\circ} \mathrm{C}$ followed by the addition of MOMchloride, and the ester then hydrolysed to carboxylic acid $\mathbf{8 9}$ by refluxing with a solution of potassium hydroxide in water/methanol (Scheme 4.11).
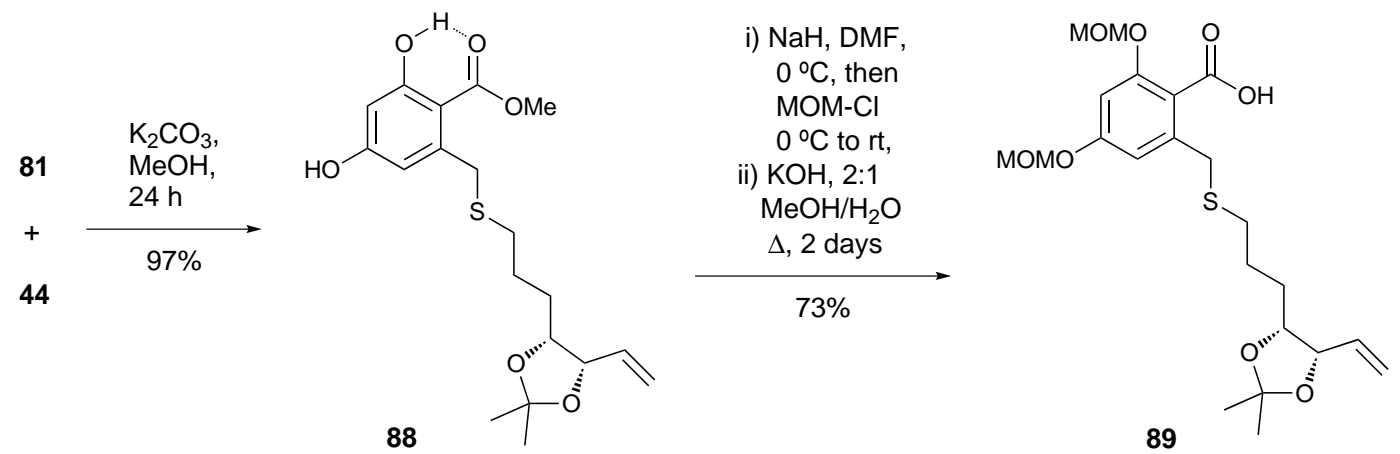

Scheme 4.11. Synthesis of acid 89 from thioacetate 81 and resorcylic bromoester 44 .

A Mitsunobu reaction was then used to couple acid $\mathbf{8 9}$ and chiral alcohol $\mathbf{1 3}$ to afford diene 90. The thioether was then oxidised to the corresponding sulfone with $m$-CPBA, followed by a microwave-assisted RCM catalysed with Grubbs' second generation catalyst (58) to form the macrocycle 91. Like the natural AmD synthesis, both the RCM and RambergBäcklund reaction afforded only the desired $(E)$-alkenes $(\mathbf{9 2})$. The product was then deprotected by stirring in a solution of 1:1 v/v methanol/1 M hydrochloric acid for 2 days. Deprotection provided a 90\% yield of epi,epi-AmD (69) and an unknown isomer (19:1 69:isomer) in an overall yield of 3\% in 15 steps (longest linear sequence) from D-ribose. 

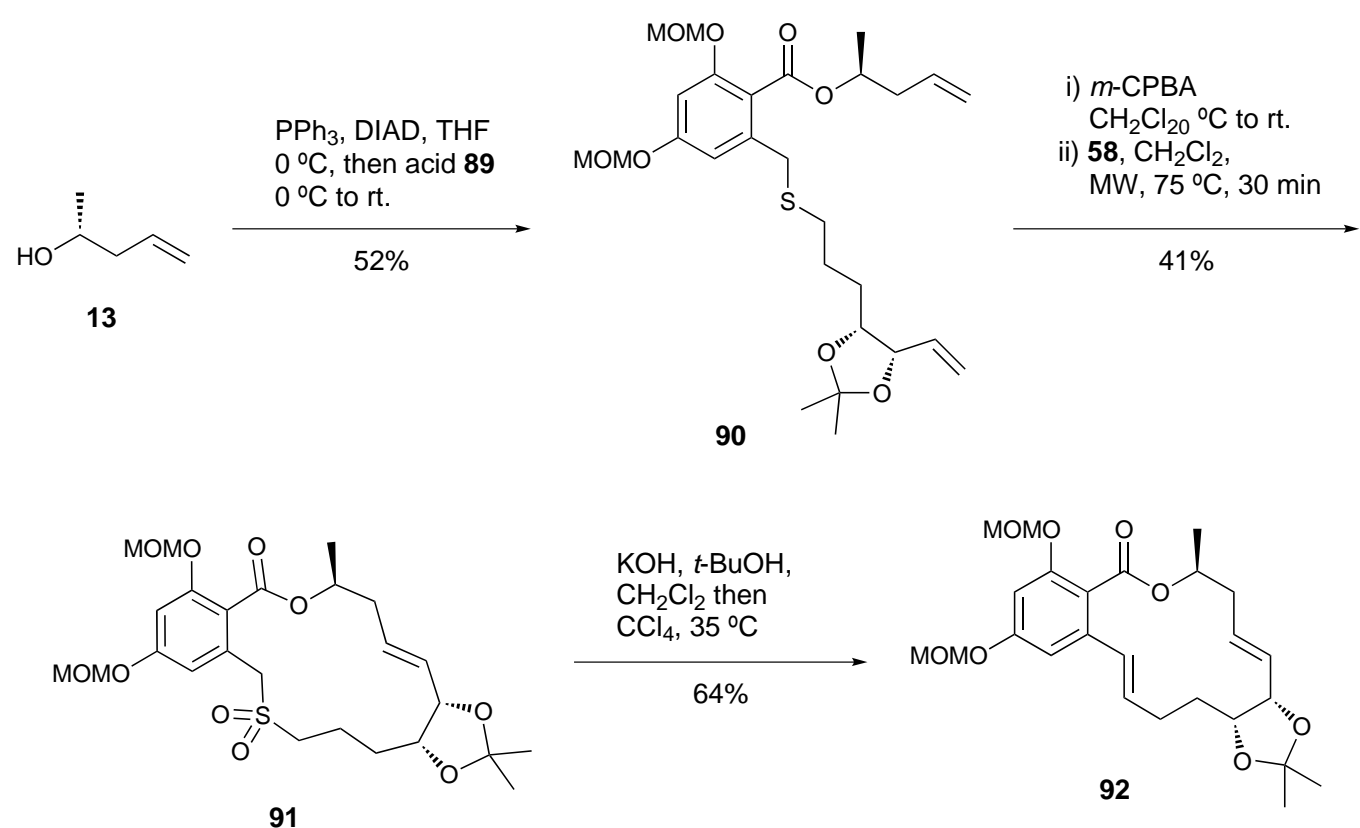

91

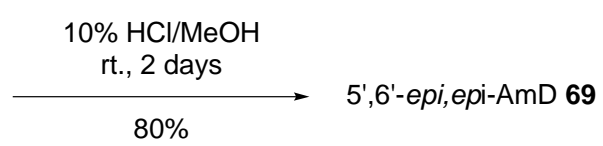

Scheme 4.12. Synthesis of $5^{\prime}, 6^{\prime}$-epi,epi-AmD 69 from acid 89.

The final reactions were found to be much lower yielding than the corresponding reactions in the natural AmD synthesis (Scheme 4.12). It is unknown whether this is due to the altered 5',6'-diol stereochemistry. The low yields of the RCM (67\%) and RambergBäcklund reaction (64\%) imply that the altered diol functionality has an impact on the conformation of the 15- and 14-membered macrocycles formed in these reactions, making the desired products less favoured. However, due to the structural distance of the diol from the carboxylic acid and thioether functionality, inversion of the diol stereochemistry would not be expected to greatly affect the Mitsunobu and thioether oxidation reactions. Simple model building (Figure 4.1) supports this hypothesis, suggesting that the low yields of these two reactions within the $5^{\prime}, 6^{\prime}$-epi,epi series were unlikely to be caused by the altered stereochemistry. As the desired product 69 had been obtained, no further investigation into the origin of the low yields or optimisation of the synthesis were undertaken. 


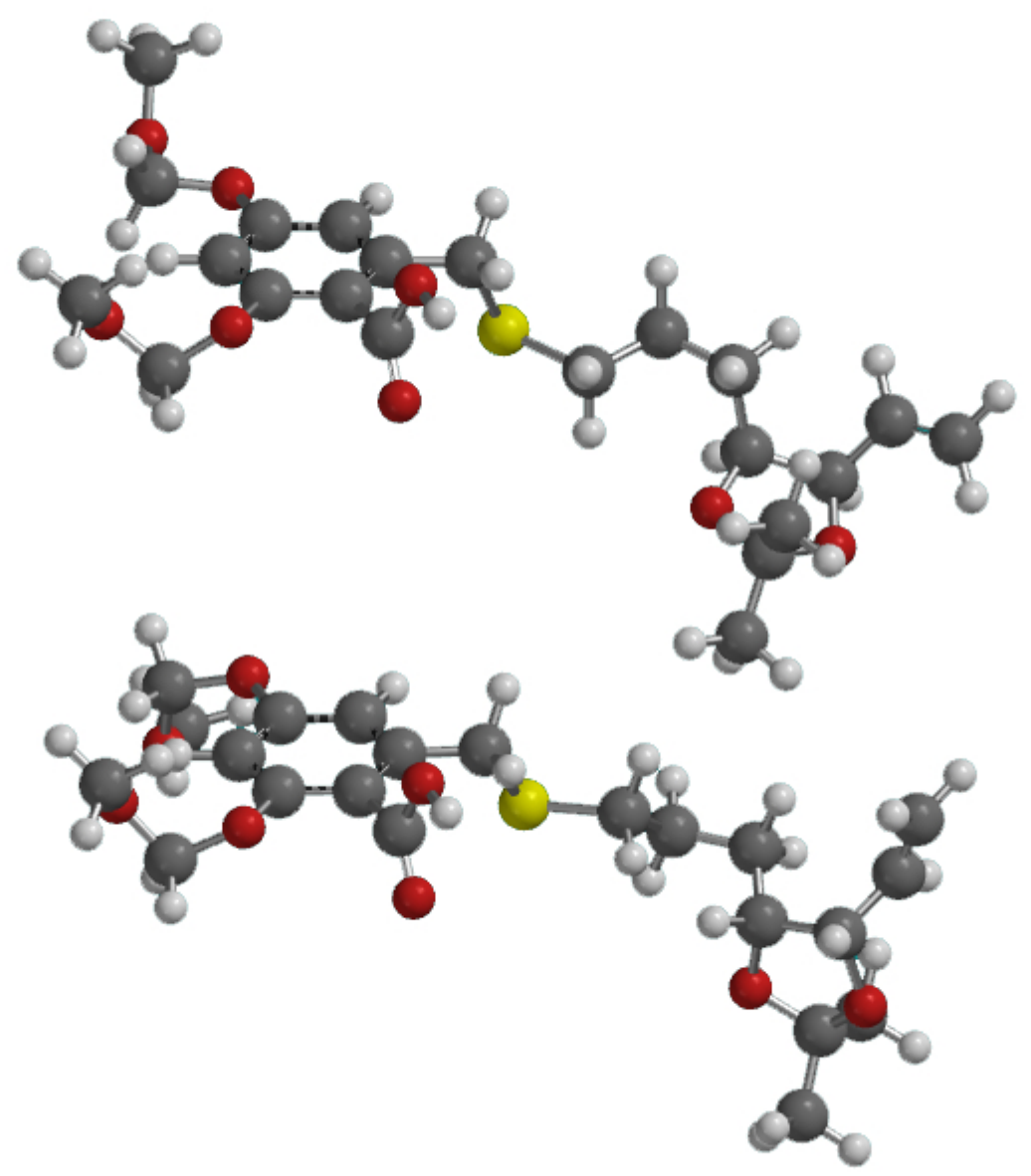

Figure 4.1. Molecular models of acid 45 (top) and the 5',6'-epi,epi-acid 89 (bottom).

Separation of the isomers was achieved with reverse phase HPLC (C18, 80\% methanol/water, $\mathrm{R}_{t}=8 \mathrm{~min}$ ), subsequent $\mathrm{NMR}$ characterisation of the compound confirmed the major product was the desired $5^{\prime}, 6^{\prime}$-epi,epi-AmD (69). In comparison to the ${ }^{1} \mathrm{H}$ NMR spectrum of $\mathrm{AmD}(4)$, the spectrum of the epi,epi-AmD analogue 69 displayed two significantly shifted peaks; unsurprisingly the peaks associated with the $\mathrm{C}^{\prime}$-proton and $\mathrm{C}^{\prime}$-proton. The peak assigned as the $\mathrm{C} 6^{\prime}$-proton was shifted from $4.35 \mathrm{ppm}$ (in the ${ }^{1} \mathrm{H}$ NMR spectrum of 4) to $4.66 \mathrm{ppm}$ (in the ${ }^{1} \mathrm{H}$ NMR of 69), and the peak assigned as the $\mathrm{C}^{\prime}$-proton was shifted from $3.63 \mathrm{ppm}$ (in the ${ }^{1} \mathrm{H}$ NMR spectrum of 4) to 4.24 (in the ${ }^{1} \mathrm{H}$ NMR spectrum of 69). There is also significant differences in the observed coupling constants relative to $\mathrm{AmD}$, these are discussed further in section 6.1.

Unfortunately, only a small amount of the unknown isomer, contaminated with $5^{\prime}, 6^{\prime}$ epi,epi-AmD in a ratio of 2:1, was isolated by HPLC, which was insufficient to fully 
characterise the compound. From high-resolution mass spectroscopy (HRMS), it was confirmed the unknown isomer had the same mass as AmD. The ${ }^{1} \mathrm{H}$ NMR spectrum suggested the compound was the $\left(7^{\prime} Z\right)$-isomer (93) based on the following evidence: i) the peak assigned as the $\mathrm{C} 8^{\prime}$-proton in the $\left(7^{\prime} E\right)$-isomer spectrum (at $\left.6.08 \mathrm{ppm}\right)$ is a minor peak in this spectrum. However, a peak which integrates for two protons is observed at $5.60 \mathrm{ppm}$, which is possibly the $\mathrm{C}^{\prime}$ - and $\mathrm{C} 8^{\prime}$-protons of the $\left(7^{\prime} Z\right)$-alkene; ii) the peak assigned as the $\mathrm{C}^{\prime}$-proton is shifted from $4.66 \mathrm{ppm}$ in the $\left(7^{\prime} E\right)$-isomer spectrum to 5.05 ppm in the unknown; iii) as the remainder of the peaks in this spectrum correlate well with those expected for the $\left(7^{\prime} E\right)$-isomer spectrum, the variation between the two compounds obtained from the deprotection reaction is probably at the $7^{\prime}, 8^{\prime}$-positions.
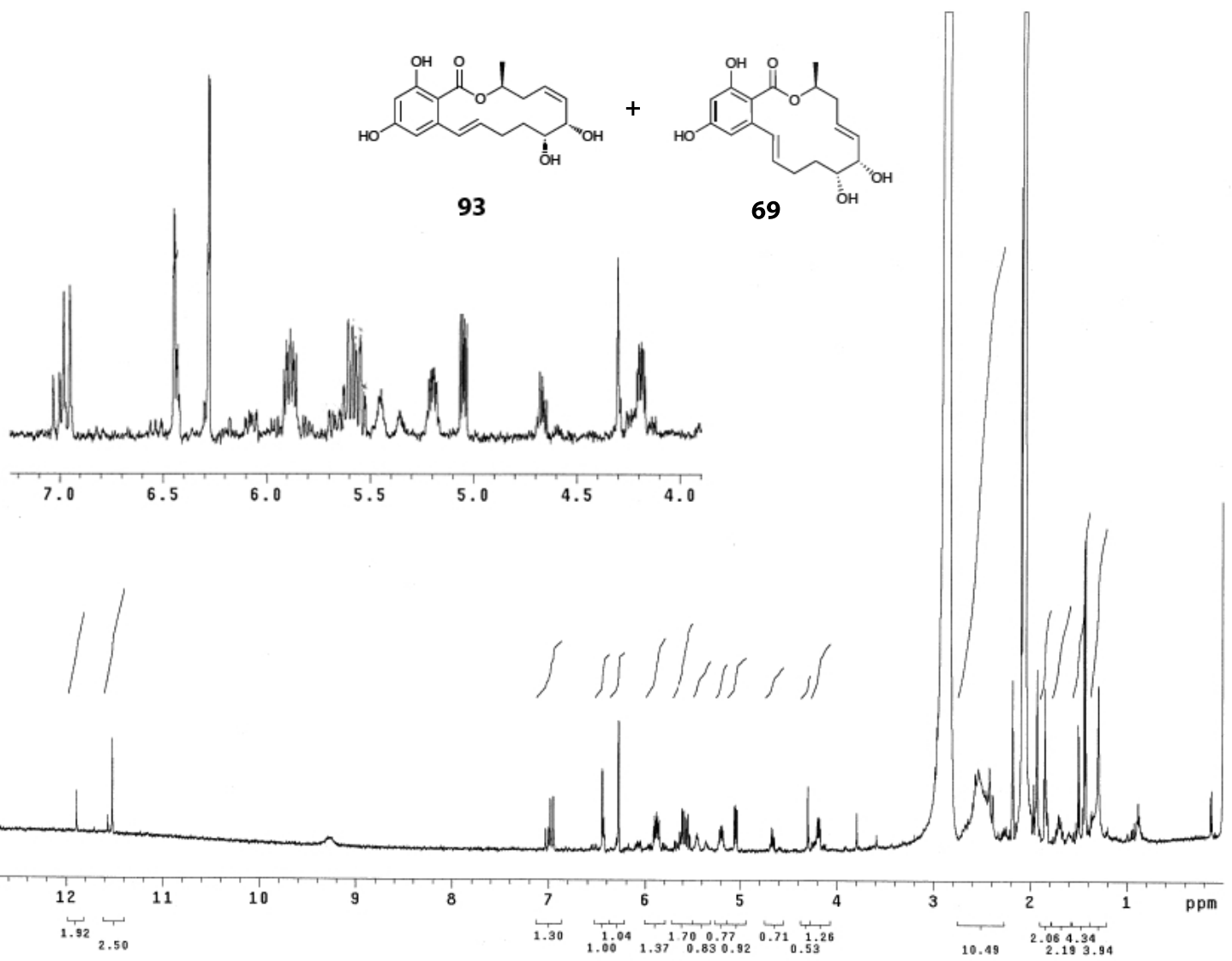

Figure 4.2. ${ }^{1} \mathrm{H}$ NMR spectrum of 2:1 mixture of putative isomer 93 and epi,epi-AmD 69 $\left(500 \mathrm{MHz}\right.$, acetone- $\left.\mathrm{d}_{6}\right)$.

A possible mechanism for the formation of the $\left(7^{\prime} Z\right)$-isomer involves acid-catalysed isomerisation (Scheme 4.13). Protonation of the $7^{\prime}, 8^{\prime}$-alkene to form a carbocation would allow rotation of the $\mathrm{C}^{\prime}-\mathrm{C} 8^{\prime}$ bond, and subsequent deprotonation would reform the alkene. It is possible the $\mathrm{C}^{\prime}$-alcohol could stabilise the positive charge at the $7^{\prime}$-position. 
The formation of the $(Z)$-isomer suggests it is more favoured relative to the $(E)$-isomer of this system compared with the natural AmD system (see chapter 6 for computational calculations)<smiles>C/C=C\C(O)[C@H](O)C/C=C/CC/C=C/c1cc(O)cc(O)c1C(=O)O</smiles>

69

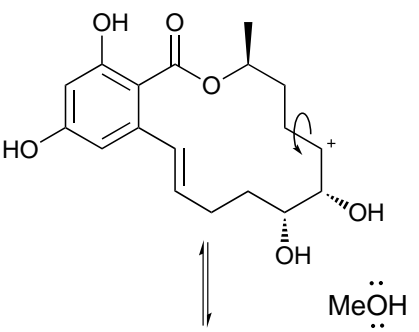

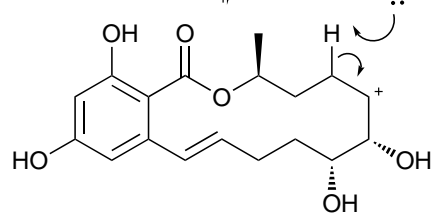<smiles>CCCC/C=C\c1cc(O)cc(O)c1C(=O)OC(C)C/C=C\CCC(O)O</smiles>

Scheme 4.13. Proposed acid-catalysed isomerisation of 5',6'-epi,epi-AmD (69). 



\section{Chapter 5}

\section{Synthesis of $10^{\prime}$-epi-Aigialomycin D (64)}

The synthetic strategy to obtain $10^{\prime}$-epi-AmD analogue 64 involved a stereo-retentive esterification of acid 45, an intermediate in the AmD synthesis, with $(R)$-4-penten-2-ol. By altering the esterification step to retain the stereochemistry of the alcohol in the coupling, the desired $(R)$-ester $(\mathbf{6 6})$ could be synthesised from the same starting materials used in the natural AmD synthesis. After this stage, the AmD synthetic methodology could be employed en route to $10^{\prime}$-epi-AmD (Scheme 5.1).
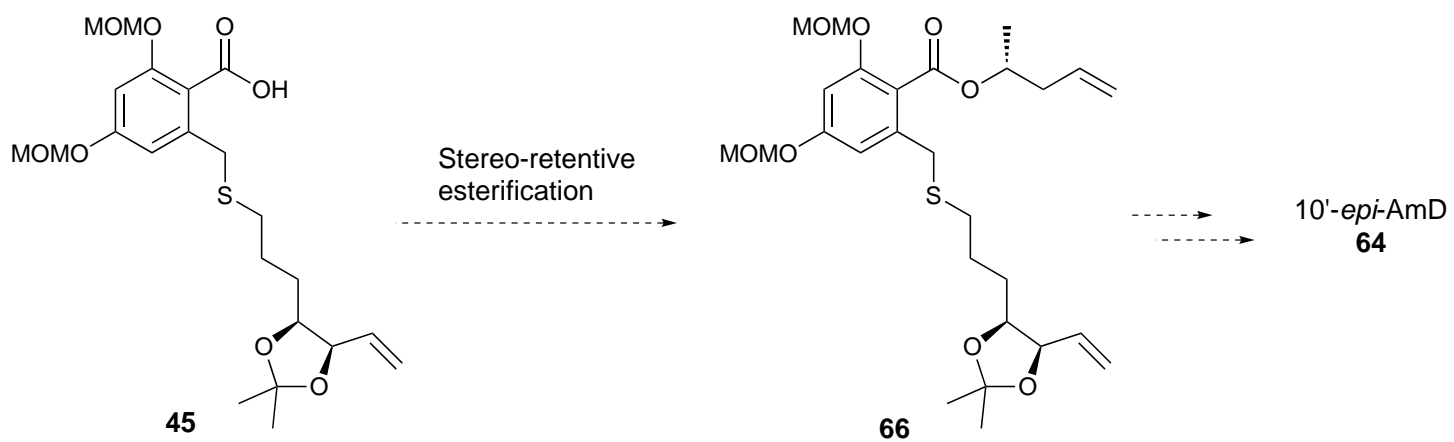

Scheme 5.1. Proposed synthesis of $10^{\prime}$-epi-AmD 64 .

\subsection{Synthesis of Ester 66}

Previous research by Dr Baird employed a Steglich esterification with limited success, therefore, model studies were conducted to optimise the conditions prior to use on the real system. The model system was the coupling of 2-methylbenzoic acid (2,4-dehydroorsellinic acid, 94) and racemic alcohol 4-penten-2-ol. (Scheme 5.2).<smiles>Cc1ccccc1C(=O)O</smiles>

94

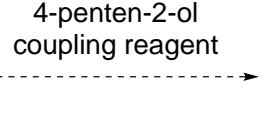

4-penten-2-ol 


\subsubsection{Stereo-Retentive Esterification Model Studies}

Stereo-retentive esterification was first done using the methodology employed by Dr Baird for comparison purposes, whereby racemic 4-penten-2-ol was added to a solution of acid 94 and DMAP (2.0 eq.) in dichloromethane followed by DCC (1.1 eq.), to afford the ester (95) in 52\% yield (entry 1, Table 5.1). EDCI (1.1 eq.) in combination with DMAP (2.0 eq.) was found to be only slightly more successful, affording ester $\mathbf{9 5}$ in $58 \%$ yield (entry 2, Table 5.1). While this yield was only slightly greater, the EDCI method was favoured due to its easier practical application.* Increasing the quantities of the reagents was found to improve the yield of the reaction, with EDCI (1.5 eq.) in combination with DMAP (3.0 eq.) gave $73 \%$ yield of the desired ester (entry 3, Table 5.1). An alternate order of reagent addition was also tried, whereby a solution of the acid 94 was stirred with DMAP (3.0 eq.) and EDCI (1.5 eq.) before addition of 4-penten-2-ol. This was based on the reaction mechanism, which involves the formation of an activated ester (96), followed by conversion into a more reactive activated DMAP-amide; after addition of the alcohol, nucleophilic attack on this species forms the ester (Scheme 5.3). However, this was found to give a lower yield of the ester (entry 4, Table 5.1).

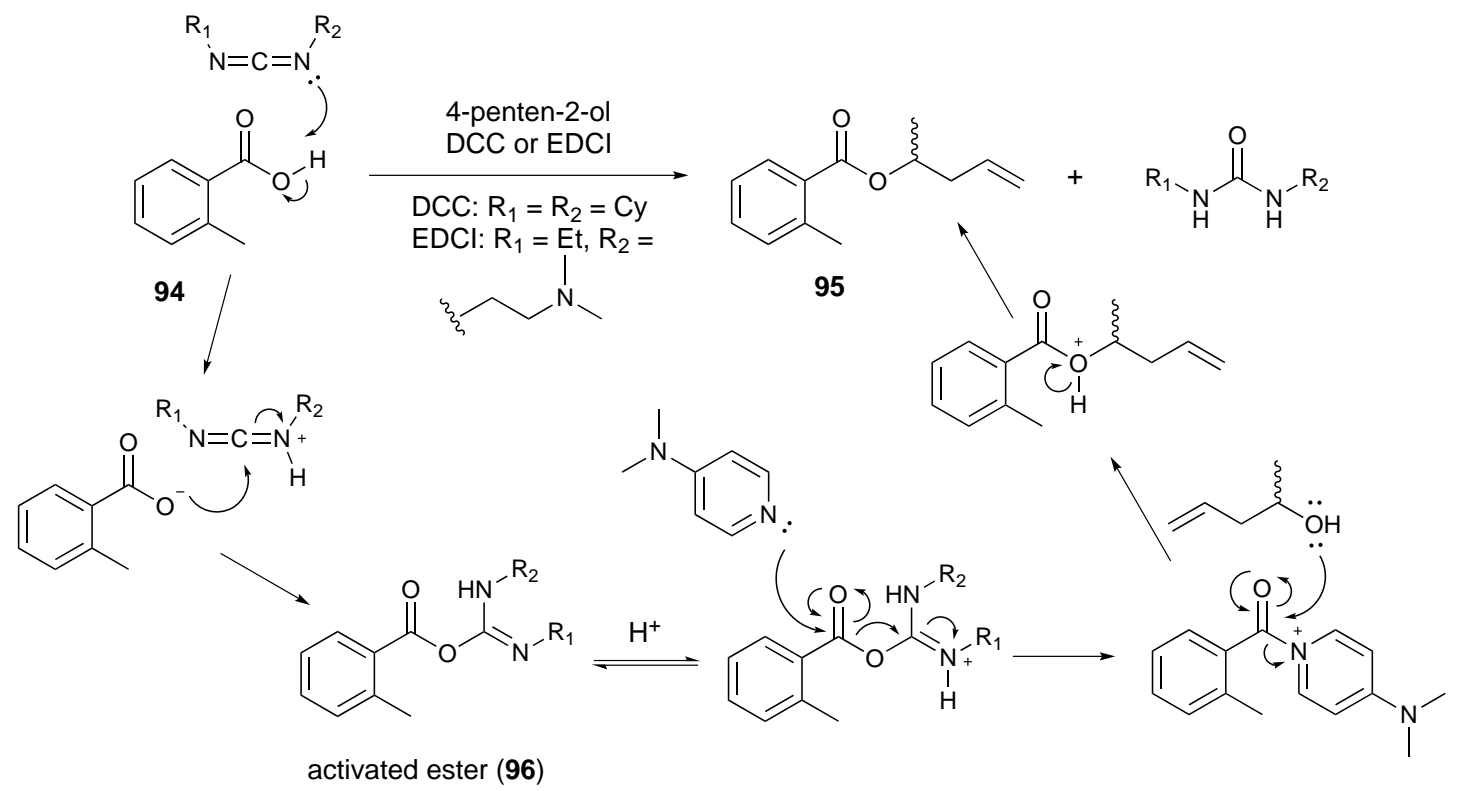

Scheme 5.3. Model stereo-retentive esterification system and proposed Steglich esterification mechanism.

${ }^{*}$ The high water solubility of the urea by-product from the EDCI reaction allows it to be easily removed by aqueous extraction. 
The coupling reagent HBTU was also investigated. HBTU (1.1 eq.), in combination with DMAP (3.0 eq.), was found to give a modest yield of 95 (57\%, entry 5, Table 5.1), while HBTU and triethylamine yielded only traces of the desired product (entry 6, Table 5.1). The best result was obtained using HBTU (1.5 eq.), DMAP (3.0 eq.) and triethylamine (3.0 eq.), affording ester $\mathbf{9 5}$ in a $75 \%$ yield (entry 7 , Table 5.1).

Table 5.1. Esterification model studies.

\begin{tabular}{lcc}
\hline Entry & Reagents $^{\boldsymbol{a}}$ & Yield (\%) $^{\boldsymbol{b}}$ \\
\hline 1 & DCC (1.1 eq.), DMAP (2.0 eq.) & $52 \%$ \\
\hline 2 & EDCI (1.1 eq.), DMAP (2.0 eq.) & $58 \%$ \\
\hline 3 & EDCI (1.5 eq.), DMAP (3.0 eq.) & $73 \%$ \\
\hline 4 & EDCI (1.5 eq.), DMAP (3.0 eq.), pre-treated acid ${ }^{c}$ & $52 \%$ \\
\hline 5 & HBTU (1.1 eq.), DMAP (3.0 eq.) & $57 \%$ \\
\hline 6 & HBTU (1.5 eq.), $\mathrm{NEt}_{3}$ (3.0 eq.) & $<1 \%$ \\
\hline 7 & HBTU (1.5 eq.), DMAP (3.0 eq.), $\mathrm{NEt}_{3}(3.0$ eq.) & $75 \%$ \\
\hline${ }^{a}$ All reactions (except 4) were done by addition of the alcohol, followed by the coupling reagent, to a \\
solution of acid $\mathbf{9 4}$ and DMAP and/or $\mathrm{NEt}_{3}$ in $\mathrm{CH}_{2} \mathrm{Cl}_{2}$ at $0^{\circ} \mathrm{C}_{\text {and left to warm to rt. overnight. }}$ \\
${ }^{b}$ Isolated yield of ester $\mathbf{9 5}$ \\
${ }^{c}$ Alcohol added to a solution of acid $\mathbf{9 4 ,}$ EDCI and DMAP in $\mathrm{CH}_{2} \mathrm{Cl}_{2}$ at $0^{\circ} \mathrm{C}$ and left to warm to rt. \\
overnight.
\end{tabular}

\subsubsection{Attempted Stereo-retentive Esterification of Acid 45}

The preceding model studies suggested two esterification methods that would be more effective than the DCC and DMAP method previously used by Dr Baird (entries 3 and 6, Table 5.1). Esterification of acid $\mathbf{4 5}$ was first attempted with EDCI and DMAP, but it was relatively unsuccessful, affording the ester $\mathbf{6 6}$ in only $30 \%$ yield.
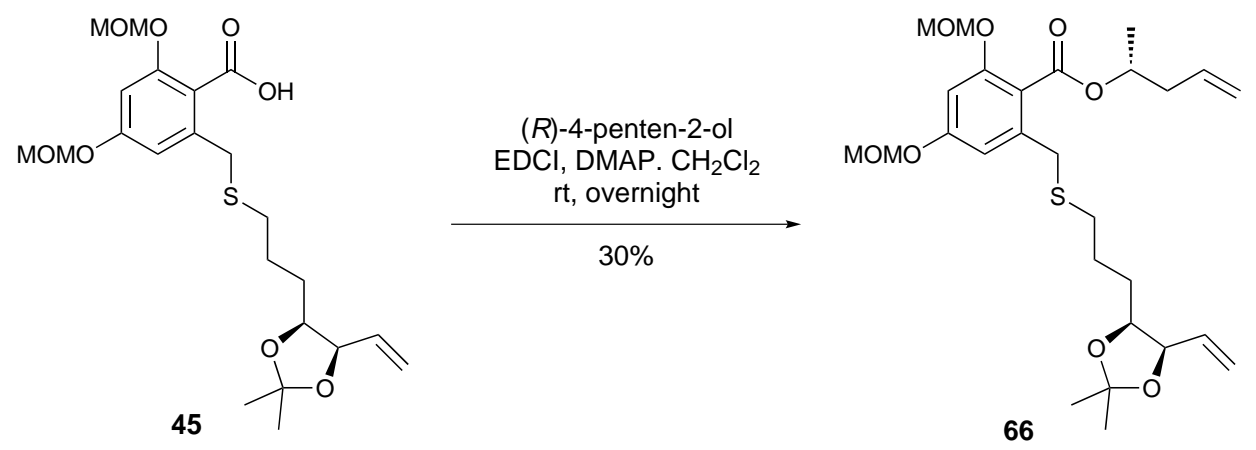

Scheme 5.4. Steglich esterification of acid $\mathbf{4 5}$. 
The esterification was then attempted with HBTU, DMAP and triethylamine, which afforded none of the desired ester. Interestingly, the only product isolated from this reaction was a product tentatively characterised as the HBTU adduct 97 (10\% yield), suggesting the activated ester was not susceptible to nucleophilic attack. This is potentially due to steric influence of the aromatic ring ortho substituents causing the carboxylic acid carbonyl to be rotated out of the plane of the ring. In this conformation, the ortho substituents would hinder the approach of nucleophiles to the carbonyl carbon. Alternatively, it was hypothesised the lack of reactivity could be due to the higher electron density of the $O$-substituted benzylic ring creating an electron-rich carbonyl moiety, which would be less susceptible to nucleophilic attack than the model system. While speculative, the electron-rich carbonyl moiety would explain the low yields observed in the Steglich and HBTU-mediated esterification reactions, which rely on nucleophilic attack at the carbonyl of the activated ester, by the alcohol (Scheme 5.3). Based on this hypothesis, reactions such as Steglich, HBTU and Yamaguchi esterification (where the acid behaves as an electrophile) would be disfavoured. However, the Mitsunobu reaction, which occurs through nucleophilic attack by the acid on an activated alcohol, would be favoured. With this in mind, it was decided that the most effective route to $(R)$-ester $\mathbf{6 6}$ would likely be through a Mitsunobu esterification of acid 45 with the enantiomeric chiral alcohol, $(S)$-4-penten-2-ol (98).
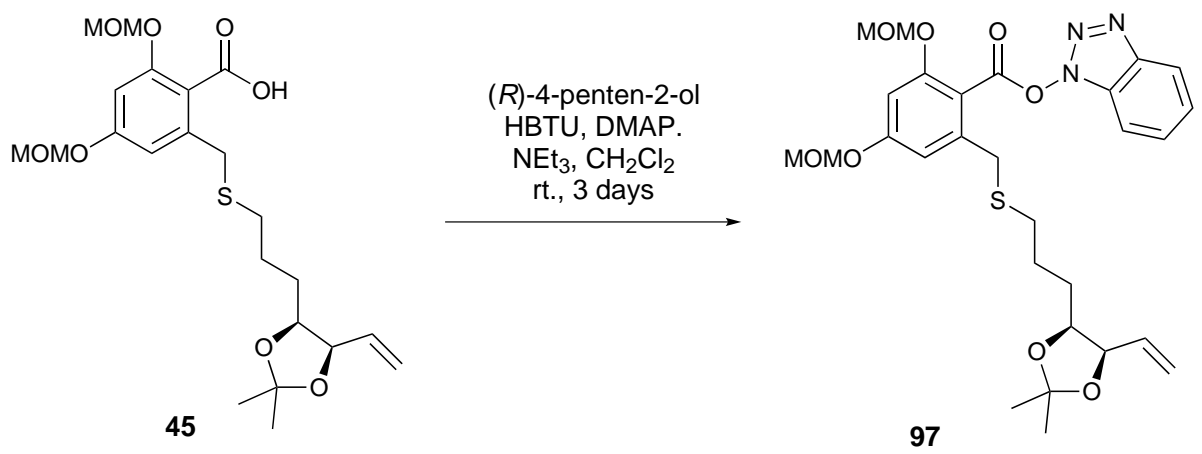

Scheme 5.5. Attempted HBTU coupling of acid 45 and alcohol 13. 


\subsubsection{Stereo-invertive Esterification of Acid 45}

The Mitsunobu reaction of (S)-4-penten-2-ol (98) with acid 45 was found to afford the desired $(R)$-ester 66 in a good yield $\left(86 \%\right.$, Scheme 5.6). The ${ }^{1} \mathrm{H}$ NMR spectrum of this compound was very similar to that of the previously synthesised $(S)$-ester (56), and in combination with ${ }^{13} \mathrm{C}$ NMR and HRMS, confirmed the desired compound had been obtained. The result of this reaction supports the previous hypothesis that the electron density of the acid functionality would favour reactions where the acid behaves as a nucleophile, such as the Mitsunobu reaction. With the $(R)$-ester (66) in hand, the synthesis of $10^{\prime}$-epi-AmD (64) could proceed.
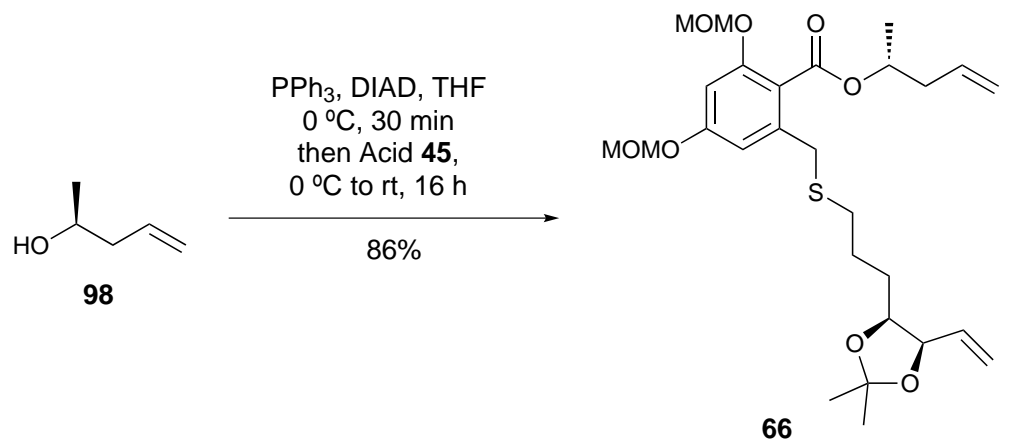

Scheme 5.6. Mitsunobu esterification of acid 45 with (S)-4-penten-2-ol (98).

\subsection{Attempted synthesis of $10^{\prime}$-epi-Aigialomycin D (64) from Ester 66}

Oxidation of the thioether $\mathbf{6 6}$ to the corresponding sulfone with $m$-CPBA, followed by the microwave-assisted RCM, to afford the macrocycle $\mathbf{6 8}$ in a reasonable overall yield (59\%, Scheme 5.7). A Ramberg-Bäcklund reaction was then used to reveal the 1'-alkene, affording the protected epi-AmD (99). As seen in previous syntheses, only the $\left(1^{\prime} E\right)$ alkene was observed, however, a relatively low yield was obtained (57\%). 


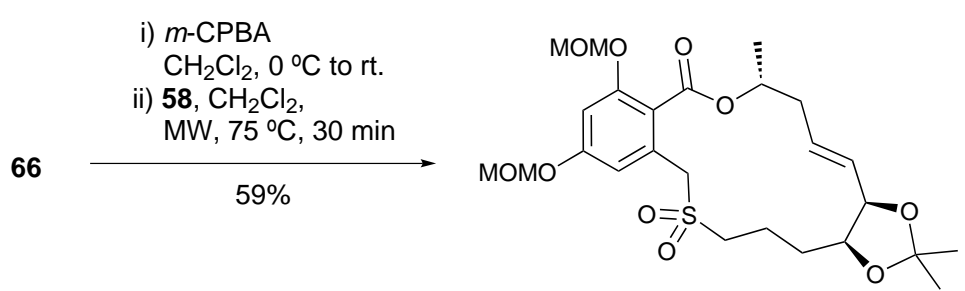

68

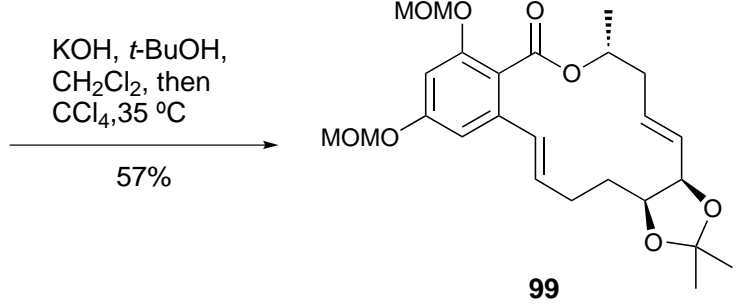

Scheme 5.7. Synthesis of protected 10'-epi-AmD 99 from epi-ester 66.

The protecting groups were then removed by stirring in $1: 1 \mathrm{v} / \mathrm{v}$ methanol/1 $\mathrm{M}$ hydrochloric acid at room temperature for two days, providing a 3:2 mixture of two RAL compounds. ${ }^{\dagger}$ The identities of the two compounds could not be accurately identified from the ${ }^{1} \mathrm{H}$ NMR of the crude reaction mixture, although, neither compound appeared to be the desired $10^{\prime}$-epi-AmD. Unfortunately, all attempts to separate the two compounds were unsuccessful.
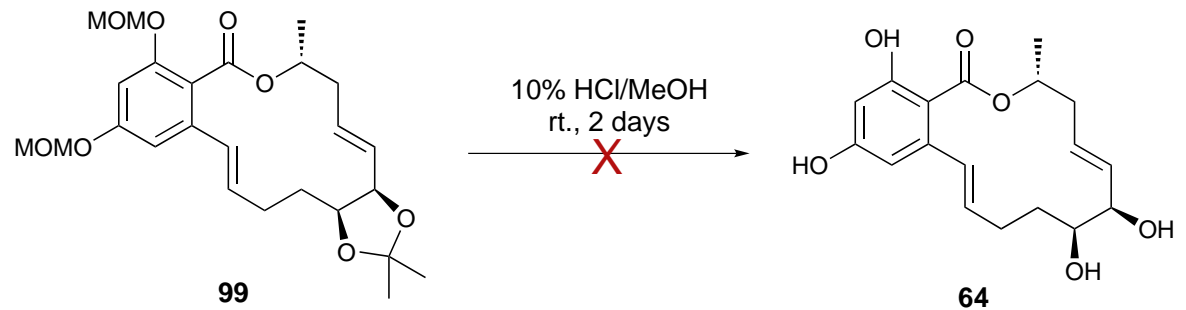

Scheme 5.8. Deprotection of protected 10'-epi-AmD 99 .

The difficulty associated with separating the compounds may have been due to the significantly higher polarity of these compounds relative to $\mathrm{AmD}(4)$ and 5',6'-epi,epiAmD (69). This higher polarity was most evident when purification by reverse-phase HPLC was attempted. In solvent systems from $75 \%$ to $95 \%$ methanol/water, a retention time $\left(\mathrm{R}_{t}\right)$ of 3 minutes was observed, which equates to the solvent front of the systems; this is compared with a retention time of $7-8$ minutes in $80 \%$ methanol/water for $\mathrm{AmD}$ (4) and 5',6'-epi,epi-AmD (69). As the two compounds could not be separated, full identification and characterisation of the compounds could not be accomplished.

\footnotetext{
${ }^{\dagger}$ Based on ${ }^{1} \mathrm{H}$ NMR spectroscopy of the crude extracted reaction mixture.
} 
HRMS confirmed the two compounds possessed the correct mass (for AmD), however, the ${ }^{1} \mathrm{H}$ NMR spectroscopic data did not match those of $5^{\prime}, 6^{\prime}$-epi,epi-AmD (69) or the putative $\left(7^{\prime} Z\right)$-isomer. As $10^{\prime}$-epi-AmD (64) is the enantiomer of $\mathbf{6 9}$, it suggests neither of the compounds is 64 or its $\left(7^{\prime} Z\right)$-isomer. ${ }^{1} \mathrm{H}$ and ${ }^{13} \mathrm{C}$ NMR spectra from earlier products (after the formation of the macrocycle) in the $10^{\prime}$-epi-and 5',6'-epi,epi-AmD syntheses are identical, indicating that isomerisation occured during the acidic deprotection reaction. The ${ }^{1} \mathrm{H}$ NMR spectroscopy suggests the most plausible to be epimerisation of the allylic alcohol, and E/Z-isomerisation of the $7^{\prime}$-alkene, as proposed to have occurred in the synthesis of 69. The products were tentatively assigned as $5^{\prime}, 10^{\prime}$-epi,epi-AmD (100) and its $\left(7^{\prime} Z\right)$-isomer (101) based on the ${ }^{1} \mathrm{H}$ NMR spectrum (Figure 5.1).

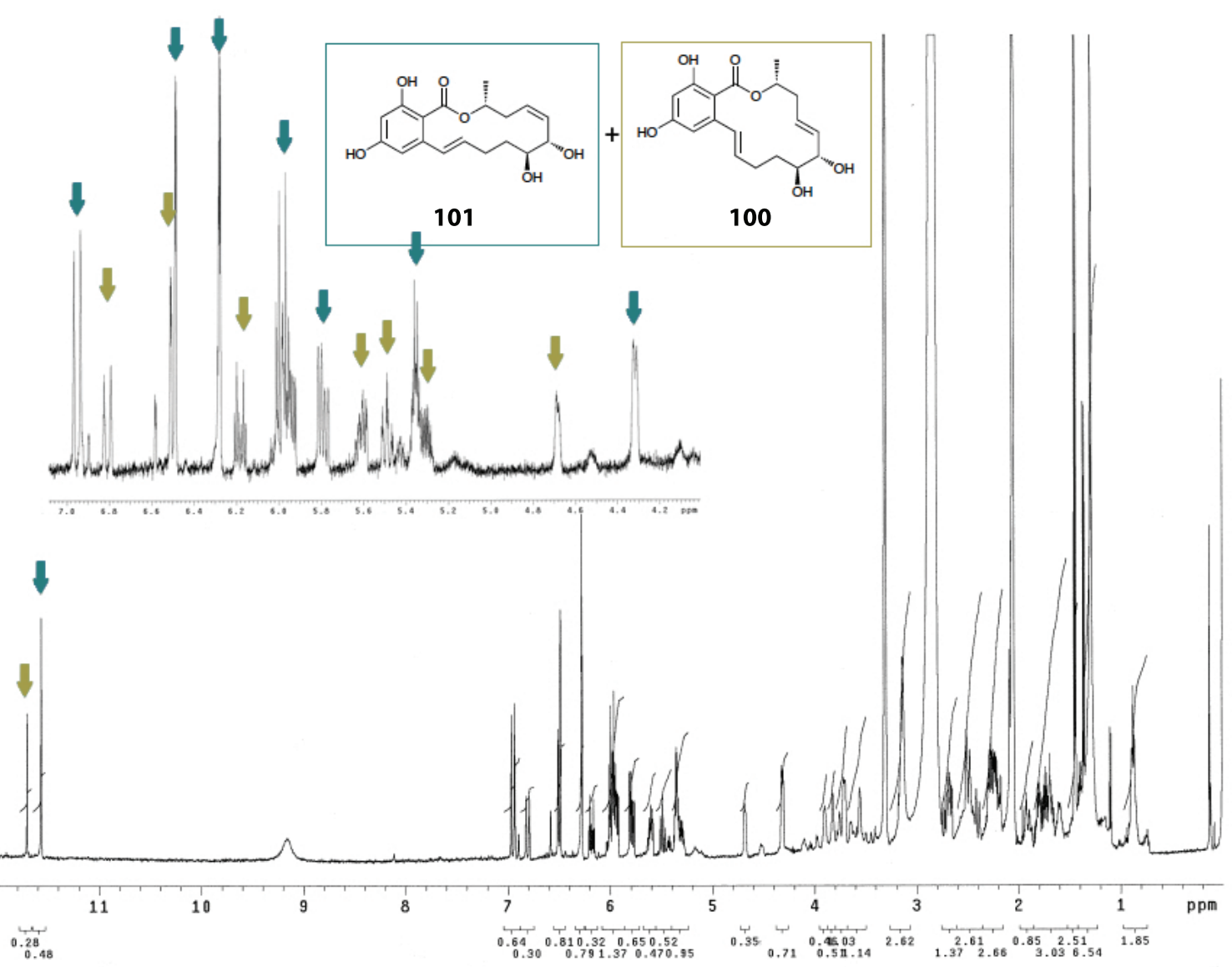

Figure 5.1. ${ }^{1} \mathrm{H}$ NMR spectrum of the putative $10^{\prime}$-epi-AmD synthesis products $\mathbf{1 0 0}$ and $101\left(500 \mathrm{MHz}\right.$, acetone- $\left.\mathrm{d}_{6}\right)$.

${ }^{1} \mathrm{H}$ NMR provides circumstantial evidence for the $\mathrm{C6}^{\prime}$-epimerisation, predominately because changes to the ${ }^{1} \mathrm{H}$ NMR spectrum expected from other plausible isomerisation mechanisms (e.g. migration of the allylic alcohol, or 7'-alkene) were not observed. The ${ }^{1} \mathrm{H}$ NMR spectrum displayed four minor peaks with ${ }^{3} J_{H, H^{\prime}}$ couplings of $\sim 15.0 \mathrm{~Hz}$ (at 
$6.81,6.18,5.60$ and $5.49 \mathrm{ppm})$, indicating the minor component contains four $(E)$-alkene protons. The minor peak at $4.68 \mathrm{ppm}$ was attributed to the $\mathrm{C} 6^{\prime}$-proton, and the minor peak at $5.28 \mathrm{ppm}$ (partially obscured by the corresponding peak of the major component) was attributed to the $\mathrm{C} 10^{\prime}$-proton. Of the major peaks in the ${ }^{1} \mathrm{H}$ NMR spectrum, two showed ${ }^{3} J_{H, H^{\prime}}$ couplings of $\sim 15.0 \mathrm{~Hz}$ (at 6.95 and $5.79 \mathrm{ppm}$ ), indicating the major compound contains at least two $(E)$-alkene protons. The other two alkene protons were assigned to peaks at 5.98 and $5.93 \mathrm{ppm}$, with their largest ${ }^{3} J_{H, H^{\prime}}$ values measured to be 15.3 and $8.3 \mathrm{~Hz}$, respectively. Unfortunately, due to the poor resolution and overlapping of these peaks, their coupling constants and splitting patterns could not be accurately determined. Proton signals at 5.36 and $4.32 \mathrm{ppm}$ were tentatively attributed to the $\mathrm{C}^{\prime} 0^{\prime}$-and $\mathrm{C6}^{\prime}$ protons, respectively.

Epimerisation of the allylic alcohol could occur through acid-catalysed loss of water at the $\mathrm{C6}^{\prime}$-position, and subsequent nucleophilic attack by water through a $\mathrm{S}_{\mathrm{N}} 1$-like substitution mechanism to reform the alcohol with inverted stereochemistry (Scheme 5.7). In the proposed mechanism, protonation and subsequent loss of the allylic alcohol would form a resonance stabilised carbocation that could potentially form a protonated epoxide through nucleophilic attack by the $\mathrm{C5}^{\prime}$-hydroxyl. As this protonated epoxide retains the stereochemistry of the $\mathrm{C} 5^{\prime}$-hydroxyl, it would block the top face of the molecule, causing the $\mathrm{S}_{\mathrm{N}} 2$ substitution by water to only occur on the bottom face and lead to exclusive formation of the $\left(6^{\prime} S\right)$-product. Epimerisation at the $\mathrm{C}^{\prime}$-position was also considered, however, without the potential resonance stabilisation of the carbocation, this route would be less favoured.

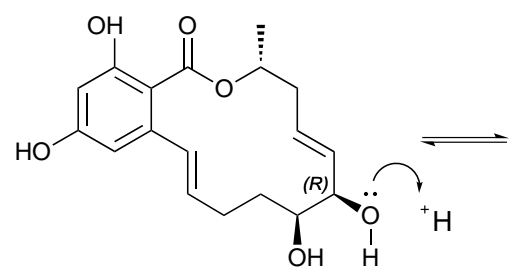<smiles>C=C/C=C\C[C@H](C)OC(=O)c1c(O)cc(O)cc1/C=C/CC[C@@H](C)O</smiles>

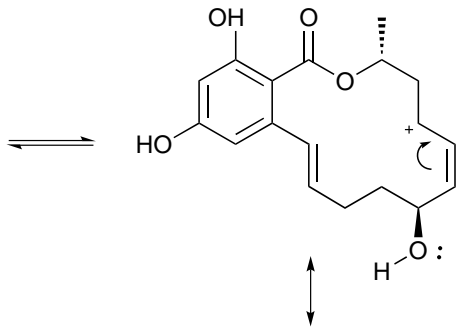<smiles>CO[C@@H](C)C/C=C/[C@@H](O)[C@@H](O)CC/C=C/c1cc(O)cc(O)c1C(=O)O</smiles><smiles>C=IC</smiles>

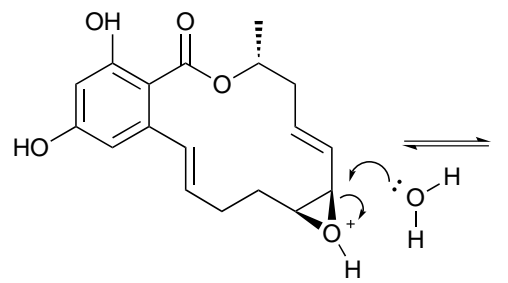<smiles>CO[C@@H](C)C/C=C/[C@H]1CCO[C@H]1CC/C=C/c1cc(O)cc(O)c1C(=O)O</smiles>

Scheme 5.9. Proposed $C 6^{\prime}$-epimerisation mechanism. 
It is unknown why the putative epimerisation/isomerisation occurred to such an extent in the $10^{\prime}$-epi-AmD system, while only slight E/Z-isomerisation occurred in the 5',6'-epi,epiAmD system. The most logical reason would be due to variation in reaction conditions. While both reactions were left for 2 days at room temperature, the $5^{\prime}, 6^{\prime}$-epi,epi-AmD reaction mixture was $7.4 \mathrm{mM}$ solution and the $10^{\prime}$-epi-AmD reaction mixture was 10.0 $\mathrm{mM}$ in 1:1 v/v methanol/1M hydrochloric acid solution. However, such an exaggerated difference would not be expected from the slight variation in reaction conditions.

In the hope of gaining a greater insight into these experimental observations, computation studies were done to calculate the lowest energy conformations of the final products. 



\section{Chapter 6}

\section{Computational Studies}

Two issues arose during the syntheses outlined in previous chapters: a varying degree of isomerisation during the final deprotection of $\mathrm{AmD}$ and its analogues, and the significantly different polarity of the $10^{\prime}$-epi-AmD synthesis product. To help rationalise these experimental observations, computational calculations were performed to predict the lowest energy conformation of the final products and their relative energies. Included in these calculations were the two expected $10^{\prime}$-epi-AmD isomers $(64$ and 102) and the proposed isomerisation products, the $6^{\prime}, 10^{\prime}$-epi,epi-AmD isomers (100 and 101) (Figure 6.1). Using the $\operatorname{Spartan}^{\odot}$ program, conformational searches were conducted to determine the equilibrium conformation of each structure at ground state using molecular mechanics force field (MMFF), with up to a limit of 70000 structures examined. Density functional theory (DFT) calculations were used to determine the self-consistent field (SCF) energies of the resultant structures. These were preformed by employing the Becke three-parameter with Lee-Yang-Parr (B3LYP) hybrid Hartree-Fock-density functional method with a $6-31 G^{*}$ basis set for the ground state structure in a vacuum.

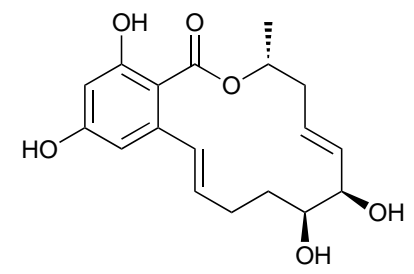

10'-epi-AmD (64)

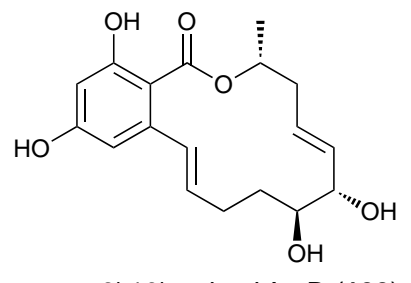

6',10'-epi,epi-AmD (100)

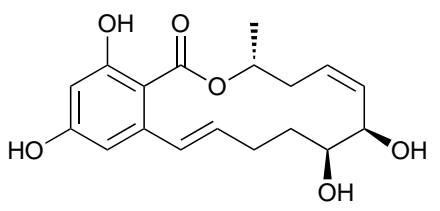

10'-epi-AmD (102)

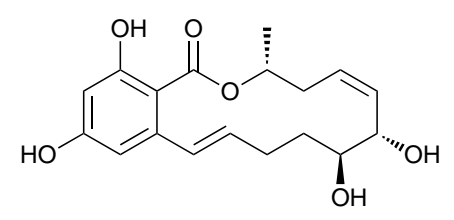

6',10'-epi,epi-AmD (101)

Figure 6.1. $10^{\prime}$-epi-AmD and $6^{\prime}, 10^{\prime}$-epi,epi-AmD isomers. 


\subsection{Calculated Energy of Lowest Energy Conformers}

Comparing the energies of the lowest energy conformations of $\mathrm{AmD}$ and its analogues led to some interesting observations. In all cases, the $\left(7^{\prime} Z\right)$-isomer was higher energy than the E-isomer, but the degree of that energy difference decreased from $\mathrm{AmD}$ to $5^{\prime}, 6^{\prime}$-epi,epiAmD to $10^{\prime}$-epi-AmD to $6^{\prime}, 10^{\prime}$-epi,epi-AmD. Interestingly, the AmD E- and Z-isomers were found to be the highest energy structures, while the $6^{\prime}, 10^{\prime}$-epi,epi-AmD isomers were found to be the lowest energy structures. As expected for enantiomers, 10'-epi-AmD and $5^{\prime}, 6^{\prime}$-epi,epi-AmD were found to have identical energies (Table 6.1).

Table 6.1. SCF energies of the lowest energy conformations of AMD and analogues

\begin{tabular}{cccc}
\hline Compound & $\begin{array}{c}\text { SCF energy } \\
\text { (Hartrees) }\end{array}$ & $\begin{array}{c}\text { SCF energy } \\
(\mathbf{k J} / \mathbf{m o l})\end{array}$ & $\begin{array}{c}\text { Energy relative } \\
\text { to AmD }(\mathbf{k J} / \mathbf{m o l})\end{array}$ \\
\hline $\mathrm{AmD}$ & -1150.4686 & -3020555.25 & 0 \\
\hline$\left(7^{\prime} \mathrm{Z}\right)-\mathrm{AmD}$ & -1150.4641 & -3020543.43 & +11.82 \\
\hline $10^{\prime}$-epi-AmD & -1150.4703 & -3020559.82 & -4.57 \\
\hline$\left(7^{\prime} \mathrm{Z}\right)-10^{\prime}$-epi-AmD & -1150.4671 & -3020551.37 & +3.88 \\
\hline $5^{\prime}, 6^{\prime}-$-epi,epi-AmD & -1150.4703 & -3020559.82 & -4.57 \\
\hline$\left(7^{\prime} Z\right)-5^{\prime}, 6^{\prime}$-epi,epi-AmD & -1150.4671 & -3020551.37 & +3.88 \\
\hline $6^{\prime}, 10^{\prime}$-epi,epi-AmD & -1150.4721 & -3020564.59 & -9.35 \\
\hline$\left(7^{\prime} Z\right)-6^{\prime}, 10^{\prime}$-epi,epi-AmD & -1150.4697 & -3020558.16 & -2.91 \\
\hline
\end{tabular}

The energy difference between the E/Z-isomers of the 5',6'-epi,epi- and 10'-epi-AmD series is slightly lower than that of the natural AmD series, $8.45 \mathrm{~kJ} / \mathrm{mol}$ compared with $11.82 \mathrm{~kJ} / \mathrm{mol}$. This indicates that should an E/Z-isomer equilibrium exist, a greater ratio of the Z-isomer would be expected in the 5',6'-epi,epi-and $10^{\prime}$-epi-AmD series relative to AmD, assuming a similar activation energy for the transformation in each system. However, it is unknown whether these energy differences are large enough to have a significant effect on experimental observations. It also does not explain the extent of isomerisation that occurred in the $10^{\prime}$-epi-AmD system compared with the $5^{\prime}, 6^{\prime}$-epi,epiAmD system. The most likely explanation for the varying degrees of isomerisation between the different $\mathrm{AmD}$ analogues remains variation in reaction conditions. Also of note is the lower energy of the $6^{\prime}, 10^{\prime}$-epi,epi-AmD analogues. This indicates that under conditions which allow for epimerisation, the $6^{\prime}-10^{\prime}$-epi,epi-AmD analogue would be the 
thermodynamically favoured product. Interestingly, the major product of the $10^{\prime}$-epiAmD deprotection is actually proposed to be the $\left(7^{\prime} Z\right)$-isomer, which may be a result of kinetic rather than thermodynamic factors.

\subsection{Structural Analysis of Lowest Energy Conformers}

The structures of the lowest energy conformers were then analysed and compared. It was hoped this would provide insight into the origin of varying chemical properties between analogues. The structure of the $\left(7^{\prime} Z\right)$-isomer of $A m D$ is omitted as it was not experimentally observed.

When viewed along the plane of the aromatic ring, the macrocycle of $\mathrm{AmD}$ has a closed, bent structure (Figure 6.2). The structure is consistent with the expected intramolecular hydrogen bonding between the C2-hydroxyl and the lactone carbonyl, which is indicated by the chemical shift and peak shape ( $\delta 11.66$, sharp singlet) of the C2-hydroxyl proton in the ${ }^{1} \mathrm{H}$ NMR spectrum. This may retain the co-planarity of the carbonyl and the aromatic ring.

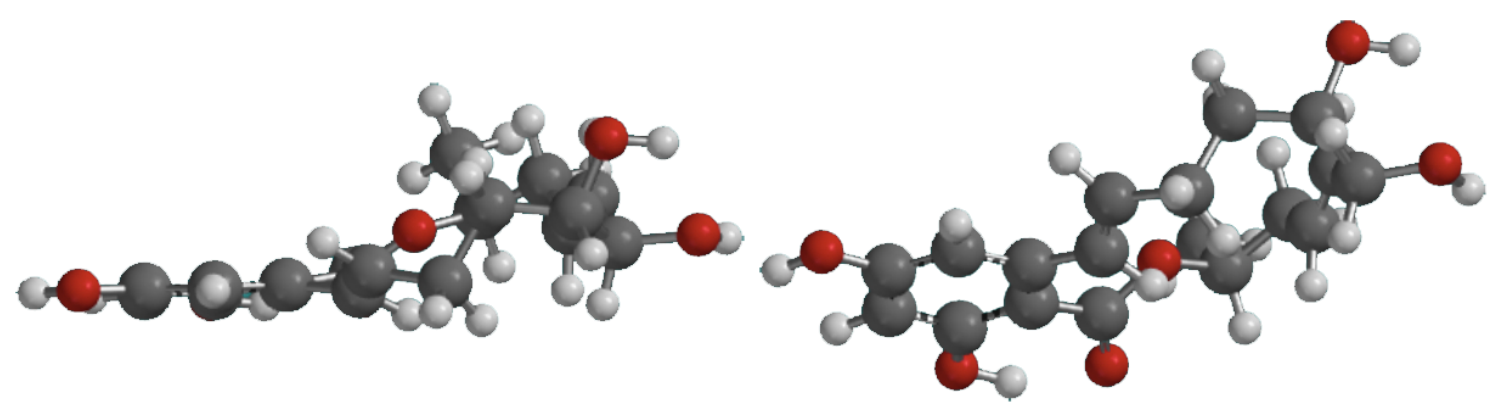

Figure 6.2. Lowest energy conformation of AmD.

The macrocycle of 5',6'-epi,epi-AmD has a closed, bent structure when viewed along the aromatic ring, highly similar to that of $\mathrm{AmD}$, with the main variation occurring about the diol moiety (Figure 6.3). This agrees with the ${ }^{1} \mathrm{H}$ NMR spectra of the two compounds in which the spectra were highly similar, excluding the peaks of the $\mathrm{C}^{\prime}$ - and $\mathrm{C}^{\prime}$-protons. As with AmD, the lactone carbonyl appeared to be in the plane of the aromatic ring with the distance between the carbonyl and C2-hydroxyl indicating potential intramolecular 

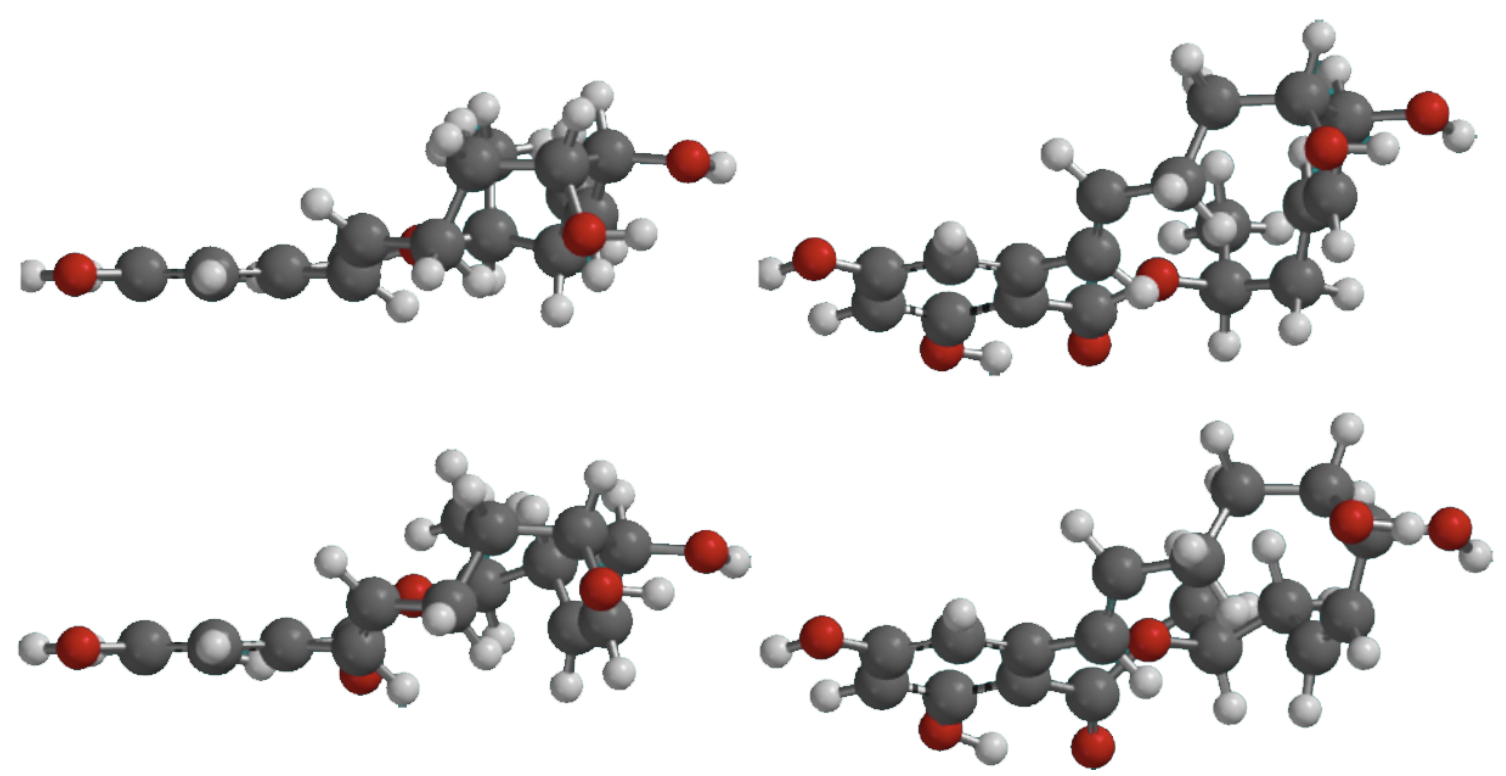

Figure 6.3. Lowest energy conformations of $5^{\prime}, 6^{\prime}$-epi,epi-AmD (top) and ( $\left.7^{\prime} Z\right)-5^{\prime}, 6^{\prime}$-epi,epi-AmD (bottom).

As expected, the structure of $10^{\prime}$-epi-AmD (64) is the mirror image of the $5^{\prime}, 6^{\prime}$-epi,epiAmD structure (69), and consequently, all the bond angles and lengths within the two compounds are identical. The macrocycle of $\mathbf{6 4}$ was calculated to be bent below the plane of the aromatic ring, in contrast with the previously analysed structures where the macrocycles were bent above the plane of the aromatic ring when viewed from the same angle. The $\left(7^{\prime} Z\right)$-isomer of $10^{\prime}$-epi-AmD (not shown for simplicity) is also identical to its 5',6'-epi,epi-AmD counterpart.

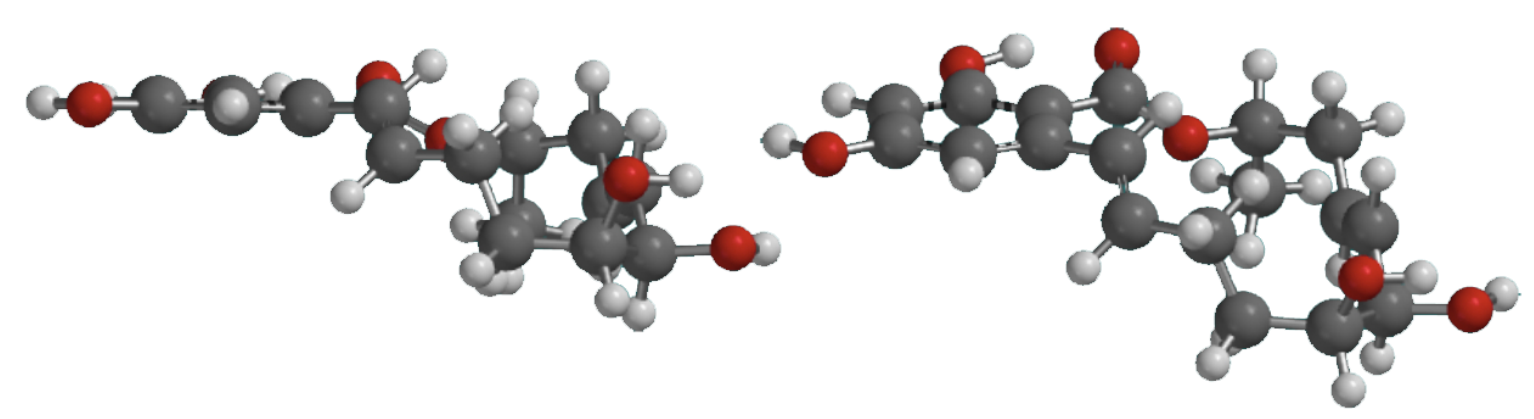

Figure 6.4. Lowest energy conformation of 10'-epi-AmD.

The calculated structure of $6^{\prime}, 10^{\prime}$-epi,epi-AmD more closely resembles that of $10^{\prime}$-epi$\mathrm{AmD}$ as the macrocycle is bent below the plane of the aromatic ring, as seen with $10^{\prime}$-epi-AmD. The structure also has a more open structure than the previously viewed 
structures. The distance between the C2-hydroxyl and the lactone carbonyl suggests hydrogen bonding between these moieties.

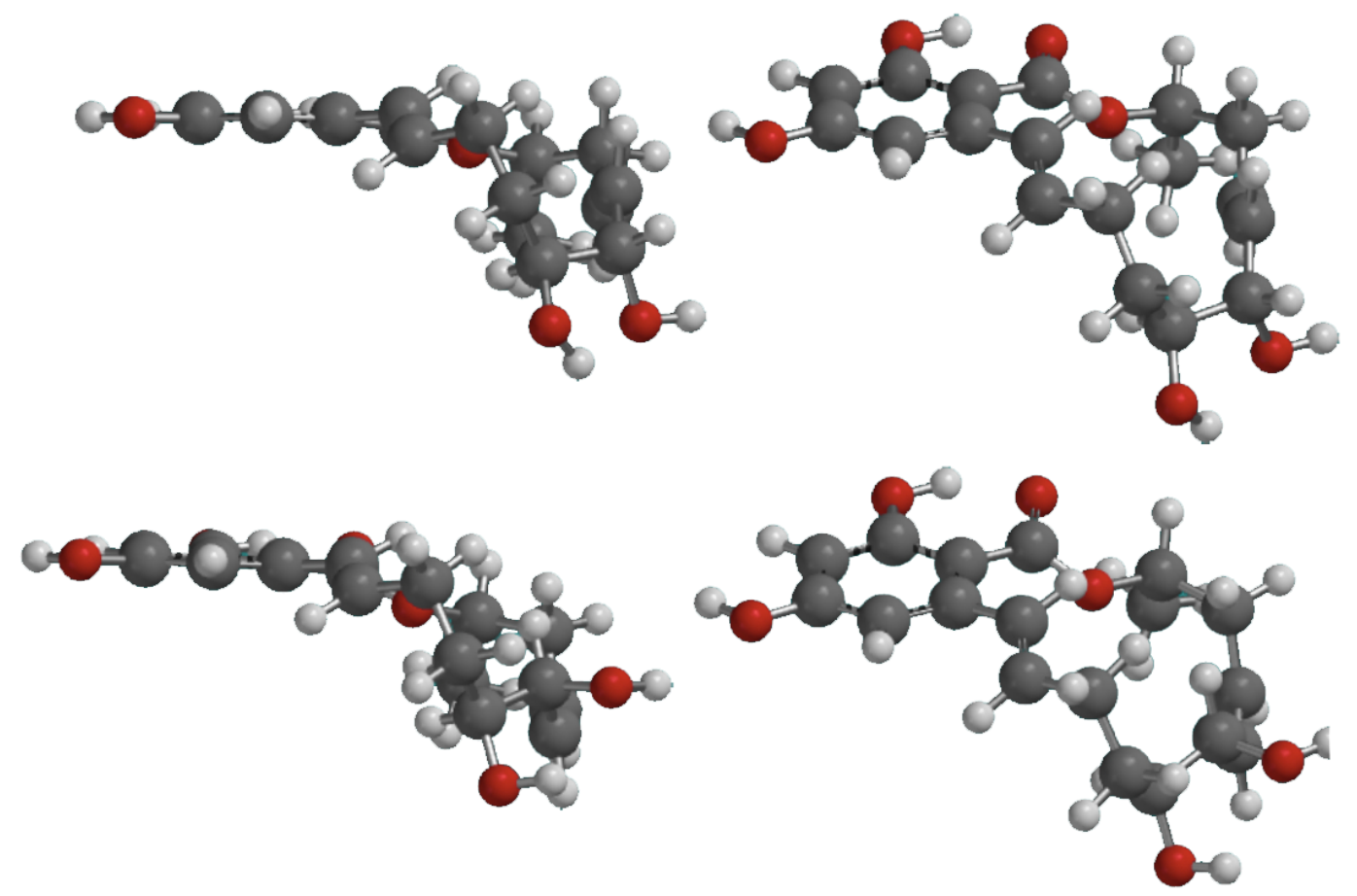

Figure 6.5. Lowest energy conformations of $6^{\prime}, 10^{\prime}$-epi,epi-AmD (top) and ( $\left.7^{\prime} Z\right)-6^{\prime}, 10^{\prime}$-epi,epi-AmD (bottom).

Comparison of the structures supports the experimental observations, where AmD and $5^{\prime}, 6^{\prime}$-epi,epi-AmD were observed to have a similar polarity, while the products from the attempted synthesis of $10^{\prime}$-epi-AmD were found to be significantly more polar. The increased polarity may be due to the rotation of the diol moiety below the plane of the aromatic ring, compared with the structures of $\mathrm{AmD}$ and $5^{\prime}, 6^{\prime}$-epi,epi-AmD, where the diol moiety is relatively aligned with the plane of the aromatic ring. This supports the proposed assignment of the unknown compounds as $6^{\prime}, 10^{\prime}$-epi,epi-AmD and its $\left(7^{\prime} Z\right)$ isomer.

Variation in chemical properties may also arise from disruption of the C2-hydroxyl hydrogen bonding system, which, as observed earlier for the $\mathrm{C} 2$ protected species, would increases the polarity of the molecule. This could occur by inversion of the $\mathrm{C} 10^{\prime}$-methyl causing the lactone carbonyl to be rotated out of the plane of the aromatic ring. There is some evidence for this hypothesis in the ${ }^{1} \mathrm{H}$ NMR, with the peak correlating to the C2-hydroxyl being shifted upfield. However, this hypothesis is not supported by the calculated conformers. Additionally, as the peak is still observed as a sharp singlet in 
the ${ }^{1} \mathrm{H}$ NMR, indicating there is still a stable hydrogen bonded system, it is unknown whether the hydrogen bonding would be sufficiently disrupted to alter the properties of $10^{\prime}$-epi-AmD as significantly as was observed experimentally. Analysis of the calculated structures suggests intramolecular hydrogen bonding may also occur between the $\mathrm{C}^{\prime}$ - and C6'-hydroxyls. The distance between the C5'-hydroxyl proton and $\mathrm{C}^{\prime}$-hydroxyl oxygen is around $2.0-2.1 \AA$, and the dihedral angle between the hydroxyls is around $45-55^{\circ}$ in all the structures, including the $6^{\prime}, 10^{\prime}$-epi,epi-AmD isomers, where the hydroxyls are rotated to align with each other. Although not predicted by the calculated structures, disruption of this hydrogen bonding is another possible source of the differing polarity between the compounds.

In summary, the energies of the conformers calculated in these computational experiments suggests isomerisation of $5^{\prime}, 6^{\prime}$-epi,epi and $10^{\prime}$-epi-AmD to their Z-isomers is more favoured relative to that of $\mathrm{AmD}$ under equilibrium conditions. However, it is unknown if these energy differences are large enough to have a significant effect on experimental observations or whether the energy barrier is surmountable. The calculated structures were found to agree with the experimental properties, in that the structural similarity between the calculated $\mathrm{AmD}$ structure and that of $5^{\prime}, 6^{\prime}$-epi,epi-AmD was consistent with the similarity in their ${ }^{1} \mathrm{H}$ NMR spectra and their chemical properties. 


\section{Chapter 7}

\section{Attempted Synthesis of Late-Stage Aigialomycin D Analogues}

The synthesis of three late-stage analogues, 6'-oxo-AmD (70), 5',6'-cyclopropyl AmD (71) and 5-chloro-AmD (65) were pursued. It was intended that these analogues could be synthesised by functionalisation of late intermediates in the natural AmD synthesis, limiting the number of new reaction sequences that would be required.

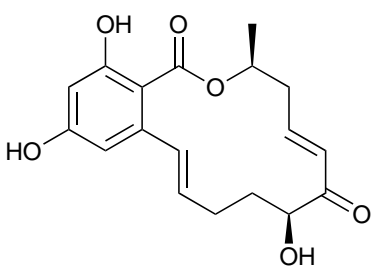

6'-Oxo-AmD 70

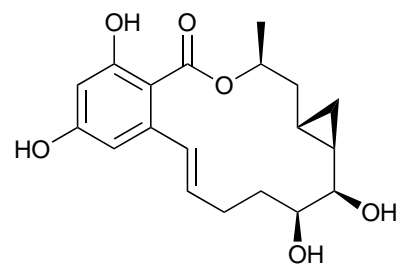

5',6'-Cyclopropyl-AmD 71

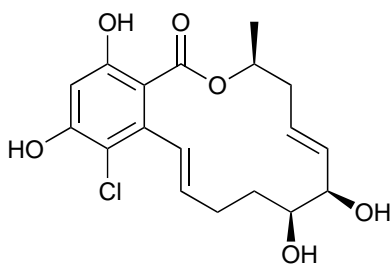

5-Chloro-AmD 65

Figure 7.1. Proposed late-stage AmD analogues

\subsection{Attempted Synthesis of $6^{\prime}$-oxo-AmD (70)}

It was proposed that the allylic alcohol of AmD could be selectively oxidised with either DDQ or manganese dioxide to afford oxo-AmD 70. DDQ was the preferred oxidising agent as manganese dioxide is known to cause C-C bond cleavage in 1,2-diol systems. ${ }^{83-86}$ Also, manganese dioxide-catalysed oxidations typically require vast excesses of the reagent (30-40 eq.), which could potentially lead to over-oxidation to the $5^{\prime}, 6^{\prime}$-di-oxo product. Reacting AmD with DDQ in dioxane at room temperature overnight was found to afford multiple compounds* which were unable to be separated and characterised. It is unknown whether any of the desired enone was present in this mixture. Selective oxidation of the allylic alcohol was then attempted by reacting $\mathrm{AmD}$ in a solution of manganese dioxide at room temperature overnight. Again, a complex mixture of products was obtained, from which none of the desired product could be isolated.

${ }^{*}$ Determined by ${ }^{1} \mathrm{H}$ NMR spectroscopy of the crude reaction mixture, which displayed various peaks characteristic of AmD with slightly different chemical shifts. 

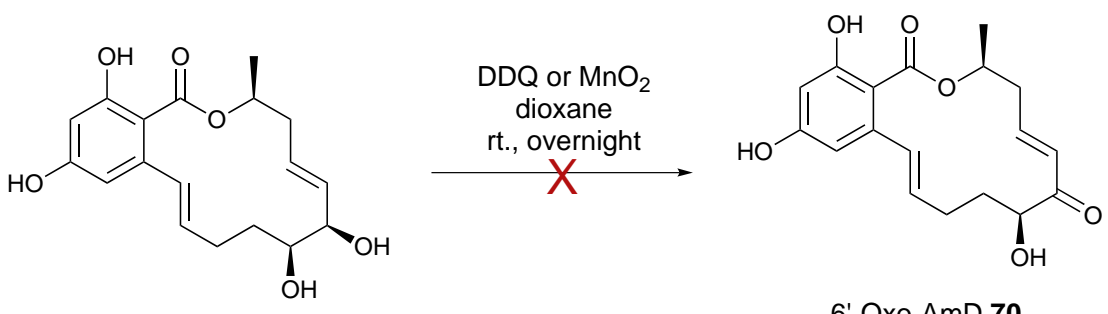

6'-Oxo-AmD 70

Scheme 7.1. Attempted synthesis of 6'-oxo-AmD 70.

\subsection{Attempted synthesis of $7^{\prime}, 8^{\prime}$-cyclopropyl AmD (71)}

It was proposed cyclopropyl AmD 71 could be synthesised by Simmons-Smith cyclopropanation of pre-Ramberg-Bäckland alkene 59. However, all attempted Simmon-Smith reactions were unsuccessful, with only starting material isolated. First, the prototype Simmons-Smith method was tried. ${ }^{87}$ This uses a zinc/copper couple and diiodomethane to form the reactive species (iodomethylzinc iodide, the Simmons-Smith reagent) in situ, which then reacts with the alkene to form a cyclopropane. Formation of the SimmonsSmith reagent was attempted by sonication of a solution of the zinc/copper couple and diiodomethane in diethyl ether for one hour, to which a solution of alkene $\mathbf{5 9}$ in diethyl ether was added. Only starting material was isolated from this reaction. It was hypothesised that the lack of reaction could be due to the quality of the zinc/copper couple. Therefore, the Furakawa modification of the Simmons-Smith reaction, which employs an alternative zinc reagent (diethyl zinc) to form the Simmons-Smith reagent, ${ }^{100}$ was investigated. Two separate reactions were tried in which a solution of alkene $\mathbf{5 9}$ was treated with diiodomethane and either a $1 \mathrm{M}$ solution of diethyl zinc, or neat diethyl zinc, with both reactions affording only starting material. It was then hypothesised that the allylic alcohol of AmD (4) itself may be more reactive towards the Simmons-Smith reagent than the allylic ether of protected compound 59. Thus, the reaction was attempted by adding a solution of AmD (4) in DMF to a solution of diethyl zinc and diiodomethane in dichloromethane, again with no success. Addition of diiodomethane to a solution of diethyl zinc and AmD in DMF again led to no observable reaction. 

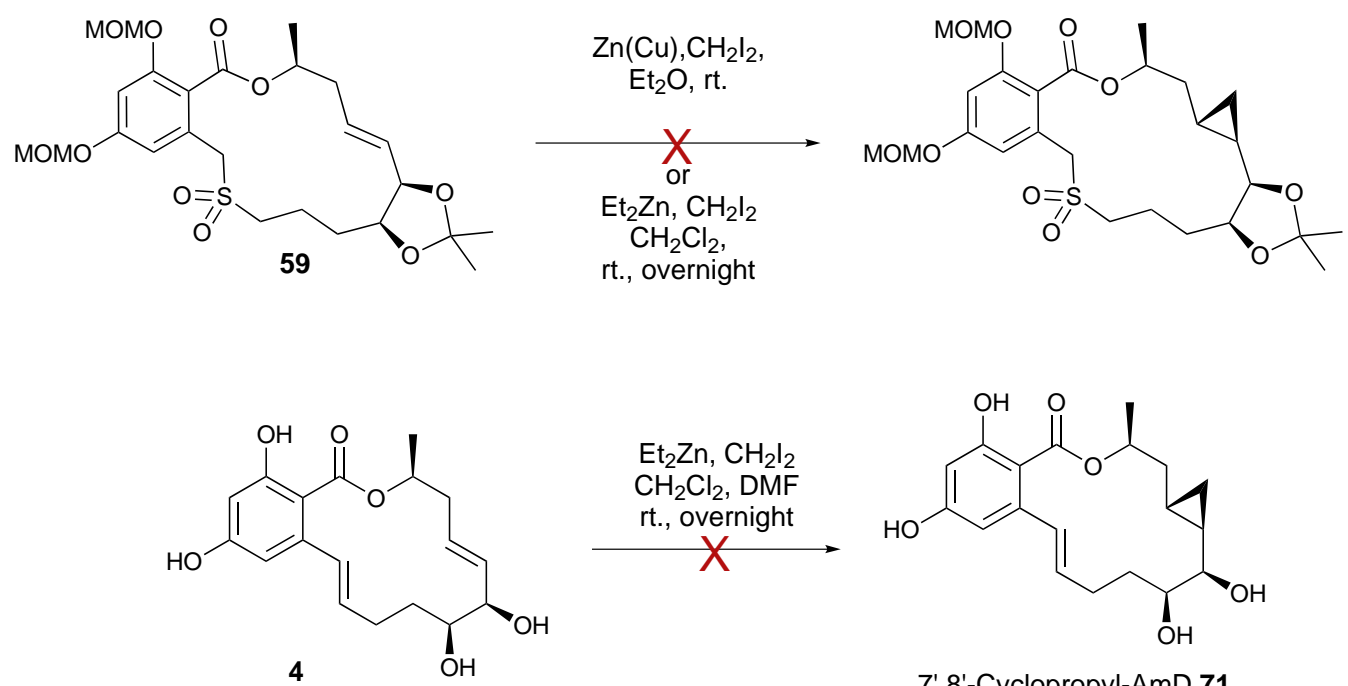

7',8'-Cyclopropyl-AmD 71

Scheme 7.2. Attempted Simmons-Smith cyclopropanations of alkenes 59 (top) and 4 (bottom).

\subsection{Attempted Synthesis of 5-chloro-AmD (65)}

Chlorination of the C5-position of AmD was also attempted. Previous syntheses of C5-Cl containing RALs suggested electrophilic aromatic substitution would favour the C5-position of the aromatic ring. ${ }^{72,101-103}$ The chlorination was attempted by addition of $N$-chlorosuccinimide (NCS) and iron (III) chloride to a solution of AmD in dioxane. ${ }^{103}$ Unfortunately, no reaction was observed.
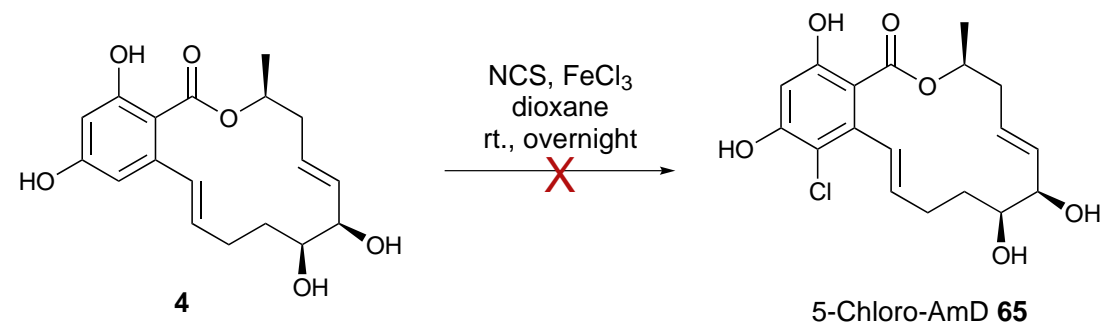

Scheme 7.3. Attempted synthesis of 5-chloro-AmD 65. 



\section{Chapter 8}

\section{Conclusions and Future Work}

\subsection{Concluding Remarks}

Driven by the emerging biological value of RALs, the synthesis of five AmD analogues was undertaken. These analogues included two diastereomers of AmD, 5', $6^{\prime}$-epi,epi-AmD (69) and 10'-epi-AmD (64), as well as analogues possessing modified functional groups, 6'-oxo-AmD (70), 7',8'-cyclopropyl AmD (71) and 5-chloro-AmD (65). To aid in the synthesis of these, and future analogues, research began with optimisation of various elements of the AmD synthesis previously developed. ${ }^{63}$

Optimisation of the methyl orsellinate synthesis had limited success, with its highest yield being $66 \%$, compared with $40 \%$ yield observed previously, however, the reaction was found to be inconsistent, with repeat attempts yielding between $20-60 \%$. The synthesis of the thioacetate $\mathbf{4 3}$ was also optimised to a seven-step procedure affording a $38 \%$ yield, an improvement on the $28 \%$ yield, eight step procedure used previously. Various other minor optimisations were also developed.

5',6'-epi,epi-AmD (69) was successfully synthesised from D-ribose in 15 steps (longest linear sequence) in an overall yield of 3\%. The synthesis was achieved by preparing the enantiomer of a key intermediate in the natural $\mathrm{AmD}$ syntheis, $\alpha, \beta$-unsaturated ester 72 (prepared in three steps from D-ribose with an overall yield of 66\%). This enantiomeric intermediate could then be employed in the natural AmD synthetic route to afford the desired analogue. A significant by-product of this synthesis was presumed to be the $\left(7^{\prime} Z\right)$ isomer 93, that is proposed to be formed via acid-catalysed isomerisation during the final deprotection step.

The synthesis of $10^{\prime}$-epi-AmD (64) was attempted through a divergent synthesis, in which $(R)$-4-penten-2-ol, the enantiomer of the natural AmD synthesis chiral starting material, 
was empoyed to provided the desired $\left(10^{\prime} S\right)$ stereochemistry. While the synthesis was successful, the product was found to isomerise during the final acidic deprotection step, leading to the isolation of two unknown isomers of $\mathrm{AmD}$, and none of the desired $10^{\prime}-$ epi-AmD. As all attempts to separate the compounds were unsuccessful, characterisation was not possible. However, based on ${ }^{1} \mathrm{H}$ NMR spectroscopy the mixture of compounds was tentatively assigned as $6^{\prime}, 10^{\prime}$-epi,epi-AmD $(\mathbf{1 0 0})$ and its $\left(7^{\prime} Z\right)$-isomer $(\mathbf{1 0 1})$.

All attempts at synthesising the three structural analogues were unsuccessful. It was proposed 6'-oxo-AmD (70) could be synthesised by selective oxidation of the $\mathrm{C6}^{\prime}$ hydroxyl of AmD with either DDQ or manganese dioxide. However, the use of either reagent afforded a complex mixture of products that could not be separated and characterised. Selective cyclopropanation of the $7^{\prime}$-alkene was attempted on both preand post-Ramberg-Bäcklund substrates with various Simmons-Smith cyclopropanation conditions. Unfortunately, only starting material was isolated from all of these reactions. Attempted chlorination of the C5-position of AmD with NCS and iron (III) chloride was also unsuccessful, returning only starting material.

Thus, one major goal (the synthesis of $5^{\prime}, 6^{\prime}$-epi,epi-AmD) and various minor goals of this research project have been achieved, affording analogues of $\mathrm{AmD}$ which will undergo biological testing to provide valuable SAR information of the AmD structure. Synthetic methodology has also been developed, which could potentially aid in the future syntheses of new and exciting AmD analogues.

\subsection{Future work}

There is huge potential for the synthesis of additional AmD analogues. After biological testing of the analogues synthesised in this research project to determine the effect of inversion of the three AmD stereo-centres, the synthesis of more elaborate second generation analogues may be undertaken. This could include the enantiomer of AmD, $5^{\prime}, 6^{\prime}, 10^{\prime}$-epi,epi,epi-AmD, which could potentially be prepared by combining the synthetic methodology developed in the synthesis of $5^{\prime}, 6^{\prime}$-epi,epi and $10^{\prime}$-epi-AmD. The 
analogue studies could then move on to modification of functional groups around the structure, towards improving the drug-like properties of the compound.

Based on research by Shen et al. in the field of RAL analogue synthesis, ${ }^{48-50}$ a useful series of analogues could involve modifications at the C4-position of AmD. The modifications published in these papers would provide a good starting point for this series of analogues, in which their synthetic methodology could be adapted to the VUW synthetic strategy (Scheme 8.1). This would involve the synthesis of a range of methyl orsellinate analogues which could then be used in the VUW AmD synthesis.

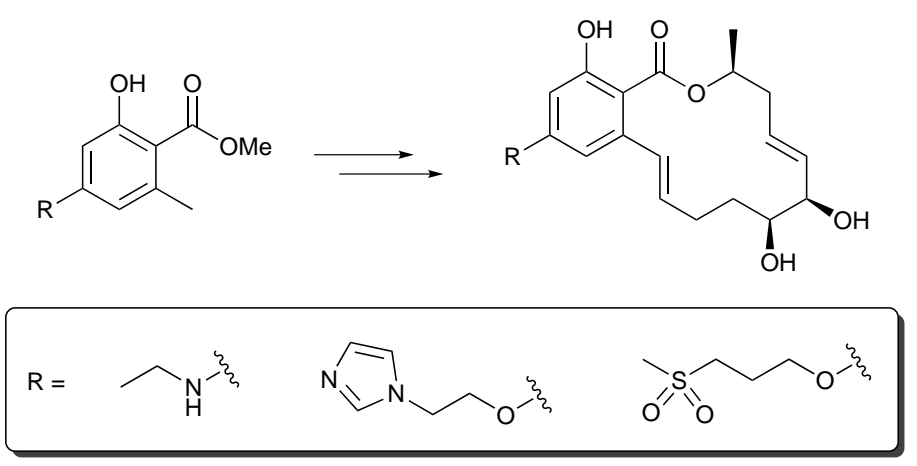

Scheme 8.1. Examples of possible C2-analogues of AmD.

Further work could also be performed on the synthesis of the $6^{\prime}$-oxo-AmD (70) and 5-chloro-AmD (65) analogues. The selective allylic oxidation of the C6'-hydroxyl of AmD could potentially be achieved through optimisation of the reaction with DDQ or manganese dioxide, or by employing an alternate oxidising agent such as barium manganate. Alternative chlorination methods which have been used in the synthesis of other RALs could potentially be used to selectively chlorinate the C5-position of AmD. These include the use of chlorinating reagents sulfuryl chloride, ${ }^{104-106}$ or hypochlorous acid. $^{101}$

An important aspect in the future synthesis of AmD analogues is the optimisation of the final deprotection step. As observed in this research, the current reaction conditions can lead to significant isomerisation and subsequent loss of material. Therefore, development of milder deprotection conditions will be a priority in future syntheses of $\mathrm{AmD}$ analogues. 



\section{Chapter 9}

\section{Experimental}

\subsection{General Experimental Details}

All reactions were performed by stirring under argon in oven-dried glassware using dry solvents and standard syringe techniques. Tetrahydrofuran (THF) and dichloromethane $\left(\mathrm{CH}_{2} \mathrm{Cl}_{2}\right)$ were freshly distilled from the sodium benzophenone ketyl radical and calcium hydride, respectively, prior to use. Triethylamine $\left(\mathrm{NEt}_{3}\right)$ and acetonitrile $(\mathrm{MeCN})$ were distilled from calcium hydride; toluene and methanol $(\mathrm{MeOH})$ were distilled from sodium, and stored in a dry bottle under argon. Anhydrous diethyl ether $\left(\mathrm{Et}_{2} \mathrm{O}\right)$ was purchased and stored over sodium. Anhydrous dimethylformamide (DMF) was purchased from Aldrich Chemical Company and used without further purification. All reagents used were available from laboratory stocks and purified as necessary, or purchased from standard chemical suppliers. Analytical thin layer chromatography (TLC) was carried out using aluminium backed TLC plates pre-coated with silica $\mathrm{UV}_{254}$ and visualised by UV radiation $(254 \mathrm{~nm})$ and anisaldehyde dip. Flash column chromatography was carried out using silica gel 60 (220-240 mesh) with solvent systems as indicated. Microwave-assisted reactions were carried out in a Milestone Microsynth reactor, monitored by a fibre optic temperature and pressure probe.

${ }^{1} \mathrm{H}$ and ${ }^{13} \mathrm{C}$ NMR spectra were recorded on either a Varian Unity Inova $300(300 \mathrm{MHz}$ for ${ }^{1} \mathrm{H}$ and $75 \mathrm{MHz}$ for $\left.{ }^{13} \mathrm{C}\right)$, or a Varian Unity Inova $500\left(500 \mathrm{MHz}\right.$ for ${ }^{1} \mathrm{H}$ and 125 $\mathrm{MHz}$ for ${ }^{13} \mathrm{C}$ ) spectrometer. All chemical shifts $(\delta)$ were referenced to residual solvent peaks $\left(\mathrm{CDCl}_{3}:{ }^{1} \mathrm{H}-7.26 \mathrm{ppm},{ }^{13} \mathrm{C}-77.0 \mathrm{ppm} ; \mathrm{d}_{6}\right.$-acetone: ${ }^{1} \mathrm{H}-2.05 \mathrm{ppm},{ }^{13} \mathrm{C}-29.8$ ppm; $\left.\mathrm{d}_{4}-\mathrm{MeOH}:{ }^{1} \mathrm{H}-3.31 \mathrm{ppm},{ }^{13} \mathrm{C}-49.00 \mathrm{ppm}\right)$. Optical rotation was measured on a Perkin-Elmer Polarimeter at the sodium D line $(589 \mathrm{~nm})$. High resolution mass spectra (HRMS) were recorded on a Waters Q-TOF Premier ${ }^{T M}$ Tandem Mass Spectrometer using electrospray ionization in the positive mode. 


\subsection{Experimental Details for the Synthesis of Reagents}

Copper (I) chloride: Granulated copper ( $2.0 \mathrm{~g})$ was added to a solution of $\mathrm{CuCl}_{2}(3.2$ $\mathrm{g})$ in conc. $\mathrm{HCl}(12.0 \mathrm{~mL})$ and refluxed until a clear solution was formed (ca. $1 \mathrm{~h})$. The solution was then filtered through a pad of Celite ${ }^{\circledR}$ into a Buchner funnel charged with an ice water slurry (ca. $100 \mathrm{~mL}$ ) and conc. $\mathrm{H}_{2} \mathrm{SO}_{4}(0.5 \mathrm{~mL})$ forming a white precipitate. The white precipitate was immediately collected on a Buchner funnel and washed with water (ca. $20 \mathrm{~mL}$ ), $\mathrm{MeOH}$ (ca. $20 \mathrm{~mL}$ ), $\mathrm{Et}_{2} \mathrm{O}$ (ca. $20 \mathrm{~mL}$ ) and dried in vacuo to afford $\mathrm{CuCl}$ as a white powder which stored under argon.

Potassium tert-butoxide: Freshly cut potassium metal (0.50 g, washed in hexanes) was added to a solution of freshly distilled $t$ - $\mathrm{BuOH}(10 \mathrm{~mL})$ stirring under argon at rt. After 24 $\mathrm{h}$ the solvent was removed in vacuo affording $t$-BuOK $(1.30 \mathrm{~g})$ as a white powder, which was stored under argon.

\subsection{Experimental Details for Chapter 2}

\section{Methyl orsellinate (46)}

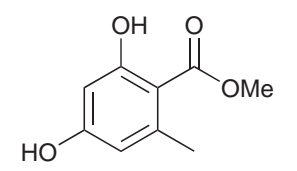

Methyl acetoacetate $(2.00 \mathrm{~mL}, 18.53 \mathrm{mmol})$ was added to a stirred solution of $\mathrm{NaH}(1.12 \mathrm{~g}, 27.79 \mathrm{mmol}, 60 \%$ in mineral oil) in THF $(40 \mathrm{~mL})$ at $0{ }^{\circ} \mathrm{C}$ and allowed to warm to $\mathrm{rt}$. over $20 \mathrm{~min}$. The solution was then cooled to $-78^{\circ} \mathrm{C}, n$-BuLi $(8.80 \mathrm{~mL}, 17.61 \mathrm{mmol}, 2.0 \mathrm{M}$ in cyclohexane) added and the solution allowed to warm to rt. After $17 \mathrm{~h}$ the solution was refluxed for $12 \mathrm{~h}$, cooled to $0{ }^{\circ} \mathrm{C}$, slowly quenched with $\mathrm{MeOH}(20 \mathrm{~mL})$ and then acidified to $\mathrm{pH} 5$ with glacial AcOH (ca. $5 \mathrm{~mL}$ ) and warmed to rt. After $18 \mathrm{~h}$ the reaction mixture was concentrated in vacuo, extracted with EtOAc (4 x $40 \mathrm{~mL}$ ), the combined organic layers dried over $\mathrm{MgSO}_{4}$, filtered and the solvent removed in vacuo to yield a red solid, which was purified by flash column chromatography (silica, 2:1 hexanes/EtOAc) to yield the title compound as a white solid $(1.01 \mathrm{~g}, 60 \%) . \mathbf{R}_{\boldsymbol{F}}=0.45\left(2: 1\right.$ hexanes/EtOAc). ${ }^{1} \mathbf{H} \mathbf{N M R}\left(500 \mathrm{MHz}, \mathrm{CDCl}_{3}\right) 11.75(\mathrm{~s}$, 
1H), $6.25(\mathrm{~d}, J=2.5 \mathrm{~Hz}, 1 \mathrm{H}), 6.21(\mathrm{~d}, J=2.5 \mathrm{~Hz}, 1 \mathrm{H}), 5.50(\mathrm{~s}, 1 \mathrm{H}), 3.89(\mathrm{~s}, 3 \mathrm{H}), 2.46$ (s, $3 \mathrm{H})$. The spectral data matched those reported in the literature. ${ }^{65}$

\section{Methyl 2,4-bis(acetyloxy)-6-methylbenzoate (103)}

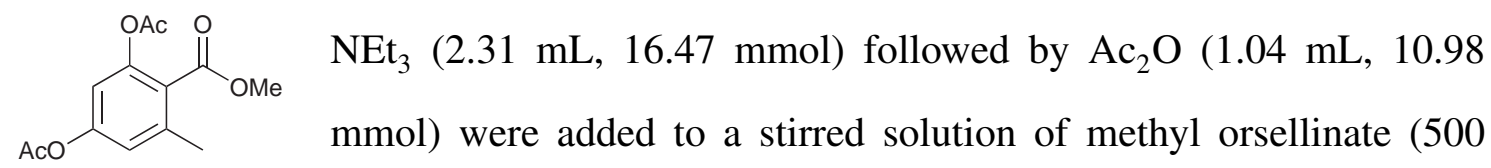
$\mathrm{mg}, 2.74 \mathrm{mmol})$ in $\mathrm{CH}_{2} \mathrm{Cl}_{2}(8 \mathrm{~mL})$ and left for $16 \mathrm{~h}$. The reaction mixture was then quenched with sat. $\mathrm{NaHCO}_{3}(15 \mathrm{~mL})$, and the organic layer separated, dried over $\mathrm{MgSO}_{4}$, filtered and evaporated to give a clear solution, which was purified by flash column chromatography (silica, 3:1 hexanes/EtOAc) to yield the title compound as a white solid (708 mg, 97\%). $\mathbf{R}_{\boldsymbol{F}}=0.30$ (2:1 hexanes/EtOAc). ${ }^{1} \mathbf{H} \mathbf{N M R}\left(500 \mathrm{MHz}, \mathrm{CDCl}_{3}\right) \delta 6.88(\mathrm{~d}$, $J=2.2 \mathrm{~Hz}, 1 \mathrm{H}), 6.78(\mathrm{~d}, J=2.2 \mathrm{~Hz}, 1 \mathrm{H}), 3.85(\mathrm{~s}, 3 \mathrm{H}), 2.37$ (s, 3H), $2.25(\mathrm{~s}, 3 \mathrm{H}), 2.23(\mathrm{~s}$, $3 \mathrm{H})$. The spectral data matched those reported in the literature. ${ }^{63}$

\section{Methyl 2,4-bis(acetyloxy)-6-(bromomethyl)benzoate (44)}

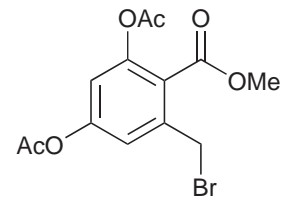

NBS (370 mg, $2.65 \mathrm{mmol})$ and benzoyl peroxide (75 mg, $0.2 \mathrm{mmol})$ were added to a refluxing solution of orsellinate $103(565 \mathrm{mg}, 2.12$ mmol) in $\mathrm{CCl}_{4}(20 \mathrm{~mL})$ in five portions over $8 \mathrm{~h}$, and left stirring at reflux. After $1 \mathrm{~h}$ the solution was cooled to $0^{\circ} \mathrm{C}$, filtered and the concentrated in vacuo to give a yellow oil, which was purified by flash column chromatography ( silica, $\mathrm{CH}_{2} \mathrm{Cl}_{2}$ ) to yield the title compound as a white solid (597 mg, $81 \%)$. $\mathbf{R}_{\boldsymbol{F}}=0.48\left(\mathrm{CH}_{2} \mathrm{Cl}_{2}\right) .{ }^{1} \mathbf{H} \mathbf{~ N M R}$ $\left(500 \mathrm{MHz}, \mathrm{CDCl}_{3}\right) \delta 7.10(\mathrm{~d}, J=2.2,1 \mathrm{H}), 6.93(\mathrm{~d}, \mathrm{~J}=2.2,1 \mathrm{H}), 4.60(\mathrm{~s}, 2 \mathrm{H}), 3.90(\mathrm{~s}, 3 \mathrm{H})$, $2.27(\mathrm{~s}, 3 \mathrm{H}), 2.24(\mathrm{~s}, 3 \mathrm{H})$. The spectral data matched those reported in the literature. ${ }^{63}$ 


\subsection{Experimental Details for Chapter 3}

\section{Methyl-2,3-O-(1-methylethylidene)- $\beta$-D-ribofuranoside (78)}

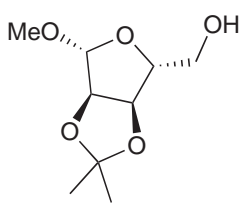

$\mathrm{AcCl}(95 \mu \mathrm{L}, 1.33 \mathrm{mmol})$ was added dropwise to a solution of D-ribose (2.00 g, $13.33 \mathrm{mmol})$ in $\mathrm{MeOH}(8.0 \mathrm{~mL})$ and $\mathrm{Me}_{2} \mathrm{CO}(8.0 \mathrm{~mL})$. The solution was then refluxed for $12 \mathrm{~h}$. The reaction was then quenched with sat. $\mathrm{NaHCO}_{3}(5 \mathrm{~mL})$ and the organic solvents concentrated in vacuo. The aqueous solution was then extracted with EtOAc $(2 \times 20 \mathrm{~mL})$ and the combined organic washings dried over $\mathrm{MgSO}_{4}$, filtered and concentrated in vacuo to yield the title compound as a colourless oil (2.18 g, 80\%), which was deemed sufficiently pure by ${ }^{1} \mathrm{H}$ NMR and subsequently used without further purification. $\mathbf{R}_{\boldsymbol{F}}=0.45$ (2:1 hexanes/EtOAc). ${ }^{1} \mathbf{H}$ NMR $\left.\left(500 \mathrm{MHz}, \mathrm{CDCl}_{3}\right)\right) \delta 4.97(\mathrm{~s}, 1 \mathrm{H}), 4.84(\mathrm{~d}, J=5.9 \mathrm{~Hz}, 1 \mathrm{H}), 4.59(\mathrm{~d}, J=5.9 \mathrm{~Hz}, 1 \mathrm{H})$, $4.44(\mathrm{t}, J=2.6 \mathrm{~Hz}, 1 \mathrm{H}), 3.70(\mathrm{dt}, J=12.6,2.4 \mathrm{~Hz}, 1 \mathrm{H}), 3.62(\mathrm{ddd}, J=12.6,10.7,3.4 \mathrm{~Hz}$, 1H), $3.44(\mathrm{~s}, 3 \mathrm{H}), 3.23(\mathrm{dd}, J=10.7,2.6 \mathrm{~Hz}, 1 \mathrm{H}), 1.49(\mathrm{~s}, 3 \mathrm{H}), 1.32(\mathrm{~s}, 3 \mathrm{H})$. The spectral data matched those reported in the literature. ${ }^{66}$

\section{Methyl 5-deoxy-5-iodo-2,3- $O$-(1-methylethylidene)- $\beta$-D-ribofuranoside (48)}

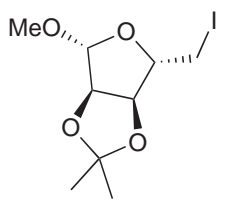

$\mathrm{PPh}_{3}(2.46 \mathrm{~g}, 9.40 \mathrm{mmol})$ and imidazole $(0.80 \mathrm{~g}, 11.75 \mathrm{mmol})$ were added to a solution of sugar $78(1.60 \mathrm{~g}, 7.831)$ in toluene $(30 \mathrm{~mL})$ and $\mathrm{MeCN}(6$ $\mathrm{mL})$. To this solution, iodine $(2.39 \mathrm{~g}, 9.40 \mathrm{mmol}))$ was added in portions and the solution refluxed for $10 \mathrm{~min}$ then the solution allowed to cool to rt. The solution was then diluted with $\mathrm{Et}_{2} \mathrm{O}(40 \mathrm{~mL})$, washed with sat. $\mathrm{Na}_{2} \mathrm{~S}_{2} \mathrm{O}_{3}(3 \times 30 \mathrm{~mL})$, water $(2 \mathrm{x}$ $40 \mathrm{~mL}$ ), brine (40 mL), dried with $\mathrm{MgSO}_{4}$ and concentrated in vacuo to give a white solid and oil. The mixture was suspended in 7:1 hexanes/EtOAc and filtered through a silica plug and eluted with additional solvent. The filtrate was then concentrated in vacuo to yield the product as a clear oil $(2.04 \mathrm{~g}, 83 \%) . \mathbf{R}_{F}=0.68$ (2:1 hexanes/EtOAc). ${ }^{1} \mathbf{H}$ NMR $\left(500 \mathrm{MHz}, \mathrm{CDCl}_{3}\right) \delta 5.04(\mathrm{~s}, 1 \mathrm{H}), 4.76(\mathrm{~d}, J=5.8 \mathrm{~Hz}, 1 \mathrm{H}), 4.62(\mathrm{~d}, J=5.9 \mathrm{~Hz}, 1 \mathrm{H})$, $4.43(\mathrm{dd}, J=10.1,6.0 \mathrm{~Hz}, 1 \mathrm{H}), 3.36(\mathrm{~s}, 3 \mathrm{H}), 3.28(\mathrm{dd}, J=9.9,6.0 \mathrm{~Hz}, 1 \mathrm{H}), 3.15(\mathrm{t}, J=$ 
$10.0 \mathrm{~Hz}, 1 \mathrm{H}), 1.47(\mathrm{~s}, 3 \mathrm{H}), 1.32(\mathrm{~s}, 3 \mathrm{H})$. The spectral data matched those reported in the literature. $^{66}$

\section{Methyl (2Z,4S,5R)-4,5-O-(1-methylethylidene) hepta-2,6-dienoate [(Z)-50] and Methyl $(2 E, 4 S, 5 R)-4,5-O-(1-m e t h y l e t h y l i d e n e)$ hepta-2,6-dienoate $[(E)-50]$}

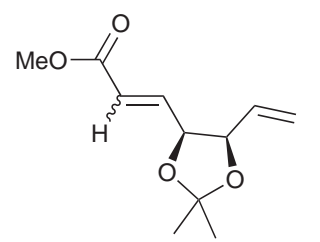

Activated zinc $(1.80 \mathrm{~g}, 27.63 \mathrm{mmol})$ was added to a solution of iodosugar 48 (1.24 g, $3.95 \mathrm{mmol})$ in $\mathrm{MeOH}(20 \mathrm{~mL})$, followed by $\mathrm{AcOH}$ $(67 \mu \mathrm{L})$ and the solution refluxed. After $3 \mathrm{~h}$ refluxing TLC confirm the consumption of starting material. The solution was then allowed to cool to rt, filtered through a wad of silica and eluted with additional $\mathrm{MeOH}$. The solution was then cooled to $0{ }^{\circ} \mathrm{C}$ and methyl (triphenylphosphoranylidene) acetate $(1.58 \mathrm{mg}, 4.73 \mathrm{mmol})$ added and the solution allowed to warm to rt. After $19 \mathrm{~h}$ TLC confirmed the consumption of starting material and the solution was concentrated in vacuo, partitioned between EtOAc $(60 \mathrm{~mL})$ and $\mathrm{NH}_{4} \mathrm{Cl}(60 \mathrm{~mL})$. The aqueous layer was extracted with EtOAc $(2 \times 40 \mathrm{~mL})$ and the combined organic washings concentrated in vacuo. The crude mixture was suspended in 7:1 hexanes/EtOAc, filtered though a silica plug, eluted with additional solvent and the filtrate concentrated in vacuo to yield a mixture of the title compounds as a clear liquid [620 mg, 74\% $(Z / E=5.1: 1)] . \quad \mathbf{R}_{F}=0.60[(Z-50], 0.50[(E-50](2: 1$ hexanes/EtOAc $)$.

The compound was deemed sufficiently pure by ${ }^{1} \mathrm{H}$ NMR and subsequently used without further purification. ${ }^{1} \mathbf{H}$ NMR $\left(500 \mathrm{MHz}, \mathrm{CDCl}_{3}\right) \delta 6.79(\mathrm{dd}, J=15.65 .5 \mathrm{~Hz}, 1 \mathrm{H}), 6.20$ $(\mathrm{dd}, J=11.6,7.5 \mathrm{~Hz}, 1 \mathrm{H}), 6.08(\mathrm{dd}, J=15.6,1.6 \mathrm{~Hz}, 1 \mathrm{H}), 5.90(\mathrm{dd}, J=11.6,1.6 \mathrm{~Hz}$, 1H), $5.68(\mathrm{ddd}, J=7.4,7.2,1.6 \mathrm{~Hz}, 1 \mathrm{H}), 5.66(\mathrm{ddd}, J=17.1,10.5,7.2 \mathrm{~Hz}, 1 \mathrm{H}), 5.37$ (dd, $J=17.1,1.5 \mathrm{~Hz}, 1 \mathrm{H}, 5.28(\mathrm{ddd}, J=17.1,1.7,1.3 \mathrm{~Hz}, 1 \mathrm{H}), 5.15(\mathrm{ddd}, J=10.3,7.2,1.1$ $\mathrm{Hz}, 1 \mathrm{H}), 4.87(\mathrm{tt}, J=7.1,0.9 \mathrm{~Hz}, 1 \mathrm{H}), 4.78(\mathrm{ddd}, J=7.0,5.6,1.6 \mathrm{~Hz}, 1 \mathrm{H}), 4.71(\mathrm{tt}, J=$ 7.0, $0.9 \mathrm{~Hz}, 1 \mathrm{H}), 3.75(\mathrm{~s}, 3 \mathrm{H}), 3.72(\mathrm{~s}, 3 \mathrm{H}), 1.55(\mathrm{~s}, 3 \mathrm{H}), 1.42(\mathrm{~s}, 3 \mathrm{H})$. The spectral data matched those reported in the literature. ${ }^{63}$ 


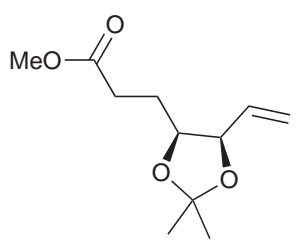

$\mathrm{NaBH}_{4}(1.51 \mathrm{~g}, 39.80 \mathrm{mmol})$ was added to a solution of $\alpha, \beta-$ unsaturated esters 50 (1.77 g, $8.29 \mathrm{mmol})$, cyclohexene $(3.36 \mathrm{~mL}$, $33.17 \mathrm{mmol})$ and $\mathrm{CuCl}(657 \mathrm{mg}, 6.33 \mathrm{mmol})$ in $\mathrm{MeOH}(130 \mathrm{~mL})$ stirring at $-78^{\circ} \mathrm{C}$. After $2 \mathrm{~h}$ the solution was concentrated in vacuo and partitioned between sat. $\mathrm{NH}_{4} \mathrm{Cl}(100 \mathrm{~mL})$ and $\mathrm{Et}_{2} \mathrm{O}(100 \mathrm{~mL})$. The aqueous layer was separated and further extracted with $\mathrm{Et}_{2} \mathrm{O}(3 \times 30 \mathrm{~mL})$. The combined organic layers were then dried over $\mathrm{MgSO}_{4}$, filtered and concentrated in vacuo to yield the title compound as a clear liquid. (1.70 g, 95\%). $\quad \mathbf{R}_{\boldsymbol{F}}=0.45$ (2:1 hexanes/EtOAc). The compound was deemed sufficiently pure by ${ }^{1} \mathrm{H}$ NMR and subsequently used without further purification. ${ }^{1} \mathbf{H}$ NMR $\left(500 \mathrm{MHz}, \mathrm{CDCl}_{3}\right) \delta 5.82(\mathrm{ddd}, J=17.2,10.3,7.6 \mathrm{~Hz}, 1 \mathrm{H}), 5.34$ (ddd, $J=17.1$, 1.7, $1.1 \mathrm{~Hz}, 1 \mathrm{H}), 5.26(\mathrm{ddd}, J=10.3,1.6,0.9 \mathrm{~Hz}, 1 \mathrm{H}), 4.54(\mathrm{dd}, J=7.5,6.4 \mathrm{~Hz}, 1 \mathrm{H})$, 4.16 (ddd, $J=8.8,6.2,5.4 \mathrm{~Hz}, 1 \mathrm{H}), 3.67$ (s, 3H), 2.49 (ddd, $J=16.3,8.3,6.4 \mathrm{~Hz}, 1 \mathrm{H})$, $2.40(\mathrm{ddd}, J=16.4,8.5,7.4 \mathrm{~Hz}, 1 \mathrm{H}), 1.80-1.70(\mathrm{~m}, 2 \mathrm{H}), 1.47(\mathrm{~s}, 3 \mathrm{H}), 1.36(\mathrm{~s}, 3 \mathrm{H})$. The spectral data matched those reported in the literature. ${ }^{63}$

\section{(4S,5R)-4,5-O-(1-Methylethylidene) hept-6-en-1-ol (104)}

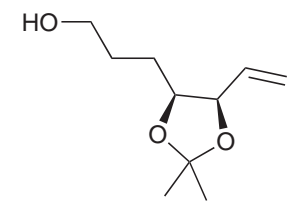

A solution of ester $51(1.70 \mathrm{~g}, 7.93 \mathrm{mmol})$ in $\mathrm{Et}_{2} \mathrm{O}(40 \mathrm{~mL})$ was added dropwise over $10 \mathrm{~min}$ to a solution of $\mathrm{LiAlH}_{4}(1.51 \mathrm{~g}, 39.67 \mathrm{mmol})$ in $\mathrm{Et}_{2} \mathrm{O}(80 \mathrm{~mL})$ stirring at $-10^{\circ} \mathrm{C}$. After $15 \mathrm{~min}$, TLC implied the consumption of starting material. The reaction was then quenched with wet $\mathrm{NaSO}_{4}$, filtered through a pad of Celite ${ }^{\circledR}$ and concentrated in vacuo to yield the title compound as a colourless liquid $(1.37 \mathrm{~g}, 93 \%) . \mathbf{R}_{F}=0.15$ (2:1 hexanes/EtOAc). The compound was deemed sufficiently pure by ${ }^{1} \mathrm{H}$ NMR and subsequently used without further purification. ${ }^{1}$ H NMR $\left(500 \mathrm{MHz}, \mathrm{CDCl}_{3}\right) \delta 5.82(\mathrm{ddd}, J=17.1,10.3,7.8 \mathrm{~Hz}, 1 \mathrm{H}), 5.30$ (ddd, $J=17.1$, 1.6, $1.1 \mathrm{~Hz}, 1 \mathrm{H}), 5.24$ (ddd, $J=10.3,1.6,0.9 \mathrm{~Hz}, 1 \mathrm{H}), 4.52(\mathrm{dd}, J=7.4,6.7 \mathrm{~Hz}, 1 \mathrm{H})$, $4.18(\mathrm{ddd}, J=8.5,6.2,5.0 \mathrm{~Hz}, 1 \mathrm{H}), 3.68(\mathrm{t}, J=5.8 \mathrm{~Hz}, 2 \mathrm{H}), 1.91(\mathrm{~s}, 1 \mathrm{H}), 1.80-1.60$ (m, $2 \mathrm{H}), 1.55(\mathrm{~m}, 2 \mathrm{H}), 1.50(\mathrm{~s}, 3 \mathrm{H}), 1.38(\mathrm{~s}, 3 \mathrm{H})$. The spectral data matched those reported in the literature. ${ }^{63}$ 


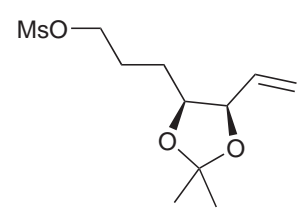

$\mathrm{MsCl}(0.86 \mathrm{~mL}, 11.04 \mathrm{mmol})$ was added to a solution of alcohol $\mathbf{1 0 4}$ $(1.37 \mathrm{~g}, 7.36 \mathrm{mmol}), \mathrm{NEt}_{3}(2.07 \mathrm{~mL}, 14.72 \mathrm{mmol})$ and DMAP (90 $\mathrm{mg}, 0.74 \mathrm{mmol})$ in $\mathrm{CH}_{2} \mathrm{Cl}_{2}$ stirring at $0{ }^{\circ} \mathrm{C}$ and the solution allowed to warm to rt. After $20 \mathrm{~h}$, the solution was concentrated in vacuo, the residue dissolved in EtOAc $(100 \mathrm{~mL})$, washed with water $(50 \mathrm{~mL})$ and brine $(50 \mathrm{~mL})$. The combined aqueous layers were then extracted with EtOAc $(2 \times 50 \mathrm{~mL})$. The combined organic layers where then washed with brine $(20 \mathrm{~mL})$, dried over $\mathrm{MgSO}_{4}$, filtered and concentrated in vacuo to give a yellow liquid, which was purified by flash column chromatography (silica, 1:1 hexanes/EtOAc) to yield the title compound as a colourless oil $(1.92 \mathrm{~g}, 99 \%) . \mathbf{R}_{F}=0.20$ (2:1 hexanes/EtOAc). ${ }^{1} \mathbf{H}$ NMR $\left(500 \mathrm{MHz}, \mathrm{CDCl}_{3}\right) \delta 5.84(\mathrm{ddd}, J=17.1,10.3,7.7 \mathrm{~Hz}$, 1H), 5.33 (ddd, $J=17.1,1.6,1.1 \mathrm{~Hz}, 1 \mathrm{H}), 5.30$ (ddd, $J=10.3,1.6,0.9 \mathrm{~Hz}, 1 \mathrm{H}), 4.57$ $(\mathrm{dd}, J=7.5,6.4 \mathrm{~Hz}, 1 \mathrm{H}), 4.30(\mathrm{dt}, J=9.9,6.3 \mathrm{~Hz}, 1 \mathrm{H}), 4.25(\mathrm{ddd}, J=9.8,7.0,6.0 \mathrm{~Hz}$, 1H), 4.19 (ddd, $J=9.0,6.2,4.7 \mathrm{~Hz}, 1 \mathrm{H}), 3.05$ (s, 3H), 1.99 (tdd, $J=12.3,9.2,6.2 \mathrm{~Hz}$, 1H), 1.91-1.82 (m, 1H), 1.60-1.52 (m, 2H), $1.50(\mathrm{~s}, 3 \mathrm{H}), 1.39$ (s, 3H). The spectral data matched those reported in the literature. ${ }^{63}$

(4S,5R)-4,5-O-O-(1-Methylethylidene) hept-6-en-1-thioacetate (43)

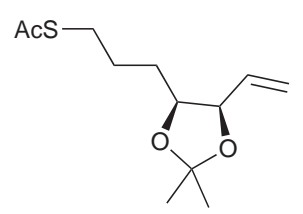

KSAc (1.06 g, $9.21 \mathrm{mmol})$ was added to a stirred solution of mesylate $105(2.03 \mathrm{~g}, 7.67 \mathrm{mmol})$ in $\mathrm{DMF}(65 \mathrm{~mL})$ at $0{ }^{\circ} \mathrm{C}$ and the solution allowed to warm to rt. TLC suggested the consumption of starting material after $20 \mathrm{~h}$. The reaction was then partitioned between EtOAc $(150 \mathrm{~mL})$ and water $(150 \mathrm{~mL})$. The organic layer was separated, washed with sat. $\mathrm{NaHCO}_{3}(3 \times 50$ $\mathrm{ml})$, followed by brine $(50 \mathrm{~mL})$, dried over $\mathrm{MgSO}_{4}$, filtered and concentrated in vacuo to give a brown liquid, which was purified by flash column chromatography (silica, 7:1 hexanes/EtOAc) to yield the title compound as a faint brown liquid $(1.70 \mathrm{~g}, 91 \%)$. $\mathbf{R}_{F}=$ 0.55 (2:1 hexanes/EtOAc). ${ }^{1} \mathbf{H}$ NMR $\left(500 \mathrm{MHz}, \mathrm{CDCl}_{3}\right) \delta 5.79(\mathrm{ddd}, J=17.1,9.7,7.8$ $\mathrm{Hz}, 1 \mathrm{H}), 5.30(\mathrm{~d}, J=17.1 \mathrm{~Hz}, 1 \mathrm{H}), 5.24(\mathrm{~d}, J=10.3 \mathrm{~Hz}, 1 \mathrm{H}), 4.49$ (t, $J=6.9 \mathrm{~Hz}, 1 \mathrm{H})$, $4.13(\mathrm{~m}, 1 \mathrm{H}), 2.95-2.83(\mathrm{~m}, 2 \mathrm{H}), 2.32(\mathrm{~s}, 3 \mathrm{H}), 1.80-1.68(\mathrm{~m}, 1 \mathrm{H}), 1.66-1.50(\mathrm{~m}, 2 \mathrm{H})$, 
1.49-1.41 (m, 1H), $1.47(\mathrm{~s}, 3 \mathrm{H}), 1.36(\mathrm{~s}, 3 \mathrm{H})$. The spectral data matched those reported in the literature. ${ }^{63}$

Methyl $\left(6^{\prime} S, 7^{\prime} R\right)-6-\left(6^{\prime}, 7^{\prime}-O-\left(1^{\prime \prime}\right.\right.$-methylethylidene $)-2^{\prime}$-thianon-8' -enyl)-2,4-dihydroxybenzoate (55)

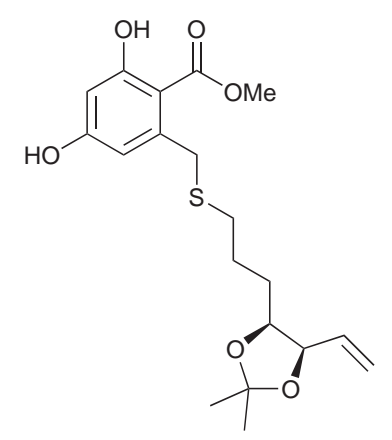

A solution of thioacetate $\mathbf{4 3}(460 \mathrm{mg}, 1.88 \mathrm{mmol})$ and resorcylic bromoester $44(650 \mathrm{mg}, 1.88 \mathrm{mmol})$ in $\mathrm{MeOH}(40 \mathrm{~mL})$ was degassed by sonicating while flushing with argon for 10 minutes. $\mathrm{K}_{2} \mathrm{CO}_{3}(651 \mathrm{mg}, 4.71 \mathrm{mmol})$ was then added to the reaction mixture. After $22 \mathrm{~h}$, the reaction was concentrated in vacuo, the crude product was dissolved in EtOAc $(50 \mathrm{~mL})$ and sat. $\mathrm{NH}_{4} \mathrm{Cl}$ $(50 \mathrm{~mL})$, the aqueous layer separated and further extracted with EtOAc $(3 \times 25 \mathrm{~mL})$. The combined organic layers were then washed with brine $(20 \mathrm{~mL})$, dried over $\mathrm{MgSO}_{4}$, filtered and concentrated in vacuo to give a brown oil, which was purified with flash column chromatography (silica, gradient elution 5:1 to 2:1 hexanes/EtOAc) to yield the title compound as a colourless oil (580 mg mg, 74\%). $\mathbf{R}_{F}=0.40$ (2:1 hexanes/EtOAc). ${ }^{1} \mathbf{H}$ NMR $\left(500 \mathrm{MHz}, \mathrm{CDCl}_{3}\right) \delta 11.68(\mathrm{~s}, 1 \mathrm{H}), 6.35(\mathrm{~d}, J=2.5 \mathrm{~Hz}, 1 \mathrm{H}), 6.28(\mathrm{~d}, J=2.5$ $\mathrm{Hz}, 1 \mathrm{H}), 5.79$ (ddd, $J=17.2,10.3,7.8 \mathrm{~Hz}, 1 \mathrm{H}), 5.31$ (ddd, $J=17.1,1.7,1.1 \mathrm{~Hz}, 1 \mathrm{H})$, $5.25(\mathrm{ddd}, J=10.3,1.5,0.9 \mathrm{~Hz}, 1 \mathrm{H}), 4.50(\mathrm{dd}, J=7.7,6.4 \mathrm{~Hz}, 1 \mathrm{H}), 4.10(\mathrm{ddd}, J=9.1$, 6.1, $4.3 \mathrm{~Hz}, 1 \mathrm{H}), 3.93$ (d, $J=13.6 \mathrm{~Hz}, 1 \mathrm{H}), 3.93$ (s, 3H), 3.87 (d, $J=13.6 \mathrm{~Hz}, 1 \mathrm{H}), 2.43$ (t, $J=7.4 \mathrm{~Hz}, 2 \mathrm{H}), 1.76-1.66(\mathrm{~m}, 1 \mathrm{H}), 1.65-1.50(\mathrm{~m}, 2 \mathrm{H}), 1.49$ (s, 3H), 1.50-1.40 (m, $1 \mathrm{H}), 1.38(\mathrm{~s}, 3 \mathrm{H})$. The spectral data matched those reported in the literature. ${ }^{63}$ 


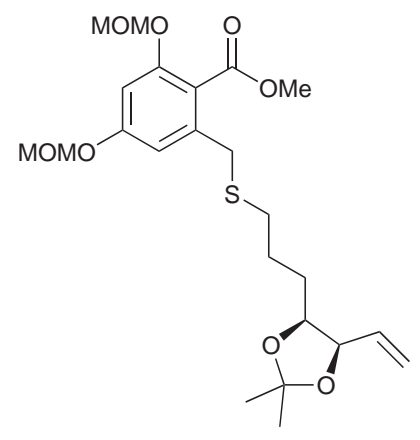

$\mathrm{NaH}$ (64 mg, $1.60 \mathrm{mmol}, 60 \%$ dispersion in mineral oil) was added to a stirred solution of diol $55(245 \mathrm{mg}, 0.64 \mathrm{mmol})$ in $\mathrm{DMF}(5 \mathrm{~mL})$ at $0{ }^{\circ} \mathrm{C}$. After $20 \mathrm{~min} \mathrm{MOMCl}(145 \mu \mathrm{l}, 1.92$ mmol) was added and the solution allowed to warm to rt. After $2 \mathrm{~h}$, the reaction was quenched with sat. $\mathrm{NH}_{4} \mathrm{Cl}(20 \mathrm{~mL})$ and extracted with $\mathrm{Et}_{2} \mathrm{O}(3 \times 20 \mathrm{~mL})$. The combined organic layers were then washed with brine $(30 \mathrm{~mL})$, dried over $\mathrm{MgSO}_{4}$, filtered and concentrated in vacuo to give a yellow oil, which was purified by flash column chromatography (silica, gradient elution, 5:1 to 2:1 hexanes/EtOAc) to yield starting material (40 mg, 16\%) as a colourless oil and the title compound as a colourless oil (244 mg, 80\%). $\mathbf{R}_{F}=0.30$ (2:1 hexanes/EtOAc). ${ }^{1} \mathbf{H}$ NMR $\left(500 \mathrm{MHz}, \mathrm{CDCl}_{3}\right) \delta 6.73(\mathrm{~d}, J=2.2 \mathrm{~Hz}, 1 \mathrm{H}), 6.67(\mathrm{~d}, J=$ $2.2 \mathrm{~Hz}, 1 \mathrm{H}), 5.78$ (ddd, $J=17.1,10.3,7.8 \mathrm{~Hz}, 1 \mathrm{H}), 5.28$ (ddd, $J=17.1,1.6,1.1 \mathrm{~Hz}, 1 \mathrm{H})$, $5.21(\mathrm{ddd}, J=10.3,1.6,0.9 \mathrm{~Hz}, 1 \mathrm{H}), 5.16(\mathrm{~s}, 2 \mathrm{H}), 5.15(\mathrm{~s}, 2 \mathrm{H}), 4.46(\mathrm{dd}, J=7.6,6.4 \mathrm{~Hz}$, 1H), 4.08 (ddd, $J=8.6,6.1,4.7 \mathrm{~Hz}, 1 \mathrm{H}), 3.88$ (s, 3H), 3.70 (s, 2H), 3.47 (s, 3H), 3.46 (s, $3 \mathrm{H}), 2.48-2.40$ (m, 2H), 1.77-1.67 (m, 1H), 1.60-1.43 (m, 3H), 1.46 (s, 3H), 1.34 (s, H). The spectral data matched those reported in the literature. ${ }^{63}$

$\left(6^{\prime} S, 7^{\prime} R\right)-6-\left(6^{\prime}, 7^{\prime}-O-\left(1^{\prime \prime}-\right.\right.$ Methylethylidene)-2' -thianon-8' -enyl)-2,4-di(methoxymethoxy)benzoic acid (45)

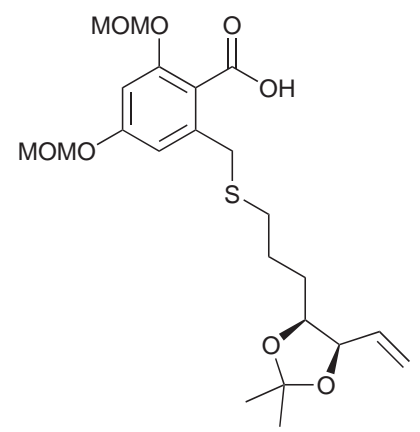

$\mathrm{KOH}$ (145 mg, $2.57 \mathrm{mmol})$ was added to a stirred solution of ester 80 (242 mg, $0.51 \mathrm{mmol})$ in $2: 1 \mathrm{MeOH} / \mathrm{H}_{2} \mathrm{O}(5 \mathrm{~mL})$ and then heated at $80^{\circ} \mathrm{C}$. After 4 days the solution was washed with $\mathrm{Et}_{2} \mathrm{O}(5 \mathrm{~mL})$, the aqueous layer acidified to $\mathrm{pH}=6$ with $10 \% \mathrm{KHSO}_{3}$ (ca. $\left.5 \mathrm{~mL}\right)$ and extracted with $\mathrm{Et}_{2} \mathrm{O}(3 \times 15 \mathrm{~mL})$. The combined organic layers were then washed with brine ( 5 $\mathrm{mL}$ ), dried over $\mathrm{MgSO}_{4}$, filtered and concentrated to give the crude product as a colourless oil (220 mg). ${ }^{1} \mathbf{H}$ NMR $\left(500 \mathrm{MHz}, \mathrm{CDCl}_{3}\right) \delta 6.79(\mathrm{~d}, J=2.2 \mathrm{~Hz}, 1 \mathrm{H}), 6.75(\mathrm{~d}, J=2.2$ 
$\mathrm{Hz}, 1 \mathrm{H}), 5.81$ (ddd, $J=17.2,10.2,7.8 \mathrm{~Hz}, 1 \mathrm{H}), 5.30$ (ddd, $J=17.1,1.6,1.0 \mathrm{~Hz}, 1 \mathrm{H})$, $5.24(\mathrm{~s}, 2 \mathrm{H}), 5.24(\mathrm{dd}, J=10.3,1.6,0.8 \mathrm{~Hz}, 1 \mathrm{H}), 5.20(\mathrm{~s}, 2 \mathrm{H}), 4.49(\mathrm{dd}, J=7.6,6.4 \mathrm{~Hz}$, 1H), $4.14(\mathrm{ddd}, J=8.4,6.1,4.6 \mathrm{~Hz}, 1 \mathrm{H}), 3.98(\mathrm{~d}, J=13.4 \mathrm{~Hz}, 1 \mathrm{H}), 3.94(\mathrm{~d}, J=13.4 \mathrm{~Hz}$, $1 \mathrm{H}), 3.52(\mathrm{~s}, 3 \mathrm{H}), 3.49(\mathrm{~s}, 3 \mathrm{H}), 2.50(\mathrm{t}, J=7.0 \mathrm{~Hz}, 2 \mathrm{H}), 1.76(\mathrm{~m}, 1 \mathrm{H}), 1.66-1.50(\mathrm{~m}, 3 \mathrm{H})$, $1.49(\mathrm{~s}, 3 \mathrm{H}), 1.36(\mathrm{~s}, 3 \mathrm{H})$. The spectral data matched those reported in the literature. ${ }^{63}$

(4S)-Pent-1-en-4-yl (6' $\left.S, 7^{\prime} R\right)-6-\left(6^{\prime}, 7^{\prime}\right.$-O-( $1^{\prime \prime}$-methylethylidene)-2' -thianon-8 -enyl)-

\section{2,4-(dimethoxymethoxy)benzoate (56)}

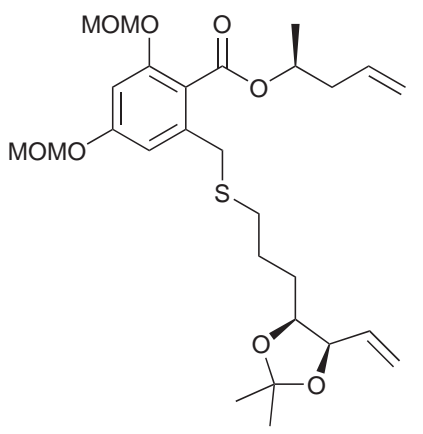

(R)-4-penten-2-ol (90 $\mu \mathrm{L}, 0.86 \mathrm{mmol})$ was added to a stirred solution of $\mathrm{PPh}_{3}(473 \mathrm{mg}, 1.81 \mathrm{mmol})$ and DIAD $(358 \mu \mathrm{L}$, $1.81 \mathrm{mmol})$ in THF $(15 \mathrm{~mL})$ at $0{ }^{\circ} \mathrm{C}$ under argon. After 30 min, a solution of acid 45 (330 mg, $0.72 \mathrm{mmol})$ in THF (10 $\mathrm{mL}$ ) was added and he solution allowed to warm to rt. After $24 \mathrm{~h}$ a small potion of silica was added to the solution and the solvent removed in vacuo. The dry silica was then loaded on a silica column and gradient eluted with 20:1 to 4:1 hexanes/EtOAc) to yield a crude product as a yellow oil, which was purified by flash column chromatography (silica, gradent elution, 9:1 to 5:1 hexanes/EtOAc) to yield the title compound as a colourless oil (269 mg, 71\%). $\mathbf{R}_{F}=0.55$ (2:1 hexanes/EtOAc). ${ }^{1} \mathbf{H}$ NMR $\left(500 \mathrm{MHz}, \mathrm{CDCl}_{3}\right) \delta 6.72(\mathrm{~d}, J=2.2 \mathrm{~Hz}, 1 \mathrm{H}), 6.69(\mathrm{~d}, J$ $=2.1 \mathrm{~Hz}, 1 \mathrm{H}), 5.85$ (dddd, $J=17.2,10.2,7.0,7.0 \mathrm{~Hz}, 1 \mathrm{H}), 5.78(\mathrm{ddd}, J=17.9,10.3,7.8$ $\mathrm{Hz}, 1 \mathrm{H}), 5.28(\mathrm{~d}, J=17.1 \mathrm{~Hz}, 1 \mathrm{H}), 5.25-5.20(\mathrm{~m}, 2 \mathrm{H}), 5.15$ (s, 2H), 5.14 (d, J = $1.7 \mathrm{~Hz}$, 2H), 5.13-5.07 (m, 2H), $4.46(\mathrm{dd}, J=7.3,6.6 \mathrm{~Hz}, 1 \mathrm{H}), 4.09$ (ddd, $J=8.5,6.0,4.8 \mathrm{~Hz}$, $1 \mathrm{H}), 3.71(\mathrm{q}, J=13.7 \mathrm{~Hz}, 2 \mathrm{H}), 3.46(\mathrm{~s}, 3 \mathrm{H}), 3.45(\mathrm{~s}, 3 \mathrm{H}), 2.46(\mathrm{qt}, J=12.9,6.6 \mathrm{~Hz}, 3 \mathrm{H})$, 2.40-2.33 (m, 1H), $1.72(\mathrm{~m}, 1 \mathrm{H}), 1.60-1.40(\mathrm{~m}, 3 \mathrm{H}), 1.46$ (s, 3H), 1.34 (s, 3H), 1.34 (d, $J=6.2 \mathrm{~Hz}, 3 \mathrm{H})$. The spectral data matched those reported in the literature. ${ }^{63}$ 


\section{2,4-(dimethoxymethoxy)benzoate $2^{\prime}, 2^{\prime}$-dioxide (57)}

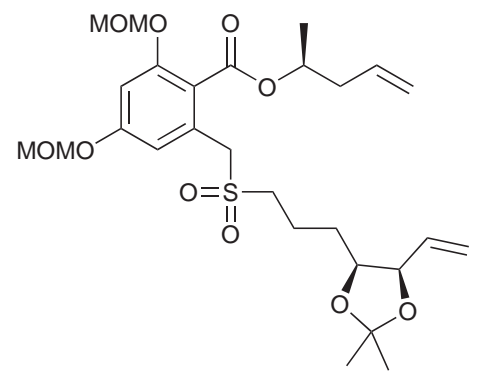

$m$-CPBA (267 mg, $1.16 \mathrm{mmol}, 77 \% \mathrm{w} / \mathrm{w})$ was added to a stirred solution of thioether $56(269 \mathrm{mg}, 0.53 \mathrm{mmol})$ in $\mathrm{CH}_{2} \mathrm{Cl}_{2}(10 \mathrm{~mL})$ at $0{ }^{\circ} \mathrm{C}$ under argon. After $2 \mathrm{~h} \mathrm{TLC}$ suggested remaining starting material, excess $m$-CPBA (38 mg, $0.17 \mathrm{mmol}, 77 \% \mathrm{w} / \mathrm{w})$ was added. After $1 \mathrm{~h}$ the reaction was quenched with $20 \% \mathrm{Na}_{2} \mathrm{SO}_{3}(20 \mathrm{~mL})$, the aqueous layer separated and further extracted with $\mathrm{CH}_{2} \mathrm{Cl}_{2}(3 \times 20 \mathrm{~mL})$. The combined organic layers were then dried over $\mathrm{MgSO}_{4}$, filtered and concentrated in vacuo to give a colourless oil, which was purified by flash column chromatography (silica, gradient elution 2:1 to 1:1 hexanes/EtOAc) to give the title compound as a colourless oil (256 mg, 90\%). $\mathbf{R}_{F}=0.20$ $\left(2: 1\right.$ hexanes/EtOAc). $[\alpha]_{D}{ }^{22}=54.3\left(c 1, \mathrm{CHCl}_{3}\right) .{ }^{1} \mathbf{H} \mathbf{~ N M R}\left(500 \mathrm{MHz}, \mathrm{CDCl}_{3}\right) \delta 6.87$ $(\mathrm{d}, J=2.2 \mathrm{~Hz}, 1 \mathrm{H}), 6.85(\mathrm{~d}, J=2,2 \mathrm{~Hz}, 1 \mathrm{H}), 5.85$ (dddd, $J=17.1,10.1,7.0,7.0 \mathrm{~Hz}, 1 \mathrm{H})$, $5.78(\mathrm{ddd}, J=17.7,10.4,7.9 \mathrm{~Hz}, 1 \mathrm{H}), 5.25-5.00(\mathrm{~m}, 6 \mathrm{H}), 5.16(\mathrm{~s}, 2 \mathrm{H}), 4.46(\mathrm{t}, J=7.0$ $\mathrm{Hz}, 1 \mathrm{H}), 4.38(\mathrm{~d}, J=14.1 \mathrm{~Hz}, 1 \mathrm{H}), 4.28$ (d, $J=14.1 \mathrm{~Hz}, 1 \mathrm{H}), 4.12-4.07$ (m, 1H), 3.46 (s, 3H), 3.45 (s, 3H). $3.02(\mathrm{ddd}, J=13.9,10.2,5.7 \mathrm{~Hz}, 1 \mathrm{H}), 2.94(\mathrm{ddd}, J=13.9,10.1,5.7$ $\mathrm{Hz}, 1 \mathrm{H}), 2.51-2.44(\mathrm{~m}, 1 \mathrm{H}), 2.42-2.35(\mathrm{~m}, 1 \mathrm{H}), 2.02-1.91(\mathrm{~m}, 1 \mathrm{H}), 1.89-1.80(\mathrm{~m}, 1 \mathrm{H})$, 1.52 (tdd, $J=11.2,7.0,3.9 \mathrm{~Hz}, 2 \mathrm{H}), 1.45$ (s, 3H), 1.34 (d, $J=6.3 \mathrm{~Hz}, 3 \mathrm{H}), 1.33$ (s, 3H). The spectral data matched those reported in the literature. ${ }^{63}$

$(5 S, 7 E, 9 R, 10 S)-1,2-\left(3^{\prime}, 5^{\prime}\right.$-Di-O-methoxymethyl)benzo-4-oxa-14-thia-3-oxo-5-methyl9,10-O-(1-methylethylidene)-pentadec-7-ene 14,14-dioxide (59)

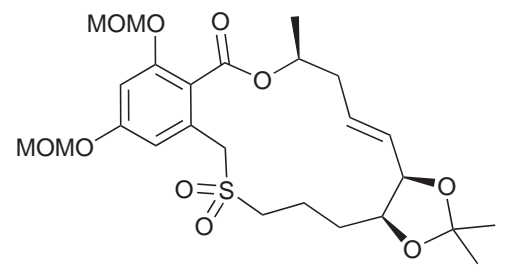

A $100 \mathrm{~mL}$ MW Teflon $^{T M}$ reaction vessel was charged with a solution of Grubbs' second generation catalyst (24 $\mathrm{mg}, 0.03 \mathrm{mmol})$ and diene $57(155 \mathrm{mg}, 0.28 \mathrm{mmol})$ in $\mathrm{CH}_{2} \mathrm{Cl}_{2}(40 \mathrm{~mL})$, flushed with argon and sealed. The reaction was then heated to $75^{\circ} \mathrm{C}$ over $2 \mathrm{~min}$ and held at this temperature for a further 28 min (see Appendix for a typical microwave heating profile). After cooling to rt. the 
reaction mixture was concentrated in vacuo to give a dark green oil, which was purified three times by flash column chromatography (silica, 1:1 hexanes/EtOAc) to yield the title compound as a colourless oil $(111 \mathrm{mg}, 75 \%) . \mathbf{R}_{F}=0.12\left(2: 1\right.$ hexanes/EtOAc). ${ }^{1} \mathbf{H}$ NMR $\left(500 \mathrm{MHz}, \mathrm{CDCl}_{3}\right) \delta 7.16(\mathrm{~d}, J=2.2 \mathrm{~Hz}, 1 \mathrm{H}), 6.85(\mathrm{~d}, J=2.2 \mathrm{~Hz}, 1 \mathrm{H}), 5.71(\mathrm{ddd}, J=$ 15.2, 9.3, 4.3 Hz, 1H), $5.55(\mathrm{ddd}, J=15.4,9.4,1.4 \mathrm{~Hz}, 1 \mathrm{H}), 5.29(\mathrm{~m}, 1 \mathrm{H}), 5.21(\mathrm{~d}, J=$ $6.8 \mathrm{~Hz}, 1 \mathrm{H}), 5.16(\mathrm{t}, J=3.4 \mathrm{~Hz}, 1 \mathrm{H}), 5.16(\mathrm{~s}, 2 \mathrm{H}), 4.47(\mathrm{~d}, J=15.3 \mathrm{~Hz}, 1 \mathrm{H}), 4.43$ (dd, $J=9.3,5.8 \mathrm{~Hz}, 1 \mathrm{H}), 4.13(\mathrm{~d}, J=15.1 \mathrm{~Hz}, 1 \mathrm{H}), 4.11(\mathrm{~m}, 1 \mathrm{H}), 3.47(\mathrm{~s}, 3 \mathrm{H}), 3.47(\mathrm{~s}, 3 \mathrm{H})$, $2.83(\mathrm{ddd}, J=14.6,11.1,5.3 \mathrm{~Hz}, 1 \mathrm{H}), 2.65(\mathrm{~m}, 1 \mathrm{H}), .47(\mathrm{~m}, 1 \mathrm{H}), 2.41(\mathrm{dd}, J=15.5,9.8$ $\mathrm{Hz}, 1 \mathrm{H}), 1.75(\mathrm{~m}, 1 \mathrm{H}), 1.67(\mathrm{~m}, 1 \mathrm{H}), 1.62-1.53(\mathrm{~m}, 2 \mathrm{H}), 1.43(\mathrm{~s}, 3 \mathrm{H}), 1.40$ (d, J = 6.2 Hz, $3 \mathrm{H}), 1.32(\mathrm{~s}, 3 \mathrm{H})$. The spectral data matched those reported in the literature. ${ }^{63}$

\section{$\left(5^{\prime} S, 6^{\prime} R, 10^{\prime} S\right)-2,4-D i-O-(m e t h o x y m e t h y l)-5^{\prime}, 6^{\prime}-O-\left(1^{\prime \prime}\right.$-methylethylidene)-}

\section{aigialomycin D (60)}

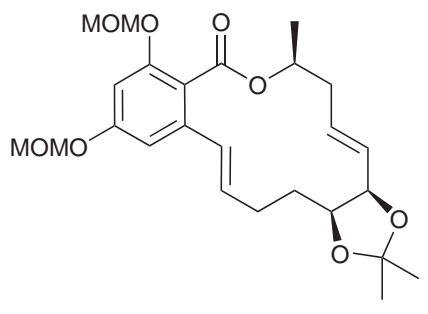

$\mathrm{KOH}(285 \mathrm{mg}, 5.07 \mathrm{mmol})$ was added to a stirred solution of sulfone 59 (134 mg, $0.25 \mathrm{mmol})$ in $t-\mathrm{BuOH}(1.0 \mathrm{~mL})$ and $\mathrm{CH}_{2} \mathrm{Cl}_{2}(0.40 \mathrm{~mL})$ under argon. $\mathrm{CCl}_{4}(98 \mu \mathrm{L})$ was then added dropwise and the solution heated to $35^{\circ} \mathrm{C}$. After $30 \mathrm{~min}$ TLC suggest the consumption of starting material. The solvent was then removed in vacuo, the crude mixture dissolved in EtOAc $(10 \mathrm{~mL})$ and sat. $\mathrm{NH}_{4} \mathrm{Cl}(10 \mathrm{~mL})$, the layers separated and the aqueous layer further extracted with EtOAc $(2 \times 10 \mathrm{~mL})$. The combined organic layers were then dried over $\mathrm{MgSO}_{4}$, filtered and concentrated in vacuo to give a yellow oil, which was purified by flash column chromatography (silica, gradient elution 5:1 to 2:1 hexanes/EtOAc) to yield the title compound as a white solid $(101 \mathrm{mg}, 86 \%) . \mathbf{R}_{F}=$ $0.40\left(2: 1\right.$ hexanes/EtOAc). ${ }^{1} \mathbf{H}$ NMR $\left(500 \mathrm{MHz}, \mathrm{CDCl}_{3}\right) \delta 6.81(\mathrm{~d}, J=2.1 \mathrm{~Hz}, 1 \mathrm{H}), 6.69$ $(\mathrm{d}, J=2.1 \mathrm{~Hz}, 1 \mathrm{H}), 6.24(\mathrm{~d}, J=15.8 \mathrm{~Hz}, 1 \mathrm{H}), 6.14(\mathrm{ddd}, J=15.3,9.6,4.2 \mathrm{~Hz}, 1 \mathrm{H}), 5.74$ (ddd, $J=15.3,9.4,3.5 \mathrm{~Hz}, 1 \mathrm{H}), 5.60(\mathrm{ddd}, J=15.4,9.7,1.7 \mathrm{~Hz}, 1 \mathrm{H}), 5.34(\mathrm{~m}, 1 \mathrm{H}), 5.20$ $(\mathrm{d}, J=6.7 \mathrm{~Hz}, 1 \mathrm{H}), 5.16(\mathrm{~s}, 2 \mathrm{H}), 5.12(\mathrm{~d}, J=6.8 \mathrm{~Hz}, 1 \mathrm{H}), 4.57(\mathrm{dd}, J=9.6,5.4 \mathrm{~Hz}, 1 \mathrm{H})$, 4.19 (ddd, $J=11.6,5.4,3.1 \mathrm{~Hz}, 1 \mathrm{H}), 3.46$ (s, 3H), 3.46 (s, 3H), 2.58-2.44 (m, 2H), 2.31 $(\mathrm{m}, 1 \mathrm{H}), 2.11(\mathrm{~m}, 1 \mathrm{H}), 1.80(\mathrm{~m}, 1 \mathrm{H}), 1.49(\mathrm{~m}, 1 \mathrm{H}), 1.47(\mathrm{~s}, 3 \mathrm{H}), 1.37(\mathrm{~d}, J=6.3 \mathrm{~Hz}, 3 \mathrm{H})$, $1.36(\mathrm{~s}, 3 \mathrm{H})$. The spectral data matched those reported in the literature. ${ }^{63}$ 


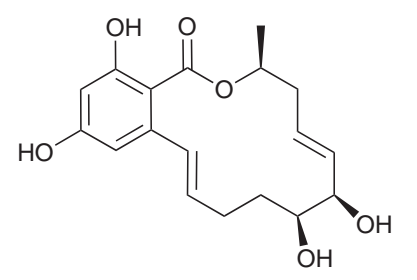

Protected AmD 60 (15 mg, $0.04 \mathrm{mmol}$ ) was stirred in a solution of in $1: 1 \mathrm{v} / \mathrm{v} \mathrm{MeOH} / 1 \mathrm{M} \mathrm{HCl}(1 \mathrm{~mL})$. After 3 days the reaction mixture was extracted with EtOAc $(3 \times 5 \mathrm{~mL})$, the combine organic layers washed with brine $(2 \mathrm{~mL})$, dried over $\mathrm{MgSO}_{4}$,

filtered and evaporated in vacuo to give a yellow oil which was purified by flash column chromatography (silica, gradient elution $1-5 \% \mathrm{MeOH} / \mathrm{CH}_{2} \mathrm{Cl}_{2}$ to yield $\mathrm{AmD}$ as a white solid $(6 \mathrm{mg}, 67 \%) . \mathbf{R}_{\boldsymbol{F}}=0.40\left(10 \% \mathrm{MeOH} / \mathrm{CH}_{2} \mathrm{Cl}_{2}\right) .{ }^{1} \mathbf{H}$ NMR $\left(500 \mathrm{MHz}, \mathrm{d}_{6}\right.$-acetone $)$ $11.66(\mathrm{~s}, 1 \mathrm{H}), 7.15(\mathrm{~d}, J=15.9 \mathrm{~Hz}, 1 \mathrm{H}), 6.53(\mathrm{~d}, \mathrm{~J}=2.0 \mathrm{~Hz}, 1 \mathrm{H}), 6.28(\mathrm{~d}, \mathrm{~J}=2.0 \mathrm{~Hz}, 1 \mathrm{H})$, $6.09(\mathrm{ddd}, \mathrm{J}=15.9,5.7,5.5 \mathrm{~Hz}, 1 \mathrm{H}), 5.88(\mathrm{ddd}, J=15.6,7.4,1.6 \mathrm{~Hz}, 1 \mathrm{H}), 5.69$ (ddd, $J$ $=15.6,5.2,1.2 \mathrm{~Hz}, 1 \mathrm{H}), 5.44(\mathrm{~m}, 1 \mathrm{H}), 4.35(\mathrm{~d}, J=4.1 \mathrm{~Hz}, 1 \mathrm{H}), 3.63(\mathrm{~m}, 1 \mathrm{H}), 2.57$ (ddd, $J=14.6,7.4,3.1 \mathrm{~Hz}, 1 \mathrm{H}), 2.43(\mathrm{~m}, 1 \mathrm{H}), 2.36-2.32(\mathrm{~m}, 2 \mathrm{H}), 2.14(\mathrm{~m}, 1 \mathrm{H}), 1.59(\mathrm{~m}, 1 \mathrm{H})$, $1.37(\mathrm{~d}, J=6.4 \mathrm{~Hz}, 3 \mathrm{H})$. The spectral data matched those reported in the literature. ${ }^{63}$

\subsection{Experimental Details for Chapter 4}

\section{2,3-O-(1-methylethylidene)- $\alpha, \beta$-D-ribofuranose (82)}

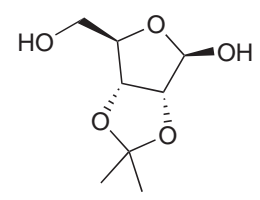

Conc. $\mathrm{H}_{2} \mathrm{SO}_{4}(36 \mu \mathrm{L}, 0.66 \mathrm{mmol})$ was added dropwise to a solution of D-ribose $(1.00 \mathrm{~g}, 6.66 \mathrm{mmol})$ in $\mathrm{Me}_{2} \mathrm{CO}(15 \mathrm{~mL})$. The reaction was deemed complete by TLC after $1 \mathrm{~h}$. The reaction was then neutralised with solid $\mathrm{NaHCO}_{3}$, filtered and evaporated to give a clear oil, which was purified with flash chromatography (silica, gradient elution 1:1 to 1:2 hexanes/EtOAc) to yield the title compound as a clear oil [1.06 g mg, 84\% ( $\alpha: \beta$ 1:5.0)]. ${ }^{1} \mathbf{H} \mathbf{N M R}\left(500 \mathrm{MHz}, \mathrm{CDCl}_{3}\right) \delta$ $5.41(\mathrm{~d}, J=5.4 \mathrm{~Hz}, 1 \mathrm{H}), 4.98(\mathrm{~d}, J=5.1 \mathrm{~Hz}, 1 \mathrm{H}), 4.83(\mathrm{~d}, J=5.9 \mathrm{~Hz}, 1 \mathrm{H}), 4.58(\mathrm{~d}, J=$ $5.9 \mathrm{~Hz}, 1 \mathrm{H}), 4.41$ (irregular t, $J=2.4 \mathrm{~Hz}, 1 \mathrm{H}), 3.7-3.8(\mathrm{~m}, 2 \mathrm{H}), 1.58$ (s, 3H) 1.49 (s, 3H), 1.40 (s, 3H), 1.32 (s, 3H). ${ }^{13} \mathbf{C}$ NMR (125 MHz, $\left.\mathrm{CDCl}_{3}\right) \delta 112.1,102.8,87.7,86.8,81.6$, 63.6, 26.35, 24.6. The spectral data matched those reported in the literature. ${ }^{73}$ 


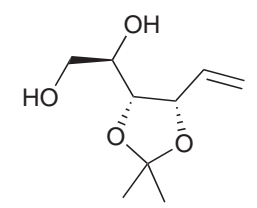

KHMDS (13.60 mL, $6.78 \mathrm{mmol}, 0.5 \mathrm{M}$ in toluene), was added to a solution of $\mathrm{CH}_{3} \mathrm{PPH}_{3} \mathrm{Br}(1857 \mathrm{mg}, 5.20 \mathrm{mmol})$ in $\mathrm{THF}(20 \mathrm{~mL})$ at $-78{ }^{\circ} \mathrm{C}$. After $1 \mathrm{~h}$ a solution of sugar $82(430 \mathrm{mg}, 2.26 \mathrm{mmol})$ and TMSCl $(0.35 \mathrm{~mL}, 2.71 \mathrm{mmol})$ in THF $(15 \mathrm{~mL})$ at $0{ }^{\circ} \mathrm{C}$ were added and the solution allowed to warm to rt. overnight. Solution cooled to $0^{\circ} \mathrm{C}$ and acidified to $\mathrm{pH} 0-1$ and left stirring. After 15 min TLC suggested complete TMS deprotection. The organic layer was then separated, the aqueous layer extracted with EtOAc $(3 \times 30 \mathrm{~mL})$. The combined organic layers were then dried over $\mathrm{MgSO}_{4}$, filtered and evaporated in vacuo to give a cream coloured solid, which was purified using flash column chromatography (silica, gradient elution 1:1 to 1:2 hexanes/EtOAc) to yield the title compound as a clear oil (370 mg, 87\%). $\mathbf{R}_{\boldsymbol{F}}=0.08\left(2: 1\right.$ hexanes/EtOAc). ${ }^{1} \mathbf{H}$ NMR $\left(500 \mathrm{MHz}, \mathrm{CDCl}_{3}\right) \delta 5.96(\mathrm{ddd}, J$ $=17 \mathrm{~Hz}, 11 \mathrm{~Hz}, 6 \mathrm{~Hz}, 1 \mathrm{H}), 5.41(\mathrm{~d}, J=17 \mathrm{~Hz}, 1 \mathrm{H}), 5.26(\mathrm{~d}, J=11 \mathrm{~Hz}, 1 \mathrm{H}), 4.65(\mathrm{t}, J$ $=6 \mathrm{~Hz}, 1 \mathrm{H}), 4.09(\mathrm{dd}, J=6.4,8.4 \mathrm{~Hz}, 1 \mathrm{H}), 3.75(\mathrm{~m}, 1 \mathrm{H}), 3.62(\mathrm{~m}, 2 \mathrm{H}), 3.20(\mathrm{brs}, 2 \mathrm{H})$, $1.42(\mathrm{~s}, 3 \mathrm{H}), 1.31(\mathrm{~s}, 3 \mathrm{H})$. The spectral data matched those reported in the literature. ${ }^{73}$

Methyl (2Z,4R,5S)-4,5-O-(1-methylethylidene) hepta-2,6-dienoate [(Z)-72] and Methyl $(2 E, 4 R, 5 S)-4,5-O-(1-m e t h y l e t h y l i d e n e)$ hepta-2,6-dienoate $[(E)-72]$

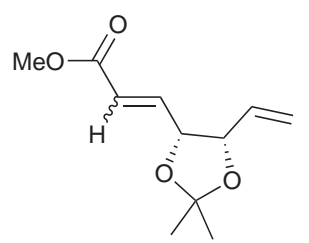
$\mathrm{NaIO}_{4}(841 \mathrm{mg}, 3.93 \mathrm{mmol})$ was added to a solution of diol $\mathbf{8 3}$ (370 $\mathrm{mg}, 1.97 \mathrm{mmol})$ in $\mathrm{MeOH}(20 \mathrm{~mL})$. After $3 \mathrm{~h}$ TLC suggested the consumption of starting material. Silica gel was then added and the solution stirred for $30 \mathrm{~min}$, then filtered through a Celite ${ }^{\circledR}$ plug and eluted with $\mathrm{MeOH}$ (20 mL). The solution was then cooled to $0{ }^{\circ} \mathrm{C}$ under argon and $\mathrm{Ph}_{3} \mathrm{P}=\mathrm{CHCO}_{2} \mathrm{CH}_{3}(789$ $\mathrm{mg}, 2.36 \mathrm{mmol}$ ) added and the solution allowed to warm to rt. After stirring overnight, the solvent was evaporated in vacuo to give a yellow solid which was partitioned between EtOAc $(20 \mathrm{~mL})$ and sat. $\mathrm{NH}_{4} \mathrm{Cl}(20 \mathrm{~mL})$, the aqueous layer extracted with EtOAc $(2 \times 10$ $\mathrm{mL}$ ), the combined organic layers dried over $\mathrm{MgSO}_{4}$, filtered and evaporated in vacuo to give a yellow solid which was purified with flash column chromatography (silica, gradient elution, 10:1 to 5:1 hexanes, EtOAc) to yield the (Z)-isomer as a colourless oil and the $(E)$ - 
isomer as colourless crystals [346 mg, 83\% $(E / Z=1: 5.1)]$. A sample was further purified by flash column chromatography (silica, gradient elution 10:1 to 5:1 hexanes/EtOAc) for characterisation purposes to yield $(E)-72$ and $(Z)-72$. $[(E)-72]:[\alpha]_{D}{ }^{21}=+30.2(c 1.00$, $\left.\mathrm{CHCl}_{3}\right) . \mathbf{R}_{\boldsymbol{F}}=0.50\left(2: 1\right.$ hexanes:EtOAc). ${ }^{1} \mathbf{H} \mathbf{N M R}\left(500 \mathrm{MHz}, \mathrm{CDCl}_{3}\right) \delta 6.79(\mathrm{dd}, J=$ 15.7, $5.6 \mathrm{~Hz}, 1 \mathrm{H}), 6.07$ (dd, $J=15.7,1.5 \mathrm{~Hz}, 1 \mathrm{H}), 5.69$ (ddd, $J=17.1,10.3,7.6 \mathrm{~Hz}, 1 \mathrm{H})$, $5.36(\mathrm{dd}, J=17.1,1.5 \mathrm{~Hz}, 1 \mathrm{H}), 5.26(\mathrm{ddd}, J=10.3,1.5,0.9 \mathrm{~Hz}, 1 \mathrm{H}), 4.78(\mathrm{ddd}, J=7.0$, 5.6, $1.6 \mathrm{~Hz}, 1 \mathrm{H}), 4.71$ (tt, $J=7.0,0.9 \mathrm{~Hz}, 1 \mathrm{H}), 3.75$ (s, 3H), 1.55 (s, 3H), 1.41 (s, 3H). $\left.[(Z)-72]:[\alpha]_{D}{ }^{21}=-167.4(c) 3.00, \mathrm{CHCl}_{3}\right) . \mathbf{R}_{\boldsymbol{F}}=0.59$ (2:1 hexanes:EtOAc). ${ }^{1} \mathbf{H} \mathbf{N M R}$ $\left(500 \mathrm{MHz}, \mathrm{CDCl}_{3}\right) \delta 6.20(\mathrm{dd}, J=11.5,7.4 \mathrm{~Hz}, 1 \mathrm{H}), 5.90(\mathrm{dd}, J=11.8,1.7 \mathrm{~Hz}, 1 \mathrm{H})$, $5.68(\mathrm{ddd}, J=7.4,7.2,1.6 \mathrm{~Hz}, 1 \mathrm{H}), 5.66(\mathrm{ddd}, J=17.1,10.4,7.3 \mathrm{~Hz}, 1 \mathrm{H}), 5.26(\mathrm{ddd}, J$ $=17.1,3.0,1.7 \mathrm{~Hz}, 1 \mathrm{H}), 5.15(\mathrm{ddd}, J=10.3,1.6,1.0 \mathrm{~Hz}, 1 \mathrm{H}), 4.86(\mathrm{ddd}, J=8.3,2.2,1.0$ $\mathrm{Hz}, 1 \mathrm{H}), 3.72(\mathrm{~s}, 3 \mathrm{H}), 1.54(\mathrm{~s}, 3 \mathrm{H}), 1.41(\mathrm{~s}, 3 \mathrm{H})$. The spectral data matched those reported in the literature. ${ }^{63}$

\section{Methyl (4R,5S)-4,5-O-(1-methylethylidene) hept-6-enoate (86)}

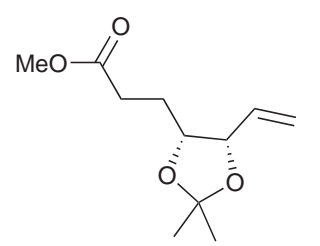

$\mathrm{NaBH}_{4}(162 \mathrm{mg}, 4.27 \mathrm{mmol})$ was added to a solution of esters 72

(189 mg, $0.89 \mathrm{mmol}), \mathrm{CuCl}(88 \mathrm{mg}, 0.89 \mathrm{mmol})$ and cyclohexene $(0.36 \mathrm{~mL}, 3.56 \mathrm{mmol})$ in $\mathrm{Et}_{2} \mathrm{O}(5 \mathrm{~mL})$ at $-78^{\circ} \mathrm{C}$. After $30 \mathrm{~min} \mathrm{TLC}$ suggested remaining starting material, additional $\mathrm{CuCl}(9 \mathrm{mg}, 0.09 \mathrm{mmol})$ and $\mathrm{NaBH}_{4}(7$ $\mathrm{mg}, 0.18 \mathrm{mmol}$ ) added. After $15 \mathrm{~min}$ TLC suggested the consumption of starting material. Solvent concentration in vacuo gave a black and white solid. The crude mixture was partitioned between EtOAc $\left(10 \mathrm{~mL} 0\right.$ and sat. $\mathrm{NH}_{4} \mathrm{Cl}(10 \mathrm{~mL})$, the aqueous layer separated and extracted with EtOAc $(2 \times 5 \mathrm{~mL})$. The combined organic layers were then dried over $\mathrm{MgSO}_{4}$, filtered and concentrated in vacuo to give a yellow oil, which was purified with flash column chromatography (silica, gradient elution, 15:1 to 9:1 hexanes/EtOAc) to yield the title compound as a clear oil $(167 \mathrm{mg}, 88 \%) . \mathbf{R}_{F}=0.52(2: 1$ hexanes:EtOAc). $[\alpha]_{D}{ }^{21}=+27.2\left(c 2.00, \mathrm{CHCl}_{3}\right) . \quad{ }^{1} \mathbf{H} \mathbf{N M R}\left(500 \mathrm{MHz}, \mathrm{CDCl}_{3}\right) \delta 5.82$ (ddd, $J=17.2$, 10.5, 7.7 Hz, 1H), 5.34 (ddd, $J=17.1,2.7,1.2 \mathrm{~Hz}, 1 \mathrm{H}), 5.26$ (ddd, $J=10.2,1.4,1.0 \mathrm{~Hz}$, $1 \mathrm{H}), 4.54(\mathrm{dd}, J=7.5,6.4 \mathrm{~Hz}, 1 \mathrm{H}), 4.15(\mathrm{ddd}, J=8.8,6.2,5.4 \mathrm{~Hz}, 1 \mathrm{H}), 3.68(\mathrm{~s}, 3 \mathrm{H}), 2.50$ (ddd, $J=16.3,8.3,6.4 \mathrm{~Hz}, 1 \mathrm{H}), 2.39$ (ddd, $J=16.4,8.5,7.4 \mathrm{~Hz}, 1 \mathrm{H}), 1.80-1.70$ (m, 2H), $1.47(\mathrm{~s}, 3 \mathrm{H}), 1.36(\mathrm{~s}, 3 \mathrm{H})$. The spectral data matched those reported in the literature. ${ }^{63}$ 


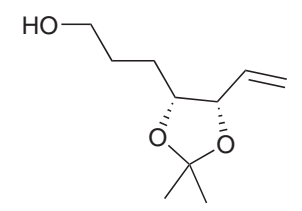

A solution of ester $86(296 \mathrm{mg}, 1.38 \mathrm{mmol})$ in $\mathrm{Et}_{2} \mathrm{O}(10 \mathrm{~mL})$ was added to a solution of $\mathrm{LiAlH}_{4}(315 \mathrm{mg}, 8.29 \mathrm{mmol})$ in $\mathrm{Et}_{2} \mathrm{O}(15$ $\mathrm{mL})$ at $-10^{\circ} \mathrm{C}$. After $30 \mathrm{~min}$ TLC suggested remaining starting material, additional $\mathrm{LiAlH}_{4}(44 \mathrm{mg}, 1.17 \mathrm{mmol})$ added. After $10 \mathrm{~min}$ TLC suggested the consumption of starting material. Reaction quenched with wet $\mathrm{NaSO}_{4}$, dried with anh. $\mathrm{NaSO}_{4}$ and concentrated in vacuo to yield the title compound as a clear oil (209 mg, 81\%). $\mathbf{R}_{\boldsymbol{F}}=0.10$ (2:1 hexanes/EtOAc). $[\alpha]_{D}{ }^{18}=+2.5$ (c 1.00, $\left.\mathrm{CHCl}_{3}\right)$. The compound was deemed sufficiently pure by ${ }^{1} \mathrm{H}$ NMR and subsequently used without further purification. ${ }^{1} \mathbf{H}$ NMR $\left(500 \mathrm{MHz}, \mathrm{CDCl}_{3}\right) \delta 5.81$ (ddd, $\left.J=17.1,10.3,7.8 \mathrm{~Hz}, 1 \mathrm{H}\right), 5.29$ (ddd, $J=17.1$, 1.6, $1.1 \mathrm{~Hz}, 1 \mathrm{H}), 5.23(\mathrm{ddd}, J=10.3,1.6,0.9 \mathrm{~Hz}, 1 \mathrm{H}), 4.51(\mathrm{dd}, J=7.4,6.7 \mathrm{~Hz}, 1 \mathrm{H})$, $4.17(\mathrm{ddd}, J=8.5,6.2,5.0 \mathrm{~Hz}, 1 \mathrm{H}), 3.67(\mathrm{t}, J=5.8 \mathrm{~Hz}, 2 \mathrm{H}), 1.91(\mathrm{~s}, 1 \mathrm{H}), 1.80-1.60(\mathrm{~m}$, $2 \mathrm{H}), 1.55(\mathrm{~m}, 2 \mathrm{H}), 1.49(\mathrm{~s}, 3 \mathrm{H}), 1.37(\mathrm{~s}, 3 \mathrm{H})$. The spectral data matched those reported in the literature. ${ }^{63}$

(4R,5S)-4,5-O-(1-Methylethylidene) hept-6-en-1-methanesulfonate: (106)

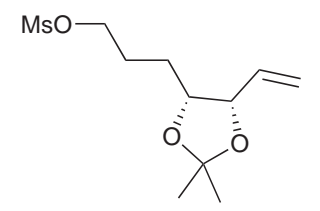

$\mathrm{MsCl}(0.11 \mathrm{~mL}, 1.48 \mathrm{mmol})$ was added to solution of alcohol $\mathbf{8 7}$ (209 mg, $1.12 \mathrm{mmol} \mathrm{mmol}), \mathrm{NEt}_{3}(0.24 \mathrm{~mL}, 0.27 \mathrm{mmol})$ and DMAP (14 mg, $0.11 \mathrm{mmol})$ in $\mathrm{CH}_{2} \mathrm{Cl}_{2}(10 \mathrm{~mL})$ at $0{ }^{\circ} \mathrm{C}$. TLC suggested the consumption of starting material after $17 \mathrm{~h}$. The solvent was then concentrated in vacuo to give a yellow solid, which was partitioned between EtOAc $(20 \mathrm{~mL})$ and water $(20$ $\mathrm{mL})$. The organic layer was then separated, washed with sat. $\mathrm{NaHCO}_{3}(10 \mathrm{~mL})$, dried over $\mathrm{MgSO}_{4}$, filtered and concentrated in vacuo to give a yellow oil, which was purified by flash column chromatography (silica, 3:1 hexanes/EtOAc) to yield the title compound as a clear oil $(270 \mathrm{mg}, 91 \%) . \mathbf{R}_{\boldsymbol{F}}=0.25$ (2:1 hexanes/EtOAc). $[\alpha]_{D}{ }^{21}=+6.1(c 1.00$, $\left.\mathrm{CHCl}_{3}\right) . \quad{ }^{1} \mathbf{H} \mathbf{N M R}\left(500 \mathrm{MHz}, \mathrm{CDCl}_{3}\right) \delta 5.84(\mathrm{ddd}, J=17.1,10.3,7.7 \mathrm{~Hz}, 1 \mathrm{H}), 5.33$ (ddd, $J=17.1,1.6,1.1 \mathrm{~Hz}, 1 \mathrm{H}), 5.30(\mathrm{ddd}, J=10.3,1.6,0.9 \mathrm{~Hz}, 1 \mathrm{H}), 4.57(\mathrm{dd}, J=7.5$, $6.4 \mathrm{~Hz}, 1 \mathrm{H}), 4.30$ (dt, $J=9.9,6.3 \mathrm{~Hz}, 1 \mathrm{H}), 4.25$ (ddd, $J=9.8,7.0,6.0 \mathrm{~Hz}, 1 \mathrm{H}), 4.19$ (ddd, $J=9.0,6.2,4.7 \mathrm{~Hz}, 1 \mathrm{H}), 3.01(\mathrm{~s}, 3 \mathrm{H}), 1.99(\mathrm{tdd}, J=12.3,9.2,6.2 \mathrm{~Hz}, 1 \mathrm{H}), 1.88-1.78$ 
$(\mathrm{m}, 1 \mathrm{H}), 1.60-1.52(\mathrm{~m}, 2 \mathrm{H}), 1.52(\mathrm{~s}, 3 \mathrm{H}), 1.40(\mathrm{~s}, 3 \mathrm{H})$. The spectral data matched those reported in the literature. ${ }^{63}$

\section{(4R,5S)-4,5-O-O-(1-Methylethylidene) hept-6-en-1-thioacetate (81)}

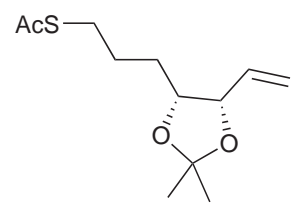

KSAc (58 mg, $0.51 \mathrm{mmol}$ ) was added to a solution of mesylate $\mathbf{1 0 6}$ (112 $\mathrm{mg}, 0.42 \mathrm{mmol})$ in DMF (4 mL) at $0{ }^{\circ} \mathrm{C}$ and allowed to warm

to rt. TLC suggested the consumption of starting material after 20

h. The reaction mixture was then partitioned between $\mathrm{Et}_{2} \mathrm{O}(10 \mathrm{~mL})$ and water $(10 \mathrm{~mL})$. The organic layer was then separated, washed with sat. $\mathrm{NaHCO}_{3}(2 \times 5 \mathrm{~mL})$, brine $(5$ $\mathrm{mL}$ ), dried over $\mathrm{MgSO}_{4}$ and concentrated in vacuo to give a faint yellow liquid, which was purified with flash column chromatography (silica, 10:1 hexanes/EtOAc) to yield the title compound as a clear liquid $(85 \mathrm{mg}, 82 \%) . \mathbf{R}_{\boldsymbol{F}}=0.60\left(2: 1\right.$ hexanes/EtOAc). $[\alpha]_{D}{ }^{21}$ $=+11.5\left(c 1.00, \mathrm{CHCl}_{3}\right) .{ }^{1} \mathbf{H} \mathbf{N M R}\left(500 \mathrm{MHz}, \mathrm{CDCl}_{3}\right) \delta 5.79(\mathrm{ddd}, J=17.1,9.7,7.8$ $\mathrm{Hz}, 1 \mathrm{H}), 5.30(\mathrm{~d}, J=17.1 \mathrm{~Hz}, 1 \mathrm{H}), 5.24(\mathrm{~d}, J=10.3 \mathrm{~Hz}, 1 \mathrm{H}), 4.49(\mathrm{t}, J=6.9 \mathrm{~Hz}, 1 \mathrm{H})$, $4.13(\mathrm{~m}, 1 \mathrm{H}), 2.95-2.83(\mathrm{~m}, 2 \mathrm{H}), 2.32(\mathrm{~s}, 3 \mathrm{H}), 1.80-1.68(\mathrm{~m}, 1 \mathrm{H}), 1.66-1.50(\mathrm{~m}, 2 \mathrm{H})$, 1.49-1.41 (m, 1H), $1.47(\mathrm{~s}, 3 \mathrm{H}), 1.35(\mathrm{~s}, 3 \mathrm{H})$. The spectral data matched those reported in the literature. ${ }^{63}$

(Methyl (6' $\left.R, 7^{\prime} S\right)-6-\left(6^{\prime}, 7^{\prime}-0-\left(1^{\prime}\right.\right.$-methylethylidene)-2'-thianon-8'-enyl)-2,4-dihydroxy benzoate (88)

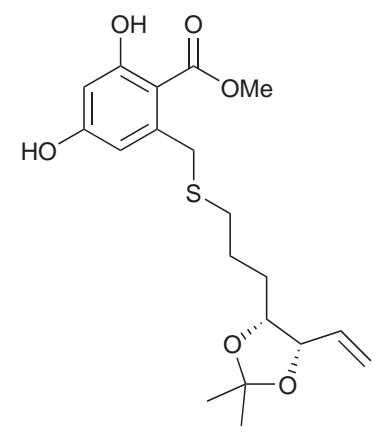

A solution of thioacetate $\mathbf{8 1}(195 \mathrm{mg}, 0.79 \mathrm{mmol})$ and resorcylic bromoester 44 (339 mg, $0.79 \mathrm{mmol})$ in $\mathrm{MeOH}(20 \mathrm{~mL})$ was degassed by sonicating while flushing with argon for 10 minutes. $\mathrm{K}_{2} \mathrm{CO}_{3}$ was then added to the reaction. After $24 \mathrm{~h}$ the solvent was removed in vacuo and the crude product dissolved in EtOAc (20 $\mathrm{mL})$ and sat. $\mathrm{NH}_{4} \mathrm{Cl}(20 \mathrm{~mL})$, the aqueous layer separated and further extracted with EtOAc $(2 \times 15 \mathrm{~mL})$. The combined organic layers were then washed with brine $(10 \mathrm{~mL})$, dried over $\mathrm{MgSO}_{4}$, filtered and concentrated in vacuo to give a brown oil, which was purified with flash column chromatography (silica, gradient elution 5:1 to 
3:1 hexanes/EtOAc) to yield the title compound as a clear oil (321 $\mathrm{mg}, 97 \%) . \mathbf{R}_{F}=0.28$ $\left(2: 1\right.$ hexanes/EtOAc). $[\alpha]_{D}{ }^{21}=+25.7\left(c 1.00, \mathrm{CHCl}_{3}\right) .{ }^{1} \mathbf{H} \mathbf{N M R}\left(500 \mathrm{MHz}, \mathrm{CDCl}_{3}\right) \delta$ $11.68(\mathrm{~s}, 1 \mathrm{H}), 6.33(\mathrm{~d}, J=2.5 \mathrm{~Hz}, 1 \mathrm{H}), 6.27(\mathrm{~d}, J=2.5 \mathrm{~Hz}, 1 \mathrm{H}), 5.78$ (ddd, $J=17.2$, $10.3,7.8 \mathrm{~Hz}, 1 \mathrm{H}), 5.30(\mathrm{ddd}, J=17.1,1.7,1.1 \mathrm{~Hz}, 1 \mathrm{H}), 5.24(\mathrm{ddd}, J=10.3,1.5,0.9 \mathrm{~Hz}$, 1H), 4.49 (dd, $J=7.7,6.4 \mathrm{~Hz}, 1 \mathrm{H}), 4.09$ (ddd, $J=9.1,6.1,4.3 \mathrm{~Hz}, 1 \mathrm{H}), 3.91$ (d, $J=13.6$ Hz, 1H), $3.92(\mathrm{~s}, 3 \mathrm{H}), 3.86(\mathrm{~d}, J=13.6 \mathrm{~Hz}, 1 \mathrm{H}), 2.42(\mathrm{t}, J=7.4 \mathrm{~Hz}, 2 \mathrm{H}), 1.75-1.65$ (m, 1H), 1.64-1.49 (m, 2H), $1.48(\mathrm{~s}, 3 \mathrm{H}), 1.49-1.39(\mathrm{~m}, 1 \mathrm{H}), 1.37(\mathrm{~s}, 3 \mathrm{H})$. The spectral data matched those reported in the literature. ${ }^{63}$

(Methyl (6' $\left.R, 7^{\prime} S\right)-6-\left(6^{\prime}, 7^{\prime}\right.$-O-(1' ${ }^{\prime \prime}$-methylethylidene)-2' -thianon-8' -enyl)-2,4-di(methoxymethoxy)benzoate (107)

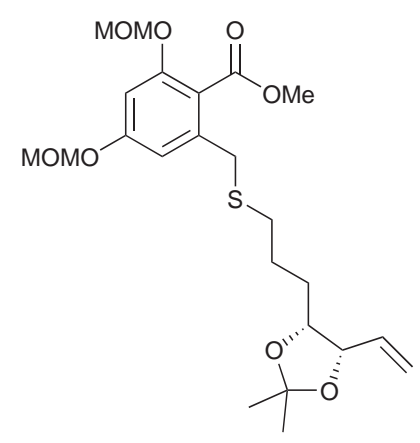

$\mathrm{NaH}$ (14 mg, $0.35 \mathrm{mmol}, 60 \%$ dispersion in mineral oil) was added to a stirred solution of diol $\mathbf{8 8}(54 \mathrm{mg}, 0.14 \mathrm{mmol})$ in DMF $(1 \mathrm{~mL})$ at $0{ }^{\circ} \mathrm{C}$. After $20 \mathrm{~min} \mathrm{MOMCl}(35 \mu \mathrm{L}, 0.42$ mmol) were added and the solution allowed to warm to rt. After $21 \mathrm{~h}$, the reaction was diluted with sat. $\mathrm{NH}_{4} \mathrm{Cl}(10$ $\mathrm{mL})$ and extracted with $\mathrm{Et}_{2} \mathrm{O}(10+2 \times 5 \mathrm{~mL})$. The combined organic layers were then washed with brine $(3 \times 5 \mathrm{~mL})$, dried over $\mathrm{MgSO}_{4}$, filtered and concentrated in vacuo to give a yellow oil, which was purified by flash column chromatography (silica, gradient elution 10:1 to 5:1 hexanes/EtOAc) to yield the title compound as a clear oil $(54 \mathrm{mg}, 81 \%) . \mathbf{R}_{\boldsymbol{F}}=0.30\left(2: 1\right.$ hexanes/EtOAc). $[\alpha]_{D}{ }^{21}=+34.5$ (c 1.00, $\left.\mathrm{CHCl}_{3}\right) .{ }^{1} \mathbf{H}$ NMR $\left(500 \mathrm{MHz}, \mathrm{CDCl}_{3}\right) \delta 6.73(\mathrm{~d}, J=2.2 \mathrm{~Hz}, 1 \mathrm{H}), 6.67(\mathrm{~d}, J=$ $2.2 \mathrm{~Hz}, 1 \mathrm{H}), 5.78(\mathrm{ddd}, J=17.1,10.3,7.8 \mathrm{~Hz}, 1 \mathrm{H}), 5.28(\mathrm{ddd}, J=17.1,1.6,1.1 \mathrm{~Hz}, 1 \mathrm{H})$, $5.21(\mathrm{ddd}, J=10.3,1.6,0.9 \mathrm{~Hz}, 1 \mathrm{H}), 5.16(\mathrm{~s}, 2 \mathrm{H}), 5.15(\mathrm{~s}, 2 \mathrm{H}), 4.46(\mathrm{dd}, J=7.6,6.4 \mathrm{~Hz}$, 1H), 4.08 (ddd, $J=8.6,6.1,4.7 \mathrm{~Hz}, 1 \mathrm{H}), 3.88$ (s, 3H), 3.70 (s, 2H), 3.47 (s, 3H), 3.46 (s, $3 \mathrm{H}), 2.48-2.40(\mathrm{~m}, 2 \mathrm{H}), 1.77-1.67$ (m, 1H), 1.60-1.43 (m, 3H), 1.46 (s, 3H), 1.34 (s, H). The spectral data matched those reported in the literature. ${ }^{63}$ 


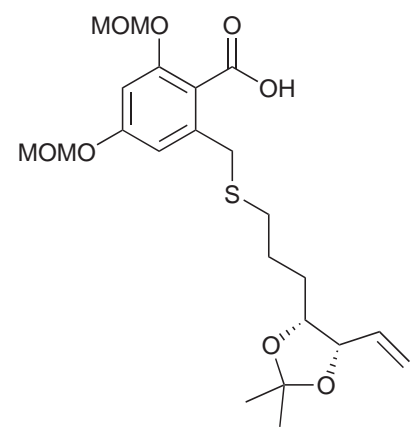

KOH (98 mg, $1.73 \mathrm{mmol}$ ) was added to a solution of ester $\mathbf{1 0 7}$ (163 mg, $0.35 \mathrm{mmol})$ in $2: 1 \mathrm{MeOH} / \mathrm{H}_{2} \mathrm{O}(4 \mathrm{~mL})$ and heating at $80^{\circ} \mathrm{C}$ with stirring. After 2 days the solution was washed with $\mathrm{Et}_{2} \mathrm{O}$, the aqueous layer acidified to $\mathrm{pH}=6$ with $10 \% \mathrm{KHSO}_{3}$ and the aqueous layer extracted with $\mathrm{Et}_{2} \mathrm{O}$. The combined organic layers were then washed with water $5 \mathrm{~mL}$, dried over $\mathrm{MgSO}_{4}$, filtered and concentrated to give the crude product as a yellow oil (160 mg). ${ }^{1} \mathbf{H}$ NMR $\left(500 \mathrm{MHz}, \mathrm{CDCl}_{3}\right) \delta 6.79(\mathrm{~d}, J=2.2 \mathrm{~Hz}, 1 \mathrm{H}), 6.75(\mathrm{~d}, J=2.2 \mathrm{~Hz}, 1 \mathrm{H}), 5.81$ (ddd, $J=17.2,10.2,7.8 \mathrm{~Hz}, 1 \mathrm{H}), 5.30(\mathrm{ddd}, J=17.1,1.6,1.0 \mathrm{~Hz}, 1 \mathrm{H}), 5.24(\mathrm{~s}, 2 \mathrm{H}), 5.24(\mathrm{dd}$, $J=10.3,1.6,0.8 \mathrm{~Hz}, 1 \mathrm{H}), 5.20(\mathrm{~s}, 2 \mathrm{H}), 4.49(\mathrm{dd}, J=7.6,6.4 \mathrm{~Hz}, 1 \mathrm{H}), 4.14(\mathrm{ddd}, J=8.4$, 6.1, $4.6 \mathrm{~Hz}, 1 \mathrm{H}), 3.98$ (d, $J=13.4 \mathrm{~Hz}, 1 \mathrm{H}), 3.94$ (d, $J=13.4 \mathrm{~Hz}, 1 \mathrm{H}), 3.52$ (s, 3H), 3.49 (s, 3H), $2.50(\mathrm{t}, J=7.0 \mathrm{~Hz}, 2 \mathrm{H}), 1.76(\mathrm{~m}, 1 \mathrm{H}), 1.66-1.50(\mathrm{~m}, 3 \mathrm{H}), 1.49$ (s, 3H), 1.36 (s, $3 \mathrm{H})$. The spectral data matched those reported in the literature. ${ }^{63}$

$\left(4 S, 6^{\prime} R, 7^{\prime} S\right)$-Pent-1-en-4-yl 6-(6', $7^{\prime}$-O-( $1^{\prime \prime}$-methylethylidene)-2' -thianon-8'-enyl)-2,4di(methoxymethoxy)benzoate (90)

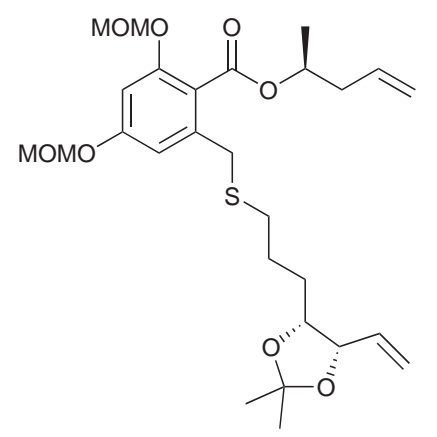

(R)-4-penten-2-ol (43 $\mu \mathrm{L}, 0.42 \mathrm{mmol})$ was added to a stirred solution of $\mathrm{PPh}_{3}(230 \mathrm{mg}, 0.88 \mathrm{mmol})$ and DIAD $(0.18 \mathrm{~mL}$, $0.88 \mathrm{mmol})$ in $\mathrm{THF}(6 \mathrm{~mL})$ at $0^{\circ} \mathrm{C}$. After $20 \mathrm{~min}$, a solution of acid 89 (160 mg, $0.35 \mathrm{mmol})$ in THF ( $5 \mathrm{~mL})$ was added and he solution allowed to warm to rt. After $24 \mathrm{~h}$ a small potion of silica was added to the solution and the solvent removed in vасио. The dry silica was then loaded on a silica column and gradient eluted with 20:1 to $7: 1$ hexanes/EtOAc) to yield the title compound as a clear oil $(96 \mathrm{mg}, 52 \%) . \mathbf{R}_{F}=0.37$ (2:1 hexanes/EtOAc). $[\alpha]_{D}{ }^{21}=-3.6\left(c 1.00, \mathrm{CHCl}_{3}\right) .{ }^{1} \mathbf{H} \mathbf{N M R}\left(500 \mathrm{MHz}, \mathrm{CDCl}_{3}\right) \delta 6.71$ $(\mathrm{d}, J=2.2 \mathrm{~Hz}, 1 \mathrm{H}), 6.68(\mathrm{~d}, J=2.2 \mathrm{~Hz}, 1 \mathrm{H}), 5.85$ (ddt, $J=17.2,10.2,7.0 \mathrm{~Hz}, 1 \mathrm{H}), 5.78$ (ddd, $J=17.9,10.3,7.8 \mathrm{~Hz}, 1 \mathrm{H}), 5.28(\mathrm{~d}, J=17.1 \mathrm{~Hz}, 1 \mathrm{H}), 5.25-5.20(\mathrm{~m}, 2 \mathrm{H}), 5.15(\mathrm{~s}$, 
2H), $5.14(\mathrm{~m}, 2 \mathrm{H}), 5.13-5.07(\mathrm{~m}, 2 \mathrm{H}), 4.46(\mathrm{dd}, J=7.3,6.6 \mathrm{~Hz}, 1 \mathrm{H}), 4.09$ (ddd, $J=8.5$, 6.0, $4.8 \mathrm{~Hz}, 1 \mathrm{H}), 3.73$ (d, J=13.7 Hz, 1H), 3.69 (d, $J=13.7 \mathrm{~Hz}, 1 \mathrm{H}), 3.46$ (s, 3H), 3.45 (s, 3H), 2.51-2.42 (m, 3H), 2.40-2.33 (m, 1H), $1.72(\mathrm{~m}, 1 \mathrm{H}), 1.60-1.40$ (m, 3H), 1.46 (s, 3H), $1.34(\mathrm{~s}, 3 \mathrm{H}), 1.34(\mathrm{~d}, J=6.2 \mathrm{~Hz}, 3 \mathrm{H}) .{ }^{13} \mathbf{C} \mathbf{N M R}\left(125 \mathrm{MHz}, \mathrm{CDCl}_{3}\right) \delta 166.9$, 158.6, 155.8, 139.0, 134.3, 133.8, 118.4, 118.3, 117.7, 110.4, 108.2, 102.3, 94.7, 94.3, 79.7, 77.8, 71.2, 56.2, 56.1, 40.2, 33.8, 31.6, 29.5, 28.2, 25.8, 25.6, 19.4. HRMS (ESI) calcd. for $\mathrm{C}_{27} \mathrm{H}_{40} \mathrm{O}_{8} \mathrm{SNa}^{+}[\mathrm{M}+\mathrm{Na}]^{+}$547.2342, found 547.2339.

$\left(4 S, 6^{\prime} R, 7^{\prime} S\right)$-Pent-1-en-4-yl 6-(6', $7^{\prime}$-O-( $1^{\prime \prime}$-methylethylidene $)-2^{\prime}$-thianon-8' -enyl)-2,4di(methoxymethoxy)benzoate $2^{\prime}, 2^{\prime}$-dioxide (108)

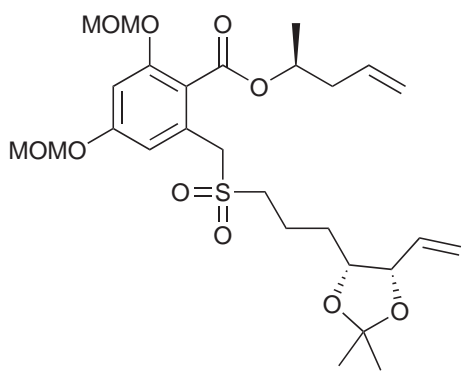

$m$-CPBA (75 mg, $0.33 \mathrm{mmol}, 77 \% \mathrm{w} / \mathrm{w})$ was added to a solution of thioether $90(77 \mathrm{mg}, 0.15 \mathrm{mmol})$ in $\mathrm{CH}_{2} \mathrm{Cl}_{2}(4$ $\mathrm{mL}$ ) stirring at $0{ }^{\circ} \mathrm{C}$. After $2 \mathrm{~h}$ TLC suggested remaining starting material, excess $m$-CPBA $(38 \mathrm{mg}, 0.17 \mathrm{mmol}$, $77 \% \mathrm{w} / \mathrm{w}$ ) was added. After $1 \mathrm{~h}$ the reaction was quenched with $20 \% \mathrm{Na}_{2} \mathrm{SO}_{3}(10 \mathrm{~mL})$, the aqueous layer separated and further extracted with $\mathrm{CH}_{2} \mathrm{Cl}_{2}$ (3 x $10 \mathrm{~mL})$. The combined organic layers were then washed with $\mathrm{NaHCO}_{3}(10 \mathrm{~mL})$, dried over $\mathrm{MgSO}_{4}$, filtered and concentrated in vacuo to give a yellow oil, which was purified by flash column chromatography (silica, 3:1 hexanes/EtOAc) to give the title compound as a clear oil (50 mg, 61\%). $[\alpha]_{D}{ }^{21}=-2.7\left(c 1.00, \mathrm{CHCl}_{3}\right) . \mathbf{R}_{\boldsymbol{F}}=0.17$ (2:1 hexanes/EtOAc). ${ }^{1} \mathbf{H}$ NMR $\left(500 \mathrm{MHz}, \mathrm{CDCl}_{3}\right) \delta 6.87(\mathrm{~d}, J=2.2 \mathrm{~Hz}, 1 \mathrm{H}), 6.85(\mathrm{~d}, J=2.2 \mathrm{~Hz}, 1 \mathrm{H}), 5.85$ (dddd, $J=17.1,10.1,7.0,7.0 \mathrm{~Hz}, 1 \mathrm{H}), 5.78(\mathrm{ddd}, J=17.7,10.4,7.9 \mathrm{~Hz}, 1 \mathrm{H}), 5.25-5.00$ (m, 7H), $5.16(\mathrm{~s}, 2 \mathrm{H}), 4.46(\mathrm{t}, J=7.0 \mathrm{~Hz}, 1 \mathrm{H}), 4.38(\mathrm{~d}, J=14.1 \mathrm{~Hz}, 1 \mathrm{H}), 4.28(\mathrm{~d}, J=14.1$ Hz, 1H), 4.09 (dd, $J=13.4,6.1 \mathrm{~Hz}, 1 \mathrm{H}), 3.46$ (s, 3H), 3.45 (s, 3H), 3.02 (ddd, $J=13.9$, $10.3,5.9 \mathrm{~Hz}, 1 \mathrm{H}), 2.94$ (ddd, $J=13.9,10.1,5.7 \mathrm{~Hz}, 1 \mathrm{H}), 2.51-2.44$ (m, 1H), 2.42-2.35 (m, 1H), 2.02-1.91 (m, 1H), 1.89-1.80 (m, 1H), 1.52 (tdd, $J=11.2,7.0,3.9 \mathrm{~Hz}, 2 \mathrm{H}), 1.45$ $(\mathrm{s}, 3 \mathrm{H}), 1.34(\mathrm{~d}, J=6.3 \mathrm{~Hz}, 3 \mathrm{H}), 1.33(\mathrm{~s}, 3 \mathrm{H}) .{ }^{13} \mathbf{C} \mathbf{N M R}\left(125 \mathrm{MHz}, \mathrm{CDCl}_{3}\right) \delta 166.6$, 159.0, 156.4, 134.0, 133.7, 128.5, 119.3, 118.6, 117.9, 112.2, 108.4, 104.2, 94.8, 94.3, 79.6, 77.6, 71.7, 56.7, 56.4, 56.3, 51.5, 40.2, 29.3, 28.1, 25.5, 19.5, 18.7. HRMS (ESI) calcd. for $\mathrm{C}_{27} \mathrm{H}_{40} \mathrm{O}_{10} \mathrm{SNa}^{+}[\mathrm{M}+\mathrm{Na}]^{+}$579.2240, found 579.2232 


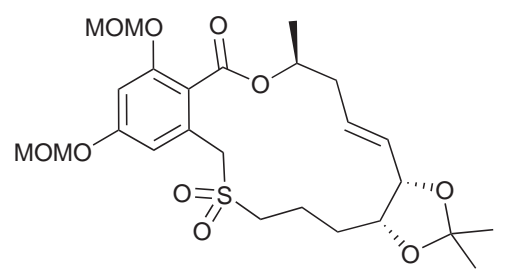

Grubbs' second generation catalyst ( $8 \mathrm{mg}, 0.009 \mathrm{mmol})$ was added to a solution of diene $\mathbf{1 0 8}(50 \mathrm{mg}, 0.09 \mathrm{mmol})$ in $\mathrm{CH}_{2} \mathrm{Cl}_{2}$ in a $100 \mathrm{~mL} \mathrm{MW} \mathrm{Teflon}{ }^{T M}$ reaction vessel. The vessel was then flushed with argon, sealed and heat to $75^{\circ} \mathrm{C}$ over $2 \mathrm{~min}$ and held at this temperature for a further $30 \mathrm{~min}$ (see Appendix for a standard microwave temperature profile). After cooling to rt. the reaction mixture was concentrated in vacuo to give a dark green oil, which was purified by flash column chromatography (silica, gradient elution, 5:1 to 1:1 hexanes/EtOAc) to give a green oil. This green oil was then dissolved in $\mathrm{CH}_{2} \mathrm{Cl}_{2}(6 \mathrm{~mL})$, activated carbon added $(10 \mathrm{mg})$ and the solution stirred for 30 min to remove remaining Grubbs' catalyst by-product. The solution was then filtered through a Celite ${ }^{\circledR}$ plug and evaporated to yield the title compound as a faint green oil $(32 \mathrm{mg}, 67 \%) \mathbf{R}_{\boldsymbol{F}}=0.11(2: 1$ hexanes/EtOAc $) .[\alpha]_{D}{ }^{21}=$ $+50.5\left(c 1.00, \mathrm{CHCl}_{3}\right) .{ }^{1} \mathbf{H}$ NMR $\left(500 \mathrm{MHz}, \mathrm{CDCl}_{3}\right) \delta 6.98(\mathrm{~d}, J=2.2 \mathrm{~Hz}, 1 \mathrm{H}), 6.86$ $(\mathrm{d}, J=2.2 \mathrm{~Hz}, 1 \mathrm{H}), 5.86(\mathrm{ddd}, J=15.7,13.2,6.4 \mathrm{~Hz}, 1 \mathrm{H}), 5.68(\mathrm{dd}, J=15.6,8.6 \mathrm{~Hz}$, 1H), $5.39(\mathrm{~m}, 1 \mathrm{H}), 5.21-5.16(\mathrm{~m}, 4 \mathrm{H}), 4.52(\mathrm{dd}, J=8.6,6.4 \mathrm{~Hz}, 1 \mathrm{H}) 4.41(\mathrm{~d}, J=14.4$ $\mathrm{Hz}, 1 \mathrm{H}), 4.17$ (m, 1H), 4.14 (d, J = 14.4 Hz, 1H), 3.47 (s, 3H), 3.46 (s, 3H), 3.08 (ddd, $\mathrm{J}=14.7,9.8,4.9 \mathrm{~Hz}, 1 \mathrm{H}), 2.95(\mathrm{~m}, 1 \mathrm{H}), 2.86(\mathrm{~m}, 1 \mathrm{H}), 2.44(\mathrm{dd}, \mathrm{J}=15.5,9.8 \mathrm{~Hz}, 1 \mathrm{H})$, $1.75(\mathrm{~m}, 1 \mathrm{H}), 1.67(\mathrm{~m}, 1 \mathrm{H}), 1.71-1.56(\mathrm{~m}, 2 \mathrm{H}), 1.43(\mathrm{~s}, 3 \mathrm{H}), 1.40(\mathrm{~d}, J=6.3 \mathrm{~Hz}, 3 \mathrm{H})$, 1.32 (s, 3H). ${ }^{13} \mathbf{C}$ NMR (125 MHz, $\left.\mathrm{CDCl}_{3}\right) \delta 167.0$ 159.3, 156.6, 132.4, 129.0 (2), 118.6, 110.9, 107.9, 103.6, 94.6, 94.4, 76.3, 77.6, 72.3, 56.4, 56.4, 55.4, 51.1, 39.5, 28.3, 27.6, 25.5, 20.8, 18.5. HRMS (ESI) calcd. for $\mathrm{C}_{25} \mathrm{H}_{36} \mathrm{O}_{10} \mathrm{SNa}^{+}[\mathrm{M}+\mathrm{Na}]^{+} 551.1927$, found 551.1925 


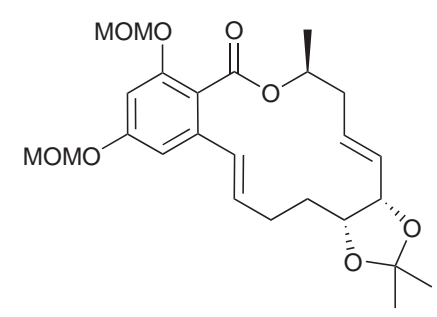

$\mathrm{KOH}(68 \mathrm{mg}, 1.21 \mathrm{mmol})$ was added to a solution of sulfone $91(32 \mathrm{mg}, 0.06 \mathrm{mmol})$ in $t-\mathrm{BuOH}(250 \mu \mathrm{L})$ and $\mathrm{CH}_{2} \mathrm{Cl}_{2}(100$ $\mu \mathrm{L})$. After $2 \mathrm{~min}, \mathrm{CCl}_{4}(0.24 \mathrm{~mL})$ was added dropwise and the solution heated to $30^{\circ} \mathrm{C}$. After $30 \mathrm{~min}$ TLC suggest the consumption of starting material. The solvent was then removed in vacuo, the crude mixture dissolved in EtOAc $(5 \mathrm{~mL})$ and sat. $\mathrm{NH}_{4} \mathrm{Cl}(5 \mathrm{~mL})$, the layers separated and the aqueous layer further extracted with EtOAc $(2 \times 5 \mathrm{~mL})$. The combined organic layers were then dried over $\mathrm{MgSO}_{4}$, filtered and concentrated in vacuo to give a brown oil, which was purified by flash column chromatography (silica, 5:1 hexanes/EtOAc) to yield the title compound as a clear oil $(18 \mathrm{mg}, 64 \%) \mathbf{R}_{F}=0.25(2: 1$ hexanes/EtOAc $) .[\alpha]_{D}{ }^{21}=+4.8(c$ 1.00, $\left.\mathrm{CHCl}_{3}\right) .{ }^{1} \mathbf{H} \mathbf{N M R}\left(500 \mathrm{MHz}, \mathrm{CDCl}_{3}\right) \delta 6.70(\mathrm{~d}, J=2.1 \mathrm{~Hz}, 1 \mathrm{H}), 6.68(\mathrm{~d}, J=2.1$ $\mathrm{Hz}, 1 \mathrm{H}), 6.43(\mathrm{~d}, J=15.6 \mathrm{~Hz}, 1 \mathrm{H}), 6.09(\mathrm{ddd}, J=15.8,12.7,6.3 \mathrm{~Hz}, 1 \mathrm{H}), 5.86$ (ddd, $J$ $=15.6,7.8,2.2 \mathrm{~Hz}, 1 \mathrm{H}), 5.67(\mathrm{dd}, J=15.6,8.0 \mathrm{~Hz}, 1 \mathrm{H}), 5.20-5.12(\mathrm{~m}, 4 \mathrm{H}), 5.16(\mathrm{~m}$, 1H), $4.57(\mathrm{dd}, J=7.8,6.1 \mathrm{~Hz}, 1 \mathrm{H}), 4.16(\mathrm{ddd}, J=10.7,5.6,2.3 \mathrm{~Hz}, 1 \mathrm{H}), 3.46(\mathrm{~s}, 3 \mathrm{H})$, 3.45 (s, 3H), 2.63 (ddd, 10.5, 7.8, $2.9 \mathrm{~Hz}, 1 \mathrm{H}), 2.45-2.30(\mathrm{~m}, 2 \mathrm{H}), 2.04(\mathrm{~m}, 1 \mathrm{H}), 1.83$ $(\mathrm{m}, 1 \mathrm{H}), 1.50(\mathrm{~m}, 1 \mathrm{H}), 1.49(\mathrm{~s}, 3 \mathrm{H}), 1.40(\mathrm{~d}, J=6.3 \mathrm{~Hz}, 3 \mathrm{H}), 1.35(\mathrm{~s}, 3 \mathrm{H}) .{ }^{13} \mathbf{C}$ NMR $\left(125 \mathrm{MHz}, \mathrm{CDCl}_{3}\right) \delta 167.4,158.9,155.1,136.8,132.3,131.9,129.3,128.4,117.9,108.3$, $104.8,102.5,94.5,94.3,80.1,77.2,71.6,56.2,56.1,39.5,29.0,28.7,28.6,25.8,21.1$. $\mathrm{C}_{25} \mathrm{H}_{34} \mathrm{O}_{8} \mathrm{Na}^{+}[\mathrm{M}+\mathrm{Na}]^{+}$485.2151, found 485.2152.

\section{$\left(5^{\prime} R, 6^{\prime} S\right)$-Aigialomycin D (69)}

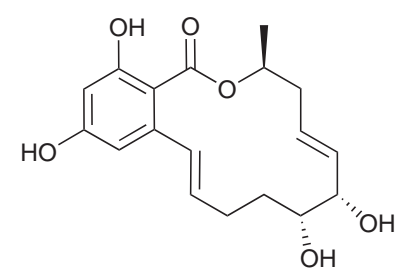

Protected 5',6'-epi,epi-AmD (17 mg, $0.037 \mathrm{mmol})$ was stirred in a solution of in 1:1 v/v MeOH/ $1 \mathrm{M} \mathrm{HCl}(5 \mathrm{~mL})$. After 2 days TLC suggest one product. The reaction was then extracted with EtOAc $(10 \mathrm{~mL})$, the combine organic layers washed with brine (3 mL), dried over $\mathrm{MgSO}_{4}$, filtered and evaporated in vacuo to give a yellow solid, which was purified by flash column chromatography (silica, $1-5 \% \mathrm{MeOH} / \mathrm{CH}_{2} \mathrm{Cl}_{2}$ ) to yield the 
title compound plus an unknown isomer (ratio 95:5) as a white solid (11 mg, 90\%). $\mathbf{R}_{F}=$ $0.45\left(9: 1 \mathrm{CH}_{2} \mathrm{Cl}_{2} / \mathrm{MeOH}\right)$. HRMS (ESI) calcd. for $\mathrm{C}_{18} \mathrm{H}_{22} \mathrm{O}_{623} \mathrm{Na}^{+}[\mathrm{M}+\mathrm{Na}]^{+} 357.1314$, found 357.1319. A portion was purified with HPLC for characterisation purposes (C18, $\left.80 \% \mathrm{MeOH} / \mathrm{H}_{2} \mathrm{O}, \mathbf{R}_{t}=8.2 \mathrm{~min}\right) .\left(9: 1 \mathrm{CH}_{2} \mathrm{Cl}_{2} / \mathrm{MeOH}\right) .[\alpha]_{D}{ }^{21}=+15.6(c 0.20, \mathrm{MeOH})$.

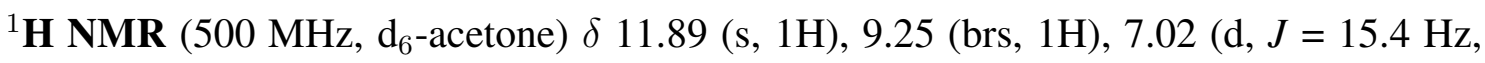
$1 \mathrm{H}), 6.43(\mathrm{~d}, J=2.2 \mathrm{~Hz}, 1 \mathrm{H}), 6.28(\mathrm{~d}, J=2.5 \mathrm{~Hz}, 1 \mathrm{H}), 6.08$ (ddd, $J=15.1,10.0,3.4 \mathrm{~Hz}$, 1H), 5.88 (ddd, $J=15.1,9.2,4.1 \mathrm{~Hz}, 1 \mathrm{H}), 5.67$ (ddd, $J=15.1,9.5,1.7 \mathrm{~Hz}, 1 \mathrm{H}), 5.45$ (m, $1 \mathrm{H}), 4.66(\mathrm{dd}, J=9.5,5.9 \mathrm{~Hz}, 1 \mathrm{H}), 4.24(\mathrm{ddd}, J=11.5,5.9,2.5 \mathrm{~Hz}, 1 \mathrm{H}), 2.67(\mathrm{ddd}, J=$ $16.2,9.8,4.0 \mathrm{~Hz}, 1 \mathrm{H}), 2.55(\mathrm{ddd}, J=15.9,5.7,3.2 \mathrm{~Hz}, 1 \mathrm{H}), 2.27-2.21(\mathrm{~m}, 1 \mathrm{H}), 2.02-$ $1.96(\mathrm{~m}, 2 \mathrm{H}), 1.92-1.48(\mathrm{~m}, 1 \mathrm{H}), 1.50(\mathrm{~d}, J=6.6 \mathrm{~Hz}, 3 \mathrm{H}) .{ }^{13} \mathbf{C ~ N M R}\left(125 \mathrm{MHz}, \mathrm{CDCl}_{3}\right)$ $\delta 172.3,166.4,163.3144 .7,132.9,131.9,131.6,128.6,108.2,103.8,102.5,80.7,77.7$, 72.1, 72.0, 38.16, 29.0, 18.5.

\subsection{Experimental Details for Chapter 5}

\section{Pent-4-en-2-yl 2-methyl benzoate (95)}

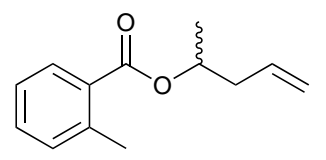

4-penten-2-ol (90 $\mu, 0.88 \mathrm{mmol})$ was added to a solution of 2methylbenzoic acid (100 mg, $0.73 \mathrm{mmol}$ ) and DMAP (179 mg, 1.47

$\mathrm{mmol})$ in $\mathrm{CH}_{2} \mathrm{Cl}_{2}(5 \mathrm{~mL})$ stirring at $0{ }^{\circ} \mathrm{C}$, followed by DCC (168 $\left.\mathrm{mg}, 0.81 \mathrm{mmol}\right)$ and the solution allowed to warm to rt. overnight. The solution was then filtered, the filtrate quenched with $5 \% \mathrm{HCl}(10 \mathrm{~mL})$ and extracted with $\mathrm{CH}_{2} \mathrm{Cl}_{2}(2 \times 5 \mathrm{~mL})$. The combined organic layers were then washed with brine $(2 \times 10 \mathrm{~mL})$, dried over $\mathrm{MgSO}_{4}$, filtered and concentrated in vacuo to pink liquid, which was purified by flash column chromatography (silica, 9:1 hexanes/EtOAc) to yield the title compound as a colourless oil (72 $\mathrm{mg}, 52 \%$ ). $\mathbf{R}_{\boldsymbol{F}}=0.50$ (9:1 hexanes/EtOAc). ${ }^{1} \mathbf{H}$ NMR $\left(500 \mathrm{MHz}, \mathrm{CDCl}_{3}\right) \delta 7.90(\mathrm{~d}, J=7.8 \mathrm{~Hz}, 1 \mathrm{H})$, $7.39(\mathrm{t}, J=7.5 \mathrm{~Hz}, 1 \mathrm{H}), 7.25(\mathrm{t}, J=7.1 \mathrm{~Hz}, 2 \mathrm{H}), 5.86(\mathrm{tdd}, J=17.1,10.0,7.1 \mathrm{~Hz}, 1 \mathrm{H})$, 5.23 (sextet, $J=6.3 \mathrm{~Hz}, 1 \mathrm{H}), 5.18-5.09(\mathrm{~m}, 2 \mathrm{H}), 2.61(\mathrm{~s}, 3 \mathrm{H}), 2.50(\mathrm{td}, J=14.0,6.9$ $\mathrm{Hz}, 1 \mathrm{H}), 2.43(\mathrm{td}, J=13.9,6.8 \mathrm{~Hz}, 1 \mathrm{H}), 1.37(\mathrm{~d}, J=6.3 \mathrm{~Hz}, 3 \mathrm{H})$. 


\section{EDCI esterification of 2-methylbenzoate}

Same procedure as used previously. EDCI (155 mg, $0.81 \mathrm{mmol})$ and DMAP (179 $\mathrm{mg}$, $1.47 \mathrm{mmol}$ ) yielded $\mathbf{9 5}$ as a colourless liquid (81 $\mathrm{mg}, 58 \%)$

\section{EDCI esterification of 2-methylbenzoate}

Same procedure as used previously. EDCI (211 mg, $1.10 \mathrm{mmol})$ and DMAP (269 mg, $2.20 \mathrm{mmol}$ ) yielded 95 as a colourless liquid (109 mg, 73\%)

\section{EDCI esterification of 2-methylbenzoate}

EDCI (211 mg, $1.10 \mathrm{mmol})$ was added to a stirred solution of 2-methylbenzoic acid (100 $\mathrm{mg}, 0.73 \mathrm{mmol})$ and DMAP (269 mg, $2.20 \mathrm{mmol})$ at $0{ }^{\circ} \mathrm{C}$. After $30 \mathrm{~min}$, 4-penten-2-ol (90 $\mu, 0.88 \mathrm{mmol}$ ) was added and the solution left to warm to rt. overnight. The solution was then quenched with $10 \% \mathrm{HCl}$, extracted with $\mathrm{CH}_{2} \mathrm{Cl}_{2}(2 \times 5 \mathrm{~mL})$, the combined organic layers washed with brine $(2 \times 10 \mathrm{~mL})$ and concentrated in vacuo to give a pale yellow liquid, which was purified by flash column chromatography (silica, 9:1 hexanes/EtOAc) to yield the title compound as a colourless liquid (72 $\mathrm{mg}, 52 \%$ )

\section{HBTU, DMAP and NEt ${ }_{3}$ esterification of 2-methylbenzoate}

HBTU (209 mg, $0.55 \mathrm{mmol}$ ) was added to a solution of 2-methylbenzoic acid (50 mg, $0.37 \mathrm{mmol}$ ), DMAP ( $135 \mathrm{mg}, 1.10 \mathrm{mmol})$ and $\mathrm{NEt}_{3}(155 \mu \mathrm{L}, 1.10 \mathrm{mmol})$ in $\mathrm{CH}_{2} \mathrm{Cl}_{2}$ (4 mL) stirring at $0^{\circ} \mathrm{C}$, followed by 4-penten-2-ol (45 $\left.\mu \mathrm{L}, 0.44 \mathrm{mmol}\right)$, and the solution left to warm to rt. overnight. The reaction was then quenched with $\mathrm{NH}_{4} \mathrm{Cl}(10 \mathrm{~mL})$, extracted with $\mathrm{CH}_{2} \mathrm{Cl}_{2}(2 \times 10 \mathrm{~mL})$, the combined organic layers was with brine $(10 \mathrm{~mL})$, dried over $\mathrm{MgSO}_{4}$, filtered and concentrated in vacuo to give a yellow liquid, which was purified with flash column chromatography (silica, 7:1 hexanse/EtOAc) to yield $\mathbf{9 5}$ as a colourless liquid (56 mg, 75\%). 


\section{HBTU and DMAP esterification of 2-methylbenzoate}

The same procedure as above without $\mathrm{NEt}_{3}$ to yield $\mathbf{9 5}$ as a colourless oil (43 $\left.\mathrm{mg}, 57 \%\right)$.

\section{Attempted HBTU and $\mathrm{NEt}_{3}$ esterification of 2-methylbenzoate}

The same procedure as above without DMAP yielded only starting material and traces of 95.

(4R,6' $\left.{ }^{\prime}, 7^{\prime} \mathrm{R}\right)$-Pent-1-en-4-yl 6-(6,7-O-(1-methylethylidene)-2-thianon-8-enyl)-2,4di(methoxymethoxy)benzoate (66)

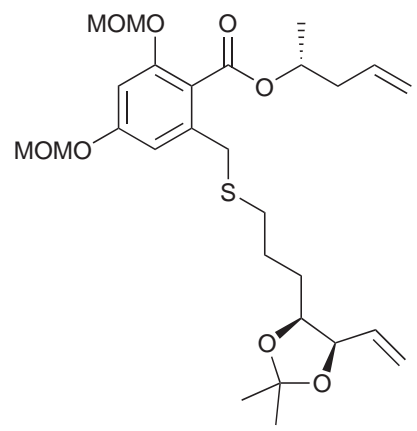

(S)-4-penten-2-ol (30 $\mu \mathrm{L}, 0.28 \mathrm{mmol})$ was added to a solution $\mathrm{PPh}_{3}(158 \mathrm{mg}, 0.60 \mathrm{mmol})$ and DIAD $(120 \mu \mathrm{L}, 0.60 \mathrm{mmol})$ in THF (5 mL). After $20 \mathrm{~min}$ a solution of acid 45 (110 mg, 0.24 mmol) in THF ( $5 \mathrm{~mL}$ ) was added and the solution allowed to warm to rt. After $16 \mathrm{~h}$, silica gel was added to the reaction and the solvent evaporated in vacuo. The silica gel was dry loaded on a silica columned and eluted (gradient elution, 20:1 to 10:1 hexanes/EtOAc) to yield the title compound as a clear oil $(105 \mathrm{mg}, 86 \%) . \mathbf{R}_{\boldsymbol{F}}=0.60\left(2: 1\right.$ hexanes/EtOAc). $[\alpha]_{D}{ }^{22}$ $=30.4\left(c\right.$ 1, $\left.\mathrm{CHCl}_{3}\right) .{ }^{1} \mathbf{H}$ NMR $\left(500 \mathrm{MHz}, \mathrm{CDCl}_{3}\right) \delta 6.72(\mathrm{~d}, J=2.2 \mathrm{~Hz}, 1 \mathrm{H}), 6.69(\mathrm{~d}, J$ $=1.9 \mathrm{~Hz}, 1 \mathrm{H}), 5.85(\mathrm{dddd}, J=17.2,10.2,7.0,7.0 \mathrm{~Hz}, 1 \mathrm{H}), 5.78(\mathrm{ddd}, J=17.7,10.4,7.9$ $\mathrm{Hz}, 1 \mathrm{H}), 5.25-5.20(\mathrm{~m}, 2 \mathrm{H}), 5.15(\mathrm{~s}, 2 \mathrm{H}), 5.14(\mathrm{~m}, 2 \mathrm{H}), 5.13-5.07(\mathrm{~m}, 2 \mathrm{H}), 4.46(\mathrm{t}, J=$ $7.0 \mathrm{~Hz}, 1 \mathrm{H}), 4.08(\mathrm{ddd}, J=8.5,6.0,4.8 \mathrm{~Hz}, 1 \mathrm{H}), 3.72(\mathrm{~d}, J=13.7 \mathrm{~Hz}, 1 \mathrm{H}), 3.68(\mathrm{~d}, J=$ $13.7 \mathrm{~Hz}, 1 \mathrm{H}), 3.45$ (s, 3H), 3.44 (s, 3H), 2.50-2.40 (m, 3H), 2.39-2.32 (m, 1H), $1.71(\mathrm{~m}$, 1H), $1.60-1.40(\mathrm{~m}, 3 \mathrm{H}), 1.45$ (s, 3H), $1.34(\mathrm{~s}, 3 \mathrm{H}), 1.33$ (d, $J=6.2 \mathrm{~Hz}, 3 \mathrm{H}) .{ }^{13} \mathbf{C}$ NMR $\left(125 \mathrm{MHz}, \mathrm{CDCl}_{3}\right) \delta 166.9,158.5,155.8,139.0,134.3,133.8,118.4,118.3,117.6,110.3$, $108.1,102.3,94.7,94.3,79.7,77.8,71.1,56.2,56.2,40.2,33.7,31.5,29.5,28.2,25.8$, 25.6, 19.4. HRMS (ESI) calcd. for $\mathrm{C}_{27} \mathrm{H}_{40} \mathrm{O}_{8} \mathrm{SNa}^{+}[\mathrm{M}+\mathrm{Na}]^{+}$547.2342, found 547.2338 


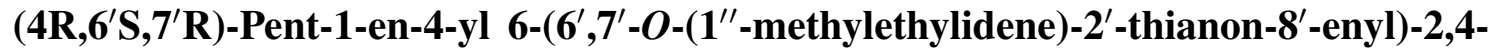
di(methoxymethoxy)benzoate $2^{\prime}, 2^{\prime}$-dioxide (67)

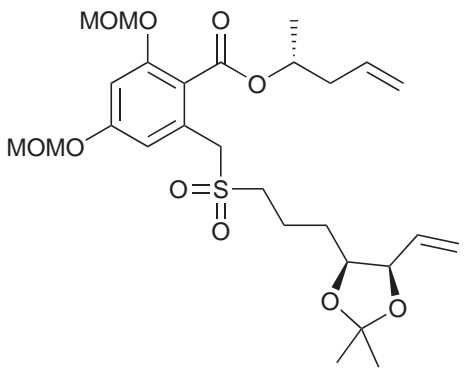

$m$-CPBA (62 mg, $0.28 \mathrm{mmol}, 77 \% \mathrm{w} / \mathrm{w})$ was added to a solution of thioether 109 (64 mg, $0.13 \mathrm{mmol})$ in $\mathrm{CH}_{2} \mathrm{Cl}_{2}$ (4 mL) stirring at $0{ }^{\circ} \mathrm{C}$ and allowed to warm to rt. After $3 \mathrm{~h}$, the solution was quenched with $20 \% \mathrm{Na}_{2} \mathrm{SO}_{3}(5 \mathrm{~mL})$, separated and the aqueous layer extracted with $\mathrm{CH}_{2} \mathrm{Cl}_{2}(3$ x $5 \mathrm{~mL}$ ). The combined organic layers were dried with $\mathrm{MgSO}_{4}$, filtered and concentrated in vacuo to give a colourless oil. The crude product was purified by flash column chromatography (silica, gradient elution, 3:1 to $1: 1$ hexanes/EtOAc) to yield the title compound as a colourless oil $(53 \mathrm{mg}, 78 \%) . \quad \mathbf{R}_{\boldsymbol{F}}=0.13\left(2: 1\right.$ hexanes/EtOAc). $[\alpha]_{D}{ }^{22}$ $=+54.3\left(c 1, \mathrm{CHCl}_{3}\right) .{ }^{1} \mathbf{H}$ NMR $\left(500 \mathrm{MHz}, \mathrm{CDCl}_{3}\right) \delta 6.87(\mathrm{~d}, J=2.2 \mathrm{~Hz}, 1 \mathrm{H}), 6.85(\mathrm{~d}, J$ $=2.2 \mathrm{~Hz}, 1 \mathrm{H}), 5.85(\mathrm{dddd}, J=17.1,10.1,7.0,7.0 \mathrm{~Hz}, 1 \mathrm{H}), 5.78(\mathrm{ddd}, J=17.7,10.4,7.9$ $\mathrm{Hz}, 1 \mathrm{H}), 5.25^{\prime} 5.00(\mathrm{~m}, 7 \mathrm{H}), 5.16(\mathrm{~s}, 2 \mathrm{H}), 4.46(\mathrm{t}, J=7.0 \mathrm{~Hz}, 1 \mathrm{H}), 4.38(\mathrm{~d}, J=14.1 \mathrm{~Hz}$, 1H), $4.28(\mathrm{~d}, J=14.1 \mathrm{~Hz}, 1 \mathrm{H}), 4.12-4.07(\mathrm{~m}, 1 \mathrm{H}), 3.46$ (s, 3H), 3.45 (s, 3H). 3.02 (ddd, $J=13.9,10.2,5.7 \mathrm{~Hz}, 1 \mathrm{H}), 2.94(\mathrm{ddd}, J=13.9,10.1,5.7 \mathrm{~Hz}, 1 \mathrm{H}), 2.51-2.44(\mathrm{~m}, 1 \mathrm{H})$, 2.42-2.35 (m, 1H), 2.02-1.91 (m, 1H), 1.89-1.80 (m, 1H), $1.52(\mathrm{tdd}, J=11.2,7.0,3.9 \mathrm{~Hz}$, 2H), 1.45 (s, 3H), 1.34 (d, $J=6.3 \mathrm{~Hz}, 3 \mathrm{H}), 1.33$ (s, 3H). ${ }^{13} \mathbf{C ~ N M R}\left(125 \mathrm{MHz}, \mathrm{CDCl}_{3}\right) \delta$ $166.6,159.0,156.4,134.0,133.7,128.5,119.3,118.6,117.9,112.2,108.4,104.2,94.8$, $94.3,79.6,77.6,71.7,56.7,56.4,56.3,51.5,40.2,29.3,28.1,25.5,19.5,18.7$. HRMS (ESI) calcd. for $\mathrm{C}_{27} \mathrm{H}_{40} \mathrm{O}_{10} \mathrm{SNa}^{+}[\mathrm{M}+\mathrm{Na}]^{+}$579.2240, found 579.2239

(5R,7E,9R,10S)-1,2-(3',5'-Di-O-methoxymethyl)benzo-4-oxa-14-thia-3-oxo-5-methyl9,10-O-(1-methylethylidene) pentadec-7-ene 14,14-dioxide (68)

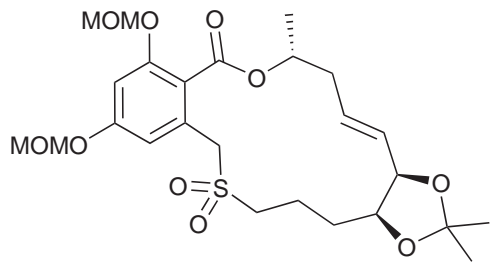

A $100 \mathrm{~mL}$ MW Teflon ${ }^{T M}$ reaction vessel was charged with a solution of Grubbs' second generation catalyst (8 $\mathrm{mg}, 0.01 \mathrm{mmol})$ and diene $67(50 \mathrm{mg}, 0.09 \mathrm{mmol})$ in $\mathrm{CH}_{2} \mathrm{Cl}_{2}(20 \mathrm{~mL})$, flushed with argon and sealed. The reaction was then heated to $75^{\circ} \mathrm{C}$ over 2 min and held at this temperature for a further 
28 min (see Appendix for a typical microwave heating profile). After cooling to rt. the reaction mixture was concentrated in vacuo to give a dark green oil, which was purified by flash column chromatography twice (silica, 1:1 hexanes/EtOAc) to yield the title compound as a colourless oil $(36 \mathrm{mg}, 76 \%) . \quad \mathbf{R}_{\boldsymbol{F}}=0.07\left(2: 1\right.$ hexanes/EtOAc). $[\alpha]_{D}{ }^{18}$ $=-41.0\left(c 1, \mathrm{CHCl}_{3}\right) .{ }^{1} \mathbf{H} \mathbf{N M R}\left(500 \mathrm{MHz}, \mathrm{CDCl}_{3}\right) \delta 6.98(\mathrm{~d}, J=2.2 \mathrm{~Hz}, 1 \mathrm{H}), 6.86(\mathrm{~d}$, $J=2.2 \mathrm{~Hz}, 1 \mathrm{H}), 5.86(\mathrm{ddd}, J=15.7,13.2,6.4 \mathrm{~Hz}, 1 \mathrm{H}), 5.68(\mathrm{dd}, J=15.6,8.6 \mathrm{~Hz}, 1 \mathrm{H})$, $5.39(\mathrm{~m}, 1 \mathrm{H}), 5.21-5.16(\mathrm{~m}, 4 \mathrm{H}), 4.52(\mathrm{dd}, J=8.6,6.4 \mathrm{~Hz}, 1 \mathrm{H}) 4.41(\mathrm{~d}, J=14.4 \mathrm{~Hz}$, 1H), $4.17(\mathrm{~m}, 1 \mathrm{H}), 4.14(\mathrm{~d}, J=14.4 \mathrm{~Hz}, 1 \mathrm{H}), 3.47$ (s, 3H), 3.46 (s, 3H), 3.08 (ddd, J = 14.7, 9.8, 4.9 Hz, 1H), 2.95 (m, 1H), 2.86 (m, 1H), 2.44 (dd, J = 15.5, 9.8 Hz, 1H), 1.75 (m, 1H), $1.67(\mathrm{~m}, 1 \mathrm{H}), 1.71-1.56(\mathrm{~m}, 2 \mathrm{H}), 1.43(\mathrm{~s}, 3 \mathrm{H}), 1.40(\mathrm{~d}, J=6.3 \mathrm{~Hz}, 3 \mathrm{H}), 1.32(\mathrm{~s}$, 3H). ${ }^{13} \mathbf{C ~ N M R}\left(125 \mathrm{MHz}, \mathrm{CDCl}_{3}\right) \delta 159.3,156.6,132.4,129.0$ (2), 118.6, 110.9, 107.9, 103.6, 94.6, 94.4, 76.3, 77.6, 72.3, 56.4, 56.4, 55.4, 51.1, 39.5, 28.3, 27.6, 25.5, 20.8, 18.5. HRMS (ESI) calcd. for $\mathrm{C}_{25} \mathrm{H}_{36} \mathrm{O}_{10} \mathrm{SNa}^{+}[\mathrm{M}+\mathrm{Na}]^{+} 551.1927$, found 551.1926

$\left(5^{\prime} S, 6^{\prime} R, 10^{\prime} S\right)-2,4-D i-O-(m e t h o x y m e t h y l)-5^{\prime}, 6^{\prime}-O-(1-m e t h y l e t h y l i d e n e)$ aigialomycin D (99)

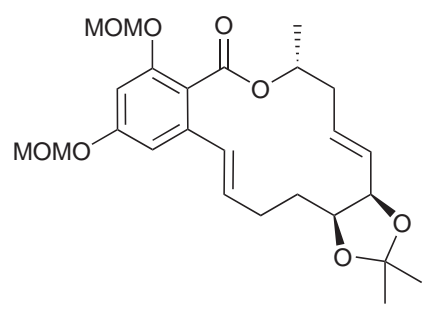

$\mathrm{KOH}$ (64 mg, $1.14 \mathrm{mmol}$ ) was added to a solution of sulfone $68(30 \mathrm{mg}, 0.06 \mathrm{mmol})$ in $t-\mathrm{BuOH}(250 \mu \mathrm{L})$ and $\mathrm{CH}_{2} \mathrm{Cl}_{2}(100$ $\mu \mathrm{L})$ stirring under argon. After $2 \mathrm{~min}, \mathrm{CCl}_{4}(22 \mu \mathrm{L})$ was added dropwise and the solution heated to $35^{\circ} \mathrm{C}$. After 45 min TLC suggest the consumption of starting material. The solvent was then removed in vacuo. the crude mixture dissolved in EtOAc $(5 \mathrm{~mL})$ and sat. $\mathrm{NH}_{4} \mathrm{Cl}(5 \mathrm{~mL})$, the layers separated and the aqueous layer further extracted with EtOAc $(2 \times 5 \mathrm{~mL})$. The combined organic layers were then dried over $\mathrm{MgSO}_{4}$, filtered and concentrated in vacuo to give a yellow oil, which was purified by flash column chromatography (silica, gradient elution, 9:1 to 4:1 hexanes/EtOAc) to yield the title compound as a clear oil $(15 \mathrm{mg}, 57 \%) \mathbf{R}_{F}=$ $0.30\left(2: 1\right.$ hexanes/EtOAc). $[\alpha]_{D}{ }^{24}=-3.9\left(c 1, \mathrm{CHCl}_{3}\right) .{ }^{1} \mathbf{H} \mathbf{~ N M R}\left(500 \mathrm{MHz}, \mathrm{CDCl}_{3}\right) \delta$ $6.70(\mathrm{~d}, J=2.1 \mathrm{~Hz}, 1 \mathrm{H}), 6.68(\mathrm{~d}, J=2.1 \mathrm{~Hz}, 1 \mathrm{H}), 6.43$ (d, $J=15.6 \mathrm{~Hz}, 1 \mathrm{H}), 6.09$ (ddd, $J=15.8,12.7,6.3 \mathrm{~Hz}, 1 \mathrm{H}), 5.86(\mathrm{ddd}, J=15.6,7.8,2.2 \mathrm{~Hz}, 1 \mathrm{H}), 5.67$ (dd, $J=15.6$, 8.0 Hz, 1H), 5.20-5.12 (m, 4H), 5.16 (m, 1H), 4.57 (dd, $J=7.8,6.1 \mathrm{~Hz}, 1 \mathrm{H}), 4.16$ (ddd, 
$J=10.7,5.6,2.3 \mathrm{~Hz}, 1 \mathrm{H}), 3.46(\mathrm{~s}, 3 \mathrm{H}), 3.45(\mathrm{~s}, 3 \mathrm{H}), 2.63(\mathrm{ddd}, 10.5,7.8,2.9 \mathrm{~Hz}, 1 \mathrm{H})$, 2.45-2.30 (m, 2H), $2.04(\mathrm{~m}, 1 \mathrm{H}), 1.83(\mathrm{~m}, 1 \mathrm{H}), 1.50(\mathrm{~m}, 1 \mathrm{H}), 1.49(\mathrm{~s}, 3 \mathrm{H}), 1.40(\mathrm{~d}, J=$ $6.3 \mathrm{~Hz}, 3 \mathrm{H}), 1.35$ (s, 3H). ${ }^{13} \mathbf{C}$ NMR $\left(125 \mathrm{MHz}, \mathrm{CDCl}_{3}\right) \delta 167.4,158.9,155.1,136.8$, $132.3,131.9,129.3,128.4,117.9,108.3,104.8,102.5,94.5,94.3,80.1,77.2,71.6,56.2$, 56.1, 39.5, 29.0, 28.7, 28.6, 25.8, 21.1. HRMS (ESI) calcd. for $\mathrm{C}_{25} \mathrm{H}_{34} \mathrm{O}_{8} \mathrm{Na}^{+}[\mathrm{M}+\mathrm{Na}]^{+}$ 485.2151, found 485.2151.

\subsection{Experimental Details for Chapter 6}

All calculations were done using $\operatorname{Spartan}^{\odot}{ }^{\prime} 08, \mathrm{v}$ 1.2.0. For each structure a conformational search was conducted to determine the equilibrium conformation at ground state using MMFF, with up to a limit of 70000 conformers examined. The SCF energy of the resulting conformation was then calculated using DFT calculations, performed by employing the B3LYP hybrid Hartree-Fock-density functional method with a 6-31G* basis set for the ground state structure in a vacuum.

\subsection{Experimental Details for Chapter 7}

\section{Attempted Simmons-Smith cyclopropanation of alkene 59}

$\mathrm{CH}_{2} \mathrm{I}_{2}(7 \mu \mathrm{L}, 0.08 \mathrm{mmol})$ was added to a suspension of $\mathrm{Zn}(\mathrm{Cu})(24 \mathrm{mg}, 0.19 \mathrm{mmol})$ in $\mathrm{Et}_{2} \mathrm{O}(1 \mathrm{~mL})$ and the mixture sonicated under argon. After $1 \mathrm{~h}$ a solution of alkene $\mathbf{5 9}$ (20 $\mathrm{mg}, 0.04 \mathrm{mmol})$ in $\mathrm{Et}_{2} \mathrm{O}(1 \mathrm{~mL})$ followed by $\mathrm{CH}_{2} \mathrm{I}_{2}(4 \mu \mathrm{L}, 0.04 \mathrm{mmol})$. After $10 \mathrm{~min}$ the solution was taken off sonication and left stirring. After $3 \mathrm{~h}$ the solution was sonicated for $1 \mathrm{~h}$ then left stirring. After $3 \mathrm{~h}$ the solution was quenched with sat. $\mathrm{NH}_{4} \mathrm{Cl}(5 \mathrm{~mL})$ and extracted with $\mathrm{Et}_{2} \mathrm{O}(3 \times 10 \mathrm{~mL})$. The combined organic layers were then dried over $\mathrm{MgSO}_{4}$, filtered and concentrated in vacuo to give a colourless oil, which was purified by flash column chromatography (silica, 1:1 hexanes/EtOAc) to yield starting material (18 $\mathrm{mg})$. 
$\mathrm{CH}_{2} \mathrm{I}_{2}(9 \mu \mathrm{L}, 0.10 \mathrm{mmol})$ was added dropwise to a solution of $\mathrm{Et}_{2} \mathrm{Zn}(0.43 \mathrm{~mL}, 0.27$ mmol, $0.28 \mathrm{M}$ in $\mathrm{CH}_{2} \mathrm{Cl}_{2}$ ) stirring at $-78^{\circ} \mathrm{C}$ under argon and left to warm to $0{ }^{\circ} \mathrm{C}$. After $1 \mathrm{~h}$ a solution of alkene $59(16 \mathrm{mg}, 0.03 \mathrm{mmol})$ in $\mathrm{CH}_{2} \mathrm{Cl}_{2}(0.40 \mathrm{~mL})$ was added and the solution allowed to warm to rt over night. The reaction was then quenched with sat. $\mathrm{NH}_{4} \mathrm{Cl}(2 \mathrm{~mL})$ and extracted with $\mathrm{CH}_{2} \mathrm{Cl}_{2}(3 \times 5 \mathrm{~mL})$. The combined organic layers were then washed with brine $(2 \mathrm{~mL})$, dried over $\mathrm{MgSO}_{4}$, filtered and concentrated in vacuo to give a colourless oil, which was purified by flash column chromatography (silica, 1:1 hexanes/EtOAc) to yield starting material $(15 \mathrm{mg})$.

\section{Attempted Simmons-Smith cyclopropanation of AmD (4) - Furukawa modification}

$\mathrm{CH}_{2} \mathrm{I}_{2}(7 \mu \mathrm{L}, 0.08 \mathrm{mmol})$ was added dropwise to a stirred solution of $\mathrm{Et}_{2} \mathrm{Zn}(0.39 \mathrm{~mL}$, $0.11 \mathrm{mmol}, 0.28 \mathrm{M}$ in $\mathrm{CH}_{2} \mathrm{Cl}_{2}$ ) at $-78^{\circ} \mathrm{C}$ under argon and left to warm to $0{ }^{\circ} \mathrm{C}$. After $1 \mathrm{~h}$ a solution of alkene $4(9 \mathrm{mg}, 0.03 \mathrm{mmol})$ in DMF $(0.50 \mathrm{~mL})$ was added and the solution allowed to warm to rt over night. The reaction was then quenched with sat. $\mathrm{NH}_{4} \mathrm{Cl}(2$ $\mathrm{mL})$ and extracted with $\mathrm{CH}_{2} \mathrm{Cl}_{2}(4 \times 5 \mathrm{~mL})$. The combined organic layers were then dried over $\mathrm{MgSO}_{4}$, filtered and concentrated in vacuo to give a yellow oil, which was purified by flash column chromatography (silica, gradient elution 3-6\% $\mathrm{MeOH} / \mathrm{CH}_{2} \mathrm{Cl}_{2}$ ) to yield starting material $(8 \mathrm{mg})$.

\section{Attempted Simmons-Smith cyclopropanation of AmD (4) - Furukawa modification}

$\mathrm{CH}_{2} \mathrm{I}_{2}(10 \mu \mathrm{L}, 0.12 \mathrm{mmol})$ followed by $\mathrm{Et}_{2} \mathrm{Zn}\left(0.56 \mathrm{~mL}, 0.16 \mathrm{mmol}, 0.28 \mathrm{M}\right.$ in $\left.\mathrm{CH}_{2} \mathrm{Cl}_{2}\right)$ were added to a stirred solution of alkene $4(13 \mathrm{mg}, 0.03 \mathrm{mmol})$ in DMF $(0.25 \mathrm{~mL})$ at $0{ }^{\circ} \mathrm{C}$ under argon and the solution allowed to warm to $\mathrm{rt}$ over night. The reaction was then quenched with sat. $\mathrm{NH}_{4} \mathrm{Cl}(2 \mathrm{~mL})$ and extracted with $\mathrm{CH}_{2} \mathrm{Cl}_{2}(4 \times 5 \mathrm{~mL})$. The combined organic layers were then washed with brine $(2 \mathrm{~mL})$, dried over $\mathrm{MgSO}_{4}$, filtered and concentrated in vacuo to give a yellow oil, which was purified by flash column chromatography (silica, gradient elution 3-6\% $\mathrm{MeOH} / \mathrm{CH}_{2} \mathrm{Cl}_{2}$ ) to yield starting material (10 mg). 


\section{Attempted oxidation of Amd (4) with DDQ}

DDQ (5 mg, $0.02 \mathrm{mmol}$ ) was added to a stirred solution of AmD 4 (6 mg, $0.01 \mathrm{mmol})$ in dioxane $(0.40 \mathrm{~mL})$ under argon. After $22 \mathrm{~h}$ the reaction was quenched with sat. $\mathrm{Na}_{2} \mathrm{~S}_{2} \mathrm{O}_{3}$ $(1 \mathrm{~mL})$ and extracted with EtOAc ( $3 \times 5 \mathrm{~mL})$. The combined organic layers were then dried over $\mathrm{MgSO}_{4}$, filtered and evaporated in vacuo to give a yellow solid that was purified by prep. TLC $\left(10 \% \mathrm{MeOH} / \mathrm{CH}_{2} \mathrm{Cl}_{2}\right)$ to yield an unknown oxidation product $(2 \mathrm{mg})$

\section{Attempted oxidation of Amd (4) with $\mathrm{MnO}_{2}$}

$\mathrm{MnO}_{2}(187 \mathrm{mg}, 2.15 \mathrm{mmol})$ was sonicated in a solution of AmD [4 (24 mg, $\left.\left.0.07 \mathrm{mmol}\right)\right]$ in dioxane $(4 \mathrm{~mL})$ for 20 min under argon, then stirred for $24 \mathrm{~h}$. The solution was then filtered through Celite ${ }^{\circledR}$ and reduce in vacuo to afford a brown oil (15 mg). ${ }^{1} \mathrm{H}$ NMR showed a complex mixture of compounds. 


\section{Appendix}

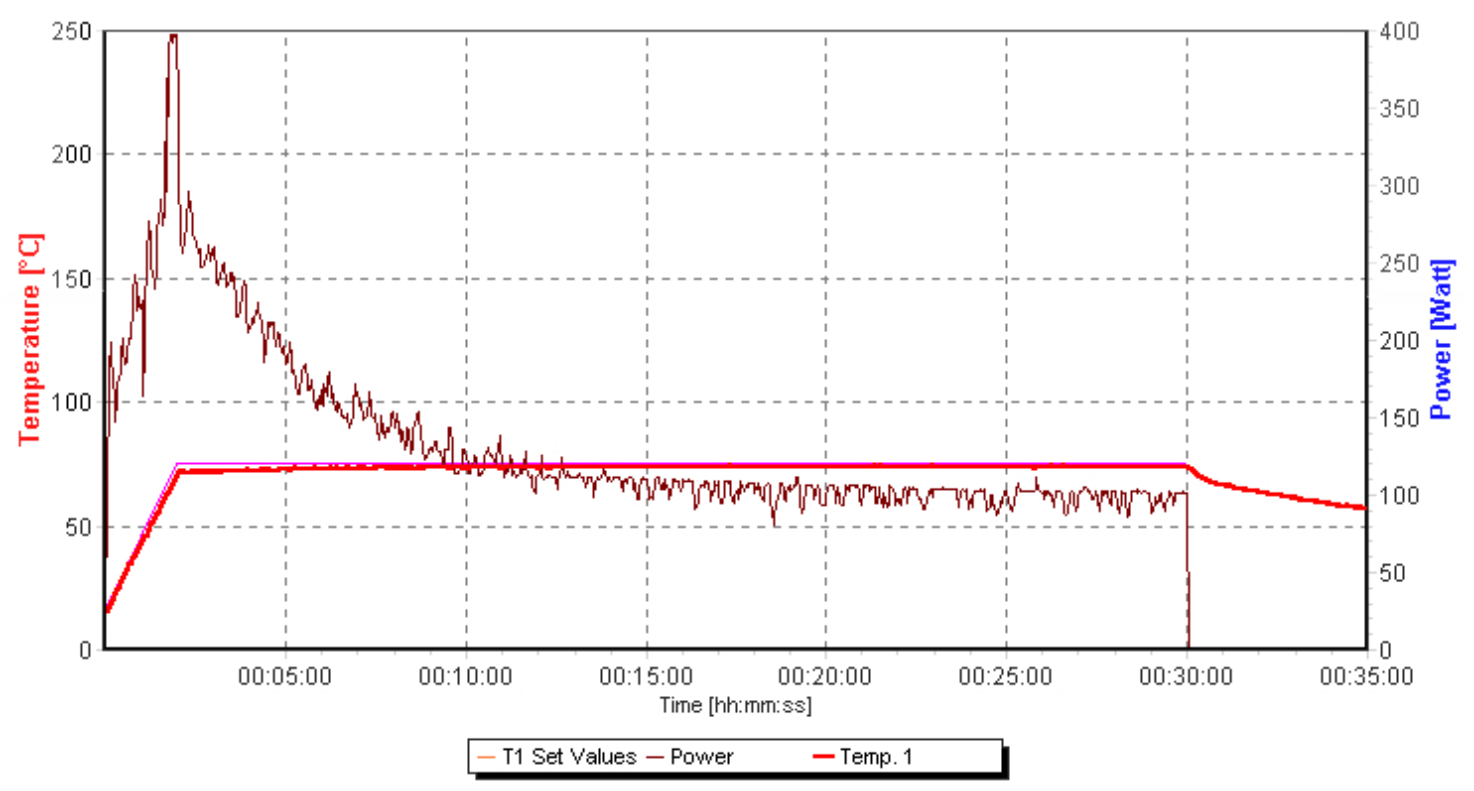

Standard temperature profile of the microwave-assisted RCM. 


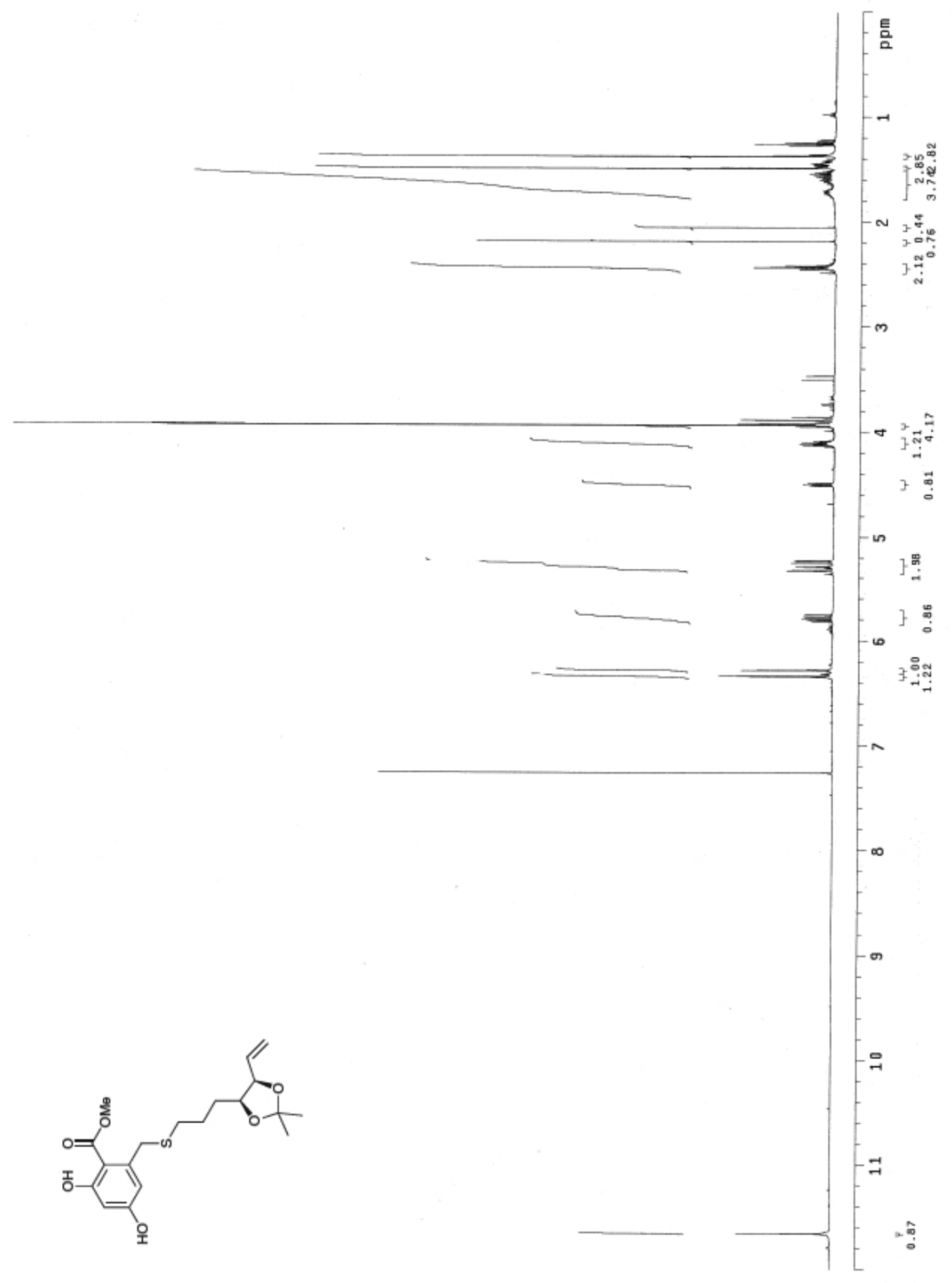

${ }^{1} \mathrm{H}$ NMR spectrum of thioether $55\left(500 \mathrm{MHz}, \mathrm{CDCl}_{3}\right)$ 


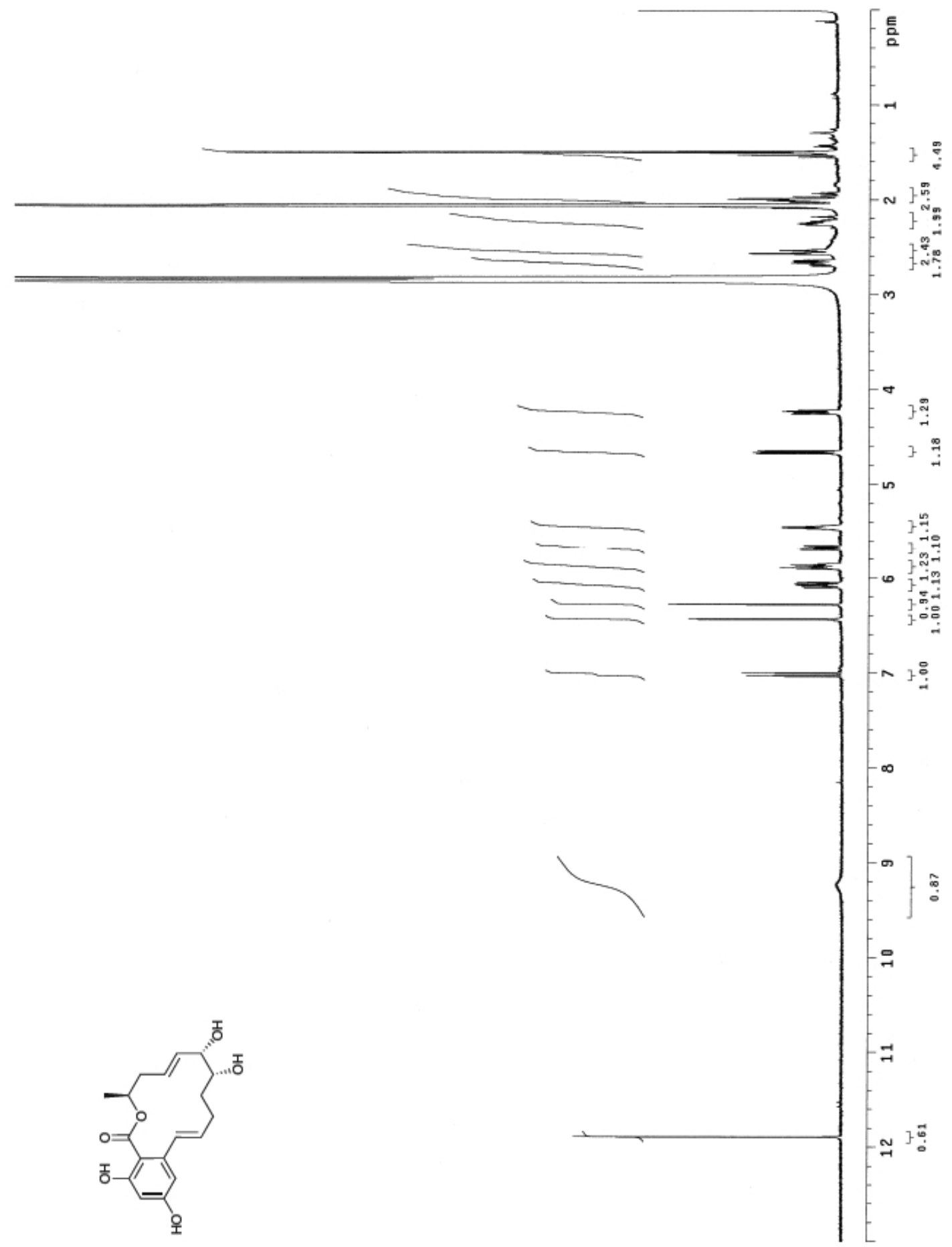

${ }^{1} \mathrm{H}$ NMR spectrum of epi,epi-AmD $69\left(500 \mathrm{MHz}\right.$, acetone- $\left.\mathrm{d}_{6}\right)$ 


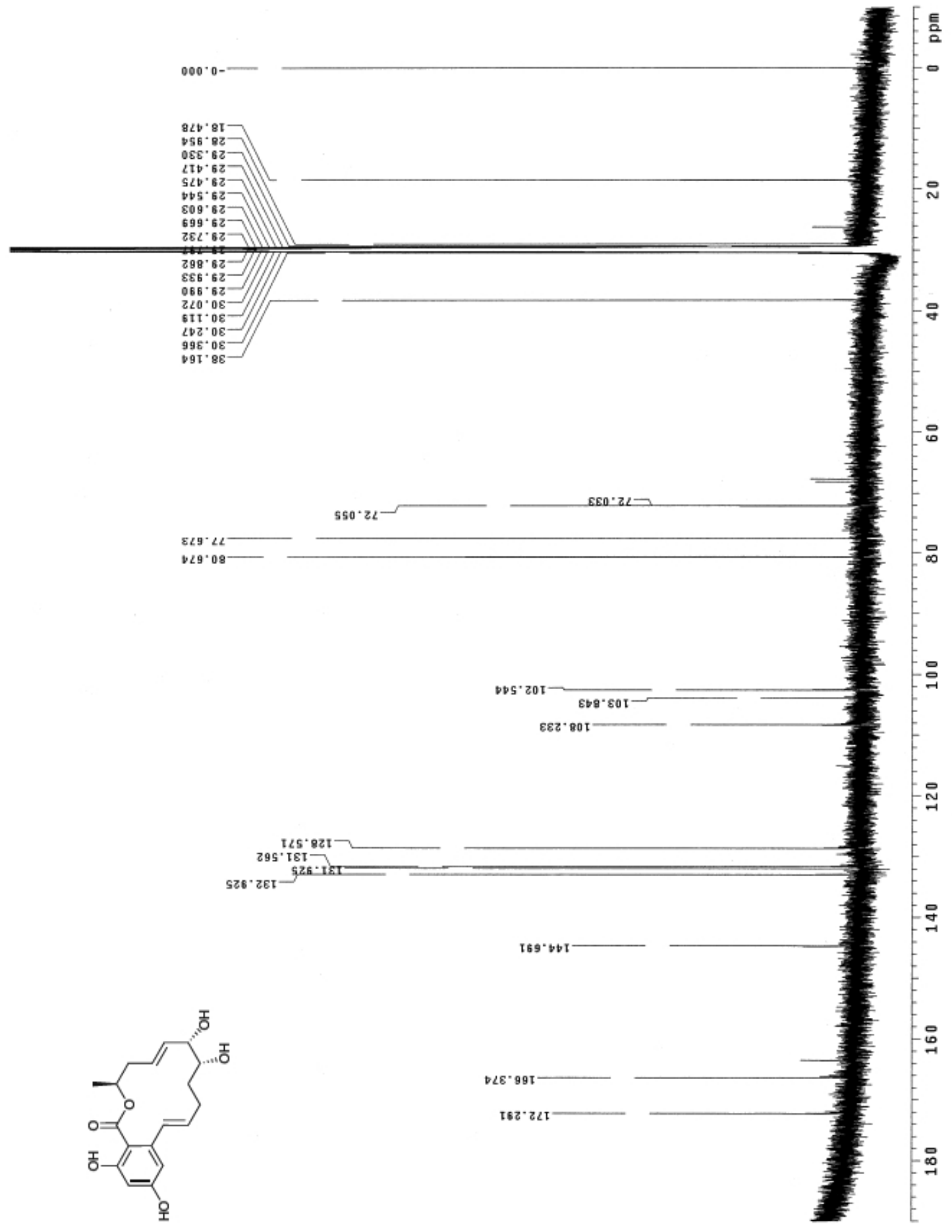

${ }^{13} \mathrm{C}$ NMR spectrum of epi,epi-AmD $69\left(600 \mathrm{MHz}\right.$, acetone- $\left.\mathrm{d}_{6}\right)$ 


\section{References}

1. Cragg, G. M.; Grothaus, P. G.; Newman, D. J. Chem. Rev. 2009, 109, 3012-3043.

2. Delmotte, P.; Delmotte-Plaquee, J. Nature 1953, 171, 344.

3. Keller Schierlein, W. Fortschr. Chem. Org. Naturst. 1973, 30, 313-460.

4. Barathova, H.; Betina, V. Folia Microbiol. 1976, 21, 355-361.

5. Barathova, H.; Betina, V.; Ulicky, L. Folia Microbiol. 1977, 22, 222-231.

6. Horakova, K.; Betina, V. Neoplasma 1977, 24, 21-27.

7. Stob, M.; Baldwin, R. S.; Tuite, J.; Andrews, F. N.; Gillette, K. G. Nature 1962, 196, 1318.

8. Ellestad, G. A.; Lovell, F. M.; Perkinson, N. A.; Hargreaves, R. T.; McGahren, W. J. J. Org. Chem. 1978, 43, 2339-2343.

9. Nair, M. S. R.; Carey, S. T. Tetrahedron Lett. 1980, 21, 2011-2012.

10. Aver, W. A.; Peña-Rodriguez, L. Phytochemistry 1987, 26, 1353-1355.

11. Schulte, T. W.; Akinaga, S.; Soga, S.; Sullivan, W.; Stensgard, B. et al. Cell Stress Chaperones 1998, 3, 100-108.

12. Sharma, S. V.; Agatsuma, T.; Nakano, H. Oncogene 1998, 16, 2639-2645.

13. Zhao, A.; Lee, S. H.; Mojena, M.; Jenkins, R. G.; Patrick, D. R. et al. J. Antibiot. 1999, 52, 1086-1094.

14. Isaka, M.; Suyarnsestakorn, C.; Tanticharoen, M.; Kongsaeree, P.; Thebtaranonth, Y. J. Org. Chem. 2002, 67, 1561-1566.

15. Hellwig, V.; Mayer-Bartschmid, A.; Muller, H.; Greif, G.; Kleymann, G. et al. J. Nat. Prod. 2003, 66, 829-837.

16. Kim, Y.-T.; Lee, Y.-R.; Jin, J.; Han, K.-H.; Kim, H. et al. Mol. Microbiol. 2005, 58, $1102-1113$.

17. Gaffoor, I.; Trail, F. Appl. Environ. Microbiol. 2006, 72, 1793-1799.

18. Zhou, H.; Zhan, J.; Watanabe, K.; Xie, X.; Tang, Y. Proc. Natl. Acad. Sci. U.S.A. 2008, 105, 6249-6254.

19. Reeves, C. D.; Hu, Z.; Reid, R.; Kealey, J. T. Appl. Environ. Microbiol. 2008, 74, 5121-5129.

20. Wang, S.; Xu, Y.; Maine, E. A.; Wijeratne, E. K.; Espinosa-Artiles, P. et al. Chem. Biol. 2008, 15, 1328-1338.

21. An, W.; Schnur, R.; Neckers, L.; Blagosklonny, M. Cancer Chemother. Pharmacol. 1997, 40, 60-64.

22. Akalin, A.; Elmore, L.; Forsythe, H.; Amaker, B.; McCollum, E. et al. Cancer Res. 2001, 61, 4791-4796. 
23. Lindquist, S.; Craig, E. Annu. Rev. Genet. 1988, 22, 631-677.

24. Lathigra, R.; Butcher, P.; Garbe, T.; Young, D. Curr. Top. Microbiol. Immunol. 1991, $167,125-143$.

25. Whitesell, L.; Lindquist, S. Nat. Rev. Cancer 2005, 5, 761-772.

26. Smith, J.; Workman, P. Drug Discov. Today 2007, 4, 219-227.

27. Chiosis, G.; Huezo, H.; Rosen, N.; Mimnaugh, E.; Whitesell, L. et al. Mol. Chem. Ther. 2003, 2, 123-129.

28. Banerji, U.; O’Donnell, A.; Scurr, M.; Pacey, S.; Stapleton, S. et al. J. Clin. Oncol. 2005, 23, 4152-4161.

29. Solit, D.; Ivy, S.; Kopil, C.; Sikorski, R.; Morris, M. et al. Clin. Cancer Res. 2007, $13,1775-1782$.

30. Ramalingam, S.; Egorin, M.; Ramanathan, R.; Remick, S.; Sikorski, R. et al. Clin. Cancer Res. 2008, 14, 3456-3461.

31. Roe, S. M.; Prodromou, C.; O’Brien, R.; Ladbury, J. E.; Piper, P. W. et al. J. Med. Chem. 1999, 42, 260-266.

32. Bergerat, A.; de Massy, B.; Gadelle, D.; Varoutas, P.-C.; Nicolas, A. et al. Nature 1997, 386, 414-417.

33. Dutta, R.; Inouye, M. Trends Biochem. Sci. 2000, 25, 24-28.

34. Cutler, H. G.; Arrendale, R. F.; Spring, J. P.; Cole, P. D.; Roberts, R. G. et al. Agric. Biol. Chem. 1987, 51, 3331-3338.

35. Rinehart Jr., K.; Shield, L. Fortschr. Chem. Org. Naturst. 1976, 33, 231-307.

36. Schnur, R. C.; Corman, M. L. J. Org. Chem. 1994, 59, 2581-2584.

37. Aver, W. A.; Lee, S. P.; Tsuneda, A.; Hiratsuka, Y. Can. J. Microbiol. 1980, 26, 766-773.

38. Shinonaga, H.; Noguchi, T.; Ikeda, A.; Aoki, M.; Fujimoto, N. et al. Bioorg. Med. Chem. 2009, 17, 4622-4635.

39. Turbyville, T. J.; Wijeratne, E. M. K.; Liu, M. X.; Burns, A. M.; Seliga, C. J. et al. J. Nat. Prod. 2006, 69, 178-184.

40. Proisy, N.; Sharp, S. Y.; Boxall, K.; Connelly, S.; Roe, S. M. et al. Chem. Biol. 2006, 13, 1203-1215.

41. Barluenga, S.; Fontaine, J.-G.; Wang, C.; Aouadi, K.; Chen, R. et al. Chembiochem 2009, 10, 2753-2759.

42. Chang, L.; Karin, M. Nature 2001, 410, 37-40.

43. Ohori, M.; Kinoshita, T.; Yoshimura, S.; Warizaya, M.; Nakajima, H. et al. Biochem. Biophys. Res. Commun. 2007, 353, 633 - 637.

44. Ninomiya-Tsuji, J.; Kajino, T.; Ono, K.; Ohtomo, T.; Matsumoto, M. et al. J. Biol. Chem. 2003, 278, 18485-18490. 
45. Dakas, P.-Y.; Barluenga, S.; Totzke, F.; Zirrgiebel, U.; Winssinger, N. Angew. Chem. Int. Ed. 2007, 46, 6899-6902.

46. Schirmer, A.; Kennedy, J.; Murli, S.; Reid, R.; Santi, D. V. Proc. Natl. Acad. Sci. U.S.A. 2006, 103, 4234-4239.

47. Wee, J. L.; Sundermann, K.; Licari, P.; Galazzo, J. J. Nat. Prod. 2006, 69, 14561459.

48. Du, H.; Matsushima, T.; Spyvee, M.; Goto, M.; Shirota, H. et al. Bioorg. Med. Chem. Lett. 2009, 19, 6196-6199.

49. Shen, Y.; Du, H.; Kotake, M.; Matsushima, T.; Goto, M. et al. Bioorg. Med. Chem. Lett. 2010, 20, 3047-3049.

50. Shen, Y.; Boivin, R.; Yoneda, N.; Du, H.; Schiller, S. et al. Bioorg. Med. Chem. Lett. 2010, 20, 3155-3157.

51. Hoshino, Y.; Ivanova, V.; Yazawa, K.; Ando, A.; Mikami, Y. et al. J. Antibiot. 2002, $55,516-519$.

52. Dong, J.; Zhu, Y.; Song, H.; Li, R.; He, H. et al. J. Chem. Ecol. 2007, 33, 11151126.

53. Isaka, M.; Chinthanom, P.; Veeranondha, S.; Supothina, S.; Luangsa-ard, J. J. Tetrahedron 2008, 64, 11028-11033.

54. Isaka, M.; Chinthanom, P.; Kongthong, S.; Supothina, S.; Ittiworapong, P. Tetrahedron 2010, 66, 955-961.

55. Barluenga, S.; Dakas, P. Y.; Ferandin, Y.; Meijer, L.; Winssinger, N. Angew. Chem. Int. Ed. 2006, 45, 3951-3954.

56. Isaka, M.; Yangchum, A.; Intamas, S.; Kocharin, K.; Jones, E. G. et al. Tetrahedron 2009, 65, 4396-4403.

57. Chrovian, C. C.; Knapp-Reed, B.; Montgomery, J. Org. Lett. 2008, 10, 811-814.

58. Bajwa, N.; Jennings, M. P. Tetrahedron Lett. 2008, 49, 390-393.

59. Geng, X.; Danishefsky, S. J. Org. Lett. 2004, 6, 413-416.

60. Lu, J.; Ma, J.; Xie, X.; Chen, B.; She, X. et al. Tetrahedron: Asymmetry 2006, 17, 1066-1073.

61. Vu, N. Q.; Chai, C. L. L.; Lim, K. P.; Chia, S. C.; Chen, A. Tetrahedron 2007, 63, 7053-7058.

62. Calo, F.; Richardson, J.; Barrett, A. Org. Lett. 2009, 11, 4910-4913.

63. Baird, L. J.; Timmer, M. S. M.; Teesdale-Spittle, P. H.; Harvey, J. E. J. Org. Chem. 2009, 74, 2271-2277.

64. Baird, L. J. Total Synthesis of Aigialomycin D and Analogues. Ph.D. thesis, Victoria University of Wellington, 2009.

65. Chiarello, J.; Joullié, M. M. Tetrahedron 1988, 44, 41-48. 
66. Lerner, L. M. Carbohydrate Research 1977, 53, 177-185.

67. Bernet, B.; Vasella, A. Helv. Chim. Acta 1979, 62, 1990-2016.

68. Mitsunobu, O.; Yamada, M. Bull. Chem. Soc. Jpn 1967, 40, 2380-2382.

69. Meyers, C. Y.; Malte, A. M.; Matthews, W. S. J. Am. Chem. Soc. 2002, 91, 75107512.

70. Ramberg, L.; Bäcklund, B. Ark. Kemi. Mineral. Geol. 1940, 13A, 50.

71. Lampilas, M.; Lett, R. Tetrahedron Lett. 1992, 33, 777-780.

72. Clevenger, R. C.; Blagg, B. S. J. Org. Lett. 2004, 6, 4459-4462.

73. Moon, H. R.; Choi, W. J.; Kim, H. O.; Jeong, L. S. Tetrahedron: Asymmetry 2002, 13, 1189-1193.

74. Harrison, C. R.; Hodge, P. J. Chem. Soc. Perkin Trans. 1 1982, 509-511.

75. Zhong, Y.-L.; Shing, T. K. M. J. Org. Chem. 1997, 62, 2622-2624.

76. Neises, B.; Steglich, W. Angew. Chem. Int. Ed. 1978, 17, 522-524.

77. Dourtoglou, V.; Gross, B. Synthesis 1984, 7, 572-574.

78. Inanaga, J.; Hirata, K.; Saeki, H.; Katsuki, T.; Yamaguch, M. Bull. Chem. Soc. Jpn 1979, 52, 1989-1993.

79. Ball, S.; Goodwin, T. W.; Morton, R. A. Biochem. J. 1948, 42, 516-523.

80. Kirk, D. N.; Petrow, V.; Williamson, M. H. J. Chem. Soc. 1960, 3872-3877.

81. Bowers, A.; Holton, P. G.; Necoechea, E.; Kincl, F. A. J. Chem. Soc. 1961, 40574060 .

82. Burstein, S. H.; Ringold, H. J. J. Am. Chem. Soc. 1964, 86, 4952-4958.

83. Ohloff, G.; Giersch, W. Angew. Chem. Int. Ed. 1973, 12, 401-402.

84. Outram, H. S.; Raw, S. A.; Taylor, R. J. Tetrahedron Lett. 2002, 43, 6185-6187.

85. Fatiadi, A. J. Synthesis 1976, 2, 65-104.

86. Danishefsky, S.; Hirama, M.; Gombatz, K.; Harayama, T.; Berman, E. et al. J. Am. Chem. Soc. 1979, 101, 7020-7031.

87. Simmons, H. E.; Smith, R. D. J. Am. Chem. Soc. 1959, 81, 4256-4264.

88. Grieco, P. A.; Oguri, T.; Wang, C.-L. J.; Williams, E. J. Org. Chem. 1977, 42, 41134118.

89. Harris, T. M.; Harris, C. M. Tetrahedron 1977, 33, 2159-2185.

90. Murray, T. P.; Harris, T. M. J. Am. Chem. Soc. 1972, 94, 8253-8255.

91. Huckin, S. N.; Weiler, L. Tetrahedron Lett. 1972, 13, 2405-2408.

92. Harris, T.; Murray, T.; Harris, C.; Gumulka, M. J. Chem. Soc. Chem. Commun. 1974, 362-363. 
93. Howarth, T. T.; Murphy, G. P.; Harris, T. M. J. Am. Chem. Soc. 1969, 91, 517-518.

94. Barrett, A. G. M.; Morris, T. M.; Barton, D. H. R. J. Chem. Soc. Perkin Trans. 1 1980, 2272-2277.

95. Basset, J.-F.; Leslie, C.; Hamprecht, D.; White, A.; Barrett, A. Tetrahedron Lett. 2010, 51, 783-785.

96. Garegg, P.; Johansson, R.; Ortega, C.; Samuelsson, B. J. Chem. Soc. Perkin Trans. 1 1982, 681-683.

97. Kang, Y.; Mei, Y.; Du, Y.; Jin, Z. Org. Lett. 2003, 5, 4481-4484.

98. Hu, H.; Harrison, T. J.; Wilson, P. D. J. Org. Chem. 2004, 69, 3782-3786.

99. Pettigrew, J. D.; Wilson, P. D. J. Org. Chem. 2006, 71, 1620-1625.

100. Ito, Y.; Fujii, S.; Nakatuska, M.; Kawamoto, F.; Saegusa, T. Org. Synth. 1979, 59, 113.

101. Moulin, E.; Zoete, V.; Barluenga, S.; Karplus, M.; Winssinger, N. J. Am. Chem. Soc. 2005, 127, 6999-7004.

102. Garbaccio, R. M.; Stachel, S. J.; Baeschlin, D. K.; Danishefsky, S. J. J. Am. Chem. Soc. 2001, 123, 10903-10908.

103. Lei, X.; Danishefsky, S. J. Adv. Synth. Catal. 2008, 350, 1677-1681.

104. Yang, Z. Q.; Geng, X.; Solit, D.; Pratilas, C. A.; Rosen, N. et al. J. Am. Chem. Soc. 2004, 126, 7881-7889.

105. Barluenga, S.; Lopez, P.; Moulin, E.; Winssinger, N. Angew. Chem. Int. Ed. 2004, 116, 3549-3552.

106. Day, J. E. H.; Sharp, S. Y.; Rowlands, M. G.; Aherne, W.; Workman, P. et al. Chem. Eur. J. 2010, 16, 2758-2763. 